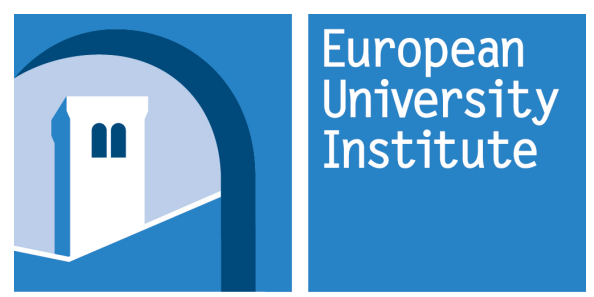

DEPARTMENT

OF LAW

\title{
The Metaethics of Constitutional Adjudication
}

\author{
Boško Tripković
}

Thesis submitted for assessment with a view to obtaining the degree of Doctor of Laws of the European University Institute

Florence, 28 May 2015 



\section{European University Institute \\ Department of Law}

\section{The Metaethics of Constitutional Adjudication}

Boško Tripković

Thesis submitted for assessment with a view to obtaining

the degree of Doctor of Laws of the European University Institute

\section{Examining Board}

Prof. Dennis Patterson, European University Institute (Supervisor)

Prof. Hans-W. Micklitz, European University Institute

Prof. Neil Walker, University of Edinburgh

Prof. George Pavlakos, University of Antwerp

(C) Boško Tripković, 2015

No part of this thesis may be copied, reproduced or transmitted without prior permission of the author 



\begin{abstract}
The thesis explores the metaethical foundations of value-based arguments in constitutional adjudication. The main argument develops in four steps. First, the thesis identifies three dominant types of value-based arguments in comparative constitutional practice: the argument from constitutional identity, the argument from common sentiments, and the argument from universal reason. Second, it brings to the fore the assumptions about the nature of moral value implicit in these arguments and subjects them to a critique. The thesis maintains that these arguments presuppose inadequate conceptions of value and fail as self-standing approaches to moral judgment. Third, the thesis develops an account of moral value and explains its practical consequences. It argues that a credible understanding of value suggests that the appropriate moral judgment emerges from the dynamics between practical confidence, which denotes the inescapability of the self and of the contingent evaluative attitudes it entails, and reflection, which denotes the process of challenging and questioning these attitudes. Fourth, departing from this conception of value, the thesis reconstructs the existing value-based arguments of constitutional courts. It applies the ethics of confidence and reflection to constitutional reasoning and shows how the arguments from constitutional identity, common sentiments and universal reason can be combined to refashion the moral perspective of a constitutional court so that it coheres with a sound understanding of value. The thesis argues that the moral inquiry of the constitutional court ought to depart from the emotive intuitions of the constitutional community and then challenge these intuitions through reflective exposure to different perspectives in order to better understand and develop the underlying constitutional identity. The thesis contends that this model enables us to perceive some common constitutional dilemmas in new light and allows us to move forward in resolving them.
\end{abstract}




\section{ACKNOWLEDGEMENTS}

There are many people that have contributed to this thesis. My supervisor Dennis Patterson has been a source of immense professional and personal support. When we first met, he told me that his goal was to enable me to write the best thesis $I$ could possibly write. And he followed through: instead of doctrines, he gave me tools; instead of solutions, he gave me options; instead of comfort, he gave me challenge; instead of help, he gave me courage. I could not be more grateful to him for giving me the freedom to express my own ideas, make my own mistakes, and take responsibility for them. It was his supervision that allowed me to grow up as an academic.

I owe deep gratitude to Hans-W. Micklitz, whose agreement to be on the thesis committee is a tip of the iceberg of intellectual insight and human kindness that I have experienced from his side over the years. I wish to thank him for his wisdom and empathy that have helped me overcome many of my doubts. I am also greatly indebted to George Pavlakos and Neil Walker for their invaluable comments and careful engagement. Not only did they show me how to improve my own research, but they also taught me a great deal on how to treat other people's research.

At the EUI, Ruth Rubio Marin supervised me during the first year of my $\mathrm{PhD}$ and gave me precious advice which I have kept in mind ever since, and Rainer Bauböck has been remarkably supportive of all my academic endeavors. At NYU, Joseph H.H. Weiler's and Stephen Gardbaum's meticulous comments made me work much harder to sustain my assumptions, and Thomas Nagel, Derek Parfit and Sharon Street's seminars have deepened my knowledge of moral philosophy and helped me articulate my own views better.

I would also like to extend my gratitude to the Italian Ministry of Foreign Affairs that has generously supported me with a grant; Ruth Gbikpi and Alexandra Howarth, who have been the nicest possible bosses at the EUI library; and Marlies Becker and Francesca Duca from the EUI Law Department who have facilitated my studies with professionalism and patience. 
It would not have been possible for me to finish the thesis without some people that I am blessed to call friends. Maciej Borowicz, Alexis Galán, and Payam Ghalehdar's unconditional friendship is one of the most valuable things I gained during these years; Alexandra Ortolja-Baird, Guilherme Sampaio, and Jan Zglinski’s optimism and affection have been an infinite source of happiness; Violeta Beširević, Mateja Đurović, Jelena Džankić, Ivana Isailović, Iassen Lazarov, Trajče Panov, Tamara Popić, Tijana Prokić Breuer, Dejan Stjepanović, and Višnja Vukov's warmth has given me a home away from home; Tom Adams, Sina Akbari, Daniel Correa, Rachel Singerman Gur, Joaquin Millon, Hillary Nye, and Nil Vijayalingam's incredible minds and hearts have enriched and inspired me in countless ways; Jacobien van Dorp, Tiago de Freitas, François-Xavier Millet, Arie Rosen, Guilherme Vasconcelos Vilaça, and Emily Kidd White’s knowledge and perception have enhanced my work immensely; and Jonas Brendebach, Jonathan Chevry, Martin Lestra, Alassane Martin, and many others at the EUI rowing club have provided me with the feeling of belonging and true sportsmanship that, also quite literally, kept me above water.

At the foundation of this thesis is the love of my family. I would like to thank my sister, Ana Tripković Marković, for always being there for me, and for - together her family, Marko, Luka, and Tara Marković - making my life joyful. I thank my mother, Gordana Tripković, for her care for my dreams, and for our endless talks from which I learned more than from all the books I have ever read. Words fail me when it comes to expressing gratitude to my wife, my love, and my best friend, Milena Tripković. I simply thank her for giving meaning to all of this.

My father, Milan Tripković, passed away before I started writing this thesis, but has been writing it with me. I dedicate the thesis to his memory. It is a part of his legacy in this world, and a tribute to his virtue. 


\section{TABLE OF CONTENTS}

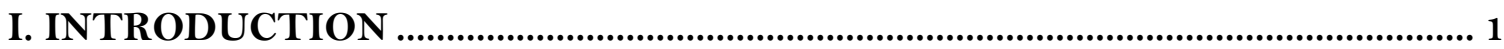

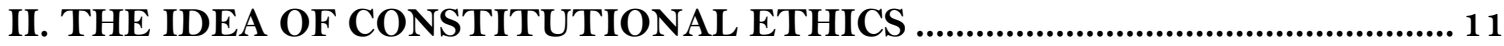

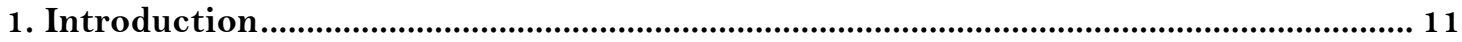

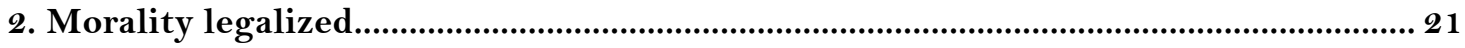

2.1 The jurisprudence of ethical arguments ..................................................................25

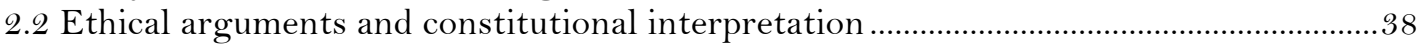

3. The argument from constitutional identity ..............................................................44

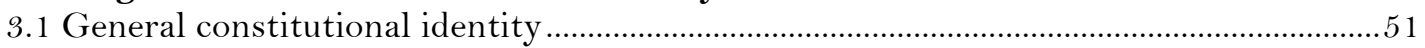

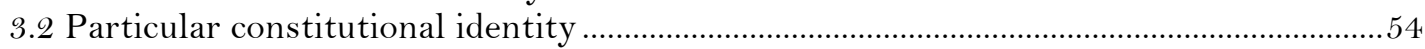

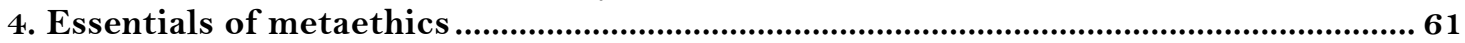

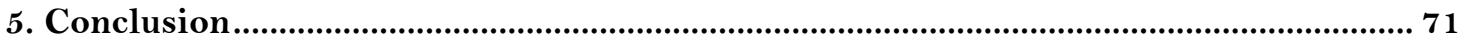

III. CONSTITUTIONAL ETHICS AND COMMON SENTIMENTS.................... 75

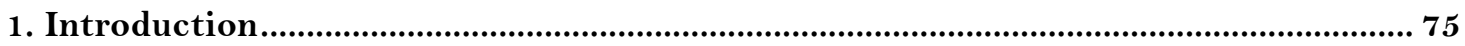

2. Elements of the argument from common sentiment..............................................76

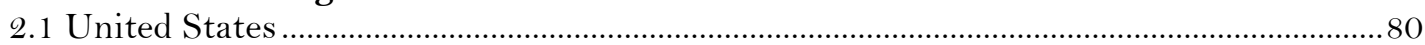

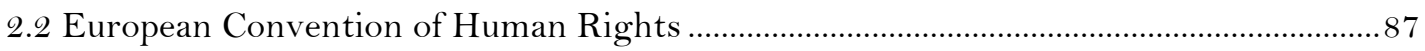

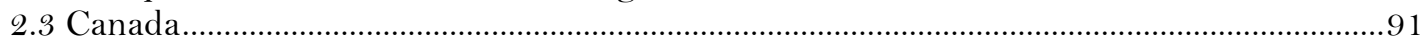

3. Moral ontology of common sentiments ......................................................................96

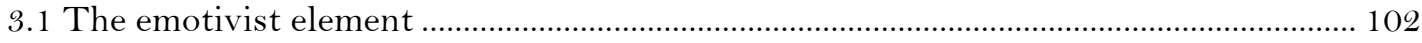

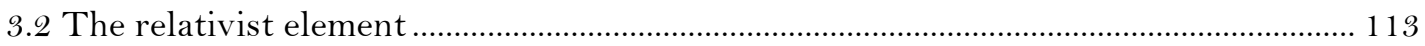

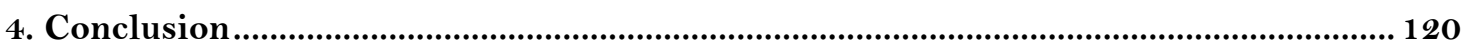

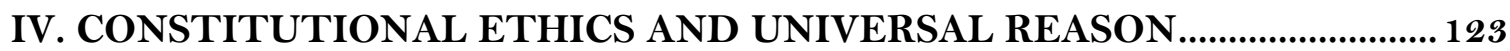

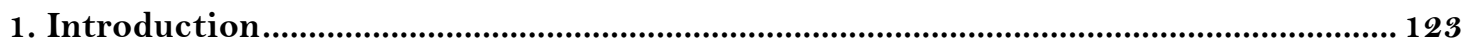

2. Elements of the argument from universal reason ....................................................... 125

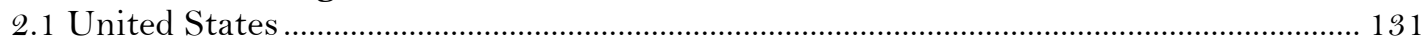

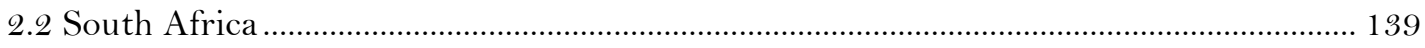

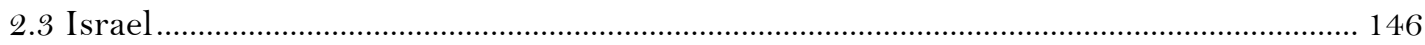

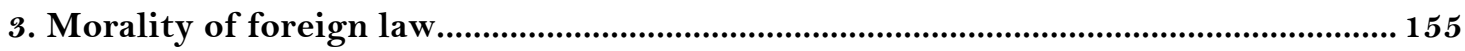

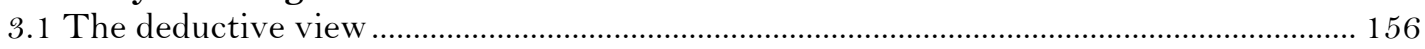

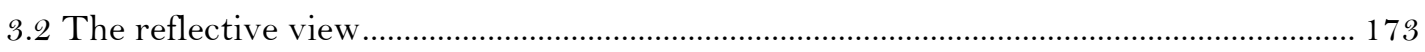

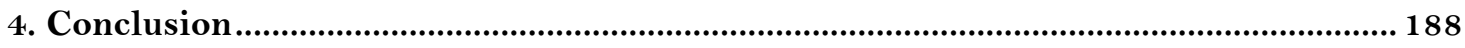

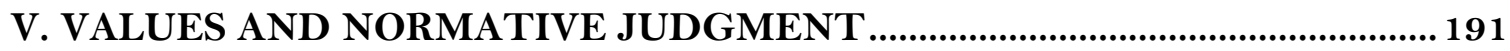

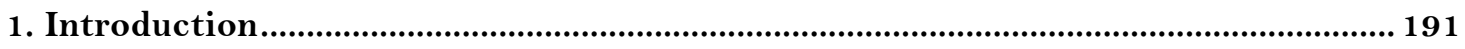

2. The theoretical and practical perspective ................................................................... 193

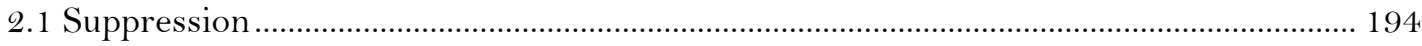

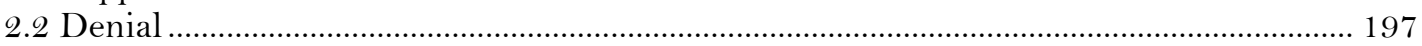

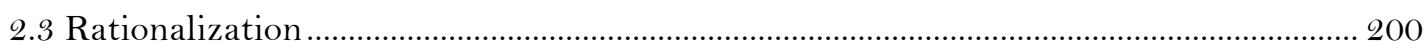

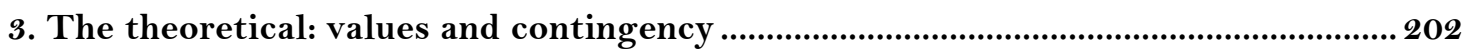

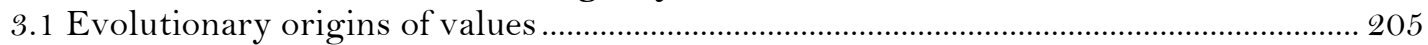

3.2 Diminishing evolutionary influence ........................................................................ 213

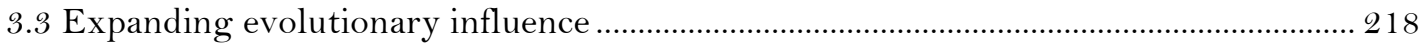

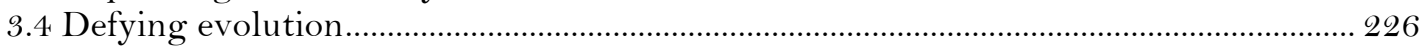

4. The practical: confidence and reflection .................................................................229

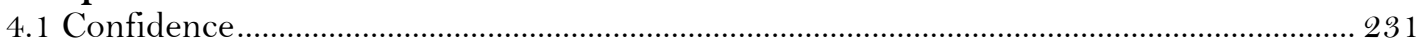

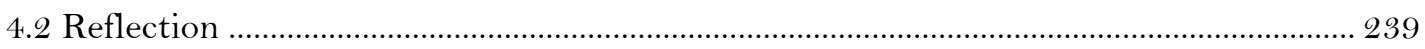

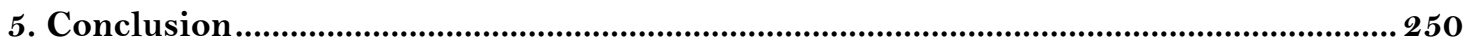


VI. CONSTITUTIONAL ETHICS, CONFIDENCE AND REFLECTION ...........253

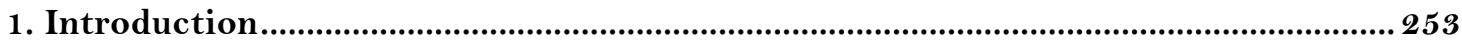

2. From metaethics to constitutional ethics ……...............................................................254

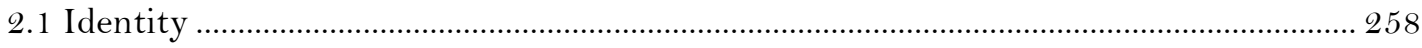

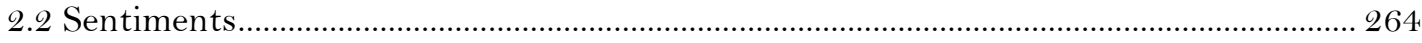

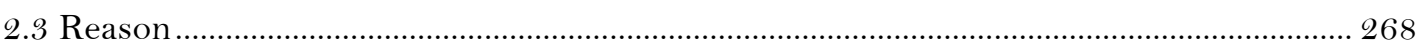

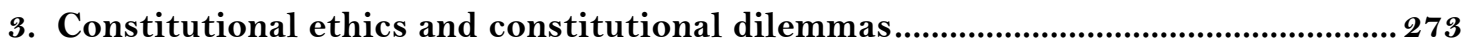

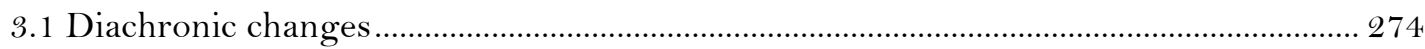

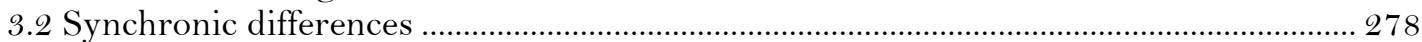

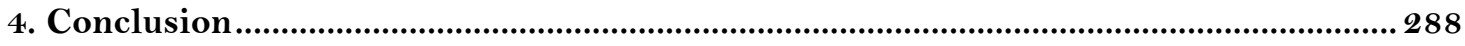

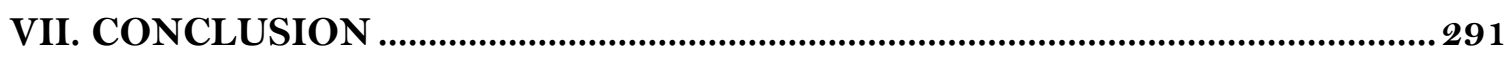

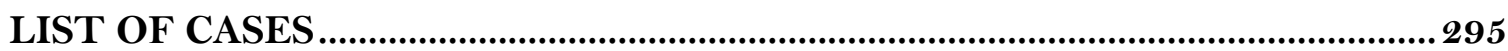

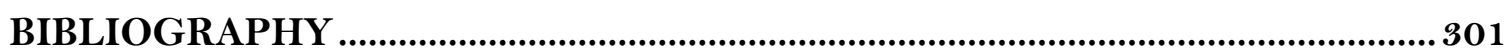




\section{INTRODUCTION}

In one of Plato's dialogues, Socrates encounters a man named Euthyphro who is prosecuting his own father. Euthyphro's confidence in this matter is based on his knowledge of what is pious. Preparing for his own trial for impiety, Socrates asks Euthyphro - not without the usual irony - to teach him about piety: if Euthyphro indeed had knowledge of piety then he would be able to explain it. But Socrates challenges and refutes each account that Euthyphro offers. Euthyphro asserts that doing what he actually does is pious, and Socrates answers that this is only an example and not a definition; Euthyphro claims that piety is what pleases the Gods, but Socrates points out that the Gods disagree among themselves; Euthyphro defines what is pious as being loved by all the Gods, but Socrates reminds him that piousness should be a property of acts that are pious and not an attribute conferred upon them by someone else. One by one, Euthyphro's attempts to specify piety fail. When Socrates makes the final plea to him to reveal his moral knowledge, Euthyphro refuses to further question his beliefs and leaves. The dialogue does not say how much confidence in his moral judgment has Euthyphro lost, but it does say that Socrates - not being enlightened by Euthyphro's moral knowledge - does not intend to renounce the speculations that will eventually cost him his life: in other words, he chooses not to disavow the philosophical reflection about the nature of moral judgment. ${ }^{1}$

Both the confidence with which we assert our moral knowledge and the reflection about its nature have endured over the centuries. They are part and parcel of the human condition: moral judgments are inescapable and so is contemplation about their origins. Metaethics - the branch of philosophy that deals with the metaphysical and epistemological foundations of moral thought and language - has thus developed with much sophistication and detail. But the question behind Socrates' dialogue with Euthyphro remains crucial: should the confidence in our moral knowledge be undermined by philosophical reflection about its source?

\footnotetext{
${ }^{1}$ Plato, The Collected Dialogues of Plato (Edith Hamilton and Huntington Cairns eds, 14 edn, Princeton University Press 1989) 185. Socrates reveals his intentions with a dose of humor: by saying that he would have abandoned his 'innovations' had Euthyphro revealed his moral knowledge to him.
} 
The thesis explores this problem in the context of contemporary constitutional law. In the spirit of Socrates' dialogue with Euthyphro, it aims to challenge and explain the metaethical foundations of value-based arguments in constitutional adjudication. The main driving force behind this project is an empirical observation that there is much confusion and uncertainty about the nature of value in comparative constitutional adjudication. As the thesis will aspire to demonstrate, constitutional courts use divergent argumentative patterns that rely on different underlying conceptions of value. Not all of these conceptions are plausible. The thesis thus identifies different types of value-based arguments in comparative judicial practice, explores the plausibility of their assumptions about the nature of value, and develops a theory that reconstructs their metaethical foundations.

While few people would deny that courts make value judgments, anyone who has ever read a single opinion of a constitutional court knows that they look nothing like the dialogue between Socrates and Euthyphro. Courts sometimes do admit that they are making moral judgments, but they rarely reflect on the source of moral value behind their judgment. Yet, the thesis aims to demonstrate that they feel the allure of both Euthyphro and Socrates.

The first temptation is Euthyphro's: to avoid these questions. Most people live their lives without caring about the source of value or metaethics. But judges might be in a specific position. They are moved to ponder the nature of value because of the constant public attention their authority receives. Under the circumstances of moral disagreement and value pluralism - and when they are unable to resort to sources of legitimacy that would remove the choice from their hands - constitutional courts face metaethical questions. How do they know what true values are and by which authority they impose them on others? The inescapability of ethical choices, which comes with the judicial role and incomplete determinacy of law, makes these questions pressing in constitutional law. Constitutional courts do not always have an option to claim that they are only applying the law and - as eventually Euthyphro did - leave the conversation about the nature of value. 
Hence, courts cannot find comfort in disregarding this issue: Socrates' challenge is pressing. But they also rarely engage with it openly. Their positions on this matter remain implicit, and can be discerned from the premises of their arguments and from the language they use. These implicit assumptions reveal the ambiguities about the source of value. As the thesis will try to demonstrate, the manner in which judges make moral judgments confirms the suspicion that they are aware of some of the questions posed by Socrates, even if this awareness is only rudimentary. The first aim of the thesis is thus to bring to the fore the implicit commitments about the nature of value that follow from judicial value-based arguments. The second aim is to subject these commitments to philosophical scrutiny and initiate a Socratic dialogue about them.

The project thus takes an unusual approach to value-based arguments in constitutional adjudication: a more common strategy is to avoid metaethical issues. ${ }^{2}$ On the one hand, we may think that constitutional adjudication has nothing to do with metaethics because, for example, value-based reasoning generally ought to be avoided. But - even if this were desirable - it is doubtful that any such strategy could be successful: it is impossible to completely reduce judicial discretion and any plausible theory of adjudication needs to accept that. On the other hand, taking the first-order judicial disagreement about values to the level of metaethics seems to invite an even greater and perhaps more esoteric - uncertainty; for instance, one might believe that constitutional adjudication needs workable solutions and not grandiose theories. But such solutions still must face Socrates, and avoiding metaethical questions cannot silence his challenge. This route would only deprive us of a satisfying explanation and thus augment the discomfort arising from the inability to specify where these moral solutions come from.

The thesis aims to show that the fruits of such metaethical inquiry - if it is successful could be rewarding. Most debates about constitutional adjudication belong to the domain of normative or applied ethics: they ponder what we ought to do in the

\footnotetext{
${ }^{2}$ For some reasons why this would be preferable see Jeremy Waldron, Law and Disagreement (Clarendon Press 1999) ch 8 and Cass R. Sunstein, One Case at a Time: Judicial Minimalism on the Supreme Court (Harvard University Press 1999).
} 
institutional context of contemporary constitutional systems. However, if we remain at the level of normative ethics we do not have a complete account of our ethical experience. We stay at the level of Euthyphro and not Socrates. If we inquired about the metaethical foundations of judicial value-based arguments we would not only see some of the old problems of constitutional adjudication in a new light, and possibly resolve them, but we might also reach a non question-begging justification of our values. Our philosophical spade would reach bedrock, and we would have a mechanism by which we could assess and refine our arguments. We could stay in the conversation with Socrates, and we would not leave without an answer as Euthyphro.

To further clarify the project, I should say why constitutional adjudication is important in this context, which value-based arguments will be analyzed, why study their metaethical foundations, and what does it mean to challenge and explain them? Let me address these questions and in so doing explain the structure of the thesis. The thesis deals with constitutional adjudication: the institutional situation in which a judicial body has a power to review actions of other branches of government on the basis of fundamental rights and freedoms. ${ }^{3}$ I have already mentioned that the project is driven by an empirical phenomenon that appears in comparative constitutional practice. A significant part of the thesis - and a recurring thread running through all of its chapters - aspires to support and explore this empirical proposition. But there are other reasons why the question about the nature of value could be particularly intense and visible in constitutional law.

The first is the specific combination of concerns about the democratic legitimacy of courts to perform constitutional review and the indeterminate moral language used in constitutions. Both concerns about legitimacy and the use of moral language are present in other areas of law, and the difference is only in degree and not in kind; however, these

\footnotetext{
${ }^{3}$ This broad understanding enables the research to include a range of institutional frameworks, including some that are outside of the nation-state setting. Disagreements about the meaning of the 'constitution' or 'constitutionalism' abound and much ink has been spilled in attempts to elucidate these concepts; they are often motivated by a normative conception of how we ought to live together in - or beyond - our current political communities. The thesis uses a concept that hopefully tracks the conventional understanding and is at the same time not extravagant in this normative sense. But most importantly, the concept allows the thesis to explore all the important metaethical dimensions of constitutional value-based judgments: the focus is on the phenomenon and not on the normative baggage of the term used to denote it.
} 
elements are particularly strong in constitutional adjudication. This puts the valuebased judgments of constitutional courts in the focus of attention, makes judges more anxious about Socrates' challenge, and consequently forces them to articulate their views on the matter. The second is the common view that constitutions are closer to the normative experience of the people than the rest of the law. People tend to think that law is normative: they abide by it most of the time and they also correct others by pointing out that their actions are illegal. But there is the idea that constitutions achieve this in a more direct, unmediated way. Constitutions are general, stable and visible enough to become more ingrained in our contingent moral commitments; it could be that we follow constitutions because we think what they say is right, and not primarily because we think that it is right to obey the law. Constitutional practice itself is sometimes seen as the embodiment of value or as a value-generating process: in other words, as the source of value that Euthyphro was unable to specify. These ideas may well be misguided, but - as we shall see - they play an important role in the way courts use value arguments.

The second issue I need to explain is: which value-based judicial arguments are examined in the thesis? The thesis deals only with the arguments that go beyond existing law and that aim to offer solutions to unregulated - or inadequately regulated - moral problems. Locating the point at which courts move from law-applying to law-making is the holy grail of legal theory: much intellectual effort has been invested in this question and there is not even agreement that such a point exists. ${ }^{4} \mathrm{I}$ do not harbor the illusion that the thesis can resolve this problem. But - since it is a preliminary question to delineate value-based arguments as the object of the study - the thesis does aim to contribute to a better understanding of this issue. A substantial part of chapter 2 therefore outlines the concept of an ethical argument ${ }^{5}$ as an important interface between law and morality, and

\footnotetext{
${ }^{4}$ See Ronald Dworkin, Law's Empire (Belknap Press 1986) and Justice for Hedgehogs (Belknap Press of Harvard University Press 2011).

${ }^{5}$ In choosing the word 'ethical', and not 'moral' arguments, I follow the convention established in Philip Bobbitt, Constitutional Fate: Theory of the Constitution (Oxford University Press 1982) and Constitutional Interpretation (Blackwell 1991). Moreover, I use the words 'ethical' and 'moral' interchangeably. Sometimes a difference is made between ethical and moral, either because the former refers to how we ought to treat ourselves and the latter how we ought to treat others, or because the latter is considered to be a distorted version of the former in post-Enlightenment ethical thinking. For the first understanding of the distinction see Jürgen Habermas, Between Facts and Norms: Contributions to a Discourse Theory of Law and Democracy (MIT Press 1996) 95-99, and for the second Bernard Williams, Ethics and the Limits of
} 
as the point in which judicial visions about the nature of value come to the fore. The thesis as a whole adds layers of complexity to this initial outline, in the hope that it will contribute to a better grasp of the paradigmatic features of ethical arguments and their variety. The important point is that such arguments - or more precisely argumentative patterns - aim to morally evaluate, but take quite a different form from ordinary moral arguments. The thesis suggests that methods of moral evaluation over time become entrenched in legal practice in the form of ethical arguments, and that they in turn embed a particular vision of moral value.

This is the point at which the third issue I need to clarify becomes important: why study the metaethical foundations of ethical arguments in constitutional reasoning? One may doubt that this question makes sense, or that it is interesting: either the validity of law depends on moral reasons, so the metaethical question does not specifically arise in the context of law; or legal validity does not depend on morality, in which case - again - the question presents a general metaethical problem that concerns moral and not legal theory. If there is a specific conception of morality in law, it can present nothing more than the contingent and uninteresting views of judges about morality. ${ }^{6}$

But even if it is true that we are not talking about morality itself, but rather about contingent judicial understandings of morality, the thesis argues that metaethical questions are nonetheless relevant. This is not to say that it is impossible - as Euthyphro - to exercise moral judgment without being aware of the background conception of value. However, such conception is often implicit in our moral judgment, or becomes explicit through a Socratic contestation of our moral attitudes. The judicial idea of value is visible in the explicit endorsement of a certain metaethical position, or -

Philosophy (2 edn, Routledge 2006 [1985]). These distinctions do not capture anything of relevance for this thesis. I thus choose the terminology that is more attuned to the common way these words are used: interchangeably. Arguably, the term 'ethical' better captures the spirit of this thesis, which aims to integrate metaethics and normative ethics more closely.

${ }^{6}$ This is however a controversial claim. Recall that in one of the challenges Socrates asks Euthyphro if piousness is the inherent property of pious actions or something ascribed to such actions by Gods. One of the most basic and yet most important metaethical questions is whether goodness is an inherent property of moral actions, or something ascribed to such actions by us. Legal theory often takes for granted the distinction between 'positive' and 'critical' morality at face value (see more in H.L.A. Hart, Law, Liberty and Morality (Oxford University Press 1962) 17-24). But there is something perplexing about drawing too sharp a line between what we believe is moral and what actually is moral. At the very least, this relationship needs to be explained: we cannot simply disregard the issue by dogmatic fiat. 
for example - in the choice of materials that are considered relevant for a moral judgment. In the legal context, this idea of value often becomes entrenched in interpretive conventions and through the use of the same arguments in subsequent cases.

Such conceptions of value can be mistaken. Hence - whereas the standard question asks whether the judges got moral answers wrong - the thesis asks instead if the judges got the morality itself wrong. As I explain in more detail in the thesis, any ethical judgment is susceptible to Socrates' challenge: if we claim that our judgment is apposite we must also be able to explain in virtue of what it is apposite. The other possibility is to be as dogmatic as Euthyphro. But this neither is nor should be an option for constitutional judges. They decide some of the most important issues in our polities: we should want our judges to get what they ought to do right, and we should want this not to be a coincidence but to arise from an understanding of what makes things right. To achieve this, judges would need to be aware of the source of value they rely on. As the thesis will attempt to show, many of the actual judicial disagreements show that they lack a clear enough conception of value, and - perhaps more importantly - the tools to understand what such disagreements are about.

The fundamental metaethical issues that the thesis tries to solve are the divergent foundations of moral value behind judicial ethical arguments. The thesis identifies and analyses the three most prominent ethical arguments understood as ideal-types: the argument from constitutional identity (examined in chapter 2), the argument from common sentiments (chapter 3) and the argument from universal reason (chapter 4). The central tension - and the main puzzle that motivates the thesis - arises along the two dimensions that threaten a coherent picture of values. Not surprisingly, these are the dimensions that match the most important metaethical dilemmas: on the one hand, there is a tension between the local and universal understanding of values, and on the other, between the place of emotions and reason in a credible conception of value. At one pole there is the argument from common sentiment that ties moral value to the emotive reactions of a particular community, and at the other there is the argument from universal reason that understands the universally human faculty of reason as the 
source of value. In between there is the argument from constitutional identity, that - in its different instantiations - contains elements of both of these rival poles: universalreasonable and local-emotional.

These different types of ethical arguments are often understood to exclude each other, not least because of their iterative use in law: as we shall see, much of the time courts or individual judges opt for one type of ethical argument and reject the other. But in so doing, they behave a bit like Euthyphro and do not justify their views. The analysis in chapters 2 to 4 aims to bring Socrates' spirit into the discussion and distinguish implausible from plausible elements in each type of ethical argument. The picture that emerges from this analysis shows that all of these arguments - from identity, sentiment and reason - are dissatisfying as self-standing sources of value, and that there are profound connections between them. This sense of dissatisfaction can only be overcome through a deep vindication of ethical arguments with an adequate conception of value. The main goal of the thesis is thus to articulate a plausible constitutional ethics: to offer a theory of ethical arguments in constitutional adjudication that would be supported by a sound conception of value.

This brings us to the final preliminary question that I need to explain: what does it mean to challenge and explain the metaethical foundations of ethical arguments in constitutional law? The thesis not only aims to expose their metaethical assumptions, but also to reconstruct them around a credible understanding of the nature of value. Chapter 5 is the metaethical epicenter of the thesis, and aims to offer such an understanding and express the dialectic between Euthyphro and Socrates in more abstract and analytic terms. It analyzes the relationship between the two perspectives that we as humans are able to occupy - practical and theoretical - and explains how they affect each other. The thesis does this with notions of confidence and reflection: the objective is to illuminate the source of practical confidence in our values after the Socratic challenge, but also to clarify the consequences of Socratic reflection for prereflective moral attitudes. 
In chapter 6, the thesis applies this conception of value to ethical arguments in constitutional adjudication. To complete the explanation of the metaethical foundations of ethical arguments in constitutional reasoning, the thesis translates the notions of confidence and reflection to the specific institutional context of constitutional adjudication. This chapter then goes back to previously identified types of ethical arguments and shows how they are vindicated and transformed once we have a better grasp of the nature of value, and how they can be integrated into a coherent constitutional ethics. The thesis then investigates to what extent this account of constitutional ethics could be a useful framework for thinking about some quintessential constitutional dilemmas. The explanation of the metaethical foundations of ethical arguments in constitutional reasoning thus takes the following pattern: first, the thesis exposes the metaethical inadequacy of some common ethical arguments; second, it offers a conception of value that could remedy these inadequacies; and third, it shows how ethical arguments can be refashioned around such a conception of value.

Finally, any explanation must specify its methodology. The thesis combines philosophical inquiry with analysis of comparative constitutional law. It builds on comparative constitutional case law and identifies the central features of ethical arguments in different jurisdictions. But the empirical analysis does not attempt to offer causal explanation of the factors that contribute to the use of these arguments; instead, it seeks to illuminate similar patterns of reasoning in different jurisdictions and capture the nuances that are relevant for the philosophical analysis. The guiding idea behind the case selection is always the same: to illustrate general trends in constitutional reasoning, clarify important distinctions, and provide the foundation for philosophical investigation. The fact that the thesis insists on an empirical grounding for all claims should not obscure the fact that its primary objective is philosophical.

This raises the question of the ambition of the conclusions of the thesis in terms of their universal validity. As will become clear, such ambitions are modest: the aim is not to discover universal truths, but to contribute to the understanding of the world we inhabit. The thesis hence studies constitutional systems that accept certain basic liberaldemocratic principles. The empirical claim of the thesis is then not that these particular 
ethical arguments exist in all constitutional systems, but that they are to a significant extent representative of many important liberal-democratic constitutional systems. The hope is that the thesis will - through a detailed empirical analysis - show the pervasive character of such arguments, and that its findings will resonate with some of the intuitions or concerns about the nature of value in constitutional reasoning. In other words, while the empirical findings are not universal, they should be relevant enough to justify the philosophical inquiry. 


\section{THE IDEA OF CONSTITUTIONAL ETHICS}

\section{Introduction}

The thesis elucidates and reconstructs the philosophical foundations of ethical arguments used in constitutional reasoning. This raises several preliminary questions. First, what are the ethical arguments used in constitutional reasoning? Second, why are their philosophical foundations specifically unclear or in need of reconstruction? Third, what is the suitable perspective to elucidate and reconstruct their philosophical foundations? This chapter seeks to answer these questions. In so doing, it explains the subject matter of the thesis, situates it within the framework of previous attempts to account for similar phenomena, and motivates its philosophical method.

Posing a question about ethical arguments in constitutional reasoning already suggests that there is something specific about them worth investigating; otherwise, we would analyze ethical arguments as such, or - once the specific context of constitutional reasoning is added to the general study of ethics - we would explore a set of ethical concerns that apply to judicial reasoning. This would imply classical questions about moral duties, principles or character traits that are apposite in contemporary constitutional systems. But this is not what I am aiming at. While these questions look at law from the standpoint of ethics, there is an equally interesting and pressing question that asks how ethics appears from the standpoint of law. The focus is on the actual ways in which constitutional courts incorporate ethical concerns in their legal reasoning. One of the central claims of the thesis is that law as a contingent social practice entrenches certain patterns of reasoning that in turn embed particular visions of moral values. These patterns of reasoning - ethical arguments - differ significantly from arguments that we find in ordinary moral discourse. The question is how morality looks like when seen through the lens of constitutional reasoning, and not only the other way round. 
Let me clarify what I mean by ethical arguments with some examples. In his opinion in Furman v Georgia, Justice Marshall of the US Supreme Court held that capital punishment violates the Eighth Amendment 'because it is morally unacceptable to the people of the United States at this time in their history', but that 'this is not to suggest that with respect to this test of unconstitutionality people are required to act rationally', and that the test is 'totally dependent on the predictable subjective, emotional reactions of informed citizens'. ${ }^{1}$ Another example is a remark the Supreme Court of Canada made in Multani v Commission scolaire Marguerite-Bourgeoys, claiming that the prohibition of wearing a Sikh religious dagger in school 'does not take into account Canadian values based on multiculturalism' and neglects the fact that ' $[\mathrm{r}]$ eligious tolerance is a very important value of Canadian society'. ${ }^{2}$ The German Federal Constitutional Court declared in Lüth that the constitution establishes the 'objective order of values' and that - when the courts interpret 'general' clauses containing ethical concepts - 'they must start from the order of values adopted by the society in its constitution at that stage of its cultural and spiritual development.'s Similarly, Justice Sachs of the Constitutional Court of South Africa reflected on - as he puts it - 'the source of values' in $S v$ Makwanyane and argued that the function of the court is to 'articulate the fundamental sense of justice and right shared by the whole nation as expressed in the text of the Constitution'. Finally, Sachs also offered a different and more universalistic conception of values in Minister of Home Affairs v Fourie when he argued that ' $[\mathrm{a}]$ ' the conditions of humanity alter and as ideas of justice and equity evolve, so do concepts of rights take on new texture and meaning' and thus that 'the horizon of rights is as limitless as the hopes and expectations of humanity..$^{5}$ Aiming at a related understanding of values, Justice Kennedy remarked in Roper $v$ Simmons: 'It is proper that we acknowledge the overwhelming weight of international opinion against the juvenile death penalty'. ${ }^{6}$

\footnotetext{
${ }^{1}$ Furman v Georgia 408 US 238 (1972) 360-362 (Marshall).

${ }^{2}$ Multani v Commission scolaire Marguerite-Bourgeoys [2006] 1 SCR 256 paras 71 and 76 (McLachlin).

${ }^{3}$ Abortion Decision I (1975) 39 BVerfGE 1 para C.I.3 Lüth(1958) 7 BVerfGE 198 para B.II.1. See also for example Abortion Decision I(1975) 39 BVerfGE 1 para C.I.3.

${ }_{4} S$ v Makwanyane and Another 1995 (3) SA 391 para 362 (Sachs).

${ }_{5}^{5}$ Minister of Home Affairs and Another v Fourie and Another 2006 (1) SA 524 (CC) para 102 (Sachs).

${ }^{6}$ Roper v Simmons 543 US 551 (2005) 578.
} 
Although these excerpts do not do justice to actual opinions and positions, they support two conclusions: first, all these arguments are ethical in the sense that they aim to contribute to an appropriate evaluative judgment; and second, although we may have an intuitive sense of the nature and place of these arguments which suffices to group them together, they appear to be so heterogeneous that it may seem that the only proper way to distinguish between them is by a negative definition and in relation to the more usual (or 'more legal') types of arguments. Particularly perplexing are the ways in which these arguments locate the source of moral value. Is it people's moral attitudes at a particular moment that matter? Could the decisive guidance be found in the traditional moral commitments of the society as a whole? Is there an objective order of values that is inherent to a properly interpreted constitution? Or can the only genuine lead be discerned from the conception of justice common to humanity? Notwithstanding their differences, all these arguments offer a vision of the nature of values that are brought to resolve constitutional dilemmas. The question hence becomes: what is the ontological status of values that are implicit in these arguments, or - in other words - what are their metaethical foundations?

The examples allow us to tentatively identify at least three distinct answers to this question. We can group them together into three 'regimes' or ideal types of ethical arguments on the basis of their understanding of the source of value. The German Constitutional Court in Lüth and Justice Sachs in Makwanyane refer to common evaluative commitments from the constitution to justify their moral claim. According to this type of ethical argument, the value stems from the constitution itself or from the specific constitutional tradition. Call this the argument from constitutional identity. Another version of ethical argument is based on the prevailing moral intuitions of citizens in the constitutional order. The examples of this approach are Marshall J's opinion in Furman and the Canadian Constitutional Court's remark in Multani. Call this the argument from common sentiment. Finally, Justice Sachs in Fourie relies on a conception of moral value that exists by virtue of our humanity, and is thus applicable to all human beings and transcends national or communal borders. This type of argument typically refers to foreign law to find support for moral judgments, as demonstrated by Justice Kennedy's opinion from Roper. Call this the argument from universal reason. Given that ethical 
arguments in constitutional reasoning have divergent foundations, it is impracticable to define them in advance; the hope is that the thesis as a whole will offer a better idea about their nature and role in constitutional reasoning. Let me nonetheless go through a set of preliminary intuitions that can help us understand the concept of ethical argument. All these intuitions are interconnected, and in the neighborhood of the main attribute of ethical arguments: their orientation towards morally justified solutions to constitutional dilemmas.

First, ethical arguments depend more on their persuasiveness than on authority. Each constitutional argument detects a source of law: an object to be interpreted, such as a constitution, statute, precedent, etc. These sources of law have prima facie authority; to even count as the sources of law they must be considered binding. If we wish to remain acting within legal practice, we need to consult them, and only then can we develop them further, make new law, or refuse to be bound by them. In other words, we cannot disregard them without first checking. In contrast, the arguments we use to interpret these sources may draw their appeal from the authority of the source or from their ability to lead to better moral answers. For example, textual, historical, doctrinal - and other arguments which are not ethical - for the most part draw their force from the authority of the source of law. This is not to say that this authority need not be justified on moral grounds, but only that the issue of justification is considered settled or at least constant when such arguments are used. Conversely, ethical arguments mostly depend on their persuasiveness and ability to lead one to discern moral values that ought to apply to a particular problem. They thus ought to be justified as a reliable source of moral knowledge themselves, and do not derive their appeal from the source of law directly.

This distinction is simplified and can only be true as a matter of degree. ${ }^{7}$ On the one hand, original intentions or particular precedents could be followed because of the belief

${ }^{7}$ Consider for example the following argument from Justice Scalia's dissent in McCreary: 'Those who wrote the Constitution believed that morality was essential to the well-being of society and that encouragement of religion was the best way to foster morality.' (McCreary County $v$ ACLU of Kentucky (2005) 545 US 844887 (Scalia)). Although it carries an ethical message, this argument is not ethical in the 
they are more likely to get the moral answers right. This view may not be common in modern legal systems, as the justification of the authority of legal sources is usually divorced from moral truth and attached to a conception of legitimacy, but it cannot be fully excluded either. ${ }^{8}$ On the other hand - as time passes - the normative appeal of ethical arguments may lessen, but the canons of interpretation may remain and obtain authority of their own. Ethical arguments can thus become more or less entrenched and acquire a binding character, but at least initially they depend on their persuasiveness and on the idea that they will point to morally appropriate solutions. ${ }^{9}$ Therefore, calling an argument 'ethical' is a function of the degree to which such argument aims at a morally apposite answer, and not at the meaning of the authoritative directive. Ethical arguments interfere with our reasons for action more because of their proximity to moral values, and less because of their proximity to (legitimate) authority. ${ }^{10}$

Second, ethical arguments are characteristically used to interpret constitutional clauses which contain ethical concepts. Constitutions - like other legal materials - encompass moral language. The examples include predicates such as 'cruel and unusual', 'equal', 'discriminatory', 'just', or 'fair', and concepts such as 'dignity' or 'liberty'. These are

sense used here. What justifies this argument is a theory about the authority of constitution-framers in constitutional application, and not the sense that framers have a better insight into moral truths.

${ }^{8}$ See Arie Rosen, 'Two Logics of Authority in Modern Law' (2014) 64 University of Toronto Law Journal 669.

9 The mixed character of ethical arguments is clearest in the case of the argument from constitutional identity as it appears to be based only on the authority of the constitution. However - as I will show later on - it in fact derives its force from layers of moral judgments that have been made over time in numerous practices that surround the constitution. The mention of the constitution is in this sense both correct and misleading: it is correct because these practices would not exist without there being a constitution, and misleading because there is typically nothing precise in the constitutional text or original intent that supports moral conclusions based on this argument. The reason I refer to the argument from constitutional sentiment as an ethical argument is two-fold. First, this is the modality of value-based argument most commonly recognized in the literature, so it is useful to see how it figures in the moral judgment of the court; it is typically the first step from legal to moral reasoning of the court. Second, it is still the case that the argument from constitutional identity relies more on its moral plausibility and less on the authority of the constitution, especially when we have in mind the specific conclusion and judgments that courts support with this argument and the sometimes very loose connection between the constitutional text and constitutional identity.

${ }^{10}$ In common law, the distinction is captured by distinguishing between binding and persuasive authority, and in civil law countries the differentiation is between 'formal' and 'informal' sources of law. Unlike common law systems, which consider precedents as 'formal' or 'binding' sources of law, in civil law systems case-law is usually considered only as a 'persuasive' or 'informal' source of law. It is somewhat misleading to call both of these 'sources', for they figure in our reasoning quite differently. On persuasive precedents see Richard Bronaugh, 'Persuasive Precedent' in Laurence Goldstein (ed), Precedent in Law (Clarendon Press 1987). 
usually thick ethical concepts which at least partially depend on an evaluative judgment. ${ }^{11}$ For example, by uttering that someone is 'just', 'fair' or 'cruel', we can competently describe that person or their actions in a particular way and evaluate them at the same time. The fact that ethical arguments interpret ethical concepts does not make them entirely different from other types of constitutional arguments. Within the legal practice of constitutional reasoning, ethical concepts are often applied using arguments that draw their force from an authority. That is why the difference between the two types of arguments is more nuanced and context-dependent: we use ethical arguments almost exclusively to interpret ethical concepts from the constitution, while we use the other types of arguments across the board. But the legal character of ethical arguments also makes them different from ordinary arguments in moral discourse that we use to explicate the very same ethical concepts outside of constitutional reasoning. The application of ethical concepts in law is different from ordinary ethical application, for the descriptive part (say, describing something as 'cruel') over time acquires layers of legal meaning that push back against the force of evaluative judgment. The evaluative judgment in constitutional reasoning thus frequently depends on arguments that are different from both legal arguments and the ethical arguments used in moral discourse. One way to capture the specific character of ethical arguments in constitutional reasoning is to say that they are legal in their form - they are legally accepted ways of argumentation - but they aspire to morally evaluate.

Third, ethical arguments are more often than not oriented towards innovative interpretation rather than towards conserving interpretation. This makes them different from other constitutional arguments in two senses. On the one hand, the sources to which ethical arguments point are more prone to change. Original intentions, textual meaning and doctrine are more fixed than - for example - the current moral feelings of citizens or foreign law. The distinction is not clear-cut: doctrines or rules of language can change, while moral opinions and foreign law can be stable. So - on the other hand - the distinction focuses on the contingent intentions of judges that use these arguments rather than on a conceptual difference between the stability of the sources behind them: ethical arguments are typically connected with the idea that the existing

11 Williams $140-142$. 
law is unsatisfactory and needs to be changed. For example, foreign law never assists the courts in confirming a clear precedent; rather, it is used to support a moral judgment that departs from the idea about the inadequacy of the existing law. Ethical arguments are almost exclusively directed towards innovation and the development of law, while other arguments predominantly preserve (but may also change) the existing state of affairs. ${ }^{12}$

Fourth, ethical arguments will sometimes be characterized as such by judges themselves. Sometimes they even explicitly engage in the question of what morality is. This is predominantly a consequence of the moral language used in constitutions, but is still a separate point because judges openly recognize that they need to have a concept of morality to resolve the constitutional issue before them. Often this is almost inescapable. For example, when a concept such as 'morals' is used as one of the justifications for limiting fundamental rights, the court that first decides on this issue has to define morality. ${ }^{13}$ In so doing - while it can still rely on non-ethical arguments, such as the intentions and purposes of the framers - the court typically opts for an understanding of morality by using a particular type of ethical argument, and this choice in turn constrains future alternatives. For example, ethical arguments may locate the source of value in constitutional identity, prevailing moral sentiments or common human nature, and consequent cases are limited by this choice.

Fifth, ethical arguments will sometimes rely on sources that are not necessarily a product of institutional activity in their legal system in order to interpret the constitution. While this element needs to be specified further, the point is simple enough if previously mentioned elements are taken into account. The sources in question can range from public polls to foreign law. This distinguishes ethical arguments from persuasive sources of interpretation, which are a consequence of institutional activity or people acting in an official capacity within the system, such as dicta from previous cases or preparatory works in the legislature. However, if taken in isolation, this element is both

${ }^{12}$ For an analysis of innovative interpretation see Aileen Kavanagh, 'The Idea of a Living Constitution' (2003) 16 The Canadian Journal of Law and Jurisprudence 55.

${ }^{13}$ See for example European Convention for the Protection of Human Rights and Fundamental Freedoms (ECHR), articles 6(1), 8(2), 9(2), 10(2) and 11(2). 
too narrow and too broad. It is too narrow, for example, because it disregards relying on the opinions of juries and legislatures as an ethical argument, and it is too broad because it includes considerations that may not always aim at reaching just solutions, such as academic articles. But the sources at the basis of ethical arguments are more fluid and underspecified, even when they are a product of institutional activity; for example, instead of pointing to a specific decision of a previous court, they rather refer to the 'spirit' of a previous practice or prevailing 'trends'. Moreover, the use of these sources is an ethical argument only if the court considers them a reliable indication of a morally appropriate judgment.

Ethical arguments could thus tentatively be described as arguments that are: at least partially explained by the belief in their moral attractiveness (regardless of whether that belief is justified); present when ethical concepts in constitutions are interpreted; aimed at innovation rather than at conservation; openly embraced as ethical by courts; or dependent on sources which are not a consequence of a particular decision of an institution in the domestic legal system. They derive their appeal from their moral soundness, whereas other arguments may be taken into account regardless of their moral status. To be accepted, ethical arguments have to obtain a legal form that is customary in the given constitutional system and - at the same time - be considered a reliable way of gaining moral knowledge or reaching a morally sound judgment. One of the central theses of this dissertation is that the legal character of ethical arguments entrenches them as particular ways of understanding morality. Over time, canons of interpretation themselves acquire the prima facie authority that characterizes sources of law, while remaining in conversation with moral considerations.

The criteria for identifying ethical arguments include a fair amount of persuasive sources that we bring to bear on the interpretation of legal sources. In this thesis, I shall focus on three particular types of ethical arguments mentioned in the beginning: argument from constitutional identity, common sentiment, and universal reason. This is because they are the most prominent ethical arguments in practice, the idea that they are connected to moral judgment is still strong, and this connection is at the same time in need of elucidation. A final terminological remark: the conglomerate of ethical 
arguments conventionally entrenched in a constitutional system forms the structure that I shall call constitutional ethics. Constitutional ethics hence presents a number of legally accepted ways in which ethical considerations enter constitutional reasoning. Because some of these ways engrain specific visions of the nature of moral value, constitutional ethics may be incoherent or metaethically implausible. As we shall see for example - the argument from common sentiment focuses on the emotive intuitions of a community, while the argument from universal reason presupposes that humans can overcome these contingent intuitions through reflection and gain true moral knowledge in that process. The goal of the thesis is to bring these problems to the fore, clarify what is at stake, and attempt to resolve them.

This chapter attempts to situate ethical arguments within our existing conceptual universe and position the thesis within several established debates. The first question is whether ethical arguments additionally problematize our understanding of the relationship between law and morality. The thesis presupposes a distinction between law and morality, for otherwise the intuitions about ethical arguments cannot escape being circular: ethical arguments must in some sense be different from all other arguments that are 'legal'. But there is something vexed about the possibility of differentiating between law and morality within legal reasoning. If ethical arguments are legal, how can they be moral at the same time if a difference between law and morality is assumed? In the first part of this chapter, I explore this question and attempt to demonstrate how the thesis can further illuminate the relationship between law and morality. While I do not aim to unlock the standoff between positivism vs. nonpositivism, I hope to take some heat off that debate and - by slightly changing the focus - advance our understanding of the many connections between law and morality. In that sense, the thesis pleas for an empirically informed philosophical analysis of the ways in which morality enters judicial reasoning: it aspires to show that the picture according to which the law runs out at some point and then pure morality takes over is not quite accurate. On the one hand, the law determines the ways in which morality enters judicial reasoning and hence extends further than we may have thought; on the other, it changes the nature of morality that enters judicial reasoning, so that it becomes different from ordinary moral discourse. The thesis thus aims at a more sophisticated 
understanding of both the interaction between morality and law, and the nature of morality in law.

Such an understanding of the nature and place of ethical arguments in constitutional reasoning puts the argument in conversation with the theories of constitutional interpretation. The thesis departs from the idea that constitutional interpretation consists in the use of modalities of arguments pertinent to a specific constitutional culture. Moral arguments thus must take legal form to be successful in constitutional litigation. This presupposes not only that law is not subverted to moral reasoning but also that morality employed through ethical arguments is different from ordinary moral reasoning. While ethical arguments pertain to what is usually understood as the moral reading of the constitution, the thesis - again - calls for a better understanding of the empirical reality of ethical arguments and in particular of their legal character; moral reading of the constitution needs to be sensitive and realistic about existing patterns of reasoning. Moreover, a closer look at ethical arguments reveals that there is a preliminary question as to their metaethical foundations and uncertainty about the place of moral value in the world. Ethical arguments sometimes demonstrate inconsistency or even confusion about the nature of values, and - consequently - about the adequate procedure to discover or construct them. The thesis suggests that a fruitful theory of constitutional interpretation ought to be aware of the actual argumentative patterns in constitutional reasoning and sort out their puzzling philosophical foundations. The message the thesis wishes to convey - for both jurisprudence and constitutional theory - is that there are two ways in which we ought to expand the horizons of contemporary debates if we wish to understand the relationship between law and morality better: first, there is a need for a more nuanced understanding of the actual ways in which moral concerns enter judicial reasoning; second, instead of focusing on the concept of law only, we also need a more refined idea of morality, and in particular of its specificities in the context of law.

The second part of the chapter further investigates the intuition that there are legal constraints to ethical arguments. It explores some previous attempts to account for these constraints. Because the canons of interpretation limit ethical arguments, certain 
scholars have been tempted by the conclusion that their content can be found in the constitution. They associate one type of ethical argument - the argument from constitutional identity - with the entirety of constitutional ethics. In this part of the chapter, I show that the argument from constitutional identity does form a significant part of the practice and consists in two distinct trends: one which relies on the idea of having a constitution in general, and the other which is grounded in the specificities of each constitutional order. However, the argument from constitutional identity does not exhaust constitutional ethics, and thus cannot be a basis for a complete account of ethical arguments in constitutional reasoning. Later chapters thus deal with these other types of ethical arguments.

The thesis starts from the intuition that patterns of ethical arguments constrain judicial metaethical choices. Each ethical argument finds a distinct place for moral value in the world. The goal of the thesis is to bring these divergent visions of value to the fore and resolve the tensions between them. The third and last part of this chapter focuses on some necessary clarifications that will enable me to execute this task: first, it motivates the philosophical approach of the thesis; and second, it introduces the elements of metaethical grammar that will present the basis of the analysis of ethical arguments in the following chapters.

\section{Morality legalized}

Let me start with a modest observation: the morality that appears in constitutional case law differs from ordinary moral reasoning. Legal reasoning is affected by morality, but legal reasoning in turn affects the kind of morality we find in law. This is rather uncontroversial. It is natural for a discourse to adjust to the ways in which moral issues are authoritatively resolved. When G.E.M. Anscombe changed the landscape of moral theory in 1958 she argued that much of moral language had been misguided because it relied on a divine authority that was absent in modern circumstances. ${ }^{14}$ Anscombe characterized this flawed morality as 'law conceptions of ethics':

\footnotetext{
${ }^{14}$ G.E.M. Anscombe, 'Modern Moral Philosophy’ (1958) 33 Philosophy 1.
} 
... between Aristotle and us came Christianity, with its law conception of ethics ... In consequence of the dominance of Christianity for many centuries, the concepts of being bound, permitted, or excused became deeply embedded in our language and thought. ${ }^{15}$

Christian ethics may not be the dominant model of ethical thinking today, but we still have - as it were - a 'law conception of ethics'. The new paradigm is constitutional ethics. All significant moral debates are profoundly influenced by the ways the supreme judicial bodies reason about them. Abortion, euthanasia, torture, hate speech, capital punishment: philosophical and political discourses about these issues are, if not hijacked by legal reasons, then at least significantly affected by them. ${ }^{16}$

Any attempt to influence the judicial decision-making must abduct the grammar of legal argumentation to be successful. Take for example the 'The Philosophers' Brief', written by six leading political philosophers about the assisted suicide cases pending before the US Supreme Court. ${ }^{17}$ The substantive part of the Brief states in its opening:

\begin{abstract}
These cases do not invite or require the Court to make moral, ethical, or religious judgments about how people should approach or confront their death or about when it is ethically appropriate to hasten one's own death or to ask others for help in doing so. On the contrary, they ask the Court to recognize that individuals have a constitutionally protected interest in making those grave judgments for themselves, free from the imposition of any religious or philosophical orthodoxy by court or legislature. ${ }^{18}$
\end{abstract}

\footnotetext{
15 Ibid $4-5$.

${ }_{16}$ This idea is captured in many different ways. Recently it has been put in the vocabulary of 'judicialization of politics' (Martin M. Shapiro and Alec Stone Sweet, On law, Politics, and Judicialization (Oxford University Press 2002)) or 'juristocracy' (Ran Hirschl, Towards Juristocracy: The Origins and Consequences of the New Constitutionalism (Harvard University Press 2004)).

${ }^{17}$ Ronald Dworkin and others, 'Assisted Suicide: The Philosopher's Brief [27 March 1997] The New York Review of Books <http://www.nybooks.com/articles/archives/1997/mar/27/assisted-suicide-thephilosophers-brief/>.

18 Ibid.
} 
Contrary to what one would expect from a perspective taken by Ronald Dworkin on behalf of other authors in the introduction to the Brief - 'I am unaware of any other occasion on which a group has intervened in Supreme Court litigation solely as general moral philosophers' ${ }^{19}$ - the philosophers begin their Brief with the explicit renouncement of what could actually be the domain of their mastery. That was not just lip service to the Court. The general tenor of the Brief is legal and doctrinal. The main conclusion of the philosophers is that a decision that would run against their Brief, would be 'flatly in conflict with the spirit and letter of the Court's past decisions'. ${ }^{20}$ This is not to say that the moral position has not been defended; however, this has been done using constitutional and not philosophical or moral grammar.

This is not surprising: success in passing a policy depends on engaging in those types of arguments that have a chance to succeed. Had the Philosophers' Brief been written as a philosophical treatise it would have been bound to fail. Culturally embedded ways of legal argumentation together with the pressure on courts to appear as law-applying and not law-making institutions makes them less sensitive to pure moral arguments and less prone to use them in their reasoning. Going back to Anscombe's argument, we can see that contemporary moral discourse is - for better or worse - influenced by legal types of arguments. We still have 'the law conception of ethics', although a different one: the divine will of today is constitutional reasoning. ${ }^{21}$ The point I wish to make with this metaphor is that it is a mistake to think of morality as something that exists apart from legal reasoning and that at times finds its way to judicial decisions while retaining its distinctive character, unaffected by the whole process. Instead, the morality used in constitutional cases is by and large constructed by constitutional reasoning. It is not the case that morality is just 'abducted' by law. Law also makes it quite different.

Let me use a classic example to illustrate this. The 8th Amendment to the US Constitution prescribes 'cruel and unusual' punishment. The clause contains an ethical

\footnotetext{
19 Ibid, footnote 2 , emphasis added.

${ }^{20}$ Ibid.

21 This much has been clear to most social theorists, with the most notable example being Durkheim. See e.g. Emile Durkheim, Durkheim and the Law (Steven Lukes and Andrew Scull eds, St. Martin's Press 1983) $\operatorname{ch} 2$.
} 
concept ('cruel'). It further refers to 'unusual' punishment, which may serve to specify what is 'cruel' (assuming that prevailing penal practices will not be cruel), or it could be a self-standing ethical concern (not to punish in unusual and broadly speaking unexpected ways). The constitution thus invites moral judgment and suggests - on one reading at least - that the court ought to look for clues about the appropriateness of punishment in worldly penal practices. But it is not clear which and whose practices are relevant: contemporary practices, or those prevailing at the time of the adoption of the constitution; American, or global? There is thus some leeway for the court's moral judgment.

The US Supreme Court developed a test in Tropp v Dulles, according to which the meaning of the phrase 'cruel and unusual' is to be derived from 'the evolving standards of decency that mark the progress of a maturing society'. ${ }^{22}$ This test has further restrained the kind of ethical arguments that might be put forward. Notice how many assumptions about morality this simple test makes: moral knowledge is expressed in contingent social practices (in their 'standards of decency'); moral truths can change over time with the development of social standards; the evolution of morality is always for the better (the reference to 'progress' of a 'maturing' society); the progress of morality is potentially ever-growing (there is no certain point in which we can tell we have achieved moral truths). This interpretation narrows down the kinds of ethical arguments that the court employs in its reasoning as it excludes the possibility to argue from a different perspective about morality; for example, one that would fix moral knowledge with a reference to the wisdom of the constitution framers or teachings of moral philosophers. It also leaves the space open to connect the idea of morally appropriate punishment to both local or global trends: as we shall see later on, one interpretation of the test is that moral answers ought to be found in the positions of domestic legislatures or juries, and the other that these positions need to be corrected on the basis of foreign legal practices. ${ }^{23}$

22 Trop v Dulles 356 US 86 (1958) 100-101.

23 See the discussion of US death penalty cases in the next chapter. 
Now we come to the main point: law limits the kinds of arguments that can be brought to interpret an ethical concept to a set of concerns that have no or very little purchase in ordinary moral discourse. Consider how this question would be answered if there were no constitution or doctrine. Would anyone in ordinary moral discourse rely on what courts in other countries do? Do we look at legislative trends to determine whether something is cruel? Almost certainly not: we would consider such arguments as confused. Thus, the layers of legal decisions restrict the understanding of morality and bring an altogether different set of concerns and arguments to bear on moral judgment. Instead of arguing - for example - whether cruel punishment violates one's dignity, brings the greatest happiness for the greatest number, or corrupts character, we look at trends in foreign or domestic legislation.

Observe the level at which the difference between ethical arguments in constitutional reasoning and pure moral arguments arises: because ethical arguments focus on certain contingent facts as proxies for moral knowledge they are compatible with many different substantive moral positions as long as they are expressed in these facts. The restriction thus occurs at the level of metaethics. Interpretive conventions answer questions such as: in virtue of what are moral judgments true; how do we know what is morally good; is moral value universally human or contingent upon different cultures; is the foundation of moral judgment emotive or reason-based? Because of entrenched patterns of ethical arguments these questions are sometimes answered by the constitutional culture which predates the choice of a particular judge. Thus, some general moral arguments may not be used in constitutional reasoning, and some legal arguments - even the ones that determine the meaning of ethical concepts - are without force in moral discourse. Ethical arguments become systematic patterns of reasoning from a particular metaethical position.

2.1 The jurisprudence of ethical arguments

While ethical arguments in constitutional reasoning do take on a different shape from ordinary moral arguments, it is hard to pin them down with sufficient precision. There 
is something about them that resists crude compartmentalization into judicial law making or law applying. As Jeremy Waldron observes, judicial moral reasoning:

\begin{abstract}
is not pervasive moral reasoning by the standards of moral theory, but a mélange of reasoning - across the board - which, in its richness and texture, differs considerably from pure moral reasoning. ${ }^{24}$
\end{abstract}

At least two reasons make ethical arguments hard to distinguish from other types of arguments. First, just like The Philosophers' Brief, they frequently start from another argument based on precedent, history or possible readings of constitutional text. (In fact, at least one of them - the argument from constitutional identity - considers constitutional tradition as a whole to be a source of value.) In the case of the $8^{\text {th }}$ Amendment, the judgment about morally appropriate punishment departs from the text itself, and previous precedent that determined the approach to its interpretation. By so doing ethical arguments tacitly accept the authority of the rule-maker, which makes them appear completely legally constrained. Second, through this process moral principles do become 'legalized' as they transform into doctrines. The process of 'creeping legalization' is obvious when principles that invite moral reading - such as 'reasonable' - are being concretized in legal practice and hence acquire legal form. For example, 'reasonable damages' might in ordinary language imply different things, but in law they would usually be set in accordance with what has been the practice in similar cases before. This is also true of ethical arguments in constitutional reasoning; a previous precedent may already answer whether - for example - capital punishment for rape is cruel and unusual. ${ }^{25}$ But more importantly, while the moral soundness of these arguments does play a role in their attractiveness and persuasive force, over time they obtain a legal form to be followed in order to reach a substantive moral judgment. As we have seen, we may intuitively describe these arguments as ethical or moral, but we never use them in ordinary moral talk.

\footnotetext{
${ }^{24}$ Jeremy Waldron, 'Do Judges Reason Morally?' in Grant Huscroft (ed), Expounding the Constitution: Essays in Constitutional Theory (Cambridge University Press 2008) 51.

${ }^{25}$ See for example, Coker v Georgia 433 US 584 (1977) and Kennedy v Louisiana 554 US 407 (2008).
} 
How can we explain this mix between law and morality? It seems to invite the conclusion that we cannot draw a sharp enough line between the two domains, even though it is deeply engrained in our vocabulary. It is typical to move from the thought about intricate connections between the two modes of reasoning to a conceptualization of law as completely subordinate to ethical concerns. A famous example is Ronald Dworkin's theory of law and adjudication. Dworkin attempts to explain this overlap between law and morality, and at the same time to account for the intuition that judges move within the domain of law when they make moral arguments. His response is to abolish the distinction between law making and law applying and deny the point in which the law 'runs out' and the judiciary exercises discretion. In his view, a proposition of law is true in virtue of moral judgment: each time we reach a conclusion as to what the law is in a particular case we resort to moral criteria. ${ }^{26}$ His ultimate answer is that law simply is a part of political morality:

\begin{abstract}
We have now scrapped the old picture that counts law and morality as two separate systems and then seeks or denies, fruitlessly, interconnections between them. We have replaced this with a one-system picture: we now treat law as a part of political morality. ${ }^{27}$
\end{abstract}

This is the conclusion I want to resist. ${ }^{28}$ As we have seen from the examples of ethical arguments - and as the thesis will attempt to show in full detail - the law has a

\footnotetext{
${ }^{26}$ Dworkin, Law's Empire ch 2.

27 Dworkin, Justice for Hedgehogs 405. While Dworkin arguably once wanted to take the middle ground between legal and moral concerns and integrate them into a coherent picture of interaction between law and morality in interpretation (through his distinction between 'fit' and 'interpretation'), in the end he has subsumed the law completely within morality. This has been the reading advocated by Stavropulos and in my view - is the only coherent one that Dworkin could take: 'The interpretivist does not accept, nor does the fit-justification distinction properly understood entail, a distinction between the data and their reading that is prior to and independent of interpretation. [...] No aspect of the practice can be taken as a non-interpretive given. Rather, they are both parts of the interpretive, thoroughly normative account.' Nicos Stavropoulos, 'Legal Interpretivism' in Edward N. Zalta (ed), The Stanford Encyclopedia of Philosophy (Summer 2014 Edition) <http://plato.stanford.edu/archives/sum2014/entries/law-interpretivist/> The picture of interpretation that I offer is directly opposed to this account in that it attempts to show that interpretation is primarily legally constrained.

${ }^{28}$ To fully understand and criticize Dworkin's theory would take much more space. For successful criticisms, along the lines I wish to pursue - roughly, because Dworkin's theory does not pay due regard to the actual practice of law - see Dennis M. Patterson, Law and Truth (Oxford University Press 1996) and Brian Leiter, 'Explaining Theoretical Disagreement' (2009) 76 The University of Chicago Law Review 1215.
} 
significant constraining force over morality. In fact, judicial efforts to develop the law further in a morally appropriate way often do not even resemble typical moral arguments. So I wish to start from the other end and see how we can account for ethical arguments as legal.

The rules determining the acceptability of a particular argument are embedded in conventions of interpretation in a given constitutional culture. Law is an argumentative practice, and even ethical arguments used in law are constrained by the rules of that practice. ${ }^{29}$ Judges are frequently criticized for not applying law but 'doing politics' or legislating their 'ideological preferences'. To remain within the practice of law - often understood as the only legitimate position for judges to take - they apply legal forms of arguments. For example, Philip Bobbitt gives an account of the accepted modalities of constitutional argument in the American context as follows:

... historical (relying on the intentions of the framers and ratifiers of the Constitution); textual (looking to the meaning of the words of the Constitution alone, as they would be interpreted by the average contemporary "man on the street"); structural (inferring rules from the relationships that the Constitution mandates from the structure it sets up); doctrinal (applying rules generated by precedent); ethical (deriving rules from those moral commitments of the American ethos that are reflected in the Constitution); and prudential (seeking to balance the costs and benefits of a particular rule). ${ }^{30}$

Just like language, constitutional interpretation has its own grammar which makes the propositions of law true. Modalities of constitutional argument are in this sense the ways in which legal propositions are characterized as true from a constitutional point of

\footnotetext{
${ }^{29}$ See more on this view of law in Patterson. For a practice-based theory of law that adds to it an element of rationality based on our autonomy and capacity to act on reasons see: George Pavlakos, Our Knowledge of the Law: Objectivity and Practice in Legal Theory (Hart Publishing 2007) and George Pavlakos, 'Practice, Reasons, and the Agent's Point of View' (2009) 22 Ratio Juris 74.

${ }^{30}$ Bobbitt, Constitutional Interpretation 12-13. The concept of ethical argument that I develop differs from Bobbitt's both to account for a wider range of phenomena in comparative practice and to underline the intrinsic connection between ethical arguments and moral value.
} 
view'. ${ }^{31}$ The philosophical lesson goes beyond the specific point about the American constitutional culture: each legal culture has its own constitutional grammar.

The question is how to account for the nature of ethical arguments within the framework of argumentative modalities? The emphasis on legal constraints to ethical arguments puts us in the neighborhood of positivist thinking about law. But although positivism revolves around the relationship between law and morality, this is not the question it has answered so far. The underlying idea behind positivism is that there must be no confusion between what the law is and what it ought to be; positivism is thus mainly concerned with the ontology of law in relation to morality and with the existence conditions for legal rules. ${ }^{32}$ The classical challenges to positivism have then argued the opposite: that moral reasons determine the validity of legal rules..$^{33}$ It is thus an altogether different and somewhat perplexing challenge to say that what the law is might determine what the law ought to be. This of course need not be seen as a paradox but as a sleight of hand: ethical arguments may not really determine what the law ought to be but merely attempt to do so. Ethical arguments would on this view try to develop law in morally acceptable ways but might well fail to accomplish this. However, this line of argument must first have an account of morality and then establish how ethical arguments fare in trying to achieve it. The thesis therefore aims to offer a plausible metaethics and an analysis of the appropriateness of ethical arguments against such metaethics.

Let me be clear. Ethical arguments need not undermine the positivist claim that the existence of law and legal systems depends on social rules constituted by persistent patterns of behavior and attitudes towards such behavior. ${ }^{34}$ But the study of ethical

\footnotetext{
${ }^{31}$ Ibid 12.

${ }^{32}$ H.L.A. Hart, 'Positivism and the Separation of Law and Morals' in Essays in Jurisprudence and Philosophy (Clarendon Press 1983).

${ }^{33} \mathrm{Or}$ - as Dworkin would have it - that they determine 'the truth of legal propositions'. See the 'grounds of law' question in Dworkin, Law's Empire ch 1.

${ }^{34}$ Raz succinctly explains the ontology of law in the following manner: 'The existence of every law depends on the existence of the legal system to which it belongs, and the existence of legal systems depends on persistent and pervasive patterns of behaviour on the part of a large proportion of the population to which they apply.' Joseph Raz, The Concept of a Legal System: An Introduction to the Theory of the Legal System (2 edn, Oxford University Press 1980) 150.
} 
arguments may expand the positivist project in yet another direction. Positivists have traditionally understood the question about the nature of law as a question of what makes normative order a legal order. ${ }^{55}$ In so doing, they have provided a satisfactory account of the structure of a modern legal system - in Hart's version - as a system of rules validated by a customary practice at its foundation. ${ }^{36}$ Dworkin has changed this perspective and pushed the positivists to answer another question: a theory of the nature of law - on his interpretation - must account for the question of what the law is, i.e. how the concrete content of the law is determined. ${ }^{37}$ Dworkin's trademark argument is that a custom cannot be the foundation of law because there is judicial disagreement about it; 38 instead, law's foundation is to be sought in right moral answers. It is up to positivism to provide a theory of adjudication that will show how the system of rules is transformed into a set of legal requirements without necessarily implicating moral concerns and - at the same time - to account for the judicial claim that they are always merely applying the law.

A standard answer to this challenge on the part of positivism is to say that the major part of legal practice does not give rise to disagreements about the social norms that give law its foundation; ${ }^{9}$ it is also implicit in this answer that judges do make law without (most of the time) explicitly acknowledging they do so. This position makes judges either disingenuous or confused about what they are doing. The study of ethical arguments adds some details to this picture. Positivists ought to say more about legal constraints to the judicial development of law which can account for at least one sense in which the judicial self-understanding is neither disingenuous nor confused. This is

\footnotetext{
35 See for example Joseph Raz, The Authority of Law: Essays on Law and Morality (Clarendon Press 1979) ch 6 .

${ }^{36}$ H.L.A. Hart, The Concept of Law (2 edn, Clarendon Press 1994) chs 5 and 6.

${ }^{37}$ In his influential critique of positivism Dworkin drew attention to an important aspect of law as an argumentative practice: to arguments that support the truth of legal claims. See in particular Dworkin, Law's Empire ch 1.

${ }^{38}$ Ibid chs 2 and 3.

${ }^{39}$ Leiter 1222; Frederick Schauer, 'Easy Cases' (1985) 58 Southern California Law Review 399. Even Dworkin used to accept the claim (which directly contradicts his later views) that every legal decision necessarily implies a moral decision as well: 'Our constitution is law, and like all law it is anchored in history, practice and integrity. Most cases in law - even most constitutional cases - are not hard cases. The ordinary craft of a judge dictates an answer and leaves no room for the play of personal moral conviction.' Freedom's Law: The Moral Reading of the American Constitution (Harvard University Press 1996) 11.
} 
not so say that there were no such attempts before, but that these attempts need more detail so that they do not collapse into a picture of interpretation as a purely moral exercise.

Joseph Raz, for example, once outlined a positivist theory of adjudication sensitive to interpretive conventions ${ }^{40}$ while also recognizing their legal nature: 'the character of the rules of interpretation prevailing in any legal system, i.e., the character of the rules for imputing intentions and directives to the legal authorities, is a matter of fact and not a moral issue.' ${ }^{41}$ Raz's picture implies that rules of interpretation are 'a matter of fact' because they are oriented towards discerning the meaning of an authoritative directive which itself is a fact. ${ }^{42}$ But this does not account for innovative interpretation that aims to develop constitutional meaning in morally apposite ways. In his later attempt to account for innovative interpretation, Raz moves towards a view of constitutional interpretation as a purely moral exercise: interpretation becomes a function of the correct explication of the legitimate authority of constitutions. ${ }^{43}$ In his view, constitutional interpretation depends on the authority of constitutions that in turn depends on substantive morality; it follows that only substantive moral concerns may determine the principles of interpretation. ${ }^{44}$ It is for this reason that there is no universal theory of interpretation that applies to all law, except as a normative theory that is, of what interpretation should be like'. ${ }^{45}$ Raz further adopts a skeptical view of the conventions of interpretation: judges as public officials may not resolve moral issues according to their personal opinions, so they need to resort to doctrines as 'distancing devices' that 'settle ... issues in a way that is independent of personal tastes of the judges'. ${ }^{46}$ Because doctrines are a function of morality - as Raz puts it, ' [1] egal doctrine can be, of course, no more than what morality dictates' 47 - to the extent they take a 'life

\footnotetext{
${ }^{40}$ Raz, The Authority of Law: Essays on Law and Morality ch 10. In Raz's view, because rules of interpretation support conclusions about factual intentions and directives they must also be facts.

${ }^{41}$ Ibid 233.

${ }^{42}$ Ibid.

${ }^{43}$ Joseph Raz, 'On the Authority and Interpretation of Constitutions: Some Preliminaries' in Between Authority and Interpretation: On the Theory of Law and Practical Reason (Oxford University Press 2009) $328-329$.

${ }^{44}$ Ibid 329-343.

45 Ibid 356.

46 Ibid 369.

47 Ibid.
} 
of their own, detached from moral considerations' they serve only as 'distancing devices'. ${ }^{48}$ Two reasons therefore make the rules of interpretation uninteresting: their contingent character and their role as a cover for an illicit moral judgment.

Whereas it is true that conventions of interpretation are used to remove the appearance of moral choice in the hands of judges, I suggest that positivists ought to have a better account of these distancing devices as they have a considerable constraining force on how constitutions are applied. These arguments show how legal rules are developed in a legal manner and thus supply positivists' statics (the account of a legal system) with the dynamics (explanation of application and development of law in adjudication). Moreover, if we wish to follow Raz's project of normative study of interpretive conventions, we need to be realistic about the ways in which morality does enter judicial reasoning. It is not completely accurate to think of ethical arguments as distancing devices'. Even if they acquire legal form over time, they still enable the court to make a moral judgment: they develop out of the sense of appropriateness for the position of judges as they interpret the constitution, and with a view of making good moral calls. Finally, canons of interpretation are not merely a function of morality, but rather morality becomes a function of them. A specific vision of morality arises from the host of these 'distancing devices'. To understand this we need to reject Raz's claim that conventions of interpretation are philosophically irrelevant because they are empirical and contingent. ${ }^{49}$ As I hope to show in the thesis, the empirical context of ethical arguments is highly relevant for philosophical analysis.

To the extent that we do not account for the patterns of reasoning through which the law is developed, we encourage Dworkin's picture of legal positivism whereby the law runs out as soon as judges start applying legal rules. This view of positivism implies metaphorically speaking - something like a highway on which we ride at full speed until we reach its end. At its end, there is a desert of discretion where no legal rules apply and pure morality (whatever it may be) takes over. Although this may not be an accurate representation of positivism, it nonetheless does point to a gap in positivist theory that

${ }^{48}$ Ibid.

49 Ibid $352-357$. 
needs to do more to account for adjudication as a legally constrained law-making exercise. What I want to suggest is that ethical arguments serve as one of the legal ways in which this highway is built; we do not reach the end of the highway without legal tools to develop it further. On this picture, we have legal rules that determine the outcome of the case, but also legal rules that determine how other legal rules are judicially developed.

This of course closely resembles Hart's account of law. As is well known, Hart's theory of law is premised upon the existence of three kinds of secondary rules, i.e. rules about other legal rules. These are: 'rules of adjudication' which empower individuals or institutions to make authoritative statements of whether primary rules have been breached or not, and which identify the procedure for doing so; 'rules of change' that authorize institutions to amend or alter the rules, and also prescribe a method for doing so; 'rules of recognition' which 'will specify some feature or features possession of which by a suggested rule is taken as a conclusive affirmative indication that it is a rule of the group to be supported by the social pressure it exerts..$^{50}$ Rules of recognition and modalities of legal and constitutional argument are quite similar. They are both social rules that exist in the practices of officials. The role of the rule of recognition is to provide a test for identifying valid rules to be applied. Modalities of argument furnish the manner in which these rules are applied. But it could also be argued that modalities of argument imply the validity of rules. They in fact often presuppose a valid rule. Textual argument entails a text to be applied, and this implies that officials will make a difference in the legal validity of, say, the text of Shakespeare's 'Hamlet' and the constitution. They must first recognize the former as legally irrelevant and the latter as legally valid. In the same way, doctrinal argument indicates the legal validity of a precedent, and so on. It is Hart's view that 'For the most part, the rule of recognition is not stated, but its existence is shown in the way in which particular rules are identified'. ${ }^{51}$ By using the modalities of argument we also show which rules are valid.

\footnotetext{
${ }^{50}$ Hart, The Concept of Law 94.

${ }^{51}$ Ibid 101.
} 
The ultimate rules of recognition and the modalities of argument are not derived from any further legal reason. To have a complete theory of law that explains both the validity of rules and the truth of legal propositions, it is useful to think of the modalities of argument as a part of the complex rule of recognition; in other words, as an important way in which valid rules are identified. To show the truth of a proposition of law - to use Dworkin's vocabulary - rules of recognition and modalities of argument must work together.

The perplexing element in this account is that rules of interpretation not only determine valid legal sources, but could also determine how we apply them and even how we change them. The question becomes particularly pressing in the case of ethical arguments and their place within this framework. Ethical arguments detect a valid source of law - for example a constitution - but they also bring other non-legal materials to interpret it. It seems unjustified to think of them as rules of recognition only. They might point to materials that would not be commonly described as 'law', such as public opinion, foreign precedents, etc. Perhaps the best way to make sense of rules about ethical arguments is to say that they are also the rules of change: they determine legally accepted ways to develop the law and apply indeterminate rules, while they do not at the same time turn the materials they refer to into valid legal rules. Their dual character may confuse us, but we may be reminded that it is not unusual for one rule to achieve two purposes: for example, in Hart's account, the rules of recognition both determine the valid sources of law and single out the officials of one legal system. Similarly, an ethical argument recognizes a source of law (e.g. constitution) but also changes or specifies its meaning in light of something that is not a legal rule (or not even a rule, e.g. public opinion).

Now, while this makes sense of the legal nature of ethical arguments, it does not even scratch the surface of their moral nature. The task of the thesis is to do precisely that. Let us however see how exclusive and inclusive positivism would account for their moral character. The purpose here is to demonstrate that a theory that aims at an account of law without having an account of morality is not apt to differentiate between the two in the context of ethical arguments. Exclusive legal positivists believe that - as 
Raz puts it - 'all law is source-based' which means that 'its existence and content can be identified by reference to social facts alone, without resort to any evaluative argument'. ${ }^{52}$ Inclusive legal positivists - according to Coleman - trust that 'the existence of the criteria of legality in any community depends on social facts', but that 'the criteria themselves need not state social facts'. ${ }^{53}$ While exclusive and inclusive legal positivism do not address ethical arguments directly, this problem may tease out some of their inadequacies. As I shall argue, we need a more sophisticated theory of the metaethical foundations of ethical arguments that should inform the positivist theory of adjudication.

Both exclusive and inclusive legal positivism accept that ethical arguments appear in judicial reasoning; the dispute is whether moral language in law only refers to or also incorporates morality. If the rule of recognition does incorporate morality, then one of its aspects is particularly perplexing. Rules of recognition provide the criteria that other rules need to fulfill in order to be legally valid. If this is the sole purpose of the rule of recognition, it follows that all rules that fulfill these criteria are legally valid and hence are law. For this reason, Scott Shapiro compares rules of recognition with a 'vortex' that 'sucks in other normative systems'; ${ }^{44}$ Leslie Green calls this property of the rule of recognition the 'King Midas Principle', because whichever other rule is recognized by the rule of recognition and applied in a legal system becomes law, just like whatever King Midas touched became gold. ${ }^{55}$ This characterization of law is indeed puzzling. For example, when laws of other jurisdictions are applied by officials in jurisdiction $Z$ under the conflict of laws rules they do not become a part of Z's legal system. In the same way, morality does not become a part of law by appearing in judicial reasoning. ${ }^{56}$ The argument has intuitive plausibility because we normally distinguish between law and

\footnotetext{
52 Joseph Raz, 'Authority, Law and Morality' in Ethics in the Public Domain: Essays in the Morality of Law and Politics (Clarendon Press 1994) 211.

${ }_{53}^{5}$ Jules L. Coleman, The Practice of Principle: In Defence of a Pragmatist Approach to Legal Theory (Oxford University Press 2001) 107.

${ }^{54}$ Scott Shapiro, 'What is the Rule of Recognition (and Does it Exist)?' in Matthew D. Adler and Kenneth Einar Himma (eds), The rule of recognition and the US Constitution (Oxford University Press 2009) 246247.

${ }^{55}$ Leslie Green, 'Legal Positivism' in Edward N. Zalta (ed), The Stanford Encyclopedia of Philosophy $<\mathrm{http}$ // / plato.stanford.edu/archives/fall2009/entries/legal-positivism/ > .

${ }^{56}$ Raz, The Authority of Law: Essays on Law and Morality 97-98.
} 
other normative systems, so we may want to rethink the conception of law that cannot account for this distinction.

Even if the inclusive positivists argue that all other normative systems are applied only by virtue of a socially-based rule of recognition, the 'vortex' character of the rules of recognition does point to the tension within the view that on the one hand differentiates between law and morality, and on the other brings them together so that morality becomes a part of law. What is missing is an account of the ways and processes by which legal rules structure the use of morality. Inclusive positivists need not deny that morality and law are separate normative systems, but if the rule of recognition is testlike and contains only criteria of validity then indeed all moral rules once applied become law because they are valid. It is apparent that something like this does occur over time, yet it is far from certain that it suffices for an external rule to satisfy the 'criteria' of validity to become law. Furthermore, morality applied through legal reasoning may not consist of 'rules': it may - for example - be expressed in moral beliefs or intuitions prevailing at the time. ${ }^{57}$

Exclusive legal positivists on the other hand come across as ripe to offer an account of ethical arguments, because they believe that social facts alone determine both the existence and content of law. ${ }^{58}$ Therefore, ethical arguments would be all those arguments that refer to things that are not social facts. This position however rests on a simplified view of morality and the ways in which it features in judicial reasoning. It fails to explain references - for example - to a social fact of something being morally accepted in a society as pertaining to morality and not law. ${ }^{59}$ Because the exclusive positivist typically (but not necessarily) thinks of morality as transcendent, ${ }^{60}$ 'popular

\footnotetext{
${ }^{57}$ See the argument in Furman $v$ Georgia cited at the beginning of the chapter.

${ }_{58}$ Raz, The Authority of Law: Essays on Law and Morality 37-52.

${ }_{59}$ Moreover, some positivists - such as Raz - are moral realists, with their moral realism having a significant role in their theory of law. For example, Raz thinks that law must preclude reasons for action that already apply to us: this assumes that there are reasons for action that law claims to preclude. See more in Brian Leiter, 'The Demarcation Problem in Jurisprudence: A New Case for Scepticism' (2011) 31 Oxford Journal of Legal Studies 663.

${ }^{60}$ Scott Shapiro offers this kind of distinction. For him, morality is universal and unchangeable: 'While legal rules routinely change over time, moral rules do not'. Scott Shapiro, 'On Hart's Way Out' in Jules L. Coleman (ed), Hart's Postscript: Essays on the Postscript to the Concept of Law (Oxford University Press 2001)
} 
morality' arguments used by Marshall $\mathrm{J}$ in Furman or the Canadian Supreme Court in Multani refer to social, thus possibly legal and not moral sources. However, this would undermine arguments that typically motivate exclusive positivism: moral conventions are uncertain and their inclusion in the concept of law would impair its coordinating function; furthermore, it is not clear why moral conventions are something altogether different from reasons for action that law is supposed to 'preclude' in the first place. ${ }^{61}$ Moreover, 'public' or 'popular' morality is still morality and not law, and it is dubious to understand prevailing moral opinions as law just because they exist in social reality. If exclusive positivism takes this path - arguing that popular morality used in legal reasoning is not law - then the claim that law is a social fact cannot do much work on its own to distinguish law from morality. ${ }^{62}$

The inclusive positivists do not have a good answer either. While the inclusive positivists match our intuitions when they argue how references to morality can be legal, it is neither clear what is gained with a claim that it is the rule of recognition that allows for morality to enter legal reasoning, nor with the conclusion that moral rules become law in the process. Ethical arguments show that this need not be the case. Inclusive positivism, for example, falls short of explaining the use of foreign law as a source of knowing morality. On the inclusivist account, such rules of foreign law determine the content of law and thus can properly be considered domestic legal rules.

498. Raz also relies on the objective reasons for action that we all have to motivate his theory, for these are the reasons that the authority of law precludes (see previous note). Exclusive positivism need not of necessity presuppose this view of morality. Brian Leiter for example accepts exclusive positivism - among other reasons - because it need not suppose a transcendent understanding of morality. See for example Brian Leiter, 'Why Legal Positivism (Again)?' [2013] University of Chicago Public Law Working Paper 442 .

${ }^{61}$ This undermines both Shapiro's and Raz's version of exclusive positivism. We have no reason to distinguish between 'transcendent' and 'social fact' morality here: they both jeopardize the law's ability to preclude reasons for action or guide human behavior. Furthermore, the acceptance of ethical arguments as legal cuts against the distinction between applying the existing law and developing new law in accordance with what it ought to be. If existing moral beliefs are law because they are a social fact, then whatever is in line with such beliefs is legal. Ethical argument based on it would not fill the gap, but rather just apply what had already been the law.

62 To avoid this conclusion, exclusive positivists may either drop the assumption that morality cannot be a social fact, or argue law is constituted only by institutional or 'pedigreed' facts and not any social facts. Both paths could be handled by exclusive positivists but at the price of having to motivate their views differently and drop the social fact thesis as crucial in distinguishing between law and morality. See more on these issues in Kenneth Einar Himma, 'Inclusive Legal Positivism' in Jules L. Coleman and Scott Shapiro (eds), The Oxford Handbook of Jurisprudence and Philosophy of Law (Oxford University Press 2002) 163-164. 
This neither corresponds with how the participants see that process, nor do these 'rules' have the same effect and influence over legal practice as other, 'proper' legal rules in a legal system. ${ }^{63}$ The most intuitive way to make sense of ethical arguments is to say: judges act legally when they use them because they have a legal warrant to do so, which is entrenched in constitutional argumentative practice, but the materials they point to are not law.

Both exclusive and inclusive legal positivism miss important aspects of ethical arguments, which are a plausible test case to analyze the relationship between law and morality. Ethical arguments pose difficult questions about the nature of morality; for example, we need to know why morality is not a social fact, or - if it is - how is it different from law? Neither exclusive nor inclusive positivism have a developed account of morality on which they would base the contrast with law. They depart from the assumption that the relationship between law and morality can be illuminated solely with an account of law (as a social fact) and not of morality (which is not a social fact). Yet, an equation with two unknowns cannot be solved unless we know both unknowns. We thus need a better understanding of ethical arguments and their philosophical foundations. Moreover, to get away from a crude understanding of law and morality as domains which can be neatly separated with a single conceptual distinction, there must be more empirical understanding of the different ways in which morality enters legal reasoning. While this need not entail thorough social-scientific empirical work, it does imply a philosophy that is more sensitive to empirics and - contrary to Raz - does not find the contingent features of legal reasoning uninteresting.

2.2 Ethical arguments and constitutional interpretation

Ethical arguments are but one of the ways in which ethical concerns enter constitutional reasoning. First, the choice between different modalities of arguments may leave a margin for moral decision. ${ }^{64}$ In this sense, judicial discretion is a matter of degree:

\footnotetext{
${ }^{63}$ See Raz, 'Authority, Law and Morality' 233.

${ }^{64}$ This has been Bobbitt's preferred view - to leave the choice between modalities to judicial conscience and reject an overarching algorithm - since , Constitutional Fate: Theory of the Constitution.
} 
constitutional arguments may all point in one direction, or two or more directions. When judges are accused of law making it is often the case that they actually prioritize one modality of argument over the others. For example, a judge may opt for an argument from original intentions while the text and doctrine suggest a different outcome. Second, the use of a particular non-ethical argument leaves the space for moral choice. For example, textual argument can be put forward at different levels of generality, the importance of historical circumstances can be differently assessed, analogies drawn from precedent may focus on different elements, etc. Third, moral judgment may take the form of ethical arguments. Their importance cannot be overemphasized: this is the way in which judges openly incorporate moral values into their judgment. Most attempts to curb judicial discretion through a theory of adjudication focus on prioritizing one modality of argument over the other; ${ }^{65}$ instead, I suggest that we try to develop further our understanding and a sense of appropriateness for ethical arguments.

It is important to realize that - with its focus on ethical arguments - the thesis does not aim to offer a comprehensive theory of constitutional interpretation. It only aspires to offer an account of ethical arguments. This approach may be challenged from two different directions that - nonetheless - ask the same question: why should the courts use ethical arguments in the first place? In one sense, we could understand this question as a plea for a complete exclusion of ethical arguments of any kind from judicial reasoning. One may for example think that judges have no business making moral judgments in our name. In another sense, one could argue that judges ought to use proper moral reasoning and not its substitution in the form of 'distancing devices'. Let me address these concerns and at the same time situate the thesis within the dominant debates about constitutional interpretation.

The first objection prefers to confine discretion by favoring non-ethical types of arguments. In contrast, the thesis opts for the acceptance of the fact that judges do make moral choices and aims to ingrain their institutional position into the way in which they

\footnotetext{
${ }^{65}$ For example, originalism favors original intentions and formalism textual meaning.
} 
make them. The focus on ethical arguments which are themselves oriented towards change puts the approach of the thesis in the ballpark of 'living constitution', 'living tree', 'dynamic' or 'evolutionary' theories of interpretation, which all allow for the possibility of change in interpretation over time; in contrast, originalism in its many forms - grounded in either the original intentions of the authors or the original public meaning of the constitution - would oppose such a dynamic approach to interpretation. ${ }^{66}$ Notice that the thesis does not aim to answer whether judicial review is a legitimate institution or whether and when we could have moral reasons to prefer ethical arguments to other types of arguments. ${ }^{67}$ It only attempts to make descriptive and normative sense of ethical arguments that are already used in constitutional reasoning. In this, it is guided by two thoughts.

First, it is doubtful that judicial reasoning can be fully purged from moral judgments by theories of interpretation that prioritize non-ethical arguments, at least in controversial constitutional cases dealing with ethical concepts. If this is correct, it is sensible to ponder how to understand and improve those moral judgments within the system that already exist: this approach suggests that we should better accept the fact that courts will make moral judgments and that - to improve these judgments - we should better focus on the ways in which ethical concerns openly enter judicial reasoning. Second, any argument for preferring one modality of argument to another must take place within the moral domain. There is no way of making a non-evaluative argument about what ought to be the dominant argument in constitutional interpretation. A normative theory of constitutional interpretation must therefore start with some idea of what is an all-

\footnotetext{
${ }_{66}^{6}$ Perhaps the best way to put this contrast is to say that there are two divergent poles or ideals in the debate - conserving and innovative interpretation - which are often combined within a single theoretical framework. For example, Dworkin thinks that evolutionary interpretation derives its appeal from the intentions of the authors, (e.g. Ronald Dworkin, 'Comment' in Antonin Scalia (ed), A Matter of Interpretation: Federal Courts and the Law (Princeton University Press 1997)) and Raz, who accepts conserving interpretation as a default interpretative position, but contends that there may be good moral reasons for innovative interpretation (Raz, 'On the Authority and Interpretation of Constitutions: Some Preliminaries'). See also: Randy Barnett, 'An Originalism for Non-originalists' (1999) 45 Loyola Law Review 611; Jack Balkin, 'Framework Originalism and the Living Constitution' (2009) 103 Northwestern University Law Review 549; Jack Balkin, Living Originalism (Harvard University Press 2011).

${ }^{67}$ The thesis however does take a position that originalism as an exclusive theory of constitutional interpretation is not adequate. I refrain from going into that debate too deeply for it would take us too far afield. For a successful critique of originalism see Mitchell N. Berman, 'Originalism Is Bunk' (2009) 84 NYU Law Review 1.
} 
things-considered better moral judgment, in whichever way this is defined. Focusing on ethical arguments and trying to adjust them is a more promising and less crude path in competition with other options that would exclude ethical arguments altogether, such as originalism or formalism; as I will show in the thesis, a theory of ethical arguments leaves enough space to accommodate institutional and democratic concerns, while nonethical approaches may fail to lead to satisfactory moral results because of their narrow focus on limiting judicial discretion. ${ }^{68}$ For example, we can incorporate the concern for stability within a conception of moral judgment that will be sensitive to history or precedent, but it is difficult to show how the need for change is accommodated within the non-ethical approach when the original intentions or meaning dramatically contradict our current moral perspective.

It is clear that a theory of ethical arguments is supported by a conception of value and not by a conception of justified authority, because ethical arguments aim at a sensible moral judgment and not at discerning the intentions behind an authoritative directive. This opens the study of ethical arguments to the second objection identified above: why should the contingent legal practice of ethical arguments matter? Why not just replace them with ordinary moral arguments? If ordinary moral reasoning is apt to reveal correct moral answers then it is puzzling why we ought to use legal proxies for such arguments. ${ }^{69}$ One answer to this is pragmatic: if there is a way to tweak the existing arguments to make them plausible this is a more fruitful strategy than an attempt at a complete overhaul of the practice. But apart from pragmatic concerns there are also more substantive reasons.

The existing ethical arguments did not arise in a vacuum, but often grew out of the awareness that courts make moral judgments in the name of others, and that the

\footnotetext{
${ }^{68}$ It is important to note that even the choice to defer to the constitution-framers or legislatures on constitutional dilemmas - if and when it is a real choice - is itself a moral choice unless there is a legal convention which favors one over the other.

${ }^{69}$ Dworkin's answer to this was the value of integrity, that is, a value of political community that speaks with one voice. This is how he explains the normative pull of previous practices and history in interpretation. See Dworkin, Law's Empire chs 6 and 7 and Dworkin, Freedom's Law: The Moral Reading of the American Constitution 7-12. I doubt that the value of integrity is a self-standing political ideal and thus do not rely on this argument.
} 
appropriate decision ought to take into account different perspectives. We could see ethical arguments as deceitful 'distancing devices' that serve as a cover for the imposition of ideological preferences, and we would probably be right to an extent, but we could also - more sympathetically - see them as genuine attempts to arrive at the best possible moral judgment under the circumstances of disagreement and concerns about the institutional position of the court. One of the aims of the thesis is to understand constitutional ethics as a reconstruction of the moral point of view through the lens of a court. A court may be unsure both about the relevance of different elements of the moral point of view - such as emotions and reason - but also about its own role as an agent that puts these pieces together. Most of the time the differences between ordinary moral arguments and judicial ethical arguments are a consequence of these kinds of concerns, which ought not to be neglected in a theory of constitutional ethics.

The final reason for focusing on the existing argumentative patterns is that moral reading of the constitution may not resonate well with those who are uncertain about the existence of timeless and universal moral values and about the judicial ability to cognize them. ${ }^{70}$ Ronald Dworkin did more than anyone else to motivate the moral reading of the constitution and most of his arguments (for this particular position) are convincing. ${ }^{71}$ The most appealing is that moral reading - in some cases we may add pace Dworkin - does not really have an alternative: there will always be cases unregulated by previous decisions, or regulated in unsatisfactory ways, and any judicial choice in such cases will entail a moral choice. But Dworkin's theory rests on a robust version of moral realism: a belief that there are mind-independent, universal and timeless moral answers. Dworkin was always very quick to dispel any skeptical worry about the existence of moral truths as confused.72 Yet, such worries persist.

\footnotetext{
${ }^{70} \mathrm{~A}$ common criticism of Dworkin is that his imaginary judge, Hercules, who is capable of moral reading and finding right legal (and thus moral) answers, is a myth. For a concise recapitulation of similar themes see Raoul Berger, 'Ronald Dworkin's The Moral Reading of the Constitution: A Critique' 72 Indiana Law Journal 1099.

${ }^{71}$ Dworkin, Law's Empire ch 10 and Dworkin, Freedom's Law: The Moral Reading of the American Constitution 1-38.

${ }^{72}$ Moral realism underlines Dworkin's whole opus. See for example Dworkin, Law's Empire 76-85 and Dworkin, Justice for Hedgehogs chs 2-5.
} 
Consider Dworkin's famous analogy between a constitution-maker and a parent. ${ }^{73}$ As a parent instructing his children on principles they should apply, one cannot be absolutely precise about each and every future case. Children should be able to exercise their own judgment in cases not covered by the examples a parent could provide. Furthermore, as a good parent, one should accept arguments of the children if they convincingly show that the principle should be applied differently. This analogy nicely illustrates the idea that the framers of the constitution entrenched certain moral principles in the constitution, but that they perhaps did not think that the concrete application of these principles was necessarily correct for all future circumstances. But where can we find the correct application of these principles? What happens when children grow up and come to disagree about the application of rules? How can we determine which of their conceptions is true? In virtue of what can we claim that there is one appropriate moral understanding of constitutional concepts? We need a plausible metaethics to resolve these concerns. As later chapters will show, much of the confusion in the domain of ethical arguments might be overcome with a sound theory about the nature of value.

A part of the answer that I will give in later chapters is that our contingent moral experiences must figure prominently in any moral judgment. This importantly gives constitutional ethics - which consists of patterns of reasoning that occur in figuring out how to live together - a constitutive role in answering this moral question. As such, contingent constitutional ethics cannot be simply disregarded, but demand careful treatment; while it might give way to our deeper ethical convictions, it cannot be simply refuted on the basis of an assumption that there might be a better procedure out there for figuring moral answers. Dworkin was able to motivate the moral reading of the constitution and draw attention to the role of moral concerns in constitutional interpretation, but we might want to have a theory that will not presuppose universal and timeless moral truths as his eventually had to. Whereas it would be inaccurate to describe this project as a moral reading of the constitution for moral skeptics, it certainly is a moral reading that is more cautious about presupposing mindindependently true moral answers, and even more cautious about developing a theory of constitutional interpretation from that metaethical premise.

${ }^{73}$ Ronald Dworkin, Taking Rights Seriously (Duckworth 1977) 134. 
3. The argument from constitutional identity

A plausible intuition that ethical arguments are legally constrained has led some to believe that their content is completely determined by law. The idea is that moral answers either follow from the constitution, or from the host of practices surrounding the constitution, which give it distinct character and purpose. The concept of constitutional identity best captures these kinds of concerns. ${ }^{74}$ As understood here, constitutional identity denotes a range of evaluative concerns that contingently develop in a society but - crucially - by virtue of the fact that such a society has (its own and sometimes quite specific) constitution. The argument from constitutional identity thus does not locate moral value in general culturally embedded traditions, but in those that evolve in relation to the constitutional framework. Even though it is attached to the constitution, the argument is ethical, as its force does not derive from specific intentions behind authoritative directives or from the textual meaning of ethical concepts in the constitution, but from a range of deep moral commitments that arise in a community that is governed by the constitution; these commitments become a part of the identity of a constitutionally established community and the way in which people recognize themselves as being a part of it..$^{75}$

The most sophisticated treatments of ethical arguments in constitutional reasoning which recognize their legal entrenchment and the metaethical problems this brings about - often identify the entire constitutional ethics with the argument from constitutional identity. This is because they are concerned not only with an accurate representation of the ways in which values penetrate constitutional reasoning, but also

\footnotetext{
${ }^{74}$ For some recent treatments of this issue see Michel Rosenfeld, The Identity of the Constitutional Subject: Selfhood, Citizenship, Culture, and Community (Routledge 2010) and Gary J. Jacobsohn, Constitutional Identity (Harvard University Press 2010).

${ }^{75}$ Of course, this is not to suggest that the constitution and constitutional identity do not themselves arise from general moral commitments or identity of a community. The process is typically dynamic and separation between the two can never be precise.
} 
with justifying the judicial review of legislation. The argument from constitutional identity seems like a candidate to carry this double burden, for it appears legally constrained and thus leaves the impression of judicial law applying and not law making. On such views, the argument from constitutional identity legitimizes constitutional review since it refers to the values that are already 'in' the constitution and are precise enough to reduce judicial discretion. But focusing on the argument from constitutional identity is neither descriptively accurate (as there are other types of ethical arguments) nor does it solve the problem of judicial discretion (as it often does not give much content to underspecified and contested ethical concepts from the constitution). Let me explain this further with some examples.

Phillip Bobbitt, the first to recognize ethical arguments as a distinct modality, defined them in the following way:

By ethical argument I mean constitutional argument whose force relies on characterization of American institutions and the role within them of the American people. It is the character, or ethos, of the American polity that is advanced in ethical argument as the source from which particular decisions derive. ${ }^{76}$

Bobbitt thus identifies ethical arguments with the arguments attached to constitutional identity. He is also quick to avoid possible confusions between ethical arguments in constitutional reasoning and general moral arguments:

As I shall use the term, ethical arguments are not moral arguments. Ethical constitutional arguments do not claim that a particular solution is right or wrong in any sense larger than that the solution comports with the sort of people we are and the means we have chosen to solve political and customary constitutional problems. ${ }^{77}$

76 Bobbitt, Constitutional Fate: Theory of the Constitution 94.

${ }^{77}$ Ibid 94-95. 
The reason to reject the use of general moral arguments in constitutional law is their suspect metaethical foundations that would bring uncertainty to constitutional reasoning. ${ }^{78}$ For Bobbitt, divorcing ethical arguments from general moral reasons and tying them to constitutional ethos is

... a way of compensating for the principal shortcoming of ethical argument, that is, its lack of nonethical referent ... If so, then we may be able to identify a class of ethical arguments that originate in a specifically constitutional ethos and hence avoid the difficulties of ethical and moral arguments generally. ${ }^{79}$

By narrowly defining ethical arguments from constitutional ethos he wishes 'to use the resolving power of constitutional argument and avoid introducing a competition of moral conventions'. ${ }^{80}$ Clearly, Bobbitt's concern is the lack of mechanisms to resolve moral disagreements and general skepticism that moral truth can be the function of a correspondence between moral statements and some kind of objective reality. But if this is the case, his argument is confused: first, Bobbitt is advancing a moral argument based on our inability to advance moral arguments; second, if the only reason for preferring the argument from constitutional identity is the stability through agreement, the argument is not morally attractive, for there are both other more important moral concerns and easier ways to achieve stability; third, while the argument from constitutional identity might be slightly more determinate then general moral arguments, it comes nowhere near resolving Bobbitt's worries about the disagreements and uncertainties that plague our moral universe. While Bobbitt is correct to recognize legal constraints to moral arguments and their unstable metaethical foundations, his

\footnotetext{
${ }^{78}$ Ibid 139. Bobbitt is opposed to the moral character of ethical arguments for two reasons. First, a justification of the modality of argument for him cannot come from outside of the practice of law, for this would undermine his understanding of the metaphysics of law. Ethical arguments as legal arguments must be true in virtue of following the legal rule. But - we may add - the truth of legal propositions also may depend on other normative systems, such as language, without subsuming legal practice to those systems. Second, he wishes to retain the possibility of moral choice in choosing between arguments. But the conscious choice between arguments need not be tacit, it may openly embrace the solution that is morally better, without - in so doing - abandoning the grammar of law. From the fact that a choice must be left for moral decision it does not follow that it must remain external to the reasoning; in fact, embracing moral arguments openly is more candid and transparent.

${ }^{79}$ Ibid $140-141$, see also $172-175$.

80 Ibid 150.
} 
concern with the legitimacy of judicial review, and the view that this could only be attained if courts remain within the practice of legal reasoning, leads him astray. ${ }^{81}$

Similarly inspired is Wil Waluchow's theory of 'constitutional morality'. ${ }^{82}$ Waluchow recognizes legal limitations to moral arguments, wishes to offer a moral reading of the constitution that is divorced from the baggage of robust moral realism, and at the same time offer a legitimation for the judicial review of legislation; again, these multiple goals leave the theory both descriptively inaccurate and normatively unstable. Waluchow differentiates 'constitutional morality' from both 'Platonic' or 'Kantian' morality, which is 'universal, valid, rationally justified, or maybe even "objectively true", ${ }^{83}$ and from 'conventional or positive morality rooted not in the fabric of universe, but in the variable beliefs and convictions of a particular community'. ${ }^{84} \mathrm{He}$ thus defines constitutional morality as 'the set of moral norms and considered judgments properly attributable to the community as a whole as representing its true commitments, but with the following additional property: they are in some way tied to its constitutional law and practices'. ${ }^{85}$ Waluchow's conception of 'constitutional morality' thus overlaps with what we have identified as 'constitutional identity'.

To motivate the theory, Waluchow differentiates between two sets of relevant motives that play role in our ordinary moral reasoning - 'true moral commitments' and 'moral opinions' - which can come into conflict. True moral commitments are more stable, deep, and significant moral principles which we accept, while moral opinions are prone to change and readjustment. Waluchow then identifies the true moral commitments

\footnotetext{
81 There are other authors that use concepts similar to ethical arguments. Richard Fallon, for example, describes 'value arguments' as those that refer to the 'moral or political significance of facts or about the normative desirability of outcomes'. Richard H. Fallon, 'A Constructivist Coherence Theory of Constitutional Interpretation' (1987) 100 Harvard Law Review 1189, 1205. Fallon correctly noticed that 'value arguments' do not only refer to values but also construe analytical processes through which these values are cognized or point to the sources of these values. Ibid 1204-1209. See also Richard H. Fallon, Implementing the Constitution (Harvard University Press 2001) 46-52.

${ }^{82}$ See Wilfrid J. Waluchow, A Common Law Theory of Judicial Review: The Living Tree (Cambridge University Press 2007) and W Waluchow, A Common Law Theory of Judicial Review: The Living Tree (CUP, 2007) and Wilfrid J. Waluchow, 'Constitutional Morality and the Bills of Rights' in Grant Huscroft (ed), Expounding the Constitution: Essays in Constitutional Theory (Cambridge University Press 2008).

${ }^{83}$ Waluchow, 'Constitutional Morality and the Bills of Rights' 65.

${ }^{84}$ Ibid.

85 Waluchow, A Common Law Theory of Judicial Review: The Living Tree 227.
} 
with constitutional morality as a social fact of overlapping consensus about the most important moral principles. ${ }^{86}$ In his interpretation, we aim for a 'reflective equilibrium' where our 'true commitments' trump our opinions, and so constitutional morality containing such principles and commitments precludes our (wrong) opinions. ${ }^{87}$ His aim is to show that the fact that courts review our moral opinions expressed in legislatures is simply bringing them in line with the more fundamental principles expressed in the constitution that we already accept.

While the distinction between principles and opinions is intuitive and uncontroversial, it might be too crude. We may be misled in our moral opinions because they conflict with the principles we also accept. ${ }^{88}$ However, it is important to notice that the same argument works both ways: we can reconsider our moral principles or 'true moral commitments' in cases when they collide with our opinions. We could for example think that killing is morally wrong under any circumstances, but then find ourselves in wartime when we realize that the principle does not represent our 'true' commitment and is in need of revision. But - more importantly - moral principles of a very general type (e.g. respect for equality) are prone to different interpretations and their content is supplied by a host of moral opinions which we find pertinent to certain kinds of moral problems. General moral principles mean different things and - as social facts - cannot be far away from our contingent moral opinions about their application. If the meaning of general principles is at least partly constituted by our own contingent attitudes about their application, then the critical force of constitutional morality does not have enough bite to be strongly counter-majoritarian and justify judicial review. The dispute about the legitimacy of judicial review is precisely about whose understanding of these principles should be controlling, and this is not something that Waluchow's theory resolves.

\footnotetext{
86 Ibid $220-222$.

87 Ibid 224-230.

${ }^{88}$ Even if one were a deontologist who accepts a moral duty not to lie, one would reconsider when, for example, this needs to be breached to save lives. Of course, Kant famously denied that we have a duty to lie from benevolent motives, for he considered that a contradiction in conceivability and thus a breach of 'perfect' moral duty. Deontological ethics in general have been steadily criticized for this counterintuitive consequence, and modern deontologists typically deny such a radical reading of his first formulation of categorical imperative and of contradiction in conceivability. See his 'On a Supposed Right to Tell Lies from Benevolent Motives' in Immanuel Kant, Critique of Practical Reason and Other Works on the Theory of Ethics (Thomas Kingsmill Abbott tr, Barnes \& Noble Books 2004).
} 
A consequence of Waluchow's account of constitutional morality is that it may collide with two other 'moralities' he identifies: 'popular' and 'ideal'. Waluchow agrees: 'One could ... explain ... much of the early-twentieth-century South African law as presupposing racist moral norms and beliefs. Such norms and beliefs were part of that community's (deplorable) "constitutional morality". ${ }^{89}$ Because it is a social fact that exists in the practices of officials, it is conceptually impossible that all those involved in this practice are mistaken about the substance of constitutional morality. This might prove to be morally hazardous: for example, if 'reflective equilibrium' exercise shows that the community is committed to racial segregation and if moral opinions of people also demonstrate the same, how can judges overcome this only by looking to these two sources of moral authority? Waluchow's answer is to depart from such practices on the basis of objective normative reasons and thus to break ties with constitutional morality as a social fact. When we run out of reasons that point to incoherent social practice, we must turn to 'ideal' morality: 'It is also important to remember ... that questions concerning legality - even those requiring appeal to community's moral standards must never be confused with, or supplant in our thinking, our ability to challenge accepted norms from the moral point of view'. ${ }^{90}$ But if the moral point of view is something different from constitutional morality, then what is the normative force of the latter? Why not simply apply ideal morality if constitutional morality is a normatively inert social fact? Finally, if there is an ideal morality, what is its connection with parochial and contingent beliefs that constitute constitutional morality?

In his attempt to justify judicial review of legislation that can void popular will, Waluchow detached the conception of constitutional morality from several commonly criticized positions. Personal moral opinions of judges are unacceptable as they are not 'philosopher kings'. Popular moral opinions of citizenry are known to be prejudicial and as such are disregarded. Ideal morality based on objective reasons is controversial. Waluchow thinks he offers a way out of this problem but his theory fails to strike a plausible middle way. Because Waluchow wants to justify judicial review he misses

\footnotetext{
89 Waluchow, A Common Law Theory of Judicial Review: The Living Tree 227.

90 Ibid 237 n 25.
} 
important types of ethical arguments in constitutional reasoning, such as the argument from common sentiment and universal reason. For the same reason he leaves his conception of constitutional morality on shaky metaethical grounds: if there is agreement on moral principles, constitutional morality has no critical bite; if there is no agreement, or we think the agreement is wrong, we need to resort to 'ideal' morality, so again constitutional morality has no critical bite. Constitutional morality is redundant.

Is there a lesson to be learned? Bobbitt and Waluchow fail to account for the full complexity of constitutional ethics or engage with the metaethical foundations of ethical arguments, because they start from the problem of the legitimacy of judicial review. Both are at pains to show that when employing ethical argument courts stay within the practice of law; for this reason, they miss other types of ethical arguments that emerge in constitutional reasoning, such as arguments from prevailing moral opinions (the argument from common sentiment) or foreign law (the argument from universal reason). Moreover, because they see argument from constitutional identity as constituted by social facts that obtain in a constitutional system, they make it appear weak in relation to 'ideal' morality. If there is 'ideal' morality, then they need to explain the normative foundations of such social facts. What we need is thus a theory of constitutional ethics that can remedy these inadequacies.

Let us however first focus in more detail on a plausible intuition behind their theories, and an important component of constitutional ethics: the argument from constitutional identity. This argument has two different dimensions. We can tentatively distinguish between 'general constitutional identity' and 'particular constitutional identity'. General constitutional identity derives its force from the fact of having an entrenched and written constitution containing the basic moral commitments of the community. It is relatively independent from the substance of any of these commitments in particular. Particular constitutional identity refers to the concrete constitutional spirit or tradition that arises from the specific constitutional experience of the community in question. We could say that the general identity relies on the value of constitution (that is, the value of having a constitution), and the particular on constitutional value (the value from the constitution). 


\subsection{General constitutional identity}

The general constitutional identity is derived from the moral authority of constitutions stated in abstract. Bobbitt provides a succinct definition: 'What is needed in judge's chambers is the same reasoning from the constitutional ethos that produced the first Bill of Rights'. ${ }^{11}$ Such reasoning is equally applicable to any constitutional system that contains bills of rights and shares the basic commitment to government limited by law. However, this kind of reasoning is more constrained than ordinary moral reasoning: it is curbed by the idea of the purpose of a constitution.

Let me illustrate this with some cases. The most obvious example is Marbury $v$ Madison, ${ }^{92}$ the decision establishing judicial review of legislation in the US, which also presents a historical foundation of the institution of judicial review in constitutional democracies. In the course of the case, the question arose of how to deal with an act of Congress that contradicts the Constitution. The American Constitution did not explicitly authorize judicial review of legislation. Justice Marshall relied on the argument that derives its force from the mere existence of a written constitution. In his opinion, judicial review of legislation logically followed from the fact that the purpose of the constitution was to limit the government and from the fact that the constitution was entrenched. He asks: 'To what purpose are powers limited, and to what purpose is that limitation committed to writing; if these limits may, at any time, be passed by those intended to be restrained?'93 His conclusions about judicial review are far-reaching and not limited to the American constitution. According to Justice Marshall, any written constitution would have such property:

Those then who controvert the principle that the constitution is to be considered, in court, as a paramount law, are reduced to the necessity of maintaining that

${ }^{91}$ Bobbitt, Constitutional Fate: Theory of the Constitution 150.

92 Marbury $v$ Madison 5 US 137 (1803).

${ }^{93}$ Ibid 176. 
courts must close their eyes on the constitution, and see only the law. This doctrine would subvert the very foundation of all written constitutions. ${ }^{94}$

The reason is hence not (only) the morality grounded in the specific American circumstances, but the moral purpose of constitutionalism. If the merit of Justice Marshall's argument is to be measured by its acceptance in other constitutional systems, then his reasoning is truly universal: today, there are no entrenched constitutions without some form of judicial review. ${ }^{95}$ Apart from being universal or general, the moral reasoning applied here is also constitutional. It is derived from the perspective of having a constitution and not from general moral reasons. To sustain the judicial review afresh without there being an entrenched constitution would require many more arguments.

The argument from general constitutional identity commonly takes a form of presumption in favor of minorities. For example, in a case before the German Federal Constitutional Court (FCC) concerning the display of crosses and crucifixes in classrooms which was made obligatory by a regulation of the state of Bavaria, the court was faced with a quintessential constitutional dilemma where competing constitutional values point to different directions. ${ }^{96}$ On the one hand, there was a positive freedom of the majority of the population to preserve their religion, identity and culture; and on the other, the negative freedom of the minority to choose the religious and philosophical setting for the education of their children. Article 135 of the Bavarian constitution supported by a popular referendum - stated: 'In [public elementary schools] pupils shall be taught and brought up in accordance with the principles of the Christian confessions. ${ }^{97}$ Christian religion was thus made a part of the constitutional identity of the state of Bavaria; moreover, such constitutional identity expressed the moral sentiments of the majority of Bavarian citizens who voted in the referendum.

\footnotetext{
${ }^{94}$ Ibid 178 emphasis added.

${ }^{95}$ See for example the discussion in chapter 4 on the influence of Marbury $v$ Madison for the establishment of constitutional review in Israel.

${ }_{96}$ Kruzifix-decision (1995) 93 BVerfGE 1.

${ }_{97}$ Act amending Art. 135 of the Constitution of the Free State of Bavaria of 22 July 1968 (GVBl, 238).
} 
The FCC refused to defer to such a particularistic conception of constitutional ethics; conversely, it relied on reasoning that could generally apply in systems that are committed to constitutionalism. At its core was the understanding of the legitimacy of the coercive authority of the state. The court distinguished between the encounters with religious symbols in everyday life which are not 'inescapable' and the public display of such symbols 'based on a compulsion enforceable where necessary through sanctions' ${ }^{98}$ In the concluding paragraph, the FCC expressed its vision of the way to resolve the case that stems from the purpose of constitutional rights: "The conflict arising cannot be resolved according to the majority principle, for the fundamental right to religious freedom is specifically aimed in a special degree at protecting minorities.' 99 The court understood the purpose of the constitution as entrenching safeguards against domination over minorities; consequently, it declared the Bavarian regulation null and void.

Similarly, in a case regarding gay marriage, Minister of Home Affairs v Fourie, the South African Constitutional Court used the same type of argument connected with the moral purpose of a constitution. The question was whether a lack of provision that would enable gay couples to marry violated the equal protection clause of the South African Constitution and unfairly discriminated homosexuals on the basis of their sexual orientation. The decision of the court starts with the observation that the bill of rights contains no general right to marry. The reason for this, Justice Sachs observes, is that marriage was unsuitable for constitutional definition as to avoid 'the questions that relate to history, culture and special circumstances of each society'. ${ }^{100}$ Sachs finds the critical perspective - from which he can dispose with the particular and contingent moral attitudes - in the protection of minorities as the general purpose of the constitution:

the fact that the law today embodies conventional majoritarian views in no way mitigates its discriminatory impact. It is precisely those groups that cannot count

\footnotetext{
${ }_{98}$ Kruzifix-decision para C.II.2.a.

${ }^{99}$ Ibid C.II.3.b.

${ }^{100}$ Minister of Home Affairs and Another v Fourie and Another para 47.
} 
on popular support and strong representation in the legislature that have a claim to vindicate their fundamental rights through application of the Bill of Rights. ${ }^{101}$

He continues the same thought later on:

\begin{abstract}
Majoritarian opinion can often be harsh to minorities that exist outside the mainstream. It is precisely the function of the Constitution and the law to step in and counteract rather than reinforce unfair discrimination against a minority ... The objective of the Constitution is to allow different concepts about the nature of human existence to inhabit the same public realm... ${ }^{102}$
\end{abstract}

After the extensive analysis of several other arguments, the court found that both equality and dignity clauses of the South African Constitution had been violated and ordered the Parliament to enact legislation that would enable homosexual couples to marry. There was little support for this conclusion from the text or precedent. The court understood standards such as equality and dignity in their generally applicable moral force that stems from the fact that minorities ought to be protected in a constitutional framework that contains a bill of rights.

This is not the only understanding of constitutional identity. Apart from general principles of constitutionalism, courts habitually rely on specific traditions of their constitutional system. Each constitution cherishes its own constitutional values. It is to these values that we now turn.

\title{
3.2 Particular constitutional identity
}

Particular constitutional identity derives its force from specific problems, historical traditions and the composition of societies that are ruled by constitutions. To avoid confusion, let me underline that a particular constitutional identity itself may favor

101 Ibid para 74 .

102 Ibid paras $94-95$. 
more universalistic values such as dignity, equality and liberty, support more parochial understandings of these values, or even celebrate specificities of the particular community. ${ }^{103}$ All these perspectives fall into the category of particular constitutional identity, for they all locate the source of value in the specific spirit of the constitution and its interpretation over time. While general identity follows from the reasons for having a constitution as such, particular constitutional values follow from the gist of the particular constitution. Among other factors, particular constitutional identity explains why constitutional rights differ between jurisdictions, and why any universal mechanism of moral reasoning tells us little about the outcomes of legal cases, even under the circumstances of strong indeterminacy.

Let me illustrate the role of particular constitutional identity with examples. For instance, what explains US jurisprudence in the affirmative action cases is not the reasoning from universal moral principles, but a specific history of racial segregation that makes the Supreme Court wary of any racially based distinctions. The specific ethics of the American constitutional order preserves liberal values of merit and competition and a unitary vision of citizenship. The equal protection clause of the American Constitution prescribes that a state cannot 'deny to any person within its jurisdiction the equal protection of the laws'. ${ }^{104}$ This has been interpreted to involve rights of persons, and not of groups. The government thus carries the burden of meeting the most stringent test when treating people differently on the basis of race: under the 'strict scrutiny' analysis the government must show that classifications based on race are 'narrowly tailored measures that further compelling governmental interests'. ${ }^{105}$ On the grounds of this test, in Bakke, Justice Powell declared that strict quota systems based on race were unconstitutional, ${ }^{106}$ and this reading was later upheld in Gratz $v$ Bollinger and Grutter $v$ Bollinger. ${ }^{107}$ The presumption was established that

\footnotetext{
${ }^{103}$ Often the orientation of the particular constitutional identity will be visible from the constitutional text or its preamble. For some examples see Gary J. Jacobsohn, 'Constitutional Values and Principles' in Michel Rosenfeld and Andras Sajo (eds), The Oxford Handbook of Comparative Constitutional Law (Oxford University Press 2012) 778-779.

${ }_{104} 14^{\text {th }}$ Amendment to the US Constitution, Section 1.

105 Adarand Constructors Inc v Peña 515 US 200 (1995) 227 (O'Connor).

106 There is a significant controversy about the reach of Powell J's conclusions in Bakke, as there was no controlling opinion in the case. See Regents of the University of California $v$ Bakke 438 US 265 (1978). ${ }^{107}$ Gratz v Bollinger 539 US 244 (2003); Grutter v Bollinger 539 US 306 (2003).
} 
affirmative action is an aberration from the principle of equality, hence discriminatory unless the opposite is proven. In the field of education, for example, legitimate governmental interests for affirmative action include only past discrimination and diversity of educational context. ${ }^{108}$

The approach to affirmative action in the US differs from other jurisdictions and international documents. ${ }^{109}$ Further, there is nothing much in the text of the constitution or in doctrines (at least prior to Gratz and Grutter) that would compel such understanding of equality. To the contrary, there is still a debate on the bench whether the constitutional ethos of the American polity demands the opposite: a substantive notion of equality that would entail more leeway for affirmative action measures. Justice Breyer, dissenting in Parents Involved in Community Schools v Seattle School District, a case which proscribed allocation of students in public schools to foster racial integration, held that the particular constitutional ethos of the American constitution actually implies the constitutionality of affirmative action measures:

In this Court's finest hour, Brown v. Board of Education challenged this history [of racial divisions] and helped to change it. For Brown held out a promise. It was a promise embodied in three Amendments designed to make citizens of slaves. It was the promise of true racial equality - not as a matter of fine words on paper, but as a matter of everyday life in the Nation's cities and schools. It was about the nature of a democracy that must work for all Americans. It sought one law, one Nation, one people, not simply as a matter of legal principle but in terms of how we actually live. ${ }^{10}$

But even though constitutional identity is disputed, there is agreement that it contains the answer. When Breyer and other justices ask 'what of the long history and moral vision that the Fourteenth Amendment itself embodies?', 111 they do not find the solution

\footnotetext{
${ }^{108}$ See for example Parents Involved in Community Schools v Seattle School District No 1551 US 701 (2007). ${ }^{109}$ See for example Minister of Finance and Other $v$ Van Heerden 2004 (6) SA 121 (CC) or Article 4 of The Convention on the Elimination of all Forms of Discrimination against Women of 1979.

110 Parents Involved in Community Schools v Seattle School District No 1 (Breyer).

111 Ibid.
} 
in universal or 'ideal' morality; the 'moral vision' they refer to is the specific ethics of the American constitution.

Racial segregation is not pertinent only to the American constitutional history, but the response to it is distinctively American. It took long enough for the Supreme Court to recognize formal equality in Brown $v$ the Board of Education, ${ }^{112}$ and it is perhaps this victory that the court is trying to preserve today by not liberalizing affirmative action. The notion of equality established in the Supreme Court case law has become - for better or worse - a part of the American constitutional identity. Although subject to different interpretations, like the one pursued by Justice Breyer, it is still distinct from the identity of other constitutional systems.

Another example of the effect of particular constitutional values also stems from a problem of racial segregation. The Constitutional Court of South Africa soon after its inception asserted that its authority rests, among other things, on a specific constitutional identity. The first articulation of this vision of constitutional values was in Makwanyane, a case involving invalidation of the Criminal Procedure Act that provided for the death sentence. ${ }^{13}$ The question of the death penalty was intentionally left out of the constitution, as there was no consensus about it at the time of drafting. The court's reasoning is important, as there was no precedent, original intent (apart from avoidance of the issue), or textual support for deciding either way. The court nevertheless found that the death penalty violated the prohibition of 'cruel, inhuman or degrading treatment or punishment', against public opinion that was supportive of it. ${ }^{14}$ Most justices relied on the specific constitutional ethos of the South African community. Justice Chaskalson opened his judgment with the quote that defines the specific moral purpose of the constitution as providing:

... a historic bridge between the past of a deeply divided society characterised by strife, conflict, untold suffering and injustice, and a future founded on the

\footnotetext{
112 Brown v Board of Education of Topeka 347 US 483 (1954).

${ }^{113} S v$ Makwanyane and Another.

${ }^{114}$ Ibid para 146 (Chaskalson).
} 
recognition of human rights, democracy and peaceful co-existence and development opportunities for all South Africans, irrespective of colour, race, class, belief or sex. ${ }^{115}$

Even more clearly, Justice Mahomed underlined the distinct character of South African constitutional identity:

In some countries, the Constitution only formalises, in a legal instrument, a historical consensus of values and aspirations evolved incrementally from a stable and unbroken past to accommodate the needs of the future. The South African Constitution is different: it retains from the past only what is defensible and represents a decisive break from, and a ringing rejection of, that part of the past which is disgracefully racist, authoritarian, insular, and repressive, and a vigorous identification of and commitment to a democratic, universalistic, caring and aspirationally egalitarian ethos expressly articulated in the Constitution. The contrast between the past which it repudiates and the future to which it seeks to commit the nation is stark and dramatic. ${ }^{116}$

This reading of the constitution allowed the court to compare and distinguish its approach from other courts and jurisdictions which normally serve as a source of inspiration for a generally cosmopolitan South African constitutional jurisprudence. The break with the past, heritage of apartheid and role of the constitution in these processes, which constitute the specific South African constitutional identity, are mentioned in most judgments that deal with controversial issues: abortion, religious accommodation, hate speech, obscenity, and sexual orientation. ${ }^{117}$

Let us take another example of a particular constitutional morality that emerged as a consequence of atrocities committed during the Second World War in Germany. The German constitution (Basic Law) of 1949 made constitutional rights foundational in the

\footnotetext{
${ }^{115}$ Ibid para 7 (Chaskalson, citing the provision on National Unity and Reconciliation from the Constitution).

116 Ibid para 262 (Mahomed).

${ }^{117}$ See more on this in the chapter that deals with the argument from universal reason.
} 
constitutional order. Unlike the Weimar constitution, which has been widely regarded as responsible for the instability of political institutions that eased Hitler's rise to power and subsequent termination of the constitutional order itself, the primary purpose of the new constitution was to establish a robust system of rights and to stabilize political institutions. ${ }^{118}$ At the apex of that order stands the simple provision of Article 1 of the constitution, that serves to remind Germans that human dignity must never again be violated: 'Human dignity shall be inviolable'.

This simple clause has been transformed through the jurisprudence of the FCC to one of the most far-reaching and yet perplexing doctrines. Human dignity has been treated as an absolute value, which - once implicated in a case - trumps all other concerns or interests that could be balanced. While no comprehensive treatment of the concept of dignity can be found in the FCC's jurisprudence, one particular interpretation has been dominant: dignity entails 'treating persons as ends and not as means to an end'. ${ }^{119}$ This Kantian understanding of dignity expresses the first principle of German constitutional identity. Its roots are to be found in a collective conscience that strives to prevent persons being treated as means, as was the case during the Second World War. This shows that even dignity as one of the most universal concepts may obtain a very specific understanding in different constitutional systems. ${ }^{120}$

The application of the Kantian dignity principle has profound consequences on the moral choices the FCC makes. In the Aviation Security Act case, ${ }^{121}$ the court ruled that the act, which provided for the possibility of shooting-down airplanes that have been hijacked with a purpose of using them as weapons, violated dignity. The act regulated the situation analogous to the 'trolley problem': succinctly put, the question is whether it is morally justified to sacrifice fewer lives to save more, and, if yes, under which circumstances. The FCC answers the question in the following way: it is justified to

\footnotetext{
${ }^{118}$ See more in Donald P. Kommers, 'Germany: Balancing Rights and Duties' in Jeffrey Goldsworthy (ed), Interpreting Constitutions: A Comparative Study (Oxford University Press 2007).

${ }^{119}$ See Kai Möller, 'On Treating Persons as Ends: The German Aviation Security Act, Human Dignity, and the Federal Constitutional Court' [2006] Public Law 457.

${ }^{120}$ See more in Christopher MacCrudden, 'Human Dignity and Judicial Interpretation of Human Rights' (2008) 19 European Journal of International Law 655.

121 Aviation Security Case(2006) 115 BVerfGE 118.
} 
sacrifice lives to save more only in the case when terrorists are alone on the plane, for they have taken the responsibility for what could happen; otherwise, it is never justified. ${ }^{122}$

The message of the decision is clear - human dignity combined with the right to life establishes a deontological principle that does not give way to any other concern. The thrust of the argument is the following:

[Shooting down the plane] ignores the status of the persons affected as subjects endowed with dignity and inalienable rights. Their death becomes a means to save others, they are treated as objects and at the same time deprived of their rights; with their lives being disposed of unilaterally by the state, the persons on board of the aircraft, who, as victims, are themselves in need of protection, are denied the value which is inherent to every human being for her own sake. ${ }^{123}$

There are no exceptions to this rule and no balancing of interests, not even in the case when it is clear that the lives of the passengers are already lost.124 What explains this unique understanding of dignity is the heritage of the Second World War, and the specific constitutional identity that emanates from it.

To conclude, although it is an important part of the practice, the argument from constitutional identity does not offer an evaluative criterion fully independent of social practices and popular opinions. ${ }^{125}$ It may offer a perspective from which popular moral opinions are assessed and brought into coherence, and has some legitimating power to the extent that it relies on evaluative commitments that people already accept, but might fail to observe in their daily moral practice. But in most cases the content of constitutional identity - of both a general and particular kind - is fluid and

122 Ibid.

123 Ibid para 124.

${ }^{124}$ Needless to say, the consequences of this understanding of dignity could be immense; for example, it would follow that any order in a defensive war that could jeopardize military personnel's lives would entail treating them as a means to an end (to save other lives).

${ }^{125}$ For a discussion of similar issues see Jeremy Waldron, 'Particular Values and Critical Morality' (1989)

77 California Law Review 561. 
underdetermined. While it does give more substance to ethical concepts from the constitution, it is often more of a tendency or a rule of thumb when there are two competing interpretations, rather than a steady and precise principle.

It is already nascent in the discussion of the argument from constitutional identity that there is a problem of locating and accounting for the nature of moral value. Is moral value another contingent social fact that differs from system to system, or does it follow from universal precepts? If the former is the case, where does its normativity come from; if the latter is the case, are all our contingent differences simply a mistake? This will become all the more clear when the argument from common sentiment and the argument from universal reason are discussed. The difference between the two tracks the division between particular and universal understanding of values, and between emotions and reason. These divisions threaten to render constitutional ethics incoherent, as they stem from divergent ideas about the sources of normativity. This is why a good account of the relationship between ethics and constitutional reasoning must equip itself with a deeper understanding of the nature of moral value, and provide us with tools to understand the philosophical foundations of ethical arguments. The next part of this chapter offers a preliminary account of the main elements of moral practice that can help us situate different ethical arguments better in the overall framework of moral theory.

\section{Essentials of metaethics}

The purpose of this part is to develop the preliminary theoretical scaffolding for the analysis of ethical arguments. It introduces the main terms of art and clarifies how different regimes of ethical arguments in constitutional interpretation will be explained and evaluated. Let me first underline the problem we are addressing once again: ethical arguments rely on different and sometimes competing understanding of the nature of value. We have seen that in the case of constitutional identity such value is connected to the contingent traditions of a community as they evolve under the constitution. Already here some preliminary metaethical problems arose; for example, whether a social fact 
such as agreement over constitutional commitments can be normative. We will see in later chapters that the situation becomes even more complicated. The argument from common sentiment refers to the emotional reactions of the members of a community, and the argument from universal reason to the universally human capacity for reason as the source of value. The question is: what is the adequate perspective to assess and make sense of these arguments?

The basic premise is that if judges do make moral judgments we want them to make good moral judgments. But how is the conception of good moral judgment connected to the nature of value? Good moral judgment is an evaluative notion itself and it might regardless of the nature of value - be a function of the most apposite ethical theory, argument or emotion. It could be that a good moral judgment is utilitarian or deontological, but that they are both equally compatible with a particular metaethical standpoint. However, the metaethical question is both pressing and prior. It is pressing because actual ethical arguments from constitutional practice demonstrate divergent conceptions of value which need to be sorted out: is value local or universal, emotion or reason-based? It is prior because we have no way of knowing whether a particular fragment of normative ethics is correct if we do not say in virtue of what it is correct. The bottom line is: we want courts to make good judgments and good judgment is a function of moral value; to the extent that a judgment relies on a wrong conception of value it is probably misguided. ${ }^{126}$

There are three concepts I shall use in the preliminary analysis of ethical arguments: coherence, practical relevance, and moral point of view. First, some arguments used in judicial reasoning may be untenable because they are incoherent. For example, one cannot simultaneously believe that moral propositions are truth-apt and not truth-apt. Although incoherence might be the main tension in using different regimes of ethical arguments, notice that the reach of a coherence-based approach is limited; one can in other words be coherently wrong about what morality is. So the role of this method should be understood as therapeutic: clearing up the ground by showing which

${ }^{126}$ I say 'probably' for it may not be misguided as a matter of coincidence (e.g. one may accidentally discover a new chemical element while doing alchemy). 
positions are not consistent. There is a value in saying if you are (for instance) a cognitivist, $\mathrm{X}, \mathrm{Y}$, and $\mathrm{Z}$ follow from your views', because then we can at least choose between different frameworks of thinking about ethical arguments. ${ }^{127}$

Second, the fact that courts rely on ethical arguments shows that they must subscribe to the practical relevance of morality. This is a minimal normative assumption. If judges use ethical arguments, it follows from their own views that they cannot believe that morality does not matter. Moreover, if we engage in the assessment of the ways they use ethical arguments it means that we must also think that morality matters. Notice that I am not making a claim about judicial motivation, as they may actually use these arguments for all kinds of reasons, but we do not want them to be cynical about their ethical choices. I will thus consider nihilism and similar positions as inadequate for judicial reasoning and as contradictory to their own views. ${ }^{128}$

Third and most important, morality cannot be very different from what we actually do when we take a particular practical perspective: the moral point of view. To explicate the moral point of view, we must start from the perspective of an ordinary and competent moral agent. Throughout the thesis I argue for an ethical theory that makes no sharp distinction between critical and popular, philosopher's and folk morality. What we seek to explain is a social and human phenomenon. Moral philosophy cannot disregard the elements of moral talk or intuitions on which ordinary people rely. These intuitions need to be addressed - vindicated or shown wrong - but using the elements of ordinary moral practice. While philosophers spend more time and resources in figuring out hard moral questions, the mechanism by which they arrive at conclusions are not very distant from how we go about these issues.

\footnotetext{
127 The working assumption for this chapter is that each major metaethical outlook is internally consistent, but that is a concession I have to make.

128 Thus - to paraphrase Camus' famous question from 'The Myth of Sisyphus' - I will not be asking whether judges should commit suicide, as a question that would follow from a nihilist view about the absurdity of life. Albert Camus, The Myth of Sisyphus and Other Essays (A.Knopf 1964).
} 
Philosophy is a humanistic discipline, and ethics in particular is about our selfunderstanding. ${ }^{129}$ In the same way W.V.O. Quine thought that ' $[\mathrm{t}]$ he scientist is indistinguishable from the common man in his sense of evidence, except that scientist is more careful,' ${ }^{130}$ so the moral philosopher is indistinguishable from an ordinary moral agent except that she might be more studious. Her 'sense of evidence' is the same: she relies on common ways of making ethical judgments, and is convinced of moral conclusions in much the same way ordinary people are convinced. But the object of inquiry of ethics, unlike science, is not the world out there; its method is introspection, not causation. It would thus fail miserably if it were not able to relate on a deep level to our self-understanding.

To be sure, just like science, moral philosophy can reach beyond what we may figure out on our own. Rawls famously compared the sense we have for native language with our moral sense, and the rules of grammar with moral rules:

... the aim [of linguistics] is to characterize the ability to recognize wellformed sentences by formulating clearly expressed principles which make the same discriminations as the native speaker. This undertaking is known to require theoretical constructions that far outrun the ad hoc precepts of our explicit grammatical knowledge. A similar situation presumably holds in moral theory. ${ }^{131}$

\footnotetext{
${ }^{129}$ I fully endorse here Bernard Williams' views, who writes: 'Once we give up that assumption [that philosophy is exclusively interested in a priori], we can take a legitimate philosophical interest in what is agreed to be a more local "us"' Bernard Williams, 'Philosophy as a Humanistic Discipline' (2000) 75 Philosophy 477, 493. As a consequence, our ethical insights cannot be divorced from what we are: ' $\ldots$ we cannot in our thought go beyond our outlook into the future and remain identified with the result: that is to say, we cannot overcome our outlook. If a possible future that figures in those shadowy speculations does not embody some interpretation of these central elements of our outlook, then it may make empirical sense to us - we can see how some one could get there - but it makes no ethical sense to us, except as a scene of retrogression, or desolation, or loss.' ibid 494.

${ }^{130}$ W.V. Quine, 'The Scope and Language of Science' in The Ways of Paradox and Other Essays (Harvard University Press 1976) 233.

${ }^{131}$ John Rawls, A Theory of Justice (Rev. edn, Belknap Press 1999 [1971]) 41, footnotes omitted. We cannot avoid evaluating moral theory against the background of our common intuitions. Take for example Kant's claim that we ought not to lie even to save someone's life, or Peter Singer's argument that we ought to donate most of our earnings to charity. These and similar accounts are too remote from the way we think about these moral problems and we are inclined to think that the theories that support such conclusions need to adjusted or rejected.
} 
Even if it reaches beyond our common intuitions, moral theory will do so by employing the same mechanisms, or it will fail as a project in self-understanding. Ethical theory must render us, ordinary people, able to make sound moral judgments starting from our own evaluative frameworks. We may fail to notice more subtle points, fully detach from our habits of the heart, or liberate ourselves from prejudice. Philosophy can help us to overcome this, but it must remain true to the ways we are as humans, and - in particular - locally situated humans.

While this position will be in the background of the analysis, I will defend it in full detail in chapter 5. Here I wish to proceed more carefully and - instead of trying to mold different positions and judicial arguments into my theory from the beginning give them space of their own and let them feed into this theory. To do this we need to understand what is at stake: what are the properties of moral judgment and the different ways to account for them. This will both enable us to understand the points of contention between different metaethical positions and identify some of the tensions in trying to account for these elements. ${ }^{132}$ It is in this sense useful to distinguish between values and reasoning as two elements of moral judgment.

\section{Values}

When we use moral language, we evaluate a course of action as good or bad. This entails reliance on some background values. There are two different types of questions we can ask about the use of values in moral talk. The first order question is about the goodness of a particular value. For instance, we may ask 'Is liberty good?'. The answer to this question will depend on our substantive moral theory (normative ethics). We can, for example, be utilitarian and believe that liberty is good so long as it promotes the aggregate human happiness. Or, we can subscribe to deontological normative ethics and think that liberty is good because it emanates from a moral rule we are able to impose on ourselves as reasonable beings. Both conceptions presuppose that there is a value in

\footnotetext{
${ }^{132}$ For a useful scheme of metaethical positions see Peter Railton, 'Realism and Its Alternatives' in John Skorupski (ed), The Routledge Companion to Ethics (Routledge 2010) 297.
} 
the background of the normative moral argument, but they disagree which value is capable of giving us such grounding: the aggregate happiness or practical reason.

There are also second order questions about the nature of value, which are important for the present argument. For instance, we can ask whether there is an objective property of being good. So we may say that liberty is good for Jones and not for Smith, or that it is universally and objectively good or bad. In the first case, the value would figure in the moral talk in a way similar to other evaluative discourses which we normally consider to be subjective. In the case of the taste for ice cream, we may be puzzled that Jones likes strawberry ice cream and Smith doesn't, but we are ultimately willing to admit that 'one cannot argue about tastes' or something to the same effect.

These kinds of questions about the nature of value are posed by metaethics. ${ }^{133}$ The main point of contention here is not only whether the value is subjective or objective, but also in virtue of what we can decide that. The controversy arises because moral language although based on values - has what Railton calls 'cognitive form' and 'objective purport'. ${ }^{134}$ We talk as if our moral utterances are objectively true and knowable in a similar way as ordinary statements of facts; also, our attitudes are different when we make moral judgments than when we merely express preferences or tastes. Moral language usually takes a different form than the ice cream talk between Smith and Jones. When we say 'I like ice cream' we take it to be a different kind of statement from 'Torturing babies for fun is wrong'. Also, it appears that nothing is added when we say “Torturing babies for fun is wrong" is true', because it is already implicit in saying 'Torturing babies for fun is wrong'.

We can distinguish two main positions regarding the question of cognitive form. The issue is whether moral utterances - and, consequently, values presupposed by these utterances - contain propositions that can be true or false. Are moral judgments even in

${ }^{133}$ This is true also even for virtue-based theories, as in the background of any virtue we are able to find values. For example, saying that we ought to do what a courageous person would do, relies on the fact that we value courage, and so on.

${ }^{134}$ Railton 299. 
the business of expressing beliefs about something that can be true, or are they just expressing our (subjective) preferences? ${ }^{135}$ On the one hand, there are cognitivist positions that take moral language at its face value and think of moral sentences as truth-apt. This implies a belief on their part that moral sentences contain propositions which can be true or false. On the other hand, there are non-cognitivist views which hold that moral statements are not truth-apt. According to the non-cognitivists, moral sentences do not express propositions, and thus lack truth conditions. Their purpose is not to declare our beliefs (which can be true or false), but to express some different state of mind. The value here is subjective, in the sense that it is not a property of the object independent from our minds, but a product of the state of mind of those who express moral statements.

David Hume, for example, thought that beliefs as states of mind capable of being true or false could not motivate us to act, and that only desires could accomplish that. ${ }^{136}$ Responding to this, Kant made a distinction between categorical and hypothetical imperatives, which is another way to capture the difference between cognitivists and non-cognitivists. In 'Groundwork for the Metaphysics of Morals' he wrote: 'if the action were good merely as a means to something else, then the imperative is hypothetical; if it is represented as good in itself, hence necessary, as the principle of the will, in a will that in itself accords with reason, then it is categorical'. ${ }^{137}$ In Kant's view, moral duties apply to us categorically, and not hypothetically; the form of moral obligation is not 'you ought to $\phi$ given that you will Y' but 'you ought to $\phi$, regardless of what you actually will'. In Hume's view, reasons play a role only as hypothetical imperatives and ultimately depend on our desires. It is now common to assume - although not without controversy - that desires and other emotional states of mind cannot be objectively true and that this view thus leads to non-cognitivism. This distinction proves to be one of

\footnotetext{
${ }^{135}$ For simplicity, we need to bracket the issue of whether our preferences can be true, but in relation to us, in a sense of it being true of me (but subjective) that I like ice cream.

${ }^{136}$ See in particular 'On the influencing motives of the will' and 'Moral distinctions not deriv'd from reason' in David Hume, A Treatise of Human Nature (L.A. Selby-Bigge and P.H. Nidditch eds, 2nd edn, Clarendon Press 1978) 413-418 and 455-470. Although the label originates from the 1930s, contemporary non-cognitivists avow Hume as their predecessor. For an alternative reading of Hume see Rachel Cohon, Hume's Morality: Feeling and Fabrication (Oxford University Press 2008).

${ }^{137}$ Immanuel Kant, Groundwork for the Metaphysics of Morals (Allen W. Wood tr, Yale University Press 2002) 31.
} 
the main points of contention between different regimes of ethical arguments in constitutional interpretation.

Related to this is the question of the objective purport of moral talk. Even if one accepts that moral sentences are truth-apt, there is a question of whether at least one of these sentences is true, and, if the answer is yes, in virtue of what it is true. Answers to these questions have uncountable variations, but the main difference builds on the distinction between cognitivism and non-cognitivism. It revolves around the question of whether moral statements are made true by mind-independent properties (which exist separately from us and hence our moral beliefs are mental-states matching that reality), or whether they are only mind-dependent (expressing our desires about how we would like the world to be and not how it actually is). ${ }^{138}$ The former position, moral realism, takes the objective purport of moral talk at face value and trusts that moral utterances aim to report mind-independent facts; ${ }^{139}$ the latter position, non-realism, denies this. While the positions in metaethics have developed in incredible depth, sophistication and complexity, it is clear that there are two main threads in thinking about value: one departs from an account of value as an emotive state of mind that does not aim to describe the mind-independent world as it is; the other starts from the idea of moral value as existing in mind-independent reality, about which we can have robustly right or wrong beliefs typically developed in virtue of the faculty of reason.

\section{Reasoning}

We have seen that the role of reason is differently understood: while some see it as a faculty that enables us to attain the values as goals we already have in virtue of our desires, others believe that our ability to reason also determines the true values (or goals) themselves. The question is how these positions can account for the role of

\footnotetext{
${ }^{138}$ But there are middle positions as well, such as 'cognitivist non-realism'. Also, there are practice-based views that do not subscribe to the correspondence theory of truth which forces realism to presuppose moral facts as separate mind-independent entities. These views typically invoke analogies between language, logic or mathematics on the one hand, and morality on the other. I hope to address most of these issues in chapter 5, but prefer to keep things more general at this point.

${ }^{139}$ Error theory takes cognitive form seriously but denies that any moral claim can be true. See John L Mackie, Ethics: Inventing Right and Wrong (2 edn, Penguin 1990 [1977]).
} 
reasoning in moral discourse. Values figure in one of the premises of our moral arguments and judgments: moral language is typically understood as the application of moral values to a set of factual circumstances. This also means that we are expected to offer justifications for our moral views. The issue is, of course, what counts as such justification, but let me first illustrate the claim that reasoning is a part of moral language with an example. Consider a verse from Buddy Holly's song 'I'm Gonna Love You Too':

\footnotetext{
You're gonna say you'll miss me, you're gonna say you'll kiss me, yes, you're gonna say you'll love me, 'cause I'm gonna love you too.
}

The verse appears as a sort of reasoning. Holly seems to infer that because he will love someone, that person will say or promise to miss, kiss and love him. However, in spite of the inferential form, it would be silly to understand that Holly is conveying an argument about love. This is not because his argument is implausible (and it is), but because the words he is using appear in the context (love song/music) that does not lend itself to the rules of logic. In fact, the beauty of the song is partly in its ability to show that love is not rational. Holly conveys an emotion using an unconvincing argument.

In contrast with artistic expressions, we do not think that implausible arguments can be moral arguments. For example, the argument 'You ought not steal, 'cause I'm gonna love you too' would not be accepted by any competent moral agent as sound (and probably wouldn't make much sense as a verse either). Moral practice entails justification of our moral judgments. While the question 'why' makes little sense in the context of love or art, we tend to ask this question and expect people to justify and explain their moral views. This is far from saying that morality is rational all the way down, but in the same way that physics uses laws of mathematics to prove its hypotheses, morality uses reasoning as a form of justification. Two caveats are 
important here in order to leave the question about values open: first, the myriad of justifications can end when we hit a normative premise we both accept (say, how would it be if everyone were stealing'); or second - as some would argue - when we reach our (common) desire that motivates us to act morally in the first place. ${ }^{140}$ Therefore, we need not say anything at this point about the possibility of justification of moral practice as such, or whether the myriad of justifications must hit the bedrock of mindindependent reality in order to make our moral language intelligible. In fact, one of the most important differences between ethical arguments in constitutional reasoning will turn out to be about different understandings of the role of reasoning in moral talk.

Let me briefly mention two features of moral reasoning that are important for the discussion later on. The first one is coherence. It is hard to talk about moral reasoning if we do not bring our opinions into (internal) coherence. ${ }^{141}$ For example, the sentence 'I like ice-cream and I don't like ice-cream' would sound schizophrenic in ordinary language, as much as someone who says 'I am committed to equality and I am not' would not be considered a competent moral speaker. The second feature is connected to coherence but goes a bit further: moral judgments supervene upon the concrete facts of the case that is at hand. ${ }^{142}$ If we believe that in case $\mathrm{X}$ it ought to be $\mathrm{A}$, then it follows that in the case $\mathrm{Y}$ it also ought to be A, if the circumstances are relevantly the same. Moral judgments purport to be impartial and demand that like cases are treated alike; in other words, they imply universalization. This is not to say that specific circumstances cannot be taken into account. But if I choose to save my own child over two unknown children - thinking this is what a good parent ought to do - I also at the same time accept that other people are justified in behaving the same way. Both of these

\footnotetext{
${ }^{140}$ This is Hume's position: 'The very feeling constitutes our praise or admiration. We go no farther; nor do we enquire into the cause of the satisfaction. We do not infer a character to be virtuous, because it pleases: But in feeling that it pleases after such a particular manner, we in effect feel that it is virtuous.' Hume 471.

${ }^{141}$ For example, Sharon Street's 'Humean constructivism' is one of the views that combine desire-based theory with the requirement of coherence. Sharon Street, 'Coming to Terms with Contingency: Humean Constructivism about Practical Reason' in James Lenman and Yonatan Shemmer (eds), Constructivism in Practical Philosophy (Oxford University Press 2012).

${ }^{142}$ Hare called this feature 'universal prescription' and thought that it was a formal requirement of language implied by the use of 'ought' sentences. See R.M. Hare, The Language of Morals (Clarendon Press 1952) ch 10.
} 
requirements are rather minimal and do not add much substance to our moral views; they are thus compatible with a range of metaethical positions.

Let me finish with some observations about the role of facts in our moral reasoning. They are of course an important factor in the universalizability requirement (which facts make the cases alike?). But facts play other roles as well. One is conveyed in the 'ought implies can' principle. Consider an example. A man is drowning in your backyard pool. All other things being equal, you ought to save him. Now, if there is a man drowning in Mississippi and you are in Austria, this is regrettable and sad, but there is no duty to save him for a simple reason that it is factually impossible. Finally, factual conditions also have a role in determining the empirical plausibility of our premises. For instance: (i) All rational beings should be treated as equals; (ii) Dogs are not rational. (iii) Dogs need not be treated as equals. The second premise is empirical, and if we discover that dogs are actually rational, given our first premise, the conclusion must be different.

With this scheme in mind, we can now proceed to examine, explain and classify different types of ethical arguments in constitutional reasoning. The cleavages in understanding of value resurface in ethical arguments entrenched in judicial practice. Some arguments presuppose that value is emotive and local, and others that it is reasonbased and universal. The thesis will examine both of these argumentative trends separately to see whether they are plausible; ultimately, I will seek to develop a theory of constitutional ethics that will rely on a sound understanding of value and reasoning in moral discourse.

\section{Conclusion}

The purpose of this chapter was to introduce the notion of constitutional ethics as a set of legally embedded patterns of ethical arguments in constitutional reasoning. While ethical arguments in constitutional reasoning have legal form, their aim is to morally evaluate, rather than to discern the meaning of an authoritative directive. This makes them different from usual legal arguments. But ethical arguments are not ordinary 
moral arguments either: the specific institutional context in which they arise and their legal entrenchment make them quite different from the arguments we typically use in moral discourse. To understand their dual character, we need to invert the standard perspective on the relationship between law and morality. Instead of thinking about law from the viewpoint of morality, we also need to understand morality from the viewpoint of law. The central argument was that ethical arguments entrench a particular vision of moral value. They locate moral value somewhere in our universe and attach it - for example - to our emotions, reasons, local constitutional traditions, or humanity.

The chapter explored how we could expand our conceptual imagination to grapple with these issues. The existing theories of law and constitutional interpretation miss important aspects of this phenomenon because they fail to notice the ways in which law structures judicial moral - and particularly metaethical - choices through ethical arguments. This occurs for two rather different reasons: first, the existing theories need a more nuanced empirical sense of the actual interaction between law and morality; second, they need a more sophisticated metaethical framework to understand this empirical reality. The same conclusion followed from the analysis of theories that specifically focus on ethical arguments. While they rely on the plausible intuition that law constrains ethical arguments, they neglect certain elements of constitutional ethics and fail to account for their metaethical foundations. In an attempt to justify the counter-majoritarian moral judgments of courts, they exclusively focus on the argument from constitutional identity; however, they neither explain why constitutional identity would be a valid source of value nor how it relates to other ethical arguments.

The chapter analyzed the argument from constitutional identity and argued that it consists of two different tendencies: one assumes a more general purpose of a constitution as establishing a check on popular will, and the other focuses on the set of moral commitments that arise in a community in relation to its constitution. The thesis will build on this analysis in later chapters and explore how the argument from constitutional identity fits into a larger puzzle of constitutional ethics. There are at least two other types of ethical arguments - from common sentiment and universal reason - 
that appear in constitutional reasoning. Later chapters shall analyze these in much more detail.

In order to do so, this chapter introduced the main points of contention in explaining moral practice and judgment. It tried to show that good moral judgment needs to be premised on a sound conception of moral value and moral reasoning; this - in turn means that constitutional ethics as a manner in which moral judgments are made in constitutional practice need also be based on an apposite understanding of moral values and reasoning. The plausibility of different kinds of ethical arguments in constitutional interpretation will depend on the credibility of their understanding of the nature of moral value, and the role of moral reasoning that follows from such an account of value. The framework of values and reasoning will help us better understand tacit metaethical choices that are entailed by certain ethical arguments, and will eventually enable us to reconstruct judicial practice. The task of the next two chapters is to focus on ethical arguments from common sentiment and universal reason and reveal their metaethical foundations. Once this is done, I will go on to reconstruct judicial practice in accordance with the best understanding of the nature of moral value and the role of reasoning in our moral judgment, but also taking into account the legitimate concerns about the role of courts in this process. 


\section{CONSTITUTIONAL ETHICS AND COMMON SENTIMENTS}

\section{Introduction}

The purpose of this chapter is to analyze the philosophical foundations of ethical argument in constitutional interpretation which holds that moral sentiments of the people in a particular community constitute the right solution to moral problems; it seeks to reveal the underlying commitments of this type of argument and subject them to critique. The chapter thus contains two sections. The first attempts to sketch the contours and general features of the argument from common sentiment by analyzing legal doctrines in three different constitutional systems. The second exposes the argument to philosophical analysis.

The argument from common sentiment looks at existing moral feelings, internal dispositions and psychological tendencies to discover solutions to moral problems. As such, it has at least one obvious advantage: a powerful moral epistemology. It is - most of the time - obvious what we are inclined to do when faced with moral problems, guided by our gut feelings. Moreover, there is nothing metaphysically mysterious in saying that our emotions exist, for we feel them all the time and we are quite aware of their normative and motivational pull. We need not populate the world with suspicious 'moral facts', whose existence is 'utterly different from anything else in the universe', as Mackie would put it. ${ }^{1}$ Therefore, we seem to have an easy answer to both the moral question before us, and to a larger metaphysical problem. But if we are inclined to do something - inflict the death penalty, legalize gay marriages, prohibit abortions - can we just go for it? Is this the right thing to do? What else is needed to reach a moral decision? Must we analyze, re-evaluate, or justify our initial reactions? What - if anything - does this process entail and does the argument from common sentiment obstruct it?

\footnotetext{
1 Mackie 38.
} 
As we have seen, the argument from common sentiment is not the only type of ethical argument in constitutional reasoning; however, I analyze it separately from other types, as a stand-alone argument. The reason is this. The nature of law, as a path-dependent social practice, entrenches particular ways of seeing morality in legal doctrines. This leaves the question of initial motives for using the argument less important, as the doctrine acquires a force of its own, and thus at times precludes other types of ethical arguments. It tends to consume the realm of constitutional ethics and become exclusionary: courts often claim that the only argument that applies to a case - legally speaking - is the ethical argument from common sentiments. In this chapter, I wish to illustrate one of these views and show that at its foundation lies an inadequate moral ontology. This is not to say that such an argument never makes sense politically, legally, or even morally. The courts may be motivated in different ways, it can be politically wise or morally justified to leave the moral issue for others to decide, or it may be legally sound to follow previous patterns of interpretation strictly. But I shall argue that, to the extent to which the ethical argument from common sentiment excludes other types of arguments, it loses much of its appeal because it does not capture the way moral questions need to be approached. The argument from common sentiment does not leave space for reflective endorsement and justification of our moral feelings.

\section{Elements of the argument from common sentiment}

To understand the argument from common sentiment, it is useful to distinguish it from a related, but different idea of popular constitutionalism. In the domain of constitutional adjudication, the notion of popular constitutionalism has been used as an explanation of the ways in which constitutional change occurs outside the formal constitutional revision procedure, ${ }^{2}$ as a manner in which a shared deliberation between courts and citizens can constitute a foundation of constitutional authority, ${ }^{3}$ and as a normative

\footnotetext{
2 Bruce A. Ackerman, We the People: Foundations (Belknap Press 1991).

${ }^{3}$ See Robert Post and Reva B. Siegel, 'Democratic Constitutionalism' in Jack M. Balkin and Reva B. Siegel (eds), Constitution in 2020 (Oxford University Press 2009).
} 
thesis about an attractive mode of constitutional interpretation. ${ }^{4}$ These accounts are motivated by the debate about the 'counter-majoritarian' difficulty: the possibility of courts overturning the decisions of a democratically elected majority. ${ }^{5}$ In contrast to this, I analyze a particular regime of ethical arguments in constitutional reasoning, which holds that the moral sentiments of the members of one community determine how moral dilemmas are to be resolved. There are two central components of this argument: the emotional reaction of the people in a particular community.

Because the idea of popular constitutionalism appears to be in the neighborhood of the argument from common sentiments, I shall differentiate them by answering an immediate objection that could arise. One may argue that the argument from common sentiment is not about its background metaethical assumptions, but about the legitimacy of judicial review, or simply about letting different institutions do what they do best. In other words, the objection states that explaining these arguments as metaethically grounded misses their point, because they are motivated by the legitimacy of judicial review, or by the comparative institutional choice, and hence popular constitutionalism presents a better theoretical framework to understand them. There are many reasons why something like popular constitutionalism may be a more legitimate way to deal with problems raised by the indeterminacy of constitutions. One reason for deference to real or hypothetical popular opinion could be the lack of democratic legitimacy of the courts, which may be further supported by the fact that there seems to be a less stark moral disagreement about the fairness of the democratic procedure, than about the substantive moral issues at stake before the courts. ${ }^{6}$ Furthermore, there are many institutional advantages of legislators over courts. Legislators, for example, can be better placed to make these choices because they do not

\footnotetext{
${ }^{4}$ A prototypical exposition of this kind of popular constitutionalism is Larry Kramer, who holds that the citizens are 'a higher authority out there with a power to overturn [Court's] decisions'. The People Themselves: Popular Constitutionalism and Judicial Review (Oxford University Press 2004) 253.

${ }^{5}$ See Alexander M. Bickel, The Least Dangerous Branch: The Supreme Court at the Bar of Politics (BobbsMerrill 1962).

${ }^{6}$ See Jeremy Waldron, 'The Core of the Case Against Judicial Review' (2006) 115 Yale Law Journal 1346 Waldron, Law and Disagreement. However, such arguments are flawed unless they show that there is agreement that the issues of rights ought to be democratically decided and unless they demonstrate the normativity of contingent moral agreement.
} 
block the policy process, unlike courts, which may incur more political and legal costs in changing the decision later on, especially if there is an entrenched constitution in place. ${ }^{7}$

I do not take issue with these arguments - they indeed seem plausible - but there are two ways in which I distinguish the ethical argument from common sentiment from the idea of popular constitutionalism (which starts from the concerns over legitimacy and questions about institutional competence). The ethical argument explained here is both narrower and broader. First, it is narrower because it does not claim that each instance of deference to representative branches can be traced back to an implicit metaethical position. In other words, I deal with a set of cases where deference to legislatures, juries, or popular opinion could be traced to certain views about morality, and these cases by no means explain all the reasons the courts may have to be deferential. Second, the concept is broader, because the argument from common sentiment may not lead the courts to respect legislative, juries' or popular opinions. As the examples below will show, the courts also use this kind of reasoning to decide the issue themselves, or to take into account other courts' decisions. Therefore, there is no correlation between this regime of ethical arguments, and deference to popular will because of legitimacy or institutional concerns. This implies that there may be other reasons and motives at play that determine the institutional choice - like democracy, fairness, self-government, respect for precedents - which could lead to the same result as the ethical argument from common sentiment. Nevertheless, it is possible to analyze its metaethical foundations, as long as we are aware of the fact that we can infer little about its nature from the institutional choice as such.

In this sense, the understanding of ethical argument from common sentiment does depart from the debate about popular constitutionalism, if the latter is perceived as a plea for giving more power to interpret the constitution to the people. This may leave conceptual space for arguing that popular constitutionalism is still sound or not, on the basis of some independent reason. Yet, while I do not deny that there may be other

\footnotetext{
${ }^{7}$ See Neil K. Komesar, Imperfect Alternatives: Choosing Institutions in Law, Economics, and Public Policy (University of Chicago Press 1994) Neil K. Komesar, Law's Limits: The Rule of Law and the Supply and Demand of Rights (Cambridge University Press 2001).
} 
arguments for letting the people decide on these issues, I do hope to show that the institutional deference to legislatures or juries often does follow from a particular metaethical perspective, entrenched in a constitutional doctrine. ${ }^{8}$

To understand what exactly is the argument from popular constitutionalism we need to take a closer look at some cases from comparative constitutional practice. In order to crystalize the underlying common denominators and central commitments of this argument - and show why the legitimacy of judicial review is not the appropriate framework to analyze them - I shall rely on cases from different institutional settings, that involve diverse ways of determining public opinion, with varying backings in precedents or text, and dealing with heterogeneous legal and moral issues. ${ }^{9}$ This means that the choice of cases is less haphazard, and their description more detailed, than what is usually the case in legal philosophy. The case studies are chosen to show the same pattern of reasoning which leads to different institutional consequence, so that our focus can remain with the metaethical foundations of these arguments. They neither exhaust all the instances of the use of ethical argument from common sentiment, nor are they intended to be representative of all constitutional cultures; they however do intend to be illustrative enough to support some general conclusions. The examples I shall use are: the United States Supreme Court decisions on the death penalty; the European Court of Human Rights obscenity doctrine; and the Canadian Supreme Court's extradition jurisprudence.

Let me briefly introduce common elements of all three examples which show that we are dealing with the same type of argument. First, in all cases the question before the

\footnotetext{
8 It is important to underline once again that the argument from common sentiment is often not about the explicit metaethical understandings of judges; judges are in fact often unaware of the assumptions behind their arguments, which may stem from a previous doctrine, or they may not be fully conscious about the consequences of these views. I believe however that they do have a rough idea of the problem and that they sense it as a problem on a deep level. As the examples will show, they certainly speak as if they are aware of it and as if they subscribe to certain metaethical views. However, it would be a misinterpretation to say that these metaethical assumptions are fully conscious judicial motives; they are typically a consequence of their under-theorized and implicit assumptions about the nature of moral value.

9 To be sure, judges sometimes do take a view that both popular and universal morality are relevant: the reality of constitutional adjudication is more chaotic than analytic categories. But judges also use popular morality arguments as exclusive or at least the most relevant type of ethical arguments, and I shall explore whether this is a tenable position. This will help us make a starker distinction between different regimes of ethical arguments, and therefore facilitate better understanding of their central commitments.
} 
court depends on moral judgment. There is no dilemma that the issue is not fully determined by text, previous precedent, or in any other intrinsically legal manner, while the courts explicitly search for moral solutions to these issues. Second, the conventions of interpretation do not exclude - at least initially - other types of ethical arguments. In all these cases, there is a dispute whether the argument from common sentiment is the only way to deal with the problem, with one side to the dispute claiming that it is. Third and centrally, in all these cases courts understand morality as consisting in the emotional reactions of a particular community. Fourth, regardless of the same moral foundation, the arguments lead to different institutional consequences. This shows that the issue is not simply a matter of institutional choice, but of something analytically separate and prior to that.

\subsection{United States}

As we have noted in the previous chapter, the 8th Amendment to the US Constitution amendment prohibits 'cruel and unusual' punishment, ${ }^{10}$ and this phrase - as the Supreme Court has held since its landmark decision in Trop v Dulles - 'must draw its meaning from the evolving standards of decency that mark the progress of a maturing society'.11 To answer whether the death penalty is cruel and unusual, the Supreme Court thus needed to grapple with the question of how these standards of decency are to be determined, and which 'maturing' society is relevant. While there is some textual support both in the Amendment itself ('unusual' punishment), and in the Trop test for understanding these standards of decency as based on socially shared values and currently dominant opinions, the question is still a matter of dispute among justices. On the one hand, some of them believe that the task of the court is to defer to moral opinions of legislatures and juries. On the other, subjection of popular opinion to reason-based evaluation has never been ruled out completely. ${ }^{12}$ The interpretation of

\footnotetext{
${ }^{10}$ It reads: 'Excessive bail shall not be required, nor excessive fines imposed, nor cruel and unusual punishments inflicted.'

${ }_{11}$ Trop v Dulles $100-101$.

${ }^{12}$ This is even true of justices who in other decisions subscribe to the ultimate relevance of popular intuitions. An example is Justice Stevens. He argued that ' $[\mathrm{i}] \mathrm{t}$ is of vital importance to the defendant and to the community that any decision to impose the death sentence be, and appear to be, based on reason rather than caprice or emotion' (Gardner v Florida 430 US 349 (1977) 358), and he subsequently
} 
the clause is hence open to different approaches: there is no immediate resolution on the basis of textual or doctrinal argument, but there are competing conventions of interpretation that can guide the court's analysis. ${ }^{13}$

The current of judicial reasoning that is relevant here takes emotional reactions as fundamental for diagnosing what is cruel and unusual. How this came to be the prominent interpretation of the 8th Amendment is well-known. Ever since it faced a robust legislative response to a split decision in Furman $v$ Georgia,${ }^{14}$ the Supreme Court took legislative and jury opinions as the starting point of the 8th Amendment analysis. Justice Stewart captured this attitude in Gregg v Georgia:

... it is now evident that a large proportion of American society continues to regard [the death penalty] as an appropriate and necessary criminal sanction ... The most marked indication of society's endorsement of the death penalty for murder is the legislative response to Furman ... In the only statewide referendum occurring since Furman and brought to our attention, the people of California adopted a constitutional amendment that authorized capital punishment ... The jury also is a significant and reliable objective index of contemporary values because it is so directly involved. ${ }^{15}$

supported a doctrine which implicates judicial moral judgment when there are 'reasons to disagree' with popular and legislative judgment which otherwise hold sway in the 8th Amendment analysis. (See his opinion in Atkins v Virginia 536 US 304 (2002), but also Coker v Georgia and Enmund v Florida 458 US 782 (1982) where the doctrine was developed.

${ }^{13}$ Some justices deny this: see in particular Justice Scalia in Atkins v Virginia and Roper v Simmons.

${ }^{14}$ Furman $v$ Georgia. Having failed to deliver a controlling opinion on the matter in Furman, the court faced an unprecedented legislative response that supported the imposition of the death penalty: the Congress and 35 state legislatures regulated the death penalty between Furman and Gregg v Georgia 428 US 153 (1976).

${ }^{15}$ Gregg v Georgia 179-181. Stewart considered values to be socially-based and dependent in some way on the reaction of the American people to a particular moral problem. But even more interesting is the way he presented this response as a matter of weighing different emotions, which presents the embryonic version of constitutionalism based on communal emotions. On the one hand, Stewart held that 'capital punishment is an expression of society's moral outrage at particularly offensive conduct', and - citing Furman - that 'the instinct for retribution is part of the nature of man, and channeling that instinct in the administration of criminal justice serves an important purpose in promoting the stability of a society governed by law.' (ibid 183, emphasis added). On the other hand, he found an emotional counterbalance to this: 'the reluctance of juries in many cases to impose the sentence may well reflect the humane feeling that this most irrevocable of sanctions should be reserved for a small number of extreme cases' (ibid 182, emphasis added). Since Coker v Georgia the jurisprudence of the court has involved determining whether there is a consensus among the states to abandon capital punishment for certain crimes or offenders. While over time the relative weight given to legislative opinion has arguably decreased - as the court has 
Notwithstanding the causal explanation of such reading of the 'cruel and unusual' clause - as a consequence of institutional deference in the aftermath of a significant popular backlash - there is a justification which parallels such reading, provides a philosophical framework to support it, and puts the institutional choice in a moral perspective. This philosophical framework takes the emotional reactions of the community as the bedrock of moral evaluation. ${ }^{16}$

Expressions of this view often take on a similar form, which can be exemplified by Justice Stevens' opinion from Spaziano $v$ Florida. ${ }^{17}$ The petitioner in this case, $\mathrm{Mr}$ Spaziano, was found guilty of first-degree murder in Florida. The jury proposed life imprisonment, but the trial court refused to follow the recommendation and sentenced Spaziano to death. This was possible under Florida law because juries' opinions were only advisory in the sentencing process, and once the case reached the Supreme Court the main question became whether the 8th Amendment allows for overriding of juries' decisions by judges. Stevens argued that the practice was not constitutional, and in so doing he relied on a particular conception of morality that affected the institutional choice between juries and courts in the sentencing process. Thus, the first step in his reasoning is to make the question of the imposition and constitutionality of the death penalty moral, both given the issue at stake and the previous doctrine which directs the court to engage in moral reasoning. As Stevens puts it, in the final analysis, capital punishment rests on not a legal, but an ethical, judgment'. ${ }^{18}$

placed more emphasis on legislative tendencies and trends and balanced them against criminological or substantive moral concerns - the view that moral opinions of citizens in some way determine the answer has remained a part of the court's jurisprudence. This changing trend is particularly observable in Atkins v Virginia, Roper $v$ Simmons and Kennedy $v$ Louisiana. For example, in Kennedy the court ignored the inclination of several legislatures, including the Congress, to prescribe capital punishment for child rape.

${ }^{16}$ David Garland also connects the trend of institutional deference to local authorities with the idea that justice is determined by community sentiments: 'the Court came to insist that justice - as shaped by the values of democracy and localism - required that juries alone might impose death sentences, since juries best understood the community sentiments that made such sentences justifiable'; 'The court systematically empowered local figures - governors, state legislators, district attorneys, state judges, and local juries: most of them elected, all of them responsive to community sentiment - to decide the questions of life and death that capital cases entailed'. David Garland, Peculiar Institution: America's Death Penalty in an Age of Abolition (Oxford University Press 2010) 273.

17 Spaziano v Florida 468 US 447 (1984).

18 Ibid 481 (Stevens). 
The second step in the argument is crucial and offers a conception of morality: a particular metaethical grounding of moral judgments. Morality is defined by two elements: it consists in the emotional, intuitive response of a specific community to a moral problem at hand. For Stevens J, the death penalty is ultimately understood only as an expression of the community's outrage - its sense that an individual has lost his moral entitlement to live'. ${ }^{19} \mathrm{He}$ argues that the deterrence rationale cannot fully justify the death penalty, and that 'the question whether the death sentence is an appropriate, nonexcessive response to the particular facts of the case will depend on the retribution justification' connected to 'society's moral outrage'. ${ }^{20}$ Notice that even if the death penalty may only be causally explained by outrage, it does not follow that such explanation is not morally deficient. ${ }^{21}$ But given that Stevens starts his moral analysis from the feeling of outrage - and granted his view that nothing more can be said to justify the death penalty - it follows for him that we ought to surrender our moral judgments to socially shared moral commitments that find expression in emotional reactions to a particular set of facts: the constitutionality of capital punishment - as Stevens puts it - 'critically depends upon whether its imposition in a particular case is consistent with the community's sense of values'. ${ }^{22}$

This step in Stevens' reasoning thus performs another role as well. Not only ought communal sentiments prevail when the sanction is imposed - because of the retributivist character of the death penalty - but they also determine the constitutionality of the practice as a whole. The logic is this: if morality is the same phenomenon, and if it informs both the infliction of the death penalty in a particular case and the constitutionality of the practice in general, then to be consistent about morality we must take into account the communal moral sentiments on both of these levels. He justifies the death penalty as an individual sanction and as a general practice with the same argument: the moral sense of the community demands it. For Stevens, the fact that all state legislatures, except the ones that abolished the punishment, have at some point

\footnotetext{
${ }^{19}$ Ibid 469 (Stevens).

${ }^{20}$ Ibid 480 (Stevens) citing Gregg v Georgia 183-184.

${ }^{21}$ For a defense of the retributivist-emotivist view of punishment see Michael S. Moore, Placing Blame: $A$ Theory of the Criminal Law (Oxford University Press 1997) ch 3.

22 Spaziano v Florida 489 emphasis added.
} 
involved juries in this process demonstrates 'a strong community feeling that it is only decent and fair to leave the life-or-death decision to the authentic voice of the community - the jury - rather than to a single governmental official. ${ }^{23}$ According to him, we must also question whether assigning ' $[\mathrm{t}]$ he decision whether or not an individual must die' to 'governmental officials, and not juries, is consistent with the community's moral sense'. ${ }^{24}$ The constitutionality of the practice does not thus follow from the separate ideal of democratic legitimacy, but from a conception of morality based on communal feelings.

This point is further evidenced by the third and final step of Stevens' argument, where he focuses on institutional choice, and grounds his analysis in the capacity of certain institutions to stay true to a community's moral sentiments:

if the decision that capital punishment is the appropriate sanction in extreme cases is justified because it expresses the community's moral sensibility - its demand that a given affront to humanity requires retribution - it follows, I believe, that a representative cross-section of the community must be given the responsibility for making that decision. ${ }^{25}$

Again, the argument has bifurcated effects: not only do moral sentiments determine the imposition of the death sentence in particular cases, but they also determine its constitutionality. Stevens believes that moral sensibility is best expressed by juries, and that both legislatures and courts are deficient in mapping it. Although the legislative opinion is a 'logical starting point'26 for the analysis of a community's sentiments, it will often be distorted by the implications of judicial decisions. Stevens thus searches for something like pure, unbiased or pre-theoretical communal sentiment; for example, he considers the legislative response to Furman $v$ Georgia as 'not entitled to the same presumption of validity' because it fails to represent a genuine 'community sentiment'. ${ }^{27}$

${ }^{23}$ Ibid 469 (Stevens).

${ }^{24}$ Ibid 476 (Stevens).

25 Ibid 481 (Stevens).

${ }^{26}$ Ibid 472 (Stevens).

27 Ibid 475 (Stevens). 
Similarly, judges themselves are a deficient litmus test for communal values as compared to juries which 'reflect more accurately the composition and experiences of the community as a whole, and inevitably make decisions based on community values more reliably, than can that segment of the community that is selected for service on the bench'. ${ }^{28}$ As a consequence, Stevens found that the imposition of the sentence in Spaziano's case was unconstitutional because it removed the sentencing power from the jury and thus did not reflect the moral sentiment of the community.

This kind of reasoning provides a philosophical and moral justification to the conclusion from Gregg quoted above, which directs the Supreme Court to look for consensus on the issue among legislatures and juries when interpreting the 8th Amendment. And such logic is also evident in cases when the court shows readiness to depart from popular opinion on the constitutionality of the death penalty. When this happens, the dissenters are usually quick to point out not only that democratic concerns should lead to more judicial restraint, but also that the nature of moral judgments - predicated upon feelings and intuitions - is better exercised by the representative branches of government. In other words, opposition to judicial activism often relies on the philosophical argument that puts communal moral sentiments at the center of the moral system. For example, when the court departed from popular opinion in Roper $v$ Simmons to reach the moral conclusion through its own reasoning, Scalia dissented and argued that the conception of morality that is dictated by precedents excludes the independent moral decision of the court on this issue. According to him, if the test for morality is:

an ever-changing reflection of "the evolving standards of decency" of our society, it makes no sense for the Justices then to prescribe those standards rather than discern them from the practices of our people. On the evolving-standards hypothesis, the only legitimate function of this Court is to identify a moral consensus of the American people. ${ }^{29}$

28 Ibid $486-487$ (Stevens).

${ }^{29}$ Roper v Simmons 616 (Scalia). 
Similarly, in Atkins v Virginia, Scalia expresses the idea that if the moral sentiments are dispositive of moral judgment, then the court should exercise restraint. As he explains:

\begin{abstract}
Beyond the empty talk of a "national consensus," the Court gives us a brief glimpse of what really underlies today's decision: pretension to a power confined neither by the moral sentiments originally enshrined in the Eight Amendment (its original meaning) nor even by the current moral sentiments of the American people ... $[\mathrm{P}\rceil$ resumably ... really good lawyers have moral sentiments superior to those of the common herd, whether in 1791 or today ... [I $] \mathrm{t}$ is the feelings and intuition of a majority of the Justices that count ... ${ }^{30}$
\end{abstract}

The gist of his argument is again the same: given that moral sentiments are fundamental to the decision, there is no reason to believe that the moral sentiments of justices are worthier than anyone else's. And indeed, if we subscribe to the first premise and believe that moral sentiments are all there is to moral judgment, it is probably cogent to defer on this issue to legislatures and juries, who are arguably also well informed about morally relevant facts, but are more representative of the community at the same time. In other words, if we accept the moral ontology the issue becomes merely epistemic: given that morality is about moral sentiments, what is the best way for us to learn about them?

Let me sum up what I have tried to demonstrate here. The argument from common sentiment - as it appears in one important strand of the 8th Amendment jurisprudence - relies on a vision of morality which consists of two elements. First, it is the emotional response that determines moral judgment. Second, the emotional response is limited to our society: in other words it is community-bound. While deference to popular emotions could be explained by textual interpretation or reasons of political prudence, the argument is analytically premised on a specific understanding of morality. The court may be right to defer on these issues to other branches of government for all kinds of reasons, but here the conclusion follows from the contingent and emotional nature of values, tied to a particular society at a particular time.

${ }^{30}$ Atkins v Virginia 348 (Scalia) references omitted. 


\subsection{European Convention on Human Rights ${ }^{31}$}

The obscenity jurisprudence of the European Court of Human Rights (ECtHR) shares the same conception of morality with the 'cruel and unusual' punishment doctrine in the US. However, it shows that the institutional consequence of such a conception of morality may be deference to other courts or constitutional systems, and not only to legislatures and juries. It demonstrates that there is no direct link between this particular metaethics and democratic values: they may coincide in terms of institutional consequences, but are not necessarily connected. Once the moral ontology is in place, the institutional issue becomes epistemological, a matter of the most reliable way of getting the community's sentiment right. Another contrast with the US example is the text of the clause which is interpreted, as the ECtHR is explicitly called on to reflect on the concept of morality by the European Convention on Human Rights. 'Morals' is one of the possible justifications for the restriction of free speech from Article 10(2) ECHR: 'The exercise of $[$ freedom of speech $][\ldots]$ may be subject to such formalities, conditions, restrictions or penalties as are prescribed by law and are necessary in a democratic society, in the interests of $[\ldots]$ the protection of health or morals [...].' ${ }^{32}$ The court therefore must have a conception of morality, for without it the analysis of limitations to the freedom of speech cannot get off the ground.

The ECtHR first developed its conception of morality in the context of free speech in Handyside $v U K .^{33}$ In this case, the applicant was convicted of obscenity for publishing a book whose audience were mainly children and which took an 'uncritical' stance towards sexual intercourse, pornography, masturbation, and the like. The same book was

\footnotetext{
${ }^{31}$ Even though the debate on the constitutional character of the court is far from being settled, the doctrine nicely illustrates the conceptual underpinnings of common sentiment arguments; furthermore, the system of the European Convention does share many features of a modern constitutional system, for example, an entrenched bill of rights protected by a judicial body in a legal procedure which are crucial for the understanding of constitutional adjudication as the object of inquiry in the thesis. At the same time, the doctrines of the court also involve assessment of the national constitutional interpretation techniques of the Council of Europe member states, and thus also touches upon the issue of constitutional reasoning even in the strict sense of the term.

32 Article $10(2)$ of the European Convention for the Protection of Human Rights and Fundamental Freedoms (ECHR).

${ }^{39}$ Handyside v United Kingdom (5493/72) [1976] ECHR 5 (7 December 1976).
} 
published without any legal problems in several other European countries, as well as in some parts of the UK; consequently, the court needed to tackle the question of how universal the conception of morality is. If morality is at least partially relative to different communities, it is possible that freedom of speech protection varies; if it is universal, then the protection should be the same. In the first case, morality is contingent and diverse, while in the latter it is universal and uniform. The court famously opted for the first view:

$[\ldots]$ it is not possible to find in the domestic law of the various Contracting States a uniform European conception of morals. The view taken by their respective laws of the requirements of morals varies from time to time and from place to place, especially in our era which is characterised by a rapid and far-reaching evolution of opinions on the subject. By reason of their direct and continuous contact with the vital forces of their countries, State authorities are in principle in a better position than the international judge to give an opinion on the exact content of these requirements $[\ldots]^{34}$

In this passage, the ECtHR effectively declared morality contingent, dependent on (legal) consensus, and prone to change over time. In the development of the argument, the institutional point ('in a better position to decide') follows from the conception of morality. Because there is divergence in moral opinions in Europe and within the UK itself, the court thinks that national authorities can have better access to values because of their direct engagement with the community which generates them. Thus - while variation between communities can be explained in other ways, such as factual circumstances or flawed reasoning - the court opts to accommodate these differences within the conception of morality. In so doing, it makes two logically separate points: it defines morality, but it also - given such definition - exercises restraint and deference to national authorities. ${ }^{35}$

\footnotetext{
${ }^{34}$ Ibid para 48. For an analysis of the margin of appreciation from a moral point of view see George Letsas, 'Two Concepts of the Margin of Appreciation' (2006) 26 Oxford Journal of Legal Studies 705.

${ }^{35}$ Notice that there is a competing explanation of the doctrine, but one which ultimately fails to account for the court's argument. One could argue that the institutional consequence follows from the court's concerns regarding its position in a supra-national system of rights-protection. Similarly to the US example, what caused the court to exercise restraint was a concern about its legitimacy in the political and
} 
Even though the doctrine has not completely precluded interpretations of free speech which rely on an autonomous judicial understanding of morals, ${ }^{36}$ the account of morals from Handyside has been at least the most dominant one in the ECtHR's obscenity jurisprudence. But this socially-based conception of morality has acquired further content over the years. In subsequent cases, the ECtHR's conception of morality incorporated two elements of the argument from common sentiment: the doctrine focused on the emotional response of a particular community.

Such interpretation became prominent in Müller $v$ Switzerland. The applicant in this case - Joseph Felix Müller - was a painter who took part in an exhibition in Fribourg (Switzerland). The exhibition was publicly advertised and open to all, and the participating artists were called to create their art on the spot. Mr Müller produced three paintings which depicted scenes of homosexuality and bestiality, causing complaints and harsh reactions from the people attending the exhibition. Before long, the paintings were removed and seized on the order of an investigating judge. The ECtHR needed to decide whether Mr Müller's freedom of speech was justifiably limited on the basis of 'morals'.

The ECtHR's analysis was primarily informed by the domestic courts. Since the Swiss criminal law contained no precise definition of obscenity, the Federal Court in Switzerland defined it as follows: 'any works or items which offend, in a manner that is difficult to accept, the sense of sexual propriety, are obscene; the effect may be to arouse a normal person sexually or to disgust or repel him'. ${ }^{37}$ While the reference to a 'normal person' was meant to provide the element of objectivity, the test in fact contained no

legal system. This may be true, but had there not been a claim about the nature of morality, the argument would have been deficient as it stands. Why would the state authorities be in a better position to determine the demands of morality if morality were universal? The court argued that because requirements of morality are determined nationally, and they thus vary 'from time to time and from place to place', deference to national authorities is warranted. The argument was not that disagreement justifies caution, but that the best explanation of disagreement is a contingent and parochial conception of morals.

${ }^{36}$ See for example Judge Mosler's separate opinion in Handyside.

${ }_{37}$ Müller v Switzerland (10737/84) [1988] ECHR 5 (24 May 1988) para 20, citing judgments of the Swiss Federal Court (ATF), vol. 83 (1957), part VI, 19-25; vol. 86 (1960), part IV, 19-25; vol. 87 (1961), part IV, $73-85$. 
precise criteria for settling the issue. The only evident specification of the test was its emotivist basis: at the bottom, it was a question of the 'sense' of sexual propriety, 'disgust', and 'repellence'. Guided by such a test, Swiss courts did not justify their decision with a separate moral argument, but tried to get to the core of the emotional reactions of the majority of the population in their community.

Domestic courts accepted the two elements of the argument from common sentiment. First, what is moral is determined by the emotional reactions of the majority of the people. Sarine District Criminal Court for example held the following view: 'The subjects [of the paintings] - sodomy, fellatio, bestiality, the erect penis - are obviously morally offensive to the vast majority of the population.' ${ }^{38}$ Similarly, the Fribourg Cantonal Court described these emotions as 'generally accepted views' ${ }^{39}$ Second, these moral reactions are temporally and spatially relative, and are hence neither timeless nor universal. Again, the District Court wrote that 'allowance has to be made for changes in the moral climate', ${ }^{40}$ and the Cantonal Court how 'public general views on morality and social mores [...] vary at different times and different places'. ${ }^{41}$ In short, morality is dependent on the emotional reactions of the majority in a certain community.

The ECtHR confirmed this understanding of morality, reiterating its margin of appreciation doctrine. ${ }^{42}$ It proclaimed that 'conceptions of sexual morality have changed in recent years', and accepted the analysis of the Swiss courts based on the 'sense of sexual propriety' of the average person. ${ }^{43}$ The court also accepted that the test would render divergent results depending on the community in question. It thus held that morality is distinct for each community which shows a convergence of emotions. In Müller, for example, the relevant 'sense' of appropriateness varied across different Swiss regions. The exhibition was prohibited in the canton of Fribourg, but not in Basel. ${ }^{44}$

\footnotetext{
38 Ibid para 14.

39 Ibid para 16.

40 Ibid para 14.

41 Ibid para 16.

${ }^{42}$ In a nutshell, the margin of appreciation denotes a leeway allowed for the member states to regulate issues affected by the Convention (ECHR) when there is no consensus on the European level.

${ }^{43}$ Müller $v$ Switzerland para 36.

${ }^{44}$ Ibid para 36. Judge Spielmann opposed such deference to municipal and cantonal authorities in his dissent: 'If, of necessity, we may regard State authorities as being in principle in a better position than the
} 
Hence, morality is not necessarily attached to a state, but even to communities on a substate level.

Again, we may try to explain the court's decision to defer to the national and subnational conception of morals by its institutional position in the pan-European system where many different traditions exist, or by the doctrine of the margin of appreciation which tied the court's hands in later cases. But at least initially - when it was forced to reflect upon the concept of morality - the ECtHR developed a type of ethical argument based on the emotional reactions of the majority of people in a particular community.

\subsection{Canada}

Another example of the argument from common sentiment appears in Canadian extradition jurisprudence. Under section 7 of the Canadian Charter of Rights and Freedoms, 'everyone has the right to life, liberty and security of the person and the right not to be deprived thereof except in accordance with the principles of fundamental justice.' The Canadian Supreme Court interpreted this clause as preventing the deportation of individuals to countries where their rights would be infringed in a way that goes against 'fundamental justice', which thus became the crucial concept for deciding extradition cases. To understand this concept - similarly to previous examples - the Canadian Supreme Court relied on the emotional, intuitive element of the comprehension of fundamental justice. Furthermore, the understanding of this concept put to the forefront the question of the relative character of values, because of the crossborder nature of extradition. As in the case of the US Supreme Court and ECtHR, one important strand of judicial reasoning tied the understanding of fundamental justice to

international court to give an opinion on the exact content of the requirements of Article 10 (art. 10) of the Convention, it remains unacceptable in a Europe composed of States that the State in question should leave such an assessment to a canton or a municipal authority.' Similarly, in Otto-Preminger v Austria - a case dealing with a forfeiture of a blasphemous movie - the ECtHR respected the conclusion of Austrian courts which had found the movie offensive for the community in Tyrol, while a theatre play with the same content could be staged in Vienna. In this case - dealing with the 'right of others' - the court further clarified its margin of appreciation doctrine by saying that 'even within a single country such conceptions [of the significance of religion] may vary'. Otto-Preminger-Institut v Austria (13470/87) [1994] ECHR 26 (20 September 1994) para 50. For similar issues see also Wingrove v United Kingdom (17419/90) [1996] ECHR 60 (25 November 1996) and Murphy v Ireland(44179/98) [2003] ECHR 352 (10 July 2003). 
the values of Canadian society alone. However, although the understanding of morality was similar, the institutional consequence was not; instead of deferring to legislatures, juries or other courts, the Canadian Supreme Court decided the issue itself, paying only loose attention to public opinion.

The issue first arose in Canada $v$ Schmidt, a case dealing with an appeal from Ms Schmidt, a Canadian citizen, who was to be extradited to the United States. Ms Schmidt abducted a two-year old girl, acting in the belief that the girl was her granddaughter who lived in inappropriate conditions. ${ }^{45}$ She was tried, found not guilty, and subsequently acquitted in the US for the federal offence of kidnapping. At the same time, she faced charges for the state offence of 'child-stealing' in Ohio. Once released by the federal court, she fled to Canada, where she was arrested and where extradition proceedings were put in motion.

Writing for the majority, Justice La Forest examined the case in light of the concept of fundamental justice from Section 7 of the Charter. ${ }^{46}$ To explicate the concept, he dwelled on two issues in particular: the test for determining its substantive content, and the leeway to be left for foreign systems. The first issue tied the concept of fundamental justice to emotions, and the second generated a gap between the Canadian and American sense of justice, making them community-relative. To determine the content of fundamental justice, La Forest proceeded by way of giving examples of what would amount to its violation, ${ }^{47}$ but at the bottom of his reasoning was a litmus test consisting in an emotional reaction to extradition. Starting from what he understood to be a paradigmatic example of fundamentally unjust treatment - torture - La Forest set out the doctrine in the following manner:

\footnotetext{
${ }_{45}$ Canada v Schmidt 1 SCR 500 [1987]

${ }^{46}$ Ibid para 45: 'The real question is whether the fugitive in the circumstances of this case would, by virtue of her proposed extradition, be deprived of this right in a manner that did not conform to the principles of fundamental justice.'

${ }^{47}$ Being convinced that in this case the possibility of double jeopardy is not real for Ms Schmidt - because the two crimes she had been charged with 'involve quite different elements' - La Forest was not compelled to give a clear-cut definition of the concept and left its borders fuzzy. Ibid para 57. However, the test is supposed to have real bite and is not satisfied in all legal systems a priori. See ibid para 47.
} 
Situations falling far short of [infliction of torture] may well arise where the nature of the criminal procedures or penalties in a foreign country sufficiently shocks the conscience as to make a decision to surrender a fugitive for trial there one that breaches the principles of fundamental justice enshrined in s. $7 .{ }^{48}$

Apart from torture, he added some examples to shed further light on what 'shocks the conscience': for instance, lack of procedural safeguards or presumption of innocence does not 'shock' it, while a recurring prosecution for the same offense does. ${ }^{49}$ However, La Forest did not say much about what connects these different cases or what could be a principle that would guide the future application of the 'shocks the conscience' test. The foundation of the test was the feeling of 'shock', an emotional reaction to a possible extradition. ${ }^{50}$

The second element of La Forest's conception of fundamental justice is relational, which at the foundation makes the question of value relative. Fundamental justice is a matter of going to the core of our intuitions about justice, and then comparing them with the values of other societies. Not all cases where Canadian law is different from the law of other countries fall within the conception of fundamental justice. Only the most central values are protected. But the core of these values is not to be found in some abstract and universal procedure: they are contingent and parochial. They are protected not because of their universal worth, but because of their worth for Canadians. ${ }^{51}$

\footnotetext{
${ }^{48}$ Ibid para 47.

49 Ibid paras 48 and 56.

${ }_{50}$ Whereas his refusal to offer guidance for future cases can be justified by judicial minimalism, or as an attempt not to prevent the wisdom of future courts to have their say in light of new cases and facts, this is not the correct interpretation. La Forest did say that torture or repeated prosecution for the same crime will always shock the conscience, thus tying the hands of future courts, he just thought that it is not possible to explain as a matter of principle what is common to these cases, or why it would be reasonable for us to think that they contravene fundamental justice.

${ }^{51}$ From this understanding of value - as the intuitive, emotional reaction of members of a society follows La Forest's view that the courts should defer as much as possible to the executive. The kind of knowledge necessary for the resolution of this issue is not unavailable in principle to members of the executive. On the contrary, the executive is better placed to know morally relevant facts, which in this case include the intricacies of foreign systems. At the same time, everyone should be shocked in the same way if they were aware of all the relevant facts, and courts have no a priori better standing in this regard: 'the courts must begin with the notion that the executive must first have determined that the general system for the administration of justice in the foreign country sufficiently corresponds to our concepts of justice to warrant entering into the treaty in the first place, and must have recognized that it too has a duty to ensure that its actions comply with constitutional standards.' Canada $v$ Schmidt para 49.
} 
A confirmation and development of such a reading of fundamental justice came about in Kindler $v$ Canada, when the court had to decide on the constitutionality of the extradition of convicted offenders to the US, where they would face the death penalty. ${ }^{52}$ Joseph Kindler fled to Canada after the jury in Pennsylvania recommended a death penalty for him, because of murder, conspiracy to commit murder, and kidnapping. Before the sentencing court reached the decision, Mr Kindler escaped from prison and was subsequently arrested in Canada. The Supreme Court had to decide whether extradition to the US would violate his rights under the Charter.

In Kindler, La Forest tied the 'shocks the conscience' doctrine more firmly to the 'Canadian community' and 'conscience of Canadians', but refused to equate the test with public opinion of the day. In his view, while polls can give us access to the concept of fundamental justice defined by the feeling of shock, we are not justified in proceeding on the basis of the feelings of the majority only: 'I do not think the courts should determine unacceptability in terms of statistical measurements of approval or disapproval by the public at large, but it is fair to say that they afford some insight into the public values of the community. ${ }^{53}$ What determines the feeling of shock is the fact that, for example, the legalization of torture is 'unimaginable' in Canadian society, while re-instatement of the death penalty is not completely out of the question. The properties that differentiate between similar feelings are their firmness and patent irreversibility; this leaves some conceptual space for public opinion to be wrong about the value, even if it is socially and emotionally contingent. For example, in United States v Allard, La Forest was also unable to explain the nature of these immutable moral feelings with more precision, and described them as 'simply unacceptable.'54

Justice McLachlin further dwelled on the relationship between public and judicial opinion, and tried to redefine what 'simply unacceptable' means in Kindler. For him, the

\footnotetext{
${ }^{52}$ Kindler v Canada (Minister of Justice) 2 SCR 779 [1991].

${ }^{53}$ Ibid (La Forest).

${ }^{54}$ United States v Allard 1 SCR 564 [1987] 572.
} 
sense of justice is tied to the Canadian community, but he thinks that the only way to objectify it is to defer to the feelings of majority:

\begin{abstract}
At the end of the day, the question is whether the provision or action in question offends the Canadian sense of what is fair, right and just [...] In determining whether, bearing all these factors in mind, the extradition in question is "simply unacceptable", the judge must avoid imposing his or her own subjective views on the matter, and seek rather to objectively assess the attitudes of Canadians on the issue of whether the fugitive is facing a situation which is shocking and fundamentally unacceptable to our society. ${ }^{55}$
\end{abstract}

McLachlin's account, however, does not explain how the court should 'assess' the attitude of Canadians: if the objectivity is dependent on what the majority of people feels, it is hard to imagine how judges can 'correct' that feeling to be more objective. ${ }^{56}$

This approach to public opinion was amended and clarified in United States v Burns. Apart from including more concerns in the balancing exercise when deciding on the principles of fundamental justice, the court also rejected blind deference to public opinion, arguing that "the phrase "shocks the conscience" and equivalent expressions are not to be taken out of context or equated to opinion polls. [...] The words were not intended to signal an abdication by judges of their constitutional responsibilities in matters involving fundamental principles of justice. ${ }^{57}$ The feeling of shock is not constitutive of the principles of fundamental justice, but is only a signal that these principles are violated: 'The rule is not that departures from fundamental justice are to be tolerated unless in a particular case it shocks the conscience. An extradition that violates the principles of fundamental justice will always shock the conscience. ${ }^{58}$ It is again not clear how judges can access the principles of fundamental justice more objectively than people themselves. Presumably, the idea here is that people can be

\footnotetext{
${ }_{55}^{5}$ Kindler v Canada (Minister of Justice) (McLachlin).

${ }^{56}$ Sopinka J confronted these views with an argument that much resembles the argument from constitutional identity. He argued that the source of value is the Charter itself, and that the court ought not to surrender to public opinion: "the requirement that the fugitive face a situation that is "simply unacceptable" must entail more than a simple consideration of majority opinion. It must be interpreted in light of the values underlying s. 7.' ibid (Sopinka).

57 United States $v$ Burns 1 SCR 283 [2001] para 67.

58 Ibid para 68.
} 
guided by different emotions, and judges can correct this either by discovering truly moral emotions, or emotions of particular strength.

To sum up: the 'shocks the conscience' doctrine relied to a significant extent on the outrage that Canadians feel when confronted with an extradition which is against the principles of fundamental justice. Who has the best insight into these feelings is a function of the knowledge of relevant facts and the ability to differentiate between feelings of moral outrage on the basis of their strength and centrality in our emotional apparatus. Institutional consequences depend on weighing these different concerns. While people may reflect popular sentiments more objectively, they can both be deluded in differentiating between truly central, irreversible feelings about 'simply inconceivable' injustices, and surface feelings which are not firmly established. We see that, in this version, the argument from common sentiment comes close to the argument from constitutional identity. The relativity of feelings to a certain community connect them to the identity of such a community; there is also the idea that there is a cluster of more central and deeper commitments that give the court the standpoint from which to assess the dominant moral feelings. However, it is still the communal feelings and popular opinions that are central to this argument, and not the identity evolved through engagement with the constitution. We can thus note these interconnections between different types of ethical arguments (which will be explored later on in the thesis) and focus on the elements of the argument from common sentiment.

\section{Moral ontology of common sentiments}

Let us now abstract from the contextual differences, and see whether in these examples there are three dots that make a line. As I mentioned in the beginning, the examples include different lines of cases, with diverse positions of the courts vis-a-vis other branches of government, divergent textual and doctrinal backing, and varying institutional consequences. However, in all of them the common denominator is a particular understanding of morality with two defining features: an emotional response of a specific community. 
We can call the first element of the argument from common sentiment the emotivist element. In all of the above cases, the communal opinion equals an emotion. So for example, in the US context, capital punishment is the expression of 'moral outrage', and its constitutionality must conform with 'the community's moral sense'. The ECtHR supports Swiss courts in relying on the emotions of 'repugnance and disgust' and on the 'sense of sexual propriety'. Finally, the Canadian Supreme Court invokes the feeling of 'shock' and 'sense' of what is moral. The second component of the argument we can label the relativist element. Morality is considered as community-bound, but the relevant communities differ: the US Supreme Court relies on a national consensus, or defers to the states; the ECtHR seeks a supra-national, European consensus or otherwise it respects even a sub-national convergence of emotions; the Canadian Supreme Court accepts only national consensus as relevant.

To unpack these elements further, we need to see whether they establish an epistemic or ontological claim. If the argument from common sentiments is an epistemic or heuristic device, the emotional reaction of a particular community to a moral problem would be a way to know the solution to that problem. This explanation is metaethically plausible; for example, there is no reason to deny that moral duties are at the very least reflected in corresponding moral feelings on the part of duty-bearers. Even Kant - who prototypically constructed his moral theory from reason and independently of experience - accepted a role for the moral feeling of 'respect' in his etiology of moral action. ${ }^{59}$ For him, the feeling of respect is induced in us by the universal moral law.

\footnotetext{
${ }^{59}$ Kant writes: 'It could be objected that I only seek refuge, behind the word respect, in an obscure feeling, instead of distinctly resolving the question by means of a concept of reason. But though respect is a feeling, it is not one received by means of influence; it is, instead, a feeling self-wrought by means of a rational concept and therefore specifically different from all feelings of the first kind, which can be reduced to inclination or fear. [...] [Respect] is regarded as the effect of the law on the subject, and not as the cause of law. Respect is properly the representation of a worth that infringes upon my self-love.' Kant, Groundwork for the Metaphysics of Morals 17. Kant describes the relations between reason, feelings and experience as follows: 'In order for a sensibly affected rational being to will that which reason alone prescribes the 'ought', there obviously must belong to it a faculty of reason to instill a feeling of pleasure or satisfaction in the fulfillment of duty, hence a causality of reason to determine sensibility in accordance with its principles. It is entirely impossible, however, to gain insight, i.e., to make comprehensible a priori, how a mere thought that contains nothing sensible in it would produce a sensation of pleasure or displeasure; for that is a particular kind of causality, of which, as of all causality, we can determine nothing at all a priori, but rather we have to ask experience alone about it. But since experience can
} 
Once we cognize the moral law, this feeling follows. Given that this feeling is, as Kant says 'the representation of a worth', it may have some epistemic value. ${ }^{60}$ For other strands of non-naturalist cognitivism, the epistemic worth of moral emotions is obvious. Intuitionism, for example, holds that there are moral facts which are knowable-inthemselves. It presupposes a special faculty - moral intuition - by virtue of which we are able to grasp non-inferential moral facts. G.E. Moore makes this famous analogy: 'good is a simple notion, just as yellow is a simple notion; that, just as you cannot, by any manner of means, explain to anyone who does not already know it, what yellow is, so you cannot explain what good is. ${ }^{61}$ We do not learn what is good through an inference from reasons, but in a way analogous to our sense-based cognition of external reality. ${ }^{62}$ Finally, the epistemic connection between feelings and morality comes naturally for an emotivist. Emotivism implies internalism about the relationship between moral judgment and action: characterizing an action as wrong presupposes a motivation not to do it. In this view, moral judgment is the desire to act upon it. For example, in a strong version of this view, Hare thought that one's true principles were only revealed by what one had actually done. ${ }^{63}$

provide no relation of cause to effect except that between two objects of experience, but here pure reason, through mere ideas (which yield no object at all for experience), ought to be the cause of an effect.' (ibid 76). For a more comprehensive treatment of Kant on moral feelings see: Paul Guyer, 'Moral Feelings in the Metaphysics of Morals' in Lara Denis (ed), Kant's Metaphysics of Morals: A Critical Guide (Cambridge University Press 2010).

${ }^{60}$ See previous note. As Lara Denis notices: 'When it comes to [Kant's] moral epistemology, feelings certainly have a role to play, but the role comes fairly late in the game. It is through reason that we discover basic moral principles; but judgment, experience, and cultivated feelings - all within the realm of what the average person can attain - can aid us in our use of these principles.' Lara Denis, 'Kant and Hume on Morality' in Edward N. Zalta (ed), The Stanford Encyclopedia of Philosophy <http://plato.stanford.edu/entries/kant-hume-morality/> Lara Denis, 'Kant and Hume on Morality', Stanford Encyclopedia of Philosophy, http://plato.stanford.edu/entries/kant-hume-morality/.

${ }^{61}$ G.E. Moore, Principia Ethica (Thomas Baldwin ed, 2 edn, Cambridge University Press 2000 [1903]) 59.

${ }^{62}$ See for example: Henry Sidgwick, The Methods of Ethics (7th edn, McMillan 1962 [1907]); Sidgwick, The Methods of Ethics (Macmillan, London 1874); W.D. Ross, The Right and the Good (Clarendon Press 1930); Robert Audi, The Good in the Right: A Theory of Intuition and Intrinsic Value (Princeton University Press 2004). While no one would deny the existence of moral intuitions, this strand of cognitivism makes them foundational for all moral knowledge. Although it is not clear what is the exact relation between intuitions, emotions and action, and even though intuitive moral knowledge is a form of a priori knowledge, we can still conclude that an intuitionist would accept that looking at people's intuitions would tell us something important about right and wrong. Given the fact that intuitions are foundational in a metaphysical sense and that basic intuitions are not derived from reason alone, it is plausible that an intuitionist judge would accept the emotivist element of the argument from common sentiment.

${ }_{63}$ 'If we were to ask of a person 'What are his moral principles?' the way in which we could be most sure of a true answer would be by studying what he did'. Hare 1 . 
The issue is however more complicated both as a matter of moral theory and as a matter of judicial practice. Not every motivational attitude is a moral attitude. ${ }^{64}$ Most of the time it seems obvious to us that we can recognize something as morally wrong and still do it. This could, for example, be a part of the explanation for the lack of convergence in our moral reactions. But then the epistemic question becomes pressing and needs to be tied to a conception of value: how can we know which emotional reactions count? Take a closer look at how different courts establish the existence of a particular emotion. In our examples, the US supreme court mostly relies on legislative opinions, the ECtHR takes into account the whole institutional and social reality (including courts), and the Canadian Supreme Court seems to be confident in its own intuitions about the issue. The apparently epistemic decision must depend on a prior conception of value. For example, the Canadian court may think that because of a weakness of will citizens fail to make good moral judgments; however, this implies that there is a conception of good moral judgment which determines the choice of the court to correct public opinion.

A purely epistemic account of the argument from common sentiment would also demand a re-description of the cases. First, even if a reason-based theory of morality such as Kant's can accommodate the feeling of duty or respect, its epistemology is radically different. In the most minimal sense, feelings could not form an exclusive way of knowing moral duties; we would, for example, be able to reach the true moral decision on our own, through a reflective process or by taking a particular point of view. But as we have seen, the argument from common sentiment is frequently considered as the only valid ethical argument. When faced with a different type of argument, the courts resort to the legal character of interpretive conventions. Recall for example justice Scalia's argument that morality is a matter of sentiment, and that the court's own understanding of it is not epistemologically valid. Justice Rehnquist, for example, argued that foreign law is immaterial to the decision whether something is cruel and unusual: if it is evidence of a national consensus for which we are looking, then the

64 Moreover, if we do not presuppose this then we cannot make sense of the distinction between moral concepts, as they would all mean the same. Railton 304. 
viewpoints of other countries simply are not relevant.' ${ }^{55}$ Such arguments make little sense if we subscribe to a reason-based and universal conception of moral value.

Second - and connected to this - these views cannot accommodate the analytic precedence of having the concept of morality. If the constitution contains concepts such as 'cruel', 'fundamental justice', or 'morals', then where one looks for their content under the circumstances of discretion - depends on what one considers as moral. You may believe that someone is in a better position to know something or reach a decision of a certain kind, but you need to have first at least a rough idea of what that something is. Suppose, for example, I broke the headlights on my car and went to a car wash to fix it. The failure of my practical rationality follows from a false idea of what constitutes my problem and who can solve it, not from the lack of desire to repair the headlights. This shows that even an institutional reference saying, for example, that legislatures will take all affected interests better into account, follows from a notion that all affected interests ought to be heard and accommodated. This is consistent with references made by courts to what morality is. In all three cases, the courts offer views on this issue that are a far cry from saying that morality is, a priori, independent of our moral feelings, etc. Quite the opposite: their understanding is that emotional communal reactions are constitutive of morality.

Third, divergent institutional consequences of the argument from common sentiment testify that epistemology follows from the understanding of the nature of value (which is a natural way to think about this relationship in general). If the argument were epistemic, we would expect that the ways of knowing morality would be the same in all these cases. If it is not epistemic, then we have one explanation for all examples. ${ }^{66}$ Given the answer of what morality is, the courts opt for different ways of knowing it: by tracking popular opinions, deferring to those who are closer to the community that generates moral feelings, or through a combination of introspection about one's own feelings verified against popular intuitions. All of these ways of knowing morality make

\footnotetext{
65 Atkins v Virginia 325 (Rehnquist).

${ }_{6}^{6}$ Notice that this argument is question-begging if the phenomenon is not the same, but I hope that the explanation given in the beginning suffices to convince the reader that the cases are relevantly similar.
} 
sense if, at their foundation, there is a conception of morality as contingent and dependent on communal feelings; on the other side, if there were no specific understanding of morality to support these epistemic consequences, they would remain far more mysterious. The argument from common sentiment becomes harder to explain: while it maybe makes sense to check our moral judgments against the gut reactions of our community, it is not a natural place to start and finish moral inquiry if we don't hold this specific metaethics.

That said, even if all these reasons do not convince completely that the argument from common sentiments implies particular metaethics, they at minimum justify analyzing the argument more closely as an ideal type. Whatever the best explanation of the argument is, the path dependency of law and the exclusivity of the argument that follows from it warrant the need to treat the argument as an ontological claim. The ontological claim of the argument from common sentiment - a claim about what morality is - takes the emotional reaction of the people in a particular community about a moral problem as constitutive of the solution to that problem, and not as a way of knowing the solution. The distinction is subtle, but highly relevant. In our examples, such an ontological account would mean that there is nothing more to morality than the moral sense of the people on issues of capital punishment, free speech, or extradition. Treating the argument from common sentiments as ontological is justified mostly because the argument from common sentiments becomes entrenched as a convention of interpretation excluding other ways of approaching the issue. The iterative practice of law forecloses other types of ethical arguments, and they by implication come to be considered as misconceptions of morality, because of the dual nature of ethical arguments in general: legal and ethical.

If understood as an ontological position, the argument from common sentiment - given its defining elements - suggests a vision of morality that is non-cognitivist (more specifically emotivist) and relativist. Because of this, it ultimately depends on the plausibility and compatibility of non-cognitivism and relativism: the ontological claim of the argument from common sentiments is true if and only if emotivist and relativist elements can both be plausible at the same time. There are thus two hurdles it needs to 
pass: on the one hand, it depends on the plausibility of both emotivist and relativist elements taken separately, and on the other, it is conditional upon their compatibility. Because of this the analysis has the following structure: I will first provide arguments for the most tenable versions of emotivist and relativist elements, and then I shall evaluate their mutual coherence.

\subsection{The emotivist element}

There is something puzzling about the use of the ethical argument from common sentiment. Recall that the soundness of ethical arguments in general depends upon the (at least minimal) practical relevance of morality. This is a normative assumption, but I think a justified one. If a judge is skeptical about morality's relevance and uses ethical arguments, there is an inconsistency in her views that we may find unacceptable. We don't want our judges to be cynical about the evaluative perspectives they take, and we don't want their argumentative practices to be based on flawed or insincere premises. A judge that uses ethical arguments thus should also believe that morality is important, that it is not just a matter of different tastes. The pressing issue here is: does the emotivist element entail subjectivism about value which is in tension with the practical relevance of morality? And if this is so, does the moral ontology of common sentiments collapse under the pressure of its own internal incoherence?

The view that judicial moral judgments are subjective is sometimes openly expressed. For example, when the US Supreme Court decided on the constitutionality of the death penalty for minors in Roper, Justice O'Connor wrote that the Court 'should not substitute its own "inevitably subjective judgment" on how best to resolve this difficult moral question for the judgments of the Nation's democratically elected legislatures' ${ }^{67}$ and Justice Scalia argued that 'the meaning of our Eighth Amendment' should not 'be determined by the subjective views of five Members of this Court'. ${ }^{68}$ Similarly, McLachlin wrote in Kindler that 'the judge must avoid imposing his or her own

\footnotetext{
${ }^{67}$ Roper $v$ Simmons 607 (O'Connor), citing in part her opinion from Thompson v Oklahoma 487 US 815 (1988) 854 .

${ }^{68}$ Roper v Simmons 608.
} 
subjective views on the matter, and seek rather to objectively assess the attitudes of Canadians on the issue'. ${ }^{69}$ O'Connor, Scalia and McLachlin thus believe that judicial moral judgments are 'subjective', while legislative moral views are presumably 'objective'. The fact that they express this issue in the language of objectivity is revealing: it is evident that leaving the issue to legislatures can help us move from less to more democratic legitimacy, but it is far from clear how we could get more moral objectivity.

Even more telling is the fact that the argument from common sentiment sometimes implies the inability to explain, systematize, or justify our moral emotions. For instance, in McCleskey $v$ Kemp, Justice Powell finds no hazard in the fact that juries' moral judgments 'defy codification' and are 'often difficult to explain'.70 The Swiss District Court in Müller denies the need to reflect upon our initial emotional reactions to obscene material: 'Comment on the confiscated works is superfluous; their vulgarity is plain to see and needs no elaborating upon ... Nor can a person of ordinary sensitivity be expected to go behind what is actually depicted and make a second assessment of the picture independently of what he can actually see .... ${ }^{71}$ In Canada, La Forest refused to make a principled argument as to what 'shocks the conscience' or amounts to 'simply unacceptable' treatment; he struggled to articulate the role of courts in the assessment of people's emotions on the basis of their 'strength' or 'immutability', precisely because it is not obvious why these properties should be valued in themselves.

A particularly vivid expression of the view that emotional reactions escape and exclude reason-based judgment is Scalia's opinion from Lawrence $v$ Texas, dealing with homosexual sodomy:

One of the benefits of leaving regulation of this matter to the people rather than to the courts is that the people, unlike judges, need not carry things to their logical conclusion. The people may feel that their disapprobation of homosexual

${ }^{69}$ Kindler v Canada (Minister of Justice) (McLachlin).

70 McCleskey $v$ Kemp 481 US 279 (1987) 311 references omitted.

${ }^{71}$ Müller v Switzerland para 14. 
conduct is strong enough to disallow homosexual marriage, but not strong enough to criminalize private homosexual acts - and may legislate accordingly. ${ }^{72}$

For Scalia, it is a virtue of people's moral judgment that it is based on a feeling of disapprobation which need not be coherent, rational or logical: he praises popular opinion for not being subject to laws of reason. Notice that here it is not the case that deference to legislature is a consequence of democratic reasons as such, regardless of the consequences. Instead, Scalia argues that the best moral judgment will be made in the process that relies on emotive moral disapproval of the people, for there is nothing more to such judgment and certainly nothing reason-related. This is the same view as the one held by - already mentioned - Justice Marshall in Furman, where he claimed that the test for cruel and unusual punishment depends on the 'subjective, emotional reactions of informed citizens' which are not 'required to act rationally'. ${ }^{73}$ Again: this is not to say that democratic concerns are discredited by this metaethics. In fact, I will later on argue that these reasons must be included in a plausible conception of constitutional ethics. Rather, the argument from common sentiment can have institutional consequences which may seem to be a mere outcome of democratic sensibilities, and thus conceal its metaethical foundations.

It also does not follow from this argument that judges necessarily subscribe to the subjectivism of moral judgments. For example, if the moral ontology of common sentiments is correct, and there is nothing more to moral judgments than emotional reaction to a set of facts, we may be cautious and check our own emotional reactions against such reactions of the community. Moreover, it is understandable that moral agents need not be able to offer a sophisticated theory of morality to make moral judgments; one, in other words, doesn't have to be a moral philosopher to make the difference between right and wrong. However, the casual expressions of skepticism by judges may actually track a deeper conceptual problem. There is a thin line between saying that moral judgments are constituted by emotional reactions, and denying the

72 Lawrence v Texas 539 US 558 (2003) 604 (Scalia).

${ }^{73}$ Furman v Georgia 360-362 (Marshall). 
possibility to curb our moral sentiments at all. The question is how to find the Archimedean point from which we can say that something is good or bad, apart from what we subjectively feel. ${ }^{74}$

This problem is pertinent to skeptical emotivism, which holds that the function of moral language is not to describe facts, but to express pro- and con-attitudes. ${ }^{75}$ According to this strand of emotivism, to utter a moral judgment of the sort the fact that you tortured babies for fun was wrong' reports the fact that you tortured babies for fun and adds nothing to it except an expression of disapproval of the action. It can be translated into two distinct utterances without anything being lost: 'you tortured babies for fun' plus 'boo torturing babies for fun'. The former presents a belief in a fact, and the latter reports a value which can only (subjectively) correspond to the speaker's state of mind (attitude, intention, etc). The purpose of such a statement is to influence someone's behavior. ${ }^{76}$ Since only beliefs about facts can be objectively true or false, statements containing values lack truth-conditions and are thus not truth-apt. And if moral statements are not truth-apt, they cannot be objective. They guide our behavior in so far as we internalize the feeling set out in moral expressions, but saying that we have an objective moral duty external to our psychological apparatus is nonsensical. ${ }^{77}$

While the references to subjectivity made by judges may be understood in a more relaxed, institutional sense, the emotivist foundation of their moral judgments cannot be easily squared with objective moral values, so there may be some deeper truth in O'Connor's stipulation that moral judgments are 'inevitably' subjective. If emotivistskeptical metaethics is the only possible background framework to such views, the attempts to justify our moral judgments invite infinite regress. Because moral emotions are merely expressions of our perspectival preferences, we have no objective grounds for

\footnotetext{
${ }^{74}$ Although the primary motivation for emotivism is to account for the practicality of moral judgment because it presupposes that beliefs cannot motivate us to act - it comes at a price regarding the possibility to answer moral questions at all. Furthermore, while providing a plausible account of values and their relation to our actions, these theories experience difficulties in explaining reasoning about values.

${ }_{75}$ This view became prominent after the influential work of A.J. Ayer, Language, Truth, and Logic (2 edn, V. Gollancz 1946) ch 6 and Charles L. Stevenson, Ethics and Language (Yale University Press 1944).

${ }^{76}$ Ayer 107.

${ }_{77}$ Bernard Williams, Moral Luck: Philosophical Papers, 1973-1980 (Cambridge University Press 1981) ch 8.
} 
looking at emotions in the first place. In other words, what establishes the value of emotions themselves is mysterious, but - given that on this view it can only be another subjective emotion - we are left with a skeptical view. To go back to our examples, translated to the skeptical emotivist explanation of moral language, our emotions about the constitutional issues at stake would amount to 'boo/hooray capital punishment', 'boo/hooray obscenity' and 'boo/hooray extradition'. A re-statement of the court's arguments (in the case of capital punishment, but this can be translated to all the examples) would then take the following form:

(i) the emotion that the majority of people expresses ought to determine whether there should be capital punishment;

(ii) the majority of the people expresses the emotion 'boo capital punishment';

(iii) there should be no capital punishment.

But how can the proposition (i) be justified or explained? Notice that (i) contains a normative statement which translates as 'hooray majority's boo or hooray', amounting to just another subjective expression of a preference. Therefore O'Connor and Scalia must be mistaken to think that deference to representative bodies can be motivated by moral objectivity, because the value on which such deference is based is just another subjective preference. They cannot conceptually escape what they wish to avoid most: imposing their own subjective views on the majority of people.

The controversial part of the argument from common sentiment - given its emotivist background - is internal inconsistency. Simon Blackburn describes this as 'schizoid attitude': having a moral commitment from (i) and at the same time thinking of it as ungrounded. ${ }^{78}$ Let me explain this attitude using one of the examples we introduced earlier. Imagine a judge who thinks that the feeling of an individual citizen concerning what is obscene amounts only to this citizen's personal preference. Now, why would she think these personal preferences matter? She would have two options. One would be to

${ }^{78}$ Simon Blackburn, Spreading the Word: Groundings in the Philosophy of Language (Oxford University Press 1984) 197. 
say that this is because the majority of the people have a feeling that their personal preferences on this issue are important. Nonetheless, it is not clear how this feeling would amount to anything more than yet another personal preference. The fact that many people feel something provides no obligation for others to follow. For example: many people like ice cream, but it does not follow that I must like it as well. The other option would be to say that it is her personal preference that what the majority feels should be the answer. If she does think that it is only her subjective emotional attitude to respect the majority's view on what is obscene, she would then either have to pretend that it is not only her preference to impose the views of the majority on this issue (hence she would run afoul of the practical relevance of morality), or she would have to commit herself to the view that her emotion is somehow different from the other emotions people express (hence she would have the schizoid attitude). To simplify: if a judge is aware that morality is about subjective feelings only, she should reject it altogether, because then it is her own view that the first premise in her reasoning is just her preference. The problem is not that emotivism accuses reasoning in morality of being mistaken, but that such reasoning is applied in constitutional interpretation while believing it is erroneous to do so. ${ }^{79}$

\footnotetext{
${ }^{79}$ The difficulty lies in the inability of skeptical emotivism to account for the functions which moral judgments have in conditional contexts. This has been known as the Frege-Geach problem. (See P.T. Geach, 'Assertion' (1965) 74 Philosophical Review 449) Consider an imaginary example based on the Canadian extradition cases. The example includes a combination of two intertwined arguments from two different cases, so that the conclusion of the second argument changes the premise of the first: (i) Extradition from Canada to countries where convicts face the death penalty is always morally justified; (ii) If extradition from Canada to countries where convicts face the death penalty is always morally justified, then extradition of Mr Burns to the United States is morally justified; (iii) However, extradition of Mr Burns to the United States is not morally justified; (iv) Therefore, extradition from Canada to countries where convicts face the death penalty is not always morally justified. This argument seems logically valid but the statement 'Extradition from Canada to countries where convicts face the death penalty is always morally justified' in the emotivist account has a different semantic role in assertive (i and iii) than in conditional contexts (ii and iv). For an argument to be valid, the meaning of identical statements must be the same in all premises. Therefore, if skeptical emotivism is true, reasoning like this is flawed. For if the meaning of the statement 'Extradition from Canada to countries where convicts face the death penalty is always morally justified' in (i) is not truth-apt, then we cannot make a conclusion in (ii) because such a conclusion can only follow from a statement which is true. Similarly, on the basis of logic we cannot infer that (i) is not true in virtue of (iv), because it was not true in the first place. Again, it is open for an emotivist to reject the application of logic to morality as an illusion; however, a judge cannot then rely on this kind of reasoning and reject it at the same time. There needs to be some other way to explain the role of reasoning and the normativity of feelings. For a more recent discussion and rejection of the problem, see Paul Horwich, 'The Frege-Geach Point' (2005) 15 Philosophical Issues 78.
} 
Whereas we may think of the worry about the objectivity of judicial moral judgments expressed by O'Connor, Scalia, or McLachlin as a rhetorical tool to articulate a concern about legitimacy, or as an expression of a value of democratic governance, the problem becomes real when we want to situate that value in a coherent philosophical system. Similarly, the inability to articulate justifications for our moral judgments that Powell, La Forest and Swiss courts do not find troubling may signal a more profound instability in their general conception of morality. The value with which their moral choice is justified is subject to the same criticism of subjectivity they wish to avoid. Justice Steven's opinion in Spaziano is a prime example of such circularity. His argument is that the community's moral sentiment dictates deference to branches which express the community's moral sentiment better. But what directs us towards the community moral sentiment in the first place? Or consider La Forest's argument that emotions have a property of strength or immutability which allows courts to evaluate them further. But is this property also valuable because someone feels it to be valuable? In short: because the subjectivist thinks that the objects in reality do not have a property of being valuable, but we only ascribe that property to them, there is no obvious way in which such ascriptions can gain objectivity, and we also must have an independent argument why only these ascriptions count as moral. ${ }^{80}$

The judges seem to think that the existence of convergence may grant us the vantage point to talk as if they were objective. This is also a familiar emotivist strategy, and probably the best for someone who implicitly relies on desire-based moral theories, but at the same time wishes to reject skepticism. Crucial to any such strategy is either to presuppose a convergence that enables us to talk as if moral values are objective or failing that - to provide tools already present in our emotive framework of values to overcome disagreements. ${ }^{81}$ The main tools for overcoming disagreements are reflection

\footnotetext{
${ }^{80}$ Skeptical emotivism equalizes our moral feelings with all other psychological dispositions, and thus must offer an account of a prior and objective delineation between moral and immoral; the problem is that this definitional delineation must already have evaluative content. Hence - as Philippa Foot observes - to avoid this, such a view does not rule out 'bizarre so-called "moral judgments" about the wrongness of running around trees right handed or looking at hedgehogs in the light of the moon'. Philippa Foot, 'Does Moral Subjectivism Rest on a Mistake?' (1995) 15 Oxford Journal of Legal Studies 1, 2, reprinted in Philippa Foot, Moral Dilemmas and Other Topics in Moral Philosophy (Oxford University Press 2002).

${ }^{81}$ One strategy discussed at length in chapter 5 is to suppose that metaethical questions about the nature of value are in fact first-order normative questions. See in particular Allan Gibbard, Wise Choices, Apt
} 
and reasoning, which are precluded by the emotive, pre-reflective and irrational foundation of argument from common sentiment. This means that the argument must eventually suppose a high level of moral agreement.

This is not necessarily a problem: while there is a lot of focus on moral disagreements, these disagreements exist and make sense only against the background of a much greater moral agreement. ${ }^{82}$ For example, while we may disagree all the time about the best welfare policies, no one probably thinks that torturing babies for fun is acceptable. But the question is whether this agreement is enough to support - in the emotivist account - the objectivity of moral talk without the backing of reflection and reasoning. To uncover whether this venue is really open for the argument from communal sentiments, let us look more closely to David Hume's moral theory as a classic example of non-skeptical emotivism. While there are countless variations of similar emotivist strategies - many of which I analyze in chapter 5 - Hume's own theory is both paradigmatic and salient in this particular case: it allows us to explore how far the argument from common sentiment can go as a stand-alone argument before collapsing under its own weight, for it nicely illustrates the tension between its emotivist and relativist limbs.

Even though the basis of a moral system for Hume was not reason but moral sentiment, it does not follow that practical rationality is irrelevant for moral judgments and that there can be no moral system. In a famous passage, Hume says ' $[\mathrm{r}]$ eason is, and ought to be the slave of the passions, and can never pretend to any other office than to serve and obey them'. ${ }^{89}$ The question is: how does it serve and obey them? Let us invoke again the distinction between hypothetical and categorical imperatives to answer this

Feelings: A Theory of Normative Judgment (Clarendon Press 1990) and Simon Blackburn, Ruling Passions: $A$ Theory of Practical Reasoning (Clarendon Press 1998).

${ }^{82}$ See for example in the context of law Waldron, Law and Disagreement. Each such theory based on disagreement is bound to fail, for it must suppose a tremendous amount of disagreement; but then not only suppose that there is agreement on how to overcome disagreements, but also to show why agreement is normatively and non-skeptically relevant, while we at the same time presuppose pervasive disagreements. This strategy thus suffers from structural problems. It must, as Rawls did, presuppose a core of 'reasonable' moral assumptions, but then it must also answer where such assumptions metaethically come from.

${ }^{83}$ Hume 415. 
question. ${ }^{84}$ Hume's view is that ought claims are hypothetical imperatives. So for example, if you say 'I want a nice bagel and I'm going to a hairdresser to get it', I can tell you that you should not go to a hairdresser to get a bagel but to a bakery. Hypothetical imperative - the reason to go to a bakery and not to a hairdresser - is an instruction that already presupposes the existence of your desire. It only tells you what is the most rational or prudential way of fulfilling it. Given that you already want a bagel, it is reasonable for you to go to a bakery. But your desire to have a bagel is uncorrectable by reason, for there is no unreasonable desire. This is strikingly similar to the argument from common sentiment. Because there cannot be reasons external to our psychological emotional sets, our moral reasons must also be internal motivational dispositions. ${ }^{85}$

However, if I have no reason to, as Hume says, 'prefer the destruction of the whole world to the scratching of my finger', ${ }^{86}$ how is it possible that there is a system of morality? This is conceivable because Hume presupposes a specifically moral motive which all humans share: the other-regarding sentiment of sympathy. Because actions which follow from sympathy are moral, this motive allows us to delineate moral motives and actions; also, sympathy enables us to morally judge both particular acts and general norms. For Hume, 'natural virtues' - kindness, benevolence, generosity and the like advance welfare directly and are not socially contingent, they flow straight from sympathy. However, our moral conventions also play a role. Hume calls these socially generated norms 'artificial virtues' (justice, property, etc). Each instantiation of artificial virtue may not contribute to the general welfare and satisfaction directly, but overall the system will benefit everyone, and as such it will produce the feeling of satisfaction. Natural virtues cannot do the trick in a large society: the human condition is marked by a scarcity of goods and self-interest, hence we need artificial virtues as well.

Notice that both artificial and natural virtues are ultimately supported by (universally human) sympathy:

\footnotetext{
${ }^{84}$ For this distinction see chapter 2.

${ }^{85}$ The best explication of this view is Williams, Moral Luck: Philosophical Papers, 1973-1980 101-113.

${ }^{86}$ Hume 416.
} 
$[\ldots]$ as the means to an end can only be agreeable, where the end is agreeable; and as the good of society, where our own interest is not concerned, or that of our friends, pleases only by sympathy: It follows, that sympathy is the source of the esteem, which we pay to all the artificial virtues. ${ }^{87}$

This is not to say that justice cannot be supported by a specific feeling. But this feeling can be traced back to sympathy, which is a part of human nature. John Stuart Mill's explanation of the process is revealing: 'What was once desired as an instrument for the attainment of happiness, has come to be desired for its own sake. In being desired for its own sake it is, however, desired as part of happiness'.88 The appropriate analogy here is between there being a desire for some pleasure which money can buy, and developing a desire for money itself. The latter may occur, but comes only as a consequence of having the initial desire. ${ }^{89}$

The question then is what ultimately gives us the sense of ought? This model does not work if we do not presuppose a shared inter-subjective common ground which gives us the platform of normativity. It is thus absolutely central for morality that there is a convergence in feelings, for this explains the illusion of objectivity. ${ }^{90} \mathrm{~A}$ common feeling shared by all enables inter-subjective agreement because it mimics the objective truth, while the normativity of morality still depends on the initial emotion of sympathy. As Hume puts it himself:

${ }^{87}$ Ibid 577. Notice the dependency of means to ends on agreement on the ends themselves. There is no self-standing reason that does not depend on agreement in emotions.

88 John Stuart Mill, 'Hedonism' in Russ Shafer-Landau (ed), Ethical Theory: An Anthology (2 edn, Blackwell 2013) 261.

89 Ibid.

${ }^{90} \mathrm{Or}$, as we have seen, a way of confirming our convictions or overcoming disagreement through reflection and reason, which are excluded by the very nature of the argument from common sentiment. 
The notion of morals implies some sentiment common to all mankind, which recommends the same object to general approbation, and makes every man, or most men, agree in the same opinion or decision concerning it. ${ }^{91}$

Now let us suppose that a judge in one of our examples shares this illusion of objectivity. Recall that the problem of the 'schizoid attitude' persists if the judge shares the illusion in the first premise and not in the second. On a Humean reading, this problem does not seem insurmountable. The second premise becomes not an expression of the attitude such as 'boo capital punishment' but an emanation of the common moral feeling of sympathy. The judge can make the inference because she is in the same kind of illusion as other citizens who express this emotion. Someone may object that, since the judge must not recognize the illusion, and because the second premise (knowing to look for emotions only) still reveals that the illusion is known to her, she could not in turn hold it important and must resist this kind of reasoning. I will deal with this objection and schizoid attitude in general at length in chapter 5 , but here we can set the objection aside, because - given that there is a convergence of desires - the judge is able to conclude what is the most reasonable way of fulfilling them (thus generating a hypothetical imperative for these desires). So we can assume for present purposes that the objection is not valid, because the illusion is supported by the factual circumstance of overlap in feelings and attitudes: it can be, in other words, an illusion all the way down.

The critical part here is the agreement or convergence of feelings. Not any convergence will do - while there may be some people who are incapable of having moral feelings or who get the facts wrong and thus their relevant beliefs are false - the vast majority of people ought to feel the same (as Hume says 'every man, or most men'). Now the distinction between artificial and natural virtues becomes important. In the case of artificial virtues (social conventions), it is plausible that judges ought to look at the moral conventions of their society and the feelings invoked by them. But because sometimes (and in controversial constitutional cases perhaps even often) there is no

${ }^{91}$ David Hume, Enquires Concerning the Human Understanding and Concerning the Principles of Morals (L.A. Selby-Bigge ed, 2 edn, Clarendon Press 1902 [1777]) 272. 
absolute convergence, the only thing a judge can do is to fall back on the general feeling of sympathy and natural virtues. If there is no convergence in our emotions about social conventions we can only rely on this universal feeling.

However, this universalizing tendency of non-skeptical emotivism is directly opposed to the community-bound character of the argument from common sentiment. ${ }^{92}$ The illusion of objectivity in all instances of reasoning is too demanding on the other element of this type of argument: the relativist element. In other words, because there is a common human nature that determines what is moral, the emotivist element clashes with the relativist element, rendering the ontological claim inadequate. The argument from communal sentiments can thus only go so far: if the convergence is fractured, the objectivity slips through the cracks of disagreement. This is because the moral ontology of this argument stops at the unreflective feelings of the people in one society; according to the argument from common sentiment, it is the only thing that matters. There is no reflection, reason or process of justification to overcome disagreement, and there is no agreement to maintain the impression of objectivity. But we are now crossing the line between the emotivist and relativist element, and the latter deserves treatment on its own.

\subsection{The relativist element}

Even though the argument from common sentiment is now in doubt, we may start from the other end and see whether we can work our way back to support it. I have so far expressed skepticism about the possibility of combining unrefined and unreflective emotivism with relativism into a sound metaethics. ${ }^{93}$ There are also good reasons to do so, for relativism seems to rebut the moral ontology based only on sentiments out of hand. While emotivism understands moral statements as non truth-apt, relativism holds

\footnotetext{
${ }^{92}$ Recall here that the ontological claim of the argument from common sentiment requires exclusiveness, that is to say it demands to be the only paradigm of ethical arguments. I will deal with the combination of the two regimes of ethical arguments later on in the thesis.

${ }^{93}$ For the defense of a version of emotivist relativism see Jesse J. Prinz, The Emotional Construction of Morals (Oxford University Press 2007). For the view that emotivism leads to relativism and that this is broadly speaking - a tension within this view see: Foot, Moral Dilemmas and Other Topics in Moral Philosophy ch 2; Russ Shafer-Landau, Moral Realism: A Defence (Oxford University Press 2003) ch 1.
} 
that moral statements are true but only in relation to a specific frame of reference; moral statements could then be true from the standpoint of one frame of reference and not from the other. As such, relativism negates both universal objectivism and the version of emotivism that informs the argument from common sentiment: if such emotivism is true then relativism is false, and vice versa. ${ }^{94}$

But what does this mean exactly? Why deny that our emotional reactions can be collective as well as individual? Couldn't we just say that if people believe something where 'believing' includes having converging desires or false beliefs in the truth of that something - then we should respect their opinion? Is this fact enough to generate the normativity of public moral opinions? While this view could make sense as a normative commitment within one's framework of values, we need to eschew it as an ontological position, for it leads to a rather banal version of relativism.

To explain why this view is not defensible, let us - following David Lyons - introduce a distinction between agent and appraiser relativism. ${ }^{95}$ Agent relativism is the view that standards relevant for moral judgments are relative to the person (or society) that is being judged, and appraiser relativism takes as relevant the moral standards of the person (or society) that is making the judgment. What I have labeled 'banal' relativism is in fact a distorted form of agent relativism.

If one is to ask people in the street what relativism is, the answer would probably be something to this effect: 'there is nothing more to morality than the socially shared values of the members of a particular culture'. ${ }^{96}$ So in our examples agent relativism together with the emotivist element which identifies moral values with emotional reactions - would mean: 'capital punishment/obscenity/extradition is good or bad

\footnotetext{
${ }^{94}$ As Nicholas Sturgeon puts it: 'What relativists maintain, characteristically, is that in these deep [moral $]$ disagreements [...] there is some sense in which both sides can be right'. On the other hand, the emotivist's answer is the opposite: 'to declare not that both sides are right but that neither is, in that there is no truth, no fact of the matter, about such issues'. Nicholas L. Sturgeon, 'Relativism' in John Skorupski (ed), The Routledge Companion to Ethics (Routledge 2010) 356.

${ }_{95}$ David Lyons, 'Ethical Relativism and the Problem of Incoherence' (1976) 86 Ethics 107.

${ }^{96}$ Harry Gensler, 'Cultural Relativism' in Russ Shafer-Landau (ed), Ethical Theory: An Anthology (2 edn, Blackwell 2013).
} 
because people in the society which is being judged feel it is good or bad'. The courts infer from this that we ought to conform to the views of the majority of people in societies that are being judged. Recall for instance the ECtHR's margin of appreciation doctrine here: different moral compacts in Europe must be respected unless there is a pan-European consensus. This is - at least up to a point - an agent-relativist view. ${ }^{97} \mathrm{On}$ the other hand, the Canadian 'shocks the consciousness' doctrine is probably better understood as a version of appraiser relativism: what is relevant is how we feel about the question and not the societies we are judging.

Even if we suppose that cultures are bounded in this way and that the one-person-oneculture view is correct, there is still a problem with this reasoning from the perspective of agent relativism. To reject it we need not presuppose the existence of mindindependent and universal moral truths, for this type of relativism entails a universalist premise to which it initially denied relevance. From the fact that there are differences in moral views between cultures and societies, the universal conclusion that we ought to respect the majority's view in these cultures cannot follow. Such a conclusion can only be supported by a value internal to the evaluative framework from which the judgment is made.

The wrongness of the inference lies in the implicit move from agent to appraiser relativism. This is analogous to a false conclusion that the value of tolerance follows if morality is a culturally embedded phenomenon. According to this argument, because we are aware that cultures are different we ought to respect them equally. But this could also be true only in relation to a particular culture; that is, it cannot hold universally because we start from the premise that all moral opinions are culturally constrained and not universal. This condition would only obtain if such a view is widely held within a given appraiser culture, and it would bind solely members of that particular culture. The ECtHR's margin of appreciation doctrine cannot follow from the fact of diversity as it is often presented - but from a specific agreement on the appropriate moral attitude

${ }^{97}$ One could of course see this position as being a part of the evaluative framework of the court making this judgment and thus as coherent. I will discuss these issues at length in chapters 5 and 6 and I will show how this view might make sense in a more refined version. Here it is important to notice different tendencies which are important for the current analysis. 
to deal with such diversity. Therefore, the relativist element can only be supported by some version of appraiser relativism.

Sophisticated relativism must thus reject the agent relativist view, but at the same time the question remains whether our (appraiser's) emotions are the only thing that matters. Recall that we are still dealing with the ontological thesis, that is, with the question of what morality is, and not how can we know it. There are two possible ways in which the thesis can be defended. One avenue would be to claim that it is actually people's belief that their feelings are the only things that matter. The other could be to claim that there is nothing more to our practice than emotions; that is, by looking closely at moral practice - and regardless of what the people believe - we can see that the truth of moral claims is established by moral practice that consists only of emotional responses to moral problems. Both defenses are implausible.

Consider an example which teases out the conceptual problem with the first response. Within a culture, it is usually the case that moral principles like 'torturing babies for fun is wrong' are understood as 'torturing babies for fun is wrong regardless of the majority's opinion'. People do not believe that this question is appropriate for some kind of referendum. It is a part of - at least our - culture that some moral issues are removed from majoritarian decision-making. ${ }^{98}$ If this is true, we face a self-contradiction by taking the first defense: we believe that our beliefs on this issue do not matter, hence if we take our beliefs to be important, we ought at the same time to abandon the view that they are important. This reveals the vicious circle this kind of explanation eventually must face.

This leads us to the second line of defense the emotivist appraiser-relativist can take. In this case, the claim is that the best explanation of the moral practice of uttering things like 'capital punishment should be abolished', 'this is obscenity' or 'extradition in this

\footnotetext{
${ }_{98}$ While some argue that moral disagreements about rights justify the abolishment of judicial review of legislation (e.g. Waldron, 'The Core of the Case Against Judicial Review'), the facts are saying the opposite: judicial review has been the most successful project of modern constitutionalism and the idea that the majority's opinion ought to be curtailed is perhaps the one thing that most constitutional systems agree about.
} 
case is not justified' is that by so doing we express our emotions only. But this argument is not sound for two reasons: first, it fails to account for the role of reflection and reasoning in our moral talk; and second, even if it can offer a causal account of how we came to adopt certain moral opinions, it is not attentive enough to the practical relevance of morality and cannot make its normativity intelligible. Ronald Dworkin conveys this point elegantly: 'What is shocking and wrong is not [the] idea that the community's morality counts, but [the] idea of what counts as the community's morality'. ${ }^{99}$

The main point is this: there is reason to doubt the position of an appraiser relativist judge who subscribes to the ontology of common moral sentiments, because - when her thesis about morality is qualified with the emotivist element - it cannot account for the ways in which morality actually functions. As David Wong observes, this kind of argument for relativism cannot explain moral criticism, or what I presented in chapter 2 as the role of reasoning in ethics:

\begin{abstract}
Whatever is communally judged to be the case, the argument goes, actually comes to be the case [...] The question with this argument, however, is whether we can accept that custom determines in a strong sense what is fine and ugly, just and unjust. It may influence what people think is fine and just. But it is quite another thing for custom to determine what is fine and just. Customs sometimes change under the pressure of moral criticism, and the argument seems to rely on a premise that contradicts the phenomenon. ${ }^{100}$
\end{abstract}

As we have seen, in ordinary moral discourse we do not believe that some questions are a matter of different feelings or opinions. This need not be the case because there are some universal and mind-independent facts of the matter about this issue, but taking solely feelings as the basis of our society's moral commitments is actually not our society's moral commitment.

\footnotetext{
${ }_{99}$ Ronald Dworkin, 'Lord Devlin and the Enforcement of Morals' (1966) 75 Yale Law Journal 986, 1001 100 David Wong, 'Relativism’ in Peter Singer (ed), A Companion to Ethics (Blackwell 1991) 443.
} 
A sophisticated appraiser relativist who is attracted to emotivism needs to explain the role of moral reasoning in our moral practice. When we take the moral point of view, we do not rely solely on other people's emotions. Resolving moral questions from our examples - capital punishment, obscenity, extradition - does not simply amount to counting our common feelings on the matter. We think of our moral judgments as justified when we are able to offer an argument for them starting from a value (that we presumably all accept), and using the basic rules of moral reasoning. In this process, we may also rethink our values, even if we are committed to the view that values are socially shared commitments to certain goals. This is because we also take into account actions that would make our lives go better, we are sensitive to the aims of our society, we compare our moral judgments with other values we believe in to reach a balanced decision, etc. Relativists may be right that all values are contingent; however, a pure emotivist relativism neglects important parts of our practice that are necessary - even on the relativist account - to make moral claims justified. ${ }^{101}$

Take for example some claims made about events, geographically and temporally outside of our immediate culture: 'What Hitler did to Jews was wrong'; 'Slavery was a morally appalling practice'; 'We should have prevented genocide in Rwanda'. By uttering these sentences we do assume that it is our feeling now that these conducts were wrong. This would describe the situation with 'one thought too many', ${ }^{102}$ because we simply think they were wrong. If someone were to claim otherwise, we would expect an argument for her claim. Similar problems arise in cases which rely on the argument from common sentiment and reach conclusions that are morally unacceptable, for then we may ask the same question: what is the argument for such conclusions? Take an example. In McCleskey $v$ Kemp, Justice Powell used the argument from common sentiment to refuse to address the fact that African Americans in Georgia had a much greater chance of being sentenced to death. He held that the objective demonstration of communal values is to be found in legislative and juries' opinions, and that there would

\footnotetext{
${ }^{101}$ Even if we assume that appraiser relativism would accept that our society could become a society that highly values torturing children, what would make this morality warranted is not a simple fact that we all came to cherish the value of child-torturing, but that we came to cherish it following the rules of our moral practice.

102 Williams, Moral Luck: Philosophical Papers, 1973-1980 18. Of course, Williams used the expression to criticize utilitarianism, but the same objection applies here.
} 
need to be 'exceptionally clear proof before [the Court] would infer that the discretion has been abused'. ${ }^{103}$ What this opinion lacks is a realization that discretion was abused, but - more importantly - a clear conception of what would amount to an abuse. If, for example, morally wrong or racist decisions of representative bodies present the abuse of discretion, this demands a prior idea of what moral answers consist; it would demand an argument that could decide either way. But if these answers are consumed by communal emotions, then the court lacks the resources to address the fact that the death penalty remains concentrated in the American South and imposed mainly on black people. ${ }^{104}$

This brings us to the problem that will prove to be central for the conception of value developed in chapter 5 . One could take an external perspective of the practice and say: what causally explains our feeling that this is wrong is that we came to learn that conduct such as this would have devastating consequences for us so we became committed to preserving peace, equality, and other values; moreover, given the importance of these values, we transmit them through cultural means to future generations as ultimate, unchangeable and universal. The question is how much purchase these external and causal statements ought to have on our internal ethical perspective. We do experience the world in both causal and normative terms. But while the causal explanation can tell us how we came to believe and act in certain ways - normative explanations account for our actions as morally appropriate or not. ${ }^{105}$ This is the source of what we have earlier identified as the 'schizoid attitude'. Much of the appeal of relativist and emotivist positions come from the force of causal perspective on morality, but we need to be cautious about making direct inferences within the normative domain. The argument from common sentiment could be an example of this: it might draw its force from the observation of factual differences between moral frameworks and the role of emotions in our moral judgments, but it is not sufficiently attentive to the normative domain and practical relevance of morality. It fails to give both causal and normative perspectives their due.

\footnotetext{
103 McCleskey v Kemp 297.

${ }^{104}$ See Garland 280-282.

${ }^{105}$ See for example Thomas Nagel, The View from Nowhere (Oxford University Press 1986) 140—144. For a discussion of the interplay between these two perspectives in the context of law see Dennis Patterson, 'Normativity and Objectivity in Law' (2001) 43 William and Mary Law Review 325.
} 
In fact, relativism itself need not deny that there is also a framework of values that we contingently share in the world. Even if this contingent agreement on values is partial and too thin to resolve the most difficult moral dilemmas, there is no reason to suppose that it is not there. While this common framework of values might be contingent and relative - perhaps most obviously in the temporal sense - there is no reason to accept relativism in a crude and empirically inaccurate form that sees different constitutional systems as constitutive of completely idiosyncratic moral commitments. ${ }^{106}$ The big question is of course where to derive the normativity of these idiosyncratic commitments if they are not universally true, but we need not answer this question yet. Suffice it to note at this point that a version of relativism which is based solely on emotions is not credible. It falsely presupposes that morality is a set of emotional solutions to concrete problems, but - even on socially based and relativist conception of morality - this is not enough. Even if we accept the empirical assumption that our moral practices are community-bound, they neither include the commitment to the relativity of moral truth nor the belief that emotions are the only basis of moral judgments. To conclude: any defensible sophisticated relativism is in fact a version of appraiser relativism which in addition must relax (if not abandon) the constraint of the emotivist element to the moral ontology of the argument from common sentiment.

\section{Conclusion}

In this chapter, I tried to demonstrate that the argument from common sentiments consists in an emotional response of a particular community to a set of morally relevant

${ }_{106}$ The trend within the relativist tradition has been to assume that there are some variations between cultures, but also to stipulate a threshold that socially based codes must pass to qualify as moral. Most of these accounts depart from assumptions about human nature and similarities in the human condition. For example, David Wong starts from the practical function of morality as a regulatory tool for resolving conflicts of interest under the circumstances of scarcity to develop universal limits to particular moralities, so that morality may be inadequate in relation to this function. See David Wong, Natural Moralities: A Defense of Pluralistic Relativism (Oxford University Press 2006). David Copp thinks that a moral code is justified only if it would be rational for people to choose it in the society in question, a notion which partly depends on the specific and contingent moral values of the society, but also on their basic natural needs. David Copp, Morality, Normativity, and Society (Oxford University Press 1995). The problem with these views however is that they assume a normative premise in their account of morality which then serves as a universal yardstick for assessing the appropriateness of any moral code. 
facts. To the extent to which it functions as an exclusive type of ethical argument in constitutional reasoning that precludes other ways of expounding moral concepts, it relies on a moral ontology which is not plausible. The immediate consequence is this: there may be other types of ethical arguments that can be compatible with arguments from common sentiments, for the latter cannot enjoy an ontologically privileged status.

The argument from common sentiment underappreciates the role of reason in moral judgments. From the emotivist standpoint, the lack of reflection and reasoning in moral practice fails to support the illusion of objectivity in the face of moral disagreements. From the relativist standpoint, the lack of reflection and reasoning fails to account for the actual ways in which our moral framework - even if relative and contingent operates. Both however face a common objection: how do the descriptive facts about our contingent moral attitudes gain any normative traction? The typical response to these kinds of concerns is to turn to the role of reason and its ability to generate universal moral imperatives. This kind of metaethical underpinning is present in another ethical argument: the argument from universal reason. Let us then explore this type of argument further and see whether starting from universal moral reasons can get us farther in moral inquiry. 



\section{CONSTITUTIONAL ETHICS AND UNIVERSAL REASON}

\section{Introduction}

The previous chapter concluded that an inadequate moral ontology underscores the argument from common sentiment, and that it cannot serve as a self-sufficient constitutional approach to moral problems. This type of argument does not account for the role of reasoning in moral judgment, and does not explain why moral inquiry necessarily stops at the borders of a community. This chapter explores another type of ethical argument that inverts both elements of the argument from common sentiment; in other words, the argument which is neither emotivist nor relativist, but reason-laden and universalistic. On the one hand, it relies on the idea that morality is universal, or at least more detached from particular communal, cultural or individual experiences. It presupposes that the value will appear to us if we take the 'view from nowhere', ${ }^{1}$ and that the moral point of view requires removing the layers of contingency induced in us by our lives here and now. On the other hand, this argument assumes that moral requirements are attainable though reason, and are not dictated by emotions; instead of sentiments, it uses the language of reason, knowledge and argument.

This chapter argues that these elements - universality and reasonableness - are present in judicial reliance on foreign law when they interpret domestic constitutional provisions. Both case law and academic commentary share the notion that the use of foreign law has to do with the idea of reasoned judgment in morally sensitive issues, and that this phenomenon depends on a more cosmopolitan understanding of the nature of value. I will thus call the use of foreign law in constitutional interpretation the argument from universal reason.

\footnotetext{
${ }^{1}$ See Nagel chs 8 and 9.
} 
Universality and reasonableness promise to give moral values solid grounds: instead of being subject to whim and caprice, they would be rooted in universally human reasons. If successful, such an argument could overcome the limitations of the argument from common sentiment. First, by introducing the possibility of moral reflection and reasoning it would remedy the lack of convergence in moral feelings; it would both help us fine-tune our own moral point of view and provide the argumentative tools to convince others. Second, it would account for the intuition that at least some values are universal. But this could also create inconsistencies in the judicial approach to the nature of value. The argument from common sentiment implies an unrefined version of emotivism that forecloses the possibility of arriving at moral judgments by reason (or by reason only), so how can we explain the role of reason-based ethical arguments within the same jurisdiction, by the same court, or even in the same judgment? Similarly, if the value is revealed by the emotional reaction of the community to a certain set of morally relevant facts, how can the judgments of courts in other jurisdictions be relevant? There are two ways to proceed: the argument from common sentiment is either to be replaced or supplemented with the argument from universal reason.

The chapter argues that the argument from universal reason ought to supplement and not replace the argument from common sentiments. This is because the most plausible account of the argument from universal reason actually fits well with the argument from common sentiment. On this account, universality is not an absolute and timeless property of values, but a mere recognition of contingent interconnections between moral codes in the world; reasonableness does not presuppose a robust relation between reasoning and categorical moral truths, but involves a reflective process through which we become aware of normatively relevant concerns. The argument from universal reason thus gives up on the foundational role of reason in moral judgments and attributes to it only a correctional function. It allows our contingent moral attitudes and emotive intuitions - present in the argument from common sentiment - to feed into moral judgments and does not completely eliminate the parochial and emotional character of constitutional ethics. This however leaves the normativity of constitutional ethics unexplained, and chapters 5 and 6 therefore deal with this issue in more depth. 
This chapter follows a similar structure to the previous one. The first part identifies the elements of argument from universal reason in comparative constitutional practice, and the second analyzes its philosophical foundations. However, instead of showing the internal inconsistency in this ethical argument, it tries to reveal distinct ways in which the use of foreign law can be connected with the idea of universal reason. The chapter attempts to demonstrate that there is such a link, but that the idea of universal reason implicit in the use of foreign law is rather modest.

2. Elements of the argument from universal reason

The use of foreign law in difficult constitutional matters - which is not mandatory and which does not create direct legal consequences typical of valid domestic legal rules has attracted an extraordinary amount of explanations. There are however no comprehensive accounts that connect this problem to metaethics. Some preliminary clarifications are then apposite: we need to understand why bringing the questions about the nature of value to bear on this phenomenon is apt to move the debate in a fruitful direction.

There are numerous causal accounts of the use of foreign law, which focus on the factors that contribute to this practice. For example, from a sociological point of view, many have noted that in a globalized world there are multiple points of contact between judges from different jurisdictions, and that many legal issues gain universal prominence; these processes lead to the creation of a global judicial community that gradually develops its own norms. ${ }^{2}$ This process is often described as legal 'socialization', whereby courts negotiate, internalize, and finally institutionalize

\footnotetext{
2 See Anne-Marie Slaughter, 'A Typology of Transjudicial Communication' (1994) 29 University of Richmond Law Review 99, 129-132, 'A Global Community of Courts' (2003) 44 Harvard International Law Journal 191, and A New World Order (Princeton University Press 2004) ch 2. For the role of increased communication and globalization see also Stephen Breyer, 'Keynote Address' (2003) 97 Proceedings of the Annual Meeting of the American Society of International Law 265, 265-267, and Sandra Day O’Connor, 'Keynote Address' (2002) 96 Proceedings of the Annual Meeting of the American Society of International Law 348.
} 
transnational norms of appropriate behavior in domestic legal systems. ${ }^{3}$ Others have emphasized psychological explanations, typically arguing that judges seek an external authority that would justify their moral choices, or that they use foreign law to convince the public to accept unpopular policies. ${ }^{4}$ These explanations are sometimes coupled with a view that judges use foreign law to alleviate the responsibility for sidestepping the democratic process; ${ }^{5}$ however, it could also be that judges refer to foreign law because they want to identify with internationally shared values, lack relevant experience, ${ }^{6}$ or because they are genuinely persuaded by the views of their peers from other countries and wish to acknowledge the source of their inspiration. ${ }^{7}$ Finally, there are comparative accounts that acknowledge the multiplicity of factors that contribute to the use of foreign law, noting in particular the role of legal context. ${ }^{8}$

In contrast, this chapter asks a normative question: why are these practices valuable? There are two ways to explain the relationship between the use of foreign law and moral value: direct and indirect. The first aims to establish a direct connection between advancing a moral value and the use of foreign law. The nature of value is not vital for this argument; it is enough that we are roughly certain that such a value - be that liberty, equality, welfare, happiness, pleasure - is considered normatively important. But

\footnotetext{
${ }^{3}$ Ryan Goodman and Derek Jinks, 'How to Influence States: Socialization and International Human Rights Law' (2004) 54 Duke Law Journal 621; Thomas Risse-Kappen and Kathryn Sikkink, 'The Socialization of International Human Rights Norms into Domestic Practices: Introduction' in Thomas Risse-Kappen, Steve C. Ropp and Kathryn Sikkink (eds), The Power of Human Rights: International Norms and Domestic Change (Cambridge University Press 1999).

${ }^{4}$ As early as 1957, Pradyumna K. Tripathi described the use of foreign law as little more than rationalizations of a choice largely shaped by the secret yet unmistakable pressures of psychological motivations.' See 'Foreign Precedents and Constitutional Law' (1957) 57 Columbia Law Review $319,346$. ${ }^{5}$ Judges who oppose the practice often rely on such psychological explanations. See Antonin Scalia, 'Foreign Legal Authority in the Federal Courts' (2004) 98 Proceedings of the Annual Meeting of the American Society of International Law 305, 309, and Richard Posner, 'Foreword: A Political Court' (2005) 119 Harvard Law Review 32, 88.

${ }_{6}^{6}$ This motivation is often relevant in new democracies. For an overview see Christopher McCrudden, 'Common Law of Human Rights?: Transnational Judicial Conversations on Constitutional Rights' (2000) 20 Oxford Journal of Legal Studies 499.

${ }^{7}$ Elaine Mak notes this attitude among British judges. Judicial Decision-Making in a Globalised World: $A$ Comparative Analysis of the Changing Practices of Western Highest Courts (Hart Publishing 2013) 51.

${ }^{8}$ Christopher McCrudden, 'Judicial Comparativism and Human Rights' in Esin Örücü and David Nelken (eds), Comparative Law: A Handbook (Hart Publishing 2007); Michal Bobek, Comparative Reasoning in European Supreme Courts (Oxford University Press 2013); Mak; Basil Markesinis and Jörg Fedtke, Judicial Recourse to Foreign Law: A New Source of Inspiration? (UCL Press 2006).
} 
it is rather challenging to show the worth of the use of foreign law with reference to a particular value. Foreign law may substantively differ and develop over time, and so its effects can vary as well; moreover, it is difficult to demonstrate the empirical link that would connect this practice to a specific valuable outcome.

Jeremy Waldron, for example, puts forward a direct normative argument for the use of foreign law. In his view, it is unfair to treat similar cases differently regardless of national borders; in other words, there is reason to prefer global consistency in legal policies that is partly independent from their moral correctness, because people legitimately expect similarity in the rules that determine their basic status. ${ }^{9}$ However, the reach of this argument is limited. ${ }^{10}$ Consistency may be appealing when there is epistemic uncertainty about specific moral requirements, while at the same time some substantive moral threshold is secured. But epistemic uncertainty is typically connected to the moral insignificance of the issue. For instance, we may opt for convergent traffic rules between countries so long as we are not sure which rules bring about better results in terms of reducing the number of accidents, but once we discover that these rules are increasing the number of accidents, then we should change them regardless of consistency; or, similarly, we may wish to slightly adjust the length of a prison sentence for a particular crime to global trends, but if we want to stop punishing people for this crime altogether, we might want to look for further moral arguments. If the issue is not insignificant, we ought not to be indifferent about it, and there are no reasons to defer to foreign consensus without substantive moral backing. The direct justification for the use of foreign law on the basis of consistency is therefore weak: it pertains to a small fraction of cases when there is an expected convergence in morally less significant policies.

The second way to justify the use of foreign law is indirect. It inserts an intermediary step between the use of foreign law and the substantive values to be attained, for it argues that this process could make us cognizant of value as such. The worthiness of the

\footnotetext{
9 Jeremy Waldron, "Partly Laws Common to All Mankind" Foreign Law in American Courts (Yale University Press 2012) ch 5.

${ }^{10}$ Waldron admits that the argument is 'pretty modest'. Ibid 141.
} 
process does not directly depend on the empirical link between the use of foreign law and a specific outcome, but makes this connection intelligible by demonstrating that given a particular understanding of the nature of value - the process is apt to lead us to better answers to moral dilemmas. Notice that the indirect justification is not completely independent from the results it delivers, but that the connection is subtler: if a process is generally able to deliver good results, then we have reason to place trust in it even when we are uncertain about its each and every particular instance. So while the direct approach focuses on the realization of some value in particular, it is best to think of the indirect approach as providing means to attain value in general. To make sense of the abstract connection between foreign law and moral value, the indirect approach must rely on a conception of value against which the use of foreign law will be epistemologically trustworthy.

Most of the existing normative accounts of the use of foreign law are of the indirect type. Mark Tushnet aptly observes that the issue has been framed as a 'disagreement between those who believe that human experience reflects and seeks to realize universal values, and those who are said to take a more relativistic view'. ${ }^{11}$ Empirical studies also demonstrate that this divide is relevant: judges with universalist sentiments tend to cite foreign law in support of their opinions, while judges with more a particularistic vision of values oppose this trend. ${ }^{12}$ However - even though the question about the nature of value is at the foundation of this disagreement - there are no clearly argued metaethical positions in the debate. ${ }^{13}$

The universalist strand of thinking about the use of foreign law is well captured by Harold Koh's metaphor of a 'global community of reason and rights'; the central idea is that constitutional interpretation ought to be in line with converging practices in

\footnotetext{
${ }^{11}$ Mark V. Tushnet, 'Referring to Foreign Law in Constitutional Interpretation: An Episode in the Culture Wars' (2006) 35 University of Baltimore Law Review 299, 310-311. Sanford Levinson explicitly considers the question of the use of foreign law as being attached to the question about moral truths and the nature of value. See his 'Looking Abroad When Interpreting the U.S. Constitution: Some Reflections' (2004) 39 Texas International Law Journal 353.

${ }_{12}$ Ran Hirschl, Comparative Matters: The Renaissance of Comparative Constitutional Law (Oxford University Press 2014) 74 and ch 1.

${ }^{13}$ With some exceptions, such as Jeremy Waldron and Youngjae Lee, which are discussed later on. As I shall argue, their position on key metaethical issues is unclear or implausible.
} 
international and comparative law, which present the earthly embodiment of universal values based on reason. ${ }^{14}$ The critics reject these metaethical premises. For instance, Richard Posner opposes such 'judicial cosmopolitanism'15 arguing - in line with many others - that the use of foreign law relies on the discredited idea of natural law:

The basic idea of natural law is that there are universal principles of law that inform - and constrain - positive law. If they are indeed universal, they should be visible in foreign legal systems and so it is "natural" to look to the decisions of foreign courts for evidence of universality. ${ }^{16}$

According to Posner, this is implausible, primarily because it does not take into account moral disagreement and violates democratic values. ${ }^{17}$ But neither Posner nor other critics of the use of foreign law offer an alternative conception of value that is capable of avoiding these pitfalls. ${ }^{18}$ For example, it is not clear why democratic values are not subject to the same disagreement objection. For consider: either the judges who use foreign law disagree with Posner about the relevance of democratic values, or he is building a straw-man; in the former cases democratic values are subject to the same disagreement problem, in the latter his argument is confused. ${ }^{19}$ The critics - however do raise a credible point that the connection between foreign law as a contingent occurrence in the world and the realm of value is not clear. ${ }^{20}$ This is the connection that needs to be elucidated if the argument from universal reason is to gain normative

\footnotetext{
${ }^{14}$ Harold Hongju Koh and William Michael Treanor, 'Keynote Address: A Community of Reason and Rights' (2008) 77 Fordham Law Review 583.

15 Posner 86.

${ }_{16}$ Ibid 85.

${ }^{17}$ Ibid 84-90.

${ }^{18}$ Natural law in this context is discussed in Eric Engle, 'European Law in American Courts: Foreign Law as Evidence of Domestic Law' (2007) 33 Ohio Northern University Law Review 99, 103; Roger P. Alford, 'In Search of a Theory for Constitutional Comparativism' (2005) 52 UCLA Law Review 639; Roger P. Alford, 'Roper v. Simmons and Our Constitution in International Equipoise' (2005) 53 UCLA Law Review 1, 16-21.

19 This argument from disagreement to democracy is invoked in many other articles in the debate without recognizing this problem. See for example Rosalind Dixon, 'A Democratic Theory of Constitutional Comparison' (2008) 56 The American Journal of Comparative Law 947, 958-959.

${ }^{20}$ Posner articulates it as the inability of judges to understand foreign context (Posner 86-88), and Joan Larsen believes that the use of foreign law cannot survive as a 'moral fact-finding' approach because it is not 'objective' in the sense that consensus in foreign law is neither consistent itself nor consistently used (Joan L. Larsen, 'Importing Constitutional Norms from a "Wider Civilization": Lawrence and the Rehnquist Court's Use of Foreign and International Law in Domestic Constitutional Interpretation' (2004) 65 Ohio State Law Journal 1283, 1322-1326).
} 
traction: we need to see why the use of foreign law is a reliable or trustworthy method to find moral answers.

To do this we need to get a better sense of the actual patterns of judicial arguments and then analyze their implicit metaethical commitments. The argument from universal reason shares some traits with the argument from common sentiment. First, it is used to support moral judgment: foreign law is brought to illuminate ethical concepts from the constitution, often developing the understanding of these concepts beyond the constitutional text, previous precedents or original intentions. Second, over time it may become an entrenched way of interpreting the constitution. ${ }^{21}$ Third, the institutional consequence of the use of foreign law need not necessarily go against the legislative will, hence it need not raise concerns connected to the legitimacy of judicial review. ${ }^{22}$

In contrast to the argument from common sentiment, the argument from universal reason rests on the idea that values are not confined to a specific community and that moral judgment is not complete without reasoning and reflection. To discern these implicit metaethical assumptions behind this argument I will turn to the constitutional practice of the United States, South Africa and Israel. The choice of cases is appropriate because it demonstrates several different attitudes towards moral value: in the United States there has been a lot of opposition to the use of foreign law and values are often seen as local, but when foreign law is cited the elements of universality and reasonableness are quite robust; South Africa is the most open to foreign law, but regardless of the strong cosmopolitan and reason-based rhetoric, the elements of

${ }^{21}$ Not only does this argument become entrenched through the iterative practice of reference to foreign law, but it also becomes relevant through a single precedent. For example, because the court mentioned the law of England, Scotland, India and Ceylon when establishing the rule against self-incrimination during the police interrogation in Miranda v Arizona 384 US 436 (1966) 486-490, Justice O'Connor argued in a subsequent case (New York v Quarles 467 US 649 (1984) 672-673) that the law of these countries is relevant for the determination of the scope of this rule. Meanwhile, much of foreign law debate focuses on the question whether foreign law becomes authoritative through the practice of reference. This problem - however - ought to be the beginning and not the end of the normative debate. See more on this issue in Bosko Tripkovic, 'Judicial Comparativism and Legal Positivism' (2014) 5 Transnational Legal Theory 285, 288-290.

${ }^{22}$ For example, even though the practice of reference to foreign law had had a very long history before Trop v Dulles, this was the first case to use foreign law in striking down legislation. See Steven G. Calabresi and Stephanie Dotson Zimdahl, 'The Supreme Court and Foreign Sources of Law: Two Hundred Years of Practice and the Juvenile Death Penalty Decision' (2005) 47 William and Mary Law Review 743, 846-847. 
universality and reasonableness are at times quite modest; in Israel, the vision of value is more parochial and context-sensitive, and the use of foreign law is constrained by the specific local identity, but the results of the use of foreign law area often universalistic. Therefore, these three jurisdictions nicely illustrate a variety of different attitudes, both towards foreign law and the nature of value.

\subsection{United States}

There are several reasons why the argument from foreign law in the United States is best understood as an ethical argument. First, the cases in which the justices of the Supreme Court use foreign law always address controversial moral issues. To mention but a few: Dred Scott v Sandford (denying citizenship rights to African Americans);23 Reynolds $v$ United States (upholding anti-polygamy laws notwithstanding the freedom of religion); ${ }^{24}$ Lochner $v$ New York (invalidating a working hours limit on the basis of liberty of contract);25 Roe $v$ Wade (establishing the right to abortion);26 Washington $v$ Glucksberg (denying the right to die); ${ }^{27}$ Bowers $v$ Hardwick and Lawrence $v$ Texas (respectively upholding and striking down sodomy laws);28 Trop v Dulles, Coker v Georgia, Enmund v Florida, Thompson v Oklahoma, Atkins v Virginia, and Roper v Simmons (determining the meaning of 'cruel and unusual' punishment). ${ }^{29}$ All these cases were groundbreaking and decided some of the most important moral dilemmas of their era.

Second, justices use foreign law to expound ambiguous moral concepts from the constitution: the practice occurs most frequently when the court interprets the prohibition of 'cruel and unusual' punishment from the $8^{\text {th }}$ Amendment and the substantive component of the due process clauses from the $5^{\text {th }}$ and $14^{\text {th }}$ Amendments, which prohibit the deprivation of 'life, liberty, or property, without due process'. Both

${ }^{23}$ Dred Scott v Sandford 60 US 393 (1856).

${ }^{24}$ Reynolds v United States 98 US 145 (1878).

${ }^{25}$ Lochner $v$ New York 198 US 66 (1905) Justice Harlan's dissenting opinion 71-72.

${ }^{26}$ Roe v Wade 410 US 113 (1973).

27 Washington v Glucksberg 521 US 702 (1997).

28 Bowers v Hardwick 478 US 186 (1986); Lawrence.

${ }_{29}^{29}$ Trop v Dulles; Coker v Georgia; Enmund v Florida; Thompson v Oklahoma; Atkins v Virginia; Roper v Simmons. 
clauses enable the court to enrich the constitution with new interpretations beyond the strict reading of its text, and - in the case of the substantive due process doctrine - to protect new rights on the basis of the notion of liberty.

Third, the attitude towards foreign law is very different from the attitude towards authoritative legal materials. As Justice Kennedy explained in Roper v Simmons: 'The opinion of the world community, while not controlling our outcome, does provide respected and significant confirmation for our own conclusions'. ${ }^{30}$ This is a different vocabulary from the one attached to sources of law: foreign law does not produce immediate outcomes, but carries a certain normative weight. The idea in each and every case is that foreign law will help judges reach a better judgment, and not that they are authoritatively compelled to consult foreign sources.

The justification of this idea typically arises from the conception of value premised upon two interconnected elements: reasonableness and universality. Let me illustrate this by using Roper as an example. Recall that in this case the court found capital punishment to be 'cruel and unusual' if the offender was less than 18 years old when he committed the crime. The decision undoubtedly included a moral judgment on the part of the court. Justice Kennedy, writing for the majority, explicitly took a moral perspective (' $\left[\right.$ f $\_$rom a moral standpoint it would be misguided to equate the failings of a minor with those of an adult' $)^{31}$ confirming a line of cases which consider moral judgment as inevitable for the $8^{\text {th }}$ Amendment analysis. ${ }^{32}$ This analysis includes a two-tier test: first, the court seeks to establish what the national moral consensus is, and then evaluates the reasonableness of the punishment, or - as Justice O'Connor puts it - its 'moral proportionality'. ${ }^{33}$ While common moral sentiments feed into the first part of the test, the majority in Roper used foreign law in the second part, to determine the

\footnotetext{
30 Roper v Simmons 578.

${ }^{31}$ Ibid 570.

32 The court not only rejected both the substantive holding from Stanford $v$ Kentucky 492 US 361 (1989), and the approach from that case which denied the relevance of the court's own moral judgment to $8^{\text {th }}$ Amendment analysis. The alternative view — that the court's moral judgment is indispensable - is for example taken by the plurality in Coker ('the Constitution contemplates that in the end our own judgment will be brought to bear on the question of the acceptability of the death penalty under the Eighth Amendment', Coker v Georgia 597).

${ }^{33}$ Roper $v$ Simmons 587 O'Connor dissenting.
} 
reasonableness of the practice. ${ }^{34}$ The connection between reasonableness and foreign law holds in other cases as well: all capital punishment cases that use foreign law adopt the two-tier analysis that includes court's evaluation of the reasonableness of the community's moral consensus..$^{35}$

In this context, reasonableness means that the punishment must be proportionate to the harm inflicted and to the blameworthiness of the offender. ${ }^{36}$ But more importantly, the idea is that common sentiments could be morally wrong, and that the court is there to provide a check on these sentiments with the assistance of foreign law; the underlying thought is that if enough people in the world reflect enough about the morality of a punishment they will reach a solution that is closer to moral truth (or be more 'reasonable', 'civilized', and 'proportionate') than are the unreflective sentiments of the population. The notion of reasonableness thus stands in an uneasy relationship with the contingent moral sentiments of the population: it hovers above these sentiments and is able to render them inappropriate, but it is at the same time unclear how the property of reasonableness can be different in kind from what the people themselves think is reasonable.

The second element of this conception of value is universality. International materials confirm or rebut the court's own reasonableness analysis, so moral values are not seen as confined to parochial traditions and sentiments. Justice Breyer once defended the use of foreign law in a case pertaining to the death-row phenomenon by describing it as a 'not technically legal, but rather law-related human question' or 'human problem'. ${ }^{37}$ This captures the spirit in which foreign law is used: judges aim to answer how we ought to live, believe that all humans share these deep moral dilemmas, and trust that true answers to these dilemmas are not limited to the existing law.

\footnotetext{
${ }^{34}$ Ibid $575-578$.

${ }_{35}$ Coker v Georgia 597; Enmund v Florida 796; Thompson v Oklahoma 833-838; Atkins v Virginia 312-313.

${ }^{36}$ Enmund v Florida 815.

37 Norman Dorsen, 'The Relevance of Foreign Legal Materials in U.S. Constitutional Cases: A Conversation between Justice Antonin Scalia and Justice Stephen Breyer' (2005) 3 International Journal of Constitutional Law 519, 528. Breyer was referring here to Knight v Florida 528 US 990 (1999).
} 
A clear expression of both elements of the argument from universal reason is found in O'Connor's dissent in Roper:

\begin{abstract}
this Nation's evolving understanding of human dignity certainly is neither wholly isolated from, nor inherently at odds with, the values prevailing in other countries. On the contrary, we should not be surprised to find congruence between domestic and international values, especially where the international community has reached clear agreement - expressed in international law or in the domestic laws of individual countries - that a particular form of punishment is inconsistent with fundamental human rights. At least, the existence of an international consensus of this nature can serve to confirm the reasonableness of a consonant and genuine American consensus. ${ }^{38}$
\end{abstract}

O'Connor's reasoning starts from a moral concept with a particularly cosmopolitan flavor: human dignity. She then argues that the convergence in the world about the meaning of this value must be telling of the value itself. Finally, the existence of consensus is attached to the idea of reason: the fact that others have reached the same conclusion can confirm the reasonableness of local American sentiments.

O'Connor's argument also illustrates the tensions between the argument from universal reason and the argument from common sentiment, stemming from uncertainty about the nature of value. For O'Connor, if there is no local agreement, and if the court is unable to independently justify its own moral decision, the global consensus has no normative weight. ${ }^{39}$ Apart from doctrinal and legitimacy reasons, this is because O'Connor's conception of value is ambivalent about the relationship between the local and global, and emotions and reason: if the consensus is reasonable, and reasonableness is a property of true moral values, then why doesn't the consensus trump misguided local opinions? What follows - normatively speaking — from the sociological fact that 'we shouldn't be surprised to find congruence' between international and domestic

\footnotetext{
${ }^{38}$ Roper $v$ Simmons 605, emphases added.
}

39 Ibid. 
values? To answer these questions we need a clear conception of the connection between comparative law, reason and moral value.

Similar issues arise in other opinions that make use of foreign law. In a number of cases the court deduces evaluative conclusions from the fact of a widespread consensus in comparative law. For example, in Trop $v$ Dulles the court found that forfeiture of citizenship was a 'cruel and unusual' punishment. The plurality opinion written by Chief Justice Warren also approached the problem from the perspective of human dignity, ${ }^{40}$ and understood it as a requirement that penal practices must be exercised 'within the limits of civilized standards'. ${ }^{.1}$ Warren assumed that comparative law would reflect such standards and found that ' $[\mathrm{t}]$ he civilized nations of the world are in virtual unanimity that statelessness is not to be imposed as punishment for crime' ${ }^{42}$ and that ' $[\mathrm{t}]$ he United Nations' survey of the nationality laws of 84 nations of the world reveals that only two countries, the Philippines and Turkey, impose denationalization as a penalty for desertion'.43 While Warren also argued that banishment was 'universally decried by civilized people' and that statelessness was 'deplored in the international community of democracies' ${ }^{44}$ - thus attaching the relevance of foreign law to a set of values shared with the American society - in the final analysis the power of the argument was statistical: only two out of eighty-two countries used revocation of citizenship as a punishment for the crime of desertion. There is a nascent idea here, used later on in many other cases, that true values will be recognized even by the most despicable regimes, or that values will somehow affect their contingent, worldly practices. The details of this connection - absent in Warren's analysis - are crucial in determining the normative weight of foreign law.

Another example of the statistical use of foreign law is Coker v Georgia, where the court found capital punishment unconstitutional for the crime of rape. In the plurality opinion Justice White followed the Trop approach and took convergence in foreign law ("the

${ }_{40}$ 'The basic concept underlying the Eight Amendment is nothing less than the dignity of man'. Trop $v$ Dulles 100.

${ }^{41}$ Ibid.

${ }^{42}$ Ibid 102

${ }_{43}$ Ibid 103.

${ }^{44}$ Ibid 102. 
climate of international opinion') as a reliable testimony about value, noticing that 'out of 60 major nations in the world surveyed in 1965, only 3 retained the death penalty for rape where death did not ensue'. ${ }^{45}$ But from Coker onwards, the universality element in this argument has not been monolithic: some cases have continued to take the pervasiveness of widespread consensus as relevant, and others have restricted the use of foreign law to countries that share common values with the United States. In Atkins v Virginia, the majority led by Justice Stevens held that execution of the mentally challenged is a cruel and unusual punishment, and argued that within the world community, the imposition of the death penalty for crimes committed by mentally retarded offenders is overwhelmingly disapproved'. ${ }^{46}$ This finding supported the majority's conclusion 'that there is a consensus among those who have addressed the issue', ${ }^{47}$ signaling that the value will reveal itself to those that reflect enough about the problem.

Similarly, the majority in Roper relied on the widespread convergence in comparative law. Justice Kennedy, who wrote the opinion, noticed that 'the United States is the only country in the world that continues to give official sanction to the juvenile death penalty.' ${ }^{48}$ Kennedy explicitly mentioned that even regimes that are not considered to be moral forerunners had abolished the death penalty for minors, such as Iran, Pakistan, Saudi Arabia, Yemen, Nigeria, the Democratic Republic of Congo, and China. ${ }^{49}$ Even though Justice Kennedy did focus on English law as historically relevant, ${ }^{50}$ he evidently also held the view that foreign legal practices will transcend their contingent differences and echo universal moral values. The connection between contingent evaluative attitudes and true moral values is here quite robust: what is valuable will find its way into attitudes not because of similarities but even in spite of differences.

\footnotetext{
${ }^{45}$ Coker v Georgia $596 \mathrm{n} 10$. He also noted that in the light of the legislative decisions in ... most of the countries around the world, it would be difficult to support a claim that the death penalty for rape is an indispensable part of the States' criminal justice system'. Ibid $592 \mathrm{n} 4$.

46 Atkins v Virginia 316 n 21.

47 Ibid.

${ }^{48}$ Roper $v$ Simmons 575.

49 Ibid 577.

${ }^{50}$ Ibid. English law was also relevant because the text of the $8^{\text {th }}$ amendment has roots in the English Bill of Rights of 1689.
} 
In contrast, another strand of jurisprudence has continued to rely on the abridged consensus, pertinent to countries that share the evaluative framework with the United States. But this approach has not been applied consistently. In Enmund v Florida the court found that capital punishment for a vicarious felony murder was unconstitutional, and cited the law of Commonwealth countries, continental Europe, England, India, and Canada in support of its conclusion, without explaining why these countries would be relevant. ${ }^{51}$ In Thompson v Oklahoma the court concluded that the death penalty was unconstitutional for minors under 16 years of age, and that this conclusion was consistent with laws of the 'nations that share our Anglo-American heritage' and the 'leading members of the Western European Community'. ${ }^{52}$ Probably, the idea was that a common heritage would lead to similar evaluative attitudes, and that this fact bears normative consequences. However, the court also stated that '[j] $]$ uvenile executions are also prohibited in the Soviet Union', indicating that common heritage may not be all that matters. ${ }^{53}$ Likewise, Justice Breyer took this 'mixed' approach to foreign law in his dissent in Knight $v$ Florida, where he considered the constitutionality of extended delays in execution of the death sentence and discussed decisions of the Privy Council of the United Kingdom (in a case dealing with the Jamaican constitution), Supreme Court of India, European Court of Human Rights, and the Supreme Court of Zimbabwe; ${ }^{54}$ for Breyer, these decisions were 'useful even though not binding' ${ }^{55}$ because they 'considered roughly comparable questions under roughly comparable legal standards' ${ }^{56}$ However even if legal standards were similar - the framework of values in Zimbabwe was different from that in the United States, so we find traces of unrestricted universalism in this opinion as well.

Part of the confusion about the scope of the universality element of the argument from universal reason arises from its nature as a legally embedded ethical argument. The approach of the court in Coker illustrates how the ethical argument from universal reason becomes entrenched through a precedent: a dictum from the plurality opinion in

\footnotetext{
${ }^{51}$ Enmund v Florida 796 n 22.

52 Thompson v Oklahoma 830.

${ }^{53}$ Ibid 831.

54. Knight v Florida 995-997.

${ }_{55}$ Ibid 998.

${ }^{56}$ Ibid 997.
} 
Trop found its way to Coker, and the use of foreign consensus became the accepted approach to moral dilemmas. The pair of sodomy cases in the context of the substantive due process - Bowers and Lawrence - demonstrates a similar pattern. In his concurrence in Bowers, Chief Justice Burger claimed that there is no right to homosexual sodomy; he further asserted that the '[c]ondemnation of [homosexual] practices is firmly rooted in Judeo-Christian moral and ethical standards', ${ }^{57}$ and that granting a right to engage in homosexual sodomy 'would be to cast aside millennia of moral teaching'. ${ }^{58}$ In Lawrence, the court overturned Bowers and held that consensual homosexual conduct falls within the scope of protected liberty under the due process clause. Justice Kennedy, in the majority opinion, specifically rebutted the claim from Burger's concurrence in Bowers that Western civilization unequivocally condemns homosexual sodomy: to support the rebuttal, Kennedy mentioned the jurisprudence of the ECtHR and British legislative history.59 In both Coker and Lawrence, the court followed a previous case in its use of foreign law: while in Coker the court looked at the global consensus, in Lawrence it used only the laws of the countries that share the cultural background of the United States.

To sum up: the argument from universal reason brings foreign law to bear on moral issues. The argument is premised upon the belief that foreign law reflects reasonable solutions to moral issues. It also assumes that values are shared beyond national borders. One strand of thinking connects such values to humanity as a whole, and the other ties it to a common cultural background. Much of the ambivalence in the conception of value follows from the way in which foreign law has been used in preceding cases; however, it also means that there is no clear idea about what makes foreign law normatively significant. The connection between moral value and foreign law thus needs to be explained.

\footnotetext{
57 Bowers 196.

58 Ibid 197.

${ }^{59}$ Lawrence 571-573 and 576-577.
} 
In contrast to the United States, the specific socio-legal context made the South African Constitutional Court very much open to foreign influences: both post-apartheid constitutions drew heavily on foreign constitutional solutions, ${ }^{60}$ the newly established court did not have domestic human rights jurisprudence to build upon, and the court was motivated to identify with liberal-democratic jurisdictions in order to renounce the authoritarian heritage of the society. ${ }^{61}$ Furthermore, the South African Constitution explicitly allows for the use of foreign law in interpretation of the bill of rights and simultaneously — calls for its moral reading:

When interpreting the Bill of Rights, a court ... must promote the values that underlie an open and democratic society based on human dignity, equality and freedom ... and ... may consider foreign law. ${ }^{62}$

The constitution confers a duty upon the court to promote moral values and authorizes it to consider foreign law. There is thus no doubt that the use of foreign law is an ethical argument, as the constitution itself connects it to the interpretation of moral concepts such as dignity, equality and freedom. The court relies on foreign law to improve its own moral judgment: when so doing, it admits to be exercising the law-making function and frequently decides against popular opinion. Let me explain.

The existence of an explicit constitutional warrant to engage in value-based reasoning affects the court's interpretive methods: while the US Supreme Court typically meets with criticism for its activism, the South African Constitutional Court is comfortable in

\footnotetext{
${ }^{60}$ See more in D. M. Davis, 'Constitutional Borrowing: The Influence of Legal Culture and Local History in the Reconstitution of Comparative Influence: The South African Experience' (2003) 1 International Journal of Constitutional Law 181, 181-189.

${ }^{61}$ Ursula Bentele, 'Mining for Gold: The Constitutional Court of South Africa's Experience with Comparative Constitutional Law' (2009) 37 Georgia Journal of International and Comparative Law 219, 228-230.

62 Constitution of the Republic of South Africa of 1996 Section 39(1). Constitution of the Republic of South Africa of 1993 (Interim Constitution) Section 35(1) contained a similar provision, but spoke only about 'comparable' foreign cases and not foreign law in general.
} 
its role as a vehicle of moral change. ${ }^{63}$ Justice Mokgoro's opinion from $S v$ Makwanyane illustrates this approach: in her understanding, constitutional interpretation entails a 'reference to a system of values extraneous to the constitutional text', ${ }^{64}$ while ethical arguments are inescapable, as the interpretation of moral concepts from the constitution draws the court 'into the realm of making necessary value choices' ${ }^{65}$ When the court makes such value choices, it does not shy away from rejecting the argument from common sentiment and replacing it with its own moral judgment. Justice Chaskalson's remark from $S v$ Makwanyane captures this attitude succinctly: 'If public opinion were to be decisive there would be no need for constitutional adjudication' ${ }^{66}$ Hence, the court accepts that constitutional interpretation may go against the will of the people and that it sometimes entails making moral calls in the name of the whole society.

The court's value choices are regularly based on the analysis of foreign law. Foreign law appears in at least half of its judgments, ${ }^{67}$ and justices openly admit that it serves to assist their law-making function. The idea is that references to foreign law improve domestic law. In K v Minister of Safety and Security, Justice O'Regan explained: 'Our courts will look at other jurisdictions for enlightenment and assistance in developing our own law' ${ }^{68}$ In her view - shared by many other justices ${ }^{69}$ - rejecting the input of foreign law deprives the 'legal system of the benefits of the learning and wisdom to be found in

\footnotetext{
${ }^{63}$ In its first judgment, the court accepted the approach from the Canadian case ( $R v$ Big M Drug Mart Ltd (1985)18 DLR (4th) 321395 - 396) that constitutional interpretation ought to be 'generous rather than legalistic'. Sv Zuma and Others 1995 (2) SA 642 para 15.

64 $S$ v Makwanyane and Another para 302.

${ }^{65}$ Ibid para 303. In making these values choices - as Mokgoro puts it - 'foreign precedent may be instructive'. Ibid para 302.

${ }^{66} \mathrm{~K} v$ Minister of Safety and Security 2005 (6) SA 419 (CC) para 35. Under the South African constitution, all public policies that limit constitutional rights must be 'reasonable and justified', and are subject to proportionality analysis by the court. $S v$ Makwanyane and Another para 88; Constitution of the Republic of South Africa of 1996 Section 36 (1).

${ }^{67}$ Constitution of the Republic of South Africa of 1993 (Interim Constitution) 33(1); Christa Rautenbach, 'South Africa: Teaching an 'Old Dog' New Tricks? An Empirical Study of the Use of Foreign Precedents by the South African Constitutional Court (1995-2010)' in Tania Groppi and Marie-Claire Ponthoreau (eds), The Use of Foreign Precedents by Constitutional Judges (Hart Publishing 2013) 194

${ }^{68} \mathrm{~K} v$ Minister of Safety and Security para 35, emphasis added. This is especially the case when there is no previous law that would guide the court's decisions. Justice Chaskalson expressed this view in $S v$ Makwanyane and Another para 37 and Mistry v Interim National Medical and Dental Council and Others 1998 (4) SA 1127 para 3.

${ }^{69}$ See generally in Bentele.
} 
other jurisdictions'. ${ }^{70}$ The usefulness of foreign law is most typically seen as epistemic: there is knowledge about values to be gained when one consults foreign legal sources.

The epistemic worth of foreign law depends on views about the nature of moral value, which rest on the elements of universality and reasonableness: the belief that at least some values are universal and grasped by virtue of reason. A typical exponent of such a view is Justice Ackermann, who trusts that the use of foreign law can reveal the universal norms that emerge in the process of reasoning:

In construing and applying our Constitution, we are dealing with fundamental legal norms which are steadily becoming more universal in character. [...] we have regard to these findings [of foreign courts], not in order to draw direct analogies, but to identify the underlying reasoning with a view to establishing the norms that apply in other open and democratic societies based on freedom and equality.71

While Ackermann's universalism is curtailed by a reference to a common liberaldemocratic evaluative framework, he believes that precisely these values are universally human and that constitutional law ought to uphold them: 'constitutional law ... is not wholly nationalistic and exclusively historical enterprise, but embodies a certain universally normative minimum core. ${ }^{72}$ In his opinion, the use of foreign law serves to facilitate the acceptance of cosmopolitan values and to sideline cultural relativism; the goal of the practice is to enable 'a greater universalising of these values as enforceable rights'. ${ }^{73}$ However - regardless of the rhetoric that is optimistic about the existence of universal moral truths revealed through the faculty of reason - the actual patterns of the use of foreign law demonstrate a less ambitious universalism and incorporate a thinner conception of reason.

${ }^{70} \mathrm{~K} v$ Minister of Safety and Security para 35.

${ }^{71}$ Ferreira v Levin; Vryenhoek v Powell 1996 (1) SA 984 (CC) para 72, emphasis added.

${ }^{72}$ Laurie W.H. Ackermann, 'Constitutional Comparativism in South Africa: A Response to Sir Basil Markesinis and Dr Jörg Tiedke’ in Basil Markesinis and Jörg Tiedke (eds), Judicial Recourse to Foreign Law: A New Source of Inspiration? (UCL Press) 274

${ }^{73}$ Ibid 286. 
Although the court does make references to global legal consensus, ${ }^{74}$ most of the time the element of universality is restricted. Quantitatively, justices have cited cases from Canada, United States, United Kingdom, European Court of Human Rights and Germany much more than any other jurisdiction. ${ }^{75}$ More importantly - qualitatively foreign precedents have not been accepted at face value; the court often distinguishes between them on the basis of differences in constitutional text and spirit, or because of distinctive social circumstances. The approach to foreign law has thus been careful in two different senses. Externally, concerning foreign law, the court has been - in the words of Justice Kentridge - sensitive to legal history, traditions and usages of the country concerned' in order to understand 'the purposes of its constitution'. ${ }^{76}$ Internally, in weighing the appropriate influence of foreign law, the court has tried to - as Chaskalson puts it - pay 'due regard to our legal system, our history and circumstances, and the structure and language of our own Constitution'. ${ }^{77}$

This approach has, for example, been prominent in the equality jurisprudence, where the heritage of systemic inequalities prompted the court to adopt a more substantive and remedial understanding of equality. ${ }^{78}$ For instance, in National Coalition for Gay and Lesbian Equality $v$ Minister of Justice - a case that declared the prohibition of sodomy unconstitutional - the South African Constitutional Court rejected the reasoning of the Supreme Court of the United States in Bowers v Hardwick. The court compared sodomy laws which target a group based on sexual orientation to apartheid laws which target racial groups, and concluded that these kinds of differentiations are no longer a part of South Africa's constitutional identity; ${ }^{79}$ it then argued that the constitutional situation in

\footnotetext{
${ }^{74}$ See for example the reference to a growing consensus about the death penalty in $S v$ Makwanyane and Another para 33 and against criminalizing sodomy in National Coalition for Gay and Lesbian Equality $v$ Minister of Justice and Others 1999 (1) SA 6 para 52.

${ }^{75}$ See Rautenbach 197.

${ }^{76} S$ v Zuma and Others para 15 (Kentridge). Justice Kentridge also explained in Du Plessis and Others v De Klerk and Another 1996 (3) SA 850 para 127, that ' $[\mathrm{t}]$ he survey [of foreign law] is conducted from the point of vantage afforded by the South African Constitution, constructed on unique foundations, built according to a unique design and intended for unique purposes.'

${ }_{77} S v$ Makwanyane and Another para 39 (Chaskalson).

${ }^{78}$ See for example President of the Republic of South Africa and Another v Hugo 1997 (4) SA 1 para 41; Minister of Home Affairs and Another $v$ Fourie and Another para 60 (Sachs).

${ }_{79}$ National Coalition for Gay and Lesbian Equality $v$ Minister of Justice and Others para 28 (Ackermann).
} 
South Africa was very different from the one in the United States on which Bowers relied, and that the domestic constitution more explicitly demands the protection of privacy, dignity, and equality. ${ }^{80}$ Similarly, in Prince $v$ President, the court rejected the reasoning of the majority in a US Supreme Court case Employment Division v Smith, ${ }^{81}$ finding the minority opinion in that case to be 'more consistent' with the South African constitution. ${ }^{82}$ The question in Prince was whether the denial of access to the legal profession based on the previous use of cannabis for religious purposes is constitutional. While the majority in Prince refused to make an exception for the religious use of prohibited substances, reaching the same conclusion as the Smith majority, it did so on different grounds and by employing a more stringent test. The Smith majority effectively denied any religious exception to general and formally neutral laws;ss in contrast, Justice Ackermann followed the minority in this case that held the state intervention justified only if it is narrowly tailored to achieve a compelling state interest. ${ }^{84}$ Thus, in both National Coalition and Prince, the court rejected the relevance of the mainstream American approach to equality on the basis of the specific evaluative commitments of South African society.

Universalism has also been circumscribed through judicial localization of moral concepts and the subsequent rejection of direct foreign influence. In some cases, justices have preferred to rely on traditional South African values that - although similar in content to moral concepts used in other jurisdictions - better express the specificities of local moral practices. For example, Justice Moseneke used a local concept of 'regstellende aksie' to underline South African commitment to substantive equality, according to which remedial measures aimed at alleviating inequalities are not a deviation but an integral part of the notion of equality. ${ }^{85}$ On the basis of this concept, Moseneke distinguished American equality jurisprudence as 'inapt', notwithstanding the

\footnotetext{
${ }^{80}$ Ibid para 55 (Ackermann).

${ }^{81}$ Employment Division v Smith 494 US 872 (1990).

82 Prince v President of the Law Society of the Cape of Good Hope 2002 (2) SA 794 para 122 (Ackermann).

${ }^{83}$ Employment Division v Smith 879.

${ }^{84}$ Prince v President of the Law Society of the Cape of Good Hope para 122 and 128-129. Justice Sachs went even further: basing his arguments in part on the specific South African heritage of discrimination, he concluded that religious exception in this case ought to be granted. Ibid para 170 (Sachs).

${ }^{85}$ Minister of Finance and Other $v$ Van Heerden para 29-30.
} 
similarities in constitutional texts. ${ }^{86}$ Similarly, in Makwanyane, several justices used the local concept of 'ubuntu' to argue for the abolition of the death penalty. ${ }^{87}$ In Justice Mokgoro's interpretation, 'ubuntu translates as humanness' and underlines 'group solidarity on survival issues';8 as such, it incorporates both the right to life and human dignity. ${ }^{89}$ The concept of ubuntu has served to express a universalistic value of dignity in the local vocabulary, but also to underline that constitutional values arise from indigenous evaluative experiences which capture the spirit of the constitution more accurately.

Analogously, the element of reasonableness has been modest. The court has not supposed that there is a strong connection between the reasoning of foreign courts and true moral values. This is not to say that the court has not assigned normative weight to consensus in foreign law or to jurisdictions with a greater pedigree in human rights protection, but that the approach has been cautious about deducing direct normative conclusions from facts about foreign law. Justice Sachs explains this method by saying that the court should 'look for rationales rather than rules' in foreign law. ${ }^{90}$ This approach implies that the court should find foreign reasoning 'persuasive' if it is to be applied. ${ }^{91}$ To be persuaded by a rationale is to realize that an evaluative judgment is appropriate, without being aware of it before or without being able to articulate it clearly. Notice that this conception of reasonableness - emerging from the process of persuasion and reflection need not suppose that foreign law contains universal moral truths external to the evaluative framework from which the court is assessing the issue; instead, to be persuasive, reasoning must fall on fertile ground and trigger some of the presuppositions or evaluative commitments that are implicit in the evaluative outlook of the court that is being persuaded. While the 'persuaded' court may in the process change some of its initial evaluative intuitions, it will do so with support from a range of other assumptions that are internal to its own framework of values.

\footnotetext{
${ }^{86}$ Ibid para 29.

${ }^{87}$ Sv Makwanyane and Another para 130-131 (Chaskalson) 223-227 (Langa) 240-244 (Madala) 306312 (Mokgoro).

88 Ibid para 307.

${ }^{89}$ Ibid para 310 and 312

${ }_{90}$ Coetzee v Government of the Republic of South Africa, Matiso and Others v Commanding Officer Port Elizabeth Prison and Others 1995 (4) SA 631 para 57.

${ }^{91} \mathrm{~K} v$ Minister of Safety and Security para 35 (O'Regan).
} 
Justice Ackermann describes this element of reasonableness as 'critical rationalism', which entails a process of reflection in order to minimize the influence of one's own 'personal preferences and dangerous intuitions' ${ }^{92}$ The idea here is not that reflection will generate knowledge of some external reality or make moral judgment robustly and universally objective through a complete detachment from the personal point of view, but that the process - as he describes it - will probably lead to a more stable equilibrium within one's own evaluative outlook. Ackermann lists a number of ways in which foreign law may be useful: to identify the problem, detect the methodology to approach it, recognize its different aspects and implicated concerns, and understand possible hazards attached to different solutions. ${ }^{93}$ The purpose, as Ackermann sees it, is to avoid the 'tunnel vision' where '[o]ne's thinking becomes unimaginative', ${ }^{94}$ and - at the same time - to be 'ruthless' about one's own presumptions in order to find 'the limits of one's own understandings' ${ }^{95}$ Instead of incorporating the solutions from foreign law directly, the approach of the South African constitutional court involves a process of raising selfawareness about the core evaluative commitments of the domestic constitutional system, and about the best ways to realize these under given social circumstances.

To conclude, regardless of the strong rhetoric of universalism and reasonableness, the South African Constitutional Court uses foreign law in a way that is sensitive to the local factual and evaluative specificities. In so doing, it does not seem to suppose that external normative truths can be attained through the faculty of reason, but it does assume that reflection is valuable in exposing the limits of one's imaginative horizons and presumptions. In this approach - even if the reflective exercise is conducted - local and contingent values feed into the final moral judgment.

\footnotetext{
92 Ackermann 285.

93 Ibid 277.

${ }^{94}$ Ibid 278.

${ }_{95}$ Justice Ackermann, cited in Bentele 232.
} 
Israeli Supreme Court has a long history of value-based reasoning entangled with the use of foreign law. On the one hand, foreign law has traditionally had strong influence in Israel. Since the establishment of the state, English precedents served as a complementary legal source; ${ }^{96}$ moreover, the development of the new legal system with limited local sources to build upon has been followed by an open attitude to foreign legal materials. ${ }^{97}$ On the other hand, the lack of a canonical constitutional text and a complete bill of rights has moved the court towards value-based reasoning without the constraints of originalism and textualism. ${ }^{98}$ When exercising its law-making authority, the court has used foreign precedents in two principle ways: first, to protect values and rights that have not been explicitly guaranteed before; and second, to expand its powers of rights-based review of administrative action and legislation. ${ }^{99}$ Thus, the use of foreign law as an ethical argument has both served to read new moral values into the constitution and to secure the position of the court as the guardian of these values.

The justification of this ethical argument has been embedded in the discourse of reasonableness. ${ }^{100}$ The views of the former President of the Supreme Court Aharon Barak

\footnotetext{
${ }_{96}$ The duty to apply British law stretched until the 1980s. For a short introduction see Suzie Navot, 'Israel: Creating a Constitution - The Use of Foreign Precedents by the Supreme Court (1994-2010)' in Tania Groppi and Marie-Claire Ponthoreau (eds), The Use of Foreign Precedents by Constitutional Judges (Hart Publishing 2013) 130-132.

${ }_{97}$ A study from the 1990 s documents around 21 per cent of foreign materials cited (including academic materials). Miron Gross, Ron Haris and Yoram Schachar, 'References Patterns of the Supreme Court in Israel - Quantitative Analysis' (1996) 26 Hebrew University Law Review 115. Although once the influence of English law weakened, this ratio dropped to around 10 per cent (ibid 151), another study shows that in the 100 most cited cases (i.e. cases with most precedential weight) the average number of foreign citations was 7.8 per case. Chanan Goldschmit, Miron Gross and Yoram Schachar, '100 Leading Precedents of the Supreme Court - A Quantitative Analysis' (2004) 7 Haifa University Law Review 243, 267. See Iddo Porat, 'The Use of Foreign Law in Israeli Constitutional Adjudication' Paper Presented in a Conference on Israeli Constitutional Law (Tel Aviv, May 2010) available at http://www.clb.ac.il/uploads/Porat\%20-\%20Foreign\%20Law\%20-\%20May\%204.pdf.

98 See 'The Decline of Formalism and the Rise of Values' in Menachem Mautner (ed), Law and the Culture of Israel (Oxford University Press 2011) ch 4.

99 The key cases in this regard are Kol Ha'am v Minister of Interior HCJ 73/53 (1953) and United Mizrahi Bank Ltd. v Migdal Cooperative Village CA 6821/93 (1995), discussed below.

100 As Ran Hirschl observes, '[o]ver the last few decades, the Supreme Court has become a bastion of "reason" and "sanity" for Israel's "enlightened public". Hirschl, Comparative Matters: The Renaissance of Comparative Constitutional Law 63. The concept of 'enlightened public' has been used by the Chief Justice, Aharon Barak, to determine the reasonableness of certain policies. The concept should express the views of a modern, informed and reflective Israeli, and is thus both rooted in contingent cultural experience and
} 
can illustrate this. In his opinion, '[c]omparative law can help judges determine the objective purpose of a constitution'.101 The emblem of Barak's interpretive approach is a belief that constitutions and legislative acts have objective purposes, which transcend national boundaries and are distinct from the contingent intentions of their framers. The objective purpose is determined by 'the intention of the reasonable legislature'. ${ }^{102}$ It is thus a normative concept discernable through reason and not a socio-historical fact: the objective purpose denotes 'the interests, values, objectives, policy, and functions that the law should realize in a democracy'. ${ }^{103}$ The role of the judge is to determine these hypothetical intentions and find the objective purpose of the constitution: it is up to the court to add the element of reason to ordinary legislative intentions. ${ }^{104}$

The objective purpose of the constitution acquires substance with the assistance of foreign law. However - while the objective purposes of the constitution are not limited to the domestic constitutional system - they are limited to jurisdictions that respect human rights and democratic values. For Barak, the universalism of the argument from foreign law is restricted: the use of foreign law is 'only proper if there is an ideological basis common to the two legal systems and a common allegiance to basic democratic principles'. ${ }^{105}$ The idea is that constitutional orders which share a common evaluative framework have similar 'functions' or 'purposes' ${ }^{106}$ which can be discerned by attending closely to foreign practices. The objective purposes detached from contingent psychological attitudes may be metaphysically unsustainable, but Barak's interpretive philosophy perhaps suggests something subtler: objective purposes are deep moral commitments shared by a number of jurisdictions with a common evaluative outlook. These commitments emerge in the process of reflection induced by foreign law. ${ }^{107}$

able to overcome it through reflection. See more in Steven M. Mazie, Israel's Higher Law: Religion and Liberal Democracy in the Jewish State (Lexington Books 2011) 37-40.

${ }^{101}$ Aharon Barak, The Judge in a Democracy (Princeton University Press 2006) 200, emphasis added.

102 Ibid 136.

${ }^{103}$ Ibid 138. See also Aharon Barak, Purposive Interpretation in Law (Princeton University Press 2005) ch 7 .

${ }^{104}$ Barak, The Judge in a Democracy 138 and 149.

${ }^{105}$ Ibid 201.

106 Ibid 200.

${ }^{107}$ See ibid $200-204$. 
This understanding of the use of foreign law has deeper roots. In the seminal Kol Ha'am $v$ Minister of the Interior case, the court for the first time established that administrative action must conform with values and rights implicit in Israel's commitment to democracy. ${ }^{108}$ The question was whether the Minister of the Interior exceeded his authority by ordering a temporary suspension of two newspapers for publishing materials which could endanger public peace. Justice Agranat, writing for the court, relied almost exclusively on foreign law to tease out the relevant concerns surrounding the restrictions to free speech in a democracy. ${ }^{109}$ His reasoning was as follows. First, he argued that the understanding of the democratic regime inevitably leads ... to the enforcement of the freedom of expression in every state where such a form of government exists'. ${ }^{110}$ Second, he analyzed foreign precedents to reveal the justifications and restrictions of freedom of expression in other democracies. ${ }^{111}$ Third, Agranat found that Israel is 'a state founded on democracy' and that although there was neither constitutional review of legislation nor an explicit textual guarantee of the freedom of expression, 'the law of people must be studied in the light of its national way of life', which he understood to be fundamentally democratic. ${ }^{112}$ Fourth - once the link between the values of other democracies and Israel was established - Agranat developed a balancing test that allowed limitations of speech in the case of imminent danger to public peace; it thus closely resembled the American 'clear and present' danger test. ${ }^{113}$ The idea was that there is a non-parochial common framework of values shared by all democracies, and that - consequently - foreign law discloses these values.

Another example of this approach is Aharon Barak's opinion in the Mizrahi Bank case. ${ }^{114}$ In this case, the court conferred constitutional status upon the basic laws and proclaimed its right to conduct judicial review of legislation. ${ }^{15}$ The case came up as a

\footnotetext{
${ }^{108}$ Kol Ha'am v Minister of Interior.

109 The case cites 9 American, 8 English, and only 3 Israeli cases.

${ }_{110} \mathrm{Kol} \mathrm{Ha}$ am v Minister of Interior section A.

${ }^{111}$ Ibid sections A-E.

112 Ibid section E.

${ }^{113}$ Ibid sections F(4) and G. For the American test, see Schenck v United States 249 US 47 (1919) 249.

${ }_{114}$ United Mizrahi Bank Ltd. v Migdal Cooperative Village. The case raised the issue of the constitutionality of measures aimed at alleviating the consequences of economic crisis in the agricultural sector that could interfere with a creditor's claims through the restructuring or cancellation of unpaid debts.

${ }^{115}$ Before Mizrahi Bank, the courts only exercised the review of administrative action, so the case is rightfully referred to as a 'constitutional revolution'. (ibid (Barak) para 109) For context, see Gideon
} 
consequence of the adoption of two basic laws, which guaranteed certain fundamental rights, but did not at the same time include an explicit warrant for the court to review legislation. ${ }^{116}$ In 'Basic Law: Dignity and Liberty' the Knesset established that ' $[\mathrm{t}]$ here shall be no violation of rights under this Basic Law except by a law befitting the values of the State of Israel', and that '[a]ll governmental authorities are bound to respect the rights under this Basic Law', ${ }^{117}$ but did not provide for a formal hierarchy of laws supervised by the court.

Justice Barak understood these laws as nothing short of a watershed constitutional moment and enthusiastically identified Israel with other constitutional democracies: 'We have now joined the community of democratic countries ... We have become part of the human rights revolution ...' ${ }^{118}$ Nonetheless, the gist of his opinion is not universalistic, and Barak's arguments are couched in the idea that a constitution is a 'reflection of national experience'. ${ }^{119}$ Values protected by the court do not arise from global norms but from 'national consciousness'120 and a 'social contract'121 reflected in the best understanding of Israel's history. Barak’s attitude towards foreign law followed from this understanding of the nature of value. While he did cite foreign law extensively, he also argued that a judge must do so carefully, because the 'scope of the constitutional right is derived from society's understanding of its importance', and the balance between a right and public interest is determined by 'society's attitude towards national interest' and the 'unique outlook of Israeli society'. ${ }^{122}$ Hence - as in Kol Ha'amthe route to foreign law in Barak’s Mizrahi opinion was not direct, but emerged from

Sapir, 'Constitutional Revolutions: Israel as a Case-study' (2009) 5 International Journal of Law in Context 355.

${ }^{116}$ Israel does not have a codified constitution, but a set of 'basic laws' that have been gradually adopted over the years. Two of those constitute a partial bill of rights - Basic Law: Human Dignity and Liberty and Basic Law: Freedom of Occupation of 1992 - and guarantee right to life, bodily integrity, dignity, property, personal liberty, privacy, freedom of movement, and freedom of occupation. The court protected other rights without an explicit textual basis. See more in Navot 130-138.

${ }^{117}$ Sections 8 and 11. Basic Law: Freedom of Occupation contains analogous provisions in sections 4 and 5 , but also establishes a more rigid amendment procedure (section 7) and provides for the possibility of the Knesset to - in exceptional cases - temporarily adopt legislation inconsistent with the law (section 8).

118 United Mizrahi Bank Ltd. v Migdal Cooperative Village (Barak) introduction.

119 Ibid (Barak) para 38.

120 Ibid.

${ }^{121}$ Ibid (Barak) para 50.

${ }^{122}$ Ibid (Barak) para 88. 
Israel's own constitutional identity and the profound moral commitments of the local community.

The basic law defines the values of the State of Israel as both 'Jewish and democratic', ${ }^{123}$ and Barak's approach to foreign law followed this dualism: on the one hand, his strategy was to make analogies with democratic jurisdictions and infer conclusions for domestic law; on the other, he refuted the direct import of foreign law when it collided with local values. In a more cosmopolitan manner, Barak used American cases to show that 'true democracy cannot exist without the limitation of the power of majority' ${ }^{124}$ and relied on German and Canadian law to confirm that the legislature must be obliged to respect fundamental rights. ${ }^{125} \mathrm{He}$ also cited Marbury $v$ Madison together with the wide acceptance of constitutional review in comparative law to support his argument that such a review is the 'soul of the constitution', which is indispensable to a system that respects the separation of powers, rule of law and democracy.126

The elements of universalism and reasonableness are also visible in Barak's lengthy references to foreign jurisdictions in relation to the proportionality analysis, which in his opinion 'does not reflect a unique social history' but a 'general analytical position'. ${ }^{127}$ Because Barak understands judicial authority as an exercise in 'reason and not power', ${ }^{128}$ it is not surprising that he saw proportionality analysis as an expression of reason and universally applicable method of moral reflection. But this idea of reason is modest. Instead of thinking that reasoning will inevitably lead to convergence on right moral answers, proportionality analysis need not command any particular outcome or lead to consensus; it figures in Barak's analysis as a reflective device that may lead to different conclusions depending on local evaluative commitments. For example, Barak distinguished between the lenient American approach to economic freedom of the state

\footnotetext{
123 Basic Law: Human Dignity and Liberty, section 1a.

124. United Mizrahi Bank Ltd. v Migdal Cooperative Village (Barak) para 47.

${ }^{125}$ Ibid (Barak) para 69.

${ }^{126}$ Ibid (Barak) paras 78 and $75-80$. He did note however that this approach is 'accepted in Israeli community'. Ibid (Barak) para 77.

${ }^{127}$ Ibid (Barak) 94, for the use of foreign law in proportionality analysis see 83-107. For a short overview of the role of foreign law in Mizrahi see Zeev Segal, 'The Israeli Constitutional Revolution: The Canadian Impact in the Midst of a Formative Period' (1997) 8 Forum Constitutionnel 53.

128 United Mizrahi Bank Ltd. v Migdal Cooperative Village(Barak) para 81.
} 
and the forbearing Canadian treatment of legislative infringement of property rights, on the basis of the specific Israeli evaluative outlook in which economic rights can be constitutionally protected, and in which the right to property is specifically guaranteed. ${ }^{129}$ In sum, Barak's approach to the nature of value from Mizrahi is not universalistic, but it is not parochial either: he accepts the relevance of foreign law, to the extent that there is a shared evaluative outlook. His understanding of the role of reason is similar: while Barak acknowledges that a proper evaluative judgment entails reflection, this does not mean that it will be completely detached from the evaluative experience of the local community.

Not surprisingly, the tensions on the borderline between the universal and the local dimension of value abound in this approach. An evaluative judgment can be widely accepted but at the same time may collide with deeper moral commitments implicit in the constitutional allegiance to democratic government. It is up to the court then to argue that - on reflection - these widely shared moral judgments fail to live up to more fundamental values. Such arguments often attempt to show that there is a blind spot in the set of domestic moral concerns that can be illuminated through the analysis of foreign law; the counter-arguments in turn try to demonstrate the inappropriateness of foreign law for the specific domestic needs and values. In contrast to the South African case, where there were rarely doubts regarding fundamental domestic values, justices of the Supreme Court of Israel sometimes had opposing visions of values intrinsic to Israeli constitutional identity.

We can illustrate these tensions and the reflective process they generate with the divergent opinions of justices Barak and Cheshin in Adalah v Minister of Interior. ${ }^{130}$ In this case, the court by a $6-5$ split judgment upheld the constitutionality of amendments to the Law on Citizenship and Entry into Israel. On the basis of the security rationale and fear of terrorist attacks, the law instituted a blanket prohibition of granting residency permits and citizenship to residents of the Occupied Territories who are

129 Ibid (Barak) paras 102-103.

130 Adalah Legal Centre for Arab Minority Rights in Israel v Minister of Interior HCJ 10650/03 (2006) 
family members of Israeli citizens. ${ }^{131}$ Since the citizens who had family ties with Palestinians were predominantly members of the Arab minority, the prohibition raised concerns regarding both their right to family life and equality. But the basic law on dignity and liberty did not guarantee these rights explicitly, and the court itself had to interpret and balance Israeli values in order to reach the judgment.

Justice Barak made two crucial moves in his minority opinion, both with extensive support from foreign law. First, he derived the right to family life and, consequently, to family reunification from the right to dignity. Foreign law served to show that all the countries that respect human dignity also guarantee the right to family life and that these two are intrinsically connected; it followed for him that in Israel family rights are also protected by virtue of human dignity. ${ }^{132}$ Second, he underlined the centrality of proportionality analysis to the democratic constitutional system and its elements by a lengthy examination of foreign law; ${ }^{133}$ in particular, Barak put much trust in the last part of the proportionality analysis - where the values are balanced against one another - as giving 'expression to the concept of reasonableness'. ${ }^{134}$ This approach enabled Barak to define the scope of the right to family life broadly, note the infringement of the right, and place the weight of scrutiny on the balance between the individual right and collective security concerns within the proportionality analysis. Ultimately, he found the law 'inconsistent with the character of Israel as a democratic freedom-seeking and liberty-seeking state'. ${ }^{135}$ Thus, Barak's conclusion followed from the Israeli commitment to the universal value of dignity and from the analysis of the reasonableness of measures that infringed it.

\footnotetext{
${ }^{131}$ The blanket ban concerned only men of 14 to 35 years of age and women from 14 to 25 , while those outside of this age span could be granted residence permits at the discretion of the minister of interior. The ban was later extended to citizens of 'enemy states' (Iran, Lebanon, Syria and Iraq). In another divided judgment (6-5), the court upheld these amendments. See MK Zahava Gal-On (Meretz-Yahad) v Attorney General HCJ 466/07 (2012).

${ }^{132}$ See Adalah Legal Centre for Arab Minority Rights in Israel v Minister of Interior (Barak) paras 33-38. He also concluded that equality is guaranteed by virtue of dignity, but did not rely on foreign law as there was already enough Israeli jurisprudence on this question.

${ }^{133}$ See in particular ibid (Barak) paras $54-75$.

${ }^{134}$ Ibid (Barak) para 74

135 Ibid (Barak) para 93.
} 
In contrast, Justice Cheshin argued that Barak's opinion is appropriate for the 'state of Utopia' but not for Israel. ${ }^{136}$ Cheshin accepted that the right to family life follows from the commitment to human dignity, but he argued that it need not be realized on the territory of Israel; unlike Barak, Cheshin limited the scope of the right to family life before conducting the proportionality analysis, which then played a subsidiary role in his opinion. There are two distinct threads in his reasoning in terms of the nature of value. On the one hand, Cheshin acknowledges the existence of universal 'natural' rights that can be discerned from foreign law, but finds their application problematic in the specific social context. He accepts that the right to family life follows from the natural right to human dignity, and that 'the state merely embraces what is already there by wrapping natural law in the garb of law and constitution', ${ }^{137}$ but he contrasts this demand with the 'basic principle in the law of the countries in the world' according to which '[e] very state has a natural right ... to determine who will be its citizens'.138 Cheshin finds that when these two universal rights are balanced against each other and applied to the 'reality of life' in Israel, there is no obligation of the state to allow family reunification by granting residency or citizenship to Palestinians. ${ }^{139}$ As he puts it, 'on the basis of this logical deduction, a deduction that is common to all human beings and to all human peoples, it has been determined in international law that when there is dispute between nations, a nation may prohibit the nationals of the foreign nation, as such, from entering or immigrating to it'. ${ }^{140}$ The process of inference from foreign and international law is here deductive: there are universally true principles expressed in global consensus, but their outcomes vary depending on the factual circumstances.

On the other hand, Cheshin's second layer of reasoning assumes that not all values are universally and timelessly true. In a system without a comprehensive bill of rights argues Justice Cheshin - it is important to distinguish between universal rights that should be imported from other constitutional systems and 'specific arrangements that are not universal'. ${ }^{141}$ Because there is no consensus in the world regarding a right of a

\footnotetext{
${ }^{136}$ Ibid (Cheshin) introduction.

${ }_{137}$ Ibid (Cheshin) para 71.

${ }^{138}$ Ibid (Cheshin) para 51.

139 Ibid (Cheshin) para $71 \mathrm{ff}$.

140 Ibid (Cheshin) para 188.

${ }^{14.1}$ Ibid (Cheshin) para 39
} 
citizen to have his foreign spouse immigrate or acquire residency, it follows that this is not a basic natural right. ${ }^{142}$ At that point, local values ought to prevail. ${ }^{143}$ The specific arrangements fall outside of the scope of natural rights, and there is no analogy between foreign and Israeli law. ${ }^{144}$ Cheshin thus adopts the view that within this non-universal margin 'every constitution expresses its own unique hierarchy of social values' and foreign law has little worth. ${ }^{145}$ Justice Cheshin thus has a two-track vision of value: there are universal and 'natural' rights that enjoy the supreme status and find expression in foreign and international law, but when these rights are silent or ambiguous, local and contingent arrangements take precedence.

To conclude, foreign law enters the Israeli constitutional system when it shares common evaluative commitments with the domestic system. It is considered appropriate to the extent that it fits the local identification with liberal-democratic values. This generates qualms regarding the nature of value and the substance of local evaluative commitments. For example, Justice Cheshin thinks that there exist both transcendent and contingent values, and that the latter take precedence when the former are ambiguous. Justice Barak sees values as local and historically embedded, but the outcome of his analysis is more in line with universal trends. They also disagree about the content of Israeli constitutional identity: while Cheshin believes that security threats prevent Israel from enforcing liberal-democratic rights to the fullest, Barak thinks the commitment to human rights is stronger than security concerns. They both however use foreign law to illuminate these differences and tease out intuitions about the moral commitments of Israeli society.

\footnotetext{
${ }^{142}$ Ibid (Cheshin) para 57.

143 'The constitution of the United States is for the people of the United States, the German constitution is for Germans and the Basic Laws in Israel are for Israelis'. Ibid (Cheshin) para 62.

${ }^{144}$ Ibid (Cheshin) para 63.

${ }_{145}$ Ibid (Cheshin) para 63 citing Justice Shamgar from Mizrahi, para 69(b) United Mizrahi Bank Ltd.v Migdal Cooperative Village
} 
3. Morality of foreign law

There is a multitude of different approaches to foreign law in comparative practice. Some of the US Supreme Court judgments rely on a robust conception of universality and reasonableness and include a belief that people who reason about values would eventually converge on moral truths regardless of their cultural background; in other cases, this link is weaker and the court takes convergence into account when there is a common evaluative framework between constitutional systems. In South Africa, the dominant approach is universalistic but not automatic: while there is trust in universally human values, foreign law is reflected upon and rejected when it does not fit local evaluative commitments. In Israel, foreign law is introduced with a reference to domestic constitutional identity; but since this identity is sometimes contested, foreign law also modifies it and reinforces cosmopolitan values. So is there a single understanding of the nature of value in all these cases?

The conception of value behind the use of foreign law always incorporates the elements of reasonableness and universality; however, these elements take different forms. On the one hand, some instances of the use of foreign law assume that foreign law and moral answers bear a direct, robust connection. Call this the deductive view. According to the deductive view, we are able to discern some principles from foreign law, which we can legitimately apply to domestic constitutional cases. The knowledge we gain is external to our system and we have reasons to accept it at face value. We are open to such knowledge because it fulfills certain conditions which give us enough reason to believe that what we learn from it is correct. Foreign law carries normative weight because it is intrinsically connected with moral values. On the other hand, the connection between moral knowledge and foreign law is sometimes more relaxed or indirect, for it only facilitates a reflective state in which we recognize the balance and consequences of our values more easily. Call this the reflective view. In the reflective view, foreign law has no direct claim on us because it carries no immediate link to moral truth. The knowledge acquired by engagement with foreign law is - perhaps counter-intuitively - about ourselves: it may be implicit, latent, or dormant but not alien to us. The reflective view sees the use of foreign law as the perfection of self-understanding, rather than gaining 
knowledge about the external world. In that sense, we do not, strictly speaking, learn moral answers but become aware of them with assistance from foreign law. Both views have difficult questions to answer. For the deductive view, it is the question of the precise relationship between moral values and foreign law. For the reflective view, it is the manner in which foreign law contributes to reflection, the ability of such reflection to provide insights into morally justified courses of action, and - most importantly - the authority of moral reflection that is divorced from the idea of universal moral truth.

Here I want to pursue two lines of argument. First, the distinction between the deductive and reflective view should not be neglected. The empirical reality does not lend itself to clear-cut distinctions, and one can often find traces of both views within a single judgment or opinion. This is detrimental to their credibility: a pure deductive view is either implausible (presupposes peculiar metaphysics) or self-defeating (collapses into the reflective view). Second, even though the reflective view is more plausible, it is in need of elucidation. I shall thus explain several ways in which the reflective view can be motivated. I will conclude however that the reflective view is quite modest in its ambition to reach universal moral knowledge.

\subsection{The deductive view}

The deductive view is, roughly, the proposition that once a principle is discovered in foreign law we have reason to follow it. This reason is a robust connection between foreign law and moral truth. We have seen that this view may take different forms: the courts may believe that true moral values will be reflected in global consensus, in convergence between similar jurisdictions, or in the opinions of a single court. Also, the courts may refer to foreign law because of a mixture of motives: they can both agree with foreign opinion and accord it some weight because of its reputable source. For example, the Israeli Supreme Court may cite the Canadian Supreme Court's understanding of proportionality analysis, both because it finds it convincing and because it respects the Canadian court. Even if the deductive character of the argument 
from universal reason cannot be a matter of degree ${ }^{146}$ - for either one relies on foreign law or reasons behind it - it is often hard to judge what kind of motive was predominant in judicial reasoning.

Although the deductive view might be interwoven with the reflective view in practice, the more we move towards consensus-based arguments the more deductive they are. The consensus carries content-independent normative weight ${ }^{147}$ and presupposes robust universality and reasonableness: it assumes that convergence in reason-based judgments will reflect universally human values. It has thus gained a lot of attention despite its relative infrequency in practice. Ernest Young, for example, argues that the argument from consensus amounts to 'counting noses', ${ }^{148}$ and believes that in such cases the court does not get 'persuaded by new rationales' because it is 'deferring to numbers, not reasons'. ${ }^{149}$

While most judges would deny that they defer to foreign law in this way, ${ }^{150}$ consensusbased arguments have normative pull in practice. The deductive consensus-based view should thus either be rejected or accounted for by demonstrating the connection of consensus with moral truth. In an attempt to account for this connection, one must assume a robust universality and reasonableness of value. The assumption that supports this model is that if enough people reasoned about a moral problem they would converge on a universal moral truth, irrespectively of their contingent moral outlooks or cultural differences. Let us look at some of the arguments that presuppose this.

\footnotetext{
${ }^{146}$ See the discussion on the authority of foreign law later on.

${ }^{147}$ See more on this issue in Frederick Schauer, 'Authority and Authorities' (2008) 94 Virginia Law Review 1931. The deductive view is not exclusively tied to the use of foreign consensus, but it is the prototypical example of such position. Vicki Jackson calls it 'the convergence model', but the deductive model is about the mode of reasoning and not necessarily about consensus. See Vicki C. Jackson, 'Constitutional Comparisons: Convergence, Resistance, Engagement' 119 Harvard Law Review 109, $123-124$.

${ }^{148}$ Ernest A. Young, 'Foreign Law and the Denominator Problem' 119 Harvard Law Review 148, 150151.

149 Ibid 155.

150 Ackermann 277; Barak, The Judge in a Democracy 199; Breyer; Ruth Bader Ginsburg, "A Decent Respect to the Opinions of [Human]Kind": The Value of a Comparative Perspective in Constitutional Adjudication’ 2005 Cambridge Law Journal 575, 580.
} 
Cass Sunstein justifies the consensus-based use of foreign law with the assumption that 'each nation is more likely than not to make the right decision'. ${ }^{151}$ The goal is to gather 'more information about what is right and what is true', ${ }^{152}$ so the use of foreign law occurs 'not out of deference to the authority of foreigners, but out of sense that they might be correct'. ${ }^{153}$ Sunstein believes that consensus can serve as a proxy for adequate moral epistemology: '[i]f we are not skeptics, and if we believe that moral questions do have right answers, then it makes sense to consult the majority's view.' ${ }^{154}$ His main point is this: more people engaged in moral reasoning under favorable conditions have better chances of reaching a morally correct result than fewer people under less beneficial circumstances.

This view presupposes a two-tier process of deductive infusion of foreign law into domestic constitutional reasoning. First, there are epistemic conditions that must be met by foreign law in order to be considered relevant. Second, if these epistemic conditions are fulfilled we have reason to accept foreign law, for it reveals true values. A crucial epistemic prerequisite is that moral answers are devoid of cultural contingency. For Sunstein, when moral issues are at stake, it is necessary to reject any strong form of cultural relativism, according to which the appropriate moral rules are culturedependent, so that the moral requirements that are suitable for one culture need not be suitable for another culture'. ${ }^{155}$ The existence of consensus is a signal that these particularistic experiences have been overcome. Sunstein's model thus relies on unrestricted trust in universality and reasonableness as the elements of value:

As long as those [foreign] nations allow free and open debate, the very fact that different societies have come to the same conclusion increases one's confidence

\footnotetext{
${ }^{151}$ Cass R. Sunstein, A Constitution of Many Minds: Why the Founding Document Doesn't Mean What It Meant Before (Princeton University Press 2009) 190.

152 Ibid $189-190$.

153 Ibid 190.

154 Ibid 191.

${ }^{155}$ Ibid 195-196. This view confuses agent and appraiser relativism (see discussion in previous chapter).
} 
that the norms are genuinely universal and transcend merely historical or institutional differences. ${ }^{156}$

But what reason do we have to believe that consensus corresponds to objective moral truths? Not only must Sunstein presuppose a robust moral realism according to which there are moral facts to be discovered in the world, he must also assume that contingent moral attitudes cannot ultimately impede the discovery of true moral facts. Sunstein does not find this problematic. For him, there is an analogy between the authority of foreign law and scientific authority: consulting foreign law is like consulting foreign doctors. ${ }^{157}$ But this analogy shows how controversial the thesis actually is. The thesis presupposes that moral judgment is world-guided much like scientific discovery. It assumes that moral consensus (a causal occurrence in the world) yields moral truth (a normative concept): it thus needs to demonstrate how universal moral truths causally affect culturally embedded moral attitudes.

Jeremy Waldron is an exponent of a similar position. In his view, '[foreign] consensus is binding upon us as a sort of law'. ${ }^{158}$ Waldron also advances a two-tier model of the deductive introduction of foreign law into the domestic legal systems: '(1) the discernment of a global consensus on various issues; (2) the identification of a body of principles arising out of that consensus; and (3) the establishment of one or more of those principles as part of the law of a particular state by its drawing down on (2)'. ${ }^{159}$ The relationship between these principles and morality is ambiguous. On the one hand, Waldron rejects the idea that they are an emanation of natural law, ${ }^{160}$ concedes to be 'not even sure how the connection between natural law and the citation of foreign law is

\footnotetext{
${ }^{156}$ Ibid 197. In the Habermasian tradition, Sunstein believes that the value will appear in the process of deliberation and discourse among free and equal individuals. Ibid 170. See Jürgen Habermas, Moral Consciousness and Communicative Action (MIT Press 1990) Habermas, Between Facts and Norms: Contributions to a Discourse Theory of Law and Democracy.

${ }^{157}$ Sunstein, A Constitution of Many Minds: Why the Founding Document Doesn't Mean What It Meant Before 190.

158 Waldron, "Partly Laws Common to All Mankind" Foreign Law in American Courts 48-49.

${ }^{159}$ Ibid 73.

${ }^{160}$ Ibid ch 2 sections 5 and 6.
} 
supposed to work', ${ }^{161}$ and thinks that 'correspondence between the out there of the wider world of foreign legal systems and the out there of moral objectivity' ${ }^{162}$ is dubious. On the other hand, he sees these principles as a mixture of law and morality. For example, he argues that 'discernment of a principle in a given body of law is not possible without the exercise of moral judgement', ${ }^{163}$ that principles present 'the accumulated wisdom of the world on rights and justice' ${ }^{164}$ and that they are a product of 'legal sensibility that is both lawyerly and moralized'. ${ }^{165}$ Notwithstanding Waldron's hesitation to commit to a position regarding the status of foreign legal consensus vis-àvis morality, the backbone of his explanation of the normativity of consensus is the following claim: '[o]ne might expect that the obviousness of certain moral principles [...] would be reflected in their ubiquitous adoption as laws in the world'. ${ }^{166}$ Consensus is therefore a causal consequence of the perception of moral truth. Waldron thus makes exactly the same metaethical assumption as Sunstein.

Waldron also invokes the scientific analogy. He trusts that there is:

a body of legal science that stands independently of any particular court $[\ldots]$ and represents the accumulated wisdom of the law on certain recurrent problems, in much the way that science reflects the accumulated results of experiments in hundreds of different laboratories checking out and building upon each other's work. ${ }^{167}$

Notice that the analogy presupposes that moral and scientific knowledge ('wisdom') are analogous, and that - consequently - moral and scientific truths must be similar. Generally, an analogy first establishes a non-controversial claim about properties A and $\mathrm{B}$ of an object X; then it shows how object $\mathrm{Y}$ also has property A; it then argues that $\mathrm{Y}$ also might have property B. Hence Waldron must demonstrate that: (i) we have reasons

\footnotetext{
${ }^{161}$ Ibid 41.

162 Ibid.

${ }^{163}$ Ibid 64.

${ }^{164}$ Ibid 42.

${ }^{165}$ Ibid 36.

166 Ibid 37.

${ }^{167}$ Ibid 77.
} 
to believe that the consensus in the scientific community is true; (ii) science and law/morality are similar in relevant respects; (iii) because of these relevant similarities we can conclude that consensus in law/morality is true.

While (i) is uncontroversial but defeasible, it is not clear which are the properties that sciences and law/morality share (ii), nor - even if there are such shared properties how we can infer from them that legal/moral consensus in the world is true (iii). To be persuasive, an analogy needs to show that the common property is directly relevant for the existence of the inferred property, or that the number of shared properties is high. Waldron fails to demonstrate this. He writes:

Scientific consensus is available as a resource and as a prescriptive starting point for individual scientific endeavor. Similarly, [foreign law] is available to lawmakers and judges in every country as an established body of legal insight, reminding them that their particular problem has been confronted before and that they, like scientists, should try to think it through in the company of those who have already had to deal with it. ${ }^{168}$

We shall see later on why this could be sensible advice, but as an analogy it rests on a mistaken premise and cannot support the deductive view. Waldron argues that the problems confronted by lawyers are the same, just like the problems scientists face are the same. It seems plausible that questions with a strong ethical component are similar: as Justice Breyer explains, these are common 'human problems'. But the similarity of questions guarantees nothing in terms of the truth of answers. The crucial difference is that science answers theoretical questions (what we have reason to believe) while law and ethics answer practical questions (what we have reason to do). It does not follow from the fact that humans ask themselves similar practical questions that there will be convergence on correct answers. It does not even guarantee that there are correct answers.

${ }^{168}$ Ibid 101. 
The second element of the analogy is the supposition that there is a common approach to legal problems, which Waldron describes as the 'way of analyzing and unpacking issues that lawyers learn from and that they can recognize in one another $[\ldots]$ even when they come from different countries'. ${ }^{169}$ Again, this is true: there are similarities between the ways in which lawyers approach legal questions. But these methods can render different results depending on the substantive legal provisions. More importantly, nothing depends on the fact that legal methods are similar to legal methods and that scientific methods are similar to scientific methods: the relevant question is whether legal methods are similar to scientific methods. There are no such similarities. The truth of a scientific proposition is demonstrated by an application of a methodology that has been successful in discovering what the world is like, whereas the truth of legal propositions is demonstrated by using contingent legal materials. There are space- and time-independent truths about the world, but there are no such legal facts.

Is the case different with morality? The scientific analogy is in fact after a worthier prize: a similarity between scientific and moral truths. In Waldron's view, 'legal analysis aims at a just solution' ${ }^{170}$ and 'modes of specifically legal analysis ... relate the elements of a problem to the basic reasons of justice'. ${ }^{171}$ This is why 'scientific analogy is dependent upon ... a view of law as, in large measure, a matter of reason, not a matter of will'. ${ }^{172}$ Thus Waldron's faith in legal consensus stems from his belief that legal analysis aspires towards moral truths. Let us for the sake of argument grant this assumption. The question is then: can we expect the convergence on moral truth, even if people engaged in moral reasoning directly? ${ }^{173}$ Both Sunstein and Waldron correctly recognize that the role of foreign law is epistemic. Foreign law is not a source of moral truth, but the courts use it to gain knowledge about moral truth. Such moral epistemology must reflect a plausible ontology of value. The scientific analogy reveals a

\footnotetext{
169 Ibid 96.

170 Ibid 106.

${ }^{171}$ Ibid 99.

172 Ibid 108.

${ }^{173}$ See generally on deductive moral reasoning Gilbert Harman, Kelby Mason and Walter SinnottArmstrong, 'Moral Reasoning' in John M. Doris and Moral Psychology Research Group (eds), The Moral Psychology Handbook (Oxford University Press 2010).
} 
background assumption of the consensus-based deductive view that moral facts exist in reality and can be traced by reasoning, which is supposed to be analogous to the scientific method; however, there is certainly no such moral truth that can acquire authority without implicating our reflection. If there is a fact of the matter of what is morally correct, that fact must be quite different from the facts sciences try to discover. This is why the deductive view at best boils down to the reflective one and at worst completely fails. Let me explain.

Someone holding the deductive view needs to argue that values are a part of the fabric of the universe. The most famous attempt to do so is Plato's: to explain the existence of values in the world we must presuppose values as non-spatial and non-temporal ideal forms. ${ }^{174}$ Moral values are on this model independent of our minds, responses, or experiences. The proponents of the deductive view are accused of presupposing such an odd metaphysics. Justice Scalia, for instance, writes:

One who believes it falls to the courts to update the list of rights guaranteed by the Constitution tends to be one who believes in a Platonic right and wrong in these matters, which wise judges are able to discern when people at large cannot [...] Platonic living constitutionalist must surely consider the views of all intelligent segments of mankind. ${ }^{175}$

This is a serious objection. The belief that values exist in the same way as other entities presupposed by scientific explanation is hard to square with the scientific worldview, which - needless to say - is the view which most people accept in their daily lives. It is of course not always clear what exactly the entities presupposed by scientific explanation are, and one could choose to reject the scientific worldview regardless of its

${ }^{174}$ See Mark Balaguer, 'Platonism in Metaphysics' in Edward N. Zalta (ed), The Stanford Encyclopedia of Philosophy (Spring 2014 Edition) <http://plato.stanford.edu/archives/spr2014/entries/platonism/> .

${ }^{175}$ Scalia 308. Note that Scalia is not consistent in rejecting Platonic living constitutionalism. For example, in Thompson he wrote: 'The practices of other nations, particularly other democracies, can be relevant to determining whether a practice uniform among our people is not merely a historical accident...' (Thompson v Oklahoma (Scalia) $868 \mathrm{n} \mathrm{4}$ ). If there is no Platonic right and wrong, then all practices are just historical accidents. See next chapter. 
undeniable success in delivering results. But the important point is that the deductive view assumes something more controversial: that values are a part of - as Bernard Williams puts it - 'the world that is there anyway' ${ }^{176}$ and must fit the conception of the world that 'might be arrived at by any investigator'. ${ }^{177}$ Why would consensus count in the deductive view if not as a consequence of grasping the realm of values, or arriving at something that is waiting to be discovered?

It is meaningful to say that convergence in science is explained - at least partially - by its ability to track this conception of the world. ${ }^{178}$ But it is doubtful that moral facts are also a part of the world as it is, and it is unclear how these facts would interact with our contingent moral attitudes. For all we know, convergence in the sciences and convergence in ethics are to be explained differently, regardless of whether such convergence actually obtains. ${ }^{179}$ The best explanation of scientific convergence needs to suppose that it will track the world-as-it-is, while ethical convergence may well be explained by the shared circumstances of human life and our contingent psychological setup. So even if there is a consensus on the death penalty, slavery or torture, the best explanation of that fact is not that it tracks the truth of the matter, but that new sensibilities and institutions have developed under contemporary social circumstances.

The assumption that moral reasoning traces the property of wrongness in the world implies a conception of moral truth that presupposes correspondence between value as the feature of the world (truth-maker) and moral belief (truth-bearer). As Mackie points out, for this to be plausible we must populate the universe with entities whose existence we cannot get grips on. The problem is two-fold: metaphysically, the view implies the

\footnotetext{
${ }^{176}$ Williams, Ethics and the Limits of Philosophy 138.

177 Ibid 139.

${ }^{178}$ Although this is controversial, it is safe to assume it here, for if this is not true for science, then it is certainly not true for moral discourse. For the skeptical view in both domains see Richard Rorty, Philosophy and the Mirror of Nature (Princeton University Press 1979). I discuss these issues at length in the next chapter.

${ }^{179}$ As Bernard Williams explains: 'It might well turn out that there will be convergence in ethical outlook, at least among human beings. The point of the contrast is that, even if this happens, it will not be correct to think it has come about because convergence has been guided by how things actually are, whereas convergence in the sciences might be explained in that way if it does happen.' Williams, Ethics and the Limits of Philosophy 136.
} 
existence of facts which are different from anything else in the world, and epistemologically, to detect these facts we would have to have a faculty different from all the other senses we have. ${ }^{180}$ We can neither experience such facts, nor interact with them; yet they seem to be action-guiding in some way and have a causal effects on our moral attitudes. The deductive model assumes precisely that: in Waldron's opinion, the 'obviousness' of moral norms will be reflected in global legal consensus. ${ }^{181}$ But neither is moral value 'obvious', nor do we have an account of moral perception that would account for this 'obviousness'.

One way to explain the 'obviousness' of moral value is to point to the similar role observations play in moral and scientific theory. This is because in both domains - as Harman argues - there are no 'pure' or pre-theoretical observations:

[...] in both science and ethics, general principles are invoked to explain particular cases and, therefore, in both science and ethics, the general principles you accept can be tested by appealing to particular judgments that certain things are right or wrong, just or unjust, and so forth; and these judgments are analogous to direct perceptual judgments about facts. ${ }^{182}$

This seems to warrant the conclusion that perception in morality and science are the same, but Harman rightly urges us to resist this conclusion. ${ }^{183}$ His argument is simple: to support a moral theory that fits our moral observation, we need not presuppose anything about the world 'as it is anyways'. Harman says:

all we need to assume is that you have certain more or less well articulated moral principles that are reflected in the judgments you make, based on your moral

\footnotetext{
180 Mackie ch 1.

181 Waldron, "Partly Laws Common to All Mankind" Foreign Law in American Courts 37.

182 Gilbert Harman, The Nature of Morality: An Introduction to Ethics (Oxford University Press 1977) 5-6.

${ }^{183}$ Ibid $6-10$
} 
sensibility. [...] there does not seem to be any way in which the actual rightness or wrongness of a given situation can have any effect on your perceptual apparatus. ${ }^{184}$

The best explanation of the fact that we make such-and-such moral judgment need not assume any other properties of causal occurrence in the world. In Harman's famous example, the observation that it is wrong for children to set a cat on fire need not presuppose any additional physical properties of the cat being set on fire by children. The observation can be explained by natural facts and psychological sensibility alone. In contrast, for an observation to figure in the best explanation of a scientific theory, we need to presuppose that it does indeed track something in the world. The observation that a siren on a police car sounds higher when the car is approaching than when it is receding from the observer confirms the theory of the Doppler effect about the change in the frequency of a wave relative to the moving source of frequency: for this observation to support the scientific theory, however, we must suppose that it actually discovers the frequency-change in the world. If Harman is right, for the deductive view to hold, there must be something in the world that affects our making of converging moral observations. Harman thinks that this can either be a mind-independent, in-theworld value, or a value that is a consequence of our psychological dispositions and learned behavior. Since the former is implausible, it must be the latter. And if it is the latter, then consensus cannot claim to represent the universal mind-independent moral truth.

There are two ways to resist Harman's conclusion. They both problematize his understanding of the inference to best explanation. The first accepts the relevance of scientific explanations for determining the fabric of the universe, but argues that they do not exclude moral facts. The basic idea is that Harman's argument proves nothing unless one is already convinced by his anti-realism. Sturgeon for example argues that moral judgments supervene on non-moral facts in a sense that normative observations ought to be the same for each cat-set-on-fire situation in reality. So if we presume the truth of a background moral theory that makes us perceive the wrongness of setting a

\footnotetext{
${ }^{184}$ Ibid $7-8$.
} 
cat on fire, then our perception is explained by that true moral theory, just as in the case of science the truth of the observation depends on the truth of the background theory. If we suppose that there are mind-independent moral truths alongside scientific truths, then seeing slavery or setting cats on fire as wrong might well be a consequence of the wrongness of the act. ${ }^{185}$

But if scientific explanations are ontologically determinative, the question is whether the best scientific explanations of moral judgments depend on non-moral natural facts and our contingent moral sensibilities only, or also include true moral facts, which supervene on/are identical to natural facts. ${ }^{186}$ Scientific explanations do regularly use concepts that denote groupings of natural facts that cannot be reduced to these facts without losing the explanatory potential; for example, we do not deny the existence of biological or psychological facts, even if they can be reduced to physical or chemical facts. But are true moral facts useful or indispensable in the same sense? The short answer is that there is nothing that is being explained better if we suppose the truth of the background moral theory, as opposed to assuming only a set of contingent moral attitudes together with natural facts.

Let us take the example of the death penalty. There is a growing consensus about its inappropriateness. If the consensus is explained by the immorality of the death penalty, then the deductive view has some purchase. But presupposing the truth of its moral inappropriateness does not add anything to the explanation of its abolition. We need only suppose that our moral attitudes have changed, regardless of their truth. On the one hand, the death penalty has been used ever since there were organized societies. The same is true of many other practices that we find appalling, such as slavery or gender inequality. It is reasonable to suppose that an explanation - e.g. that the moral wrongness of the death penalty will lead to its abolition - will have some predictive value; if it is unable to explain why the perception of moral wrongness of the death

\footnotetext{
${ }^{185}$ See Nicholas L Sturgeon, 'Moral Explanations' in Geoffrey Sayre-McCord (ed), Essays on Moral Realism (Cornell University Press 1988).

${ }^{186}$ For this variant of naturalist realism see: ibid; Richard N Boyd, 'How to Be a Moral Realist' in Geoffrey Sayre-McCord (ed), Essays on Moral Realism (Cornell University Press 1988); David O Brink, Moral Realism and the Foundations of Ethics (Cambridge University Press 1989).
} 
penalty has not led to any change for millennia, then it is probably an ex post facto rationalization and not an explanation. On the other hand, it is doubtful that moral truth plays any role in actual social scientific explanations. This is because the abolition or survival of the death penalty, slavery and the like is much better explained by social, economic, and cultural variables than the perception of moral truth. ${ }^{187}$ This is not to say that contingent moral attitudes are not accounted for in social processes, but that they themselves have social and psychological causes which explain them better than the convergence towards moral truth. ${ }^{188}$

The second objection is that Harman's understanding of what constitutes the best explanation is too restrictive in another sense. It focuses only on the model of the inference to the best causal explanation. This distinction brings the problem to the fore: 'Certain moral principles might help to explain why it was wrong of the children to set the cat on fire, but moral principles seem to be of no help in explaining your thinking that that is wrong.' ${ }^{189}$ In the first case, we make a normative and in the second a causal judgment. The role of moral principles is different from the laws of physics: they help us make normative, not causal inferences. The idea here is that the normative domain enjoys autonomy from the causal world, but that it is real nonetheless. Moral observations are not causal explanations of the world 'out there', and moral facts are not natural facts. Even the argument about the truth of moral facts is a moral argument independent from the realm in which causal explanations count. ${ }^{190}$

For the purposes of this chapter it is enough to show the incompatibility of this position with the deductive view. I will thus proceed in two steps. First, let us grant that this conception of ethics is cogent in a sense that it could at least qualify as apt to avoid the pitfalls of robust realism. It makes the claim of the mind-independent objectivity of

\footnotetext{
${ }^{187}$ For example, in a much praised sociological study on the death penalty in the US, David Garland never mentions moral truth as playing any role in his explanation. Garland.

${ }^{188}$ For a critique of naturalist realism along these lines see Brian Leiter, 'Moral Facts and Best Explanations' (2001) 18 Social Philosophy \& Policy 79. See also the next chapter in which these issues are discussed at greater length.

${ }^{189}$ Harman 8.

190 See for example Ronald Dworkin, 'Objectivity and Truth: You'd Better Believe It' (1996) 25 Philosophy \& Public Affairs 87
} 
value intelligible, even if not necessarily true. ${ }^{191}$ So I shall assume that this conception could in principle support the deductive view. Second, we then need to see if such a conception of ethics - which is a candidate to account for the universality of objective normative reason and does not rely on false metaphysics - hangs well together with the assumptions implicit in the deductive view. If convergence around moral facts with causal force is an implausible explanation of the convergence of normative responses in foreign law, proponents of the deductive view may still argue that each moral reasoner under idealized conditions would reach moral truth starting from normative premises within his evaluative outlook.

Indeed, the stronghold of realism against this skeptical challenge has been to resort to our internal possibility of transcendence of experiences through reflection and reason. If skeptics push hard against moral truth being a matter of correspondence between our responses and moral facts in the world, realists respond that we need not populate the world with spooky stuff to account for the objectivity of moral talk. ${ }^{192}$ Kantians, for example, think that the truth of moral propositions is not a matter of their correspondence with something in the world, but a matter of our ability to construct moral laws. The idea is that, in the same way that we can grasp mathematical and logical laws through our capacity to reason theoretically, we can proceed by reflection to impose on ourselves the laws of practical reason. Christine Korsgaard puts forward such an account that attempts to avoid the pitfalls of Platonism. She thinks that what makes us human is the ability to be guided by reason: to reflect upon our motives - 'call them into view' - and decide what to do. Normativity arises not from the causal force that some moral facts exert on us, standing outside of our psychological apparatus, but

${ }^{191}$ Bernard Williams, Making Sense of Humanity (Cambridge University Press 1995) 174-175.

192 A simplistic recapitulation of Kant's argument is: we have free will, but such free will is at the same time unrestricted (because it is free), and subject to causality (as it exerts itself in the causal world); as a something that gives rise to causal occurrences in the world, it must be subject to some laws as all causal occurrences are, but because it is free this presents a problem. How can it be subject to laws and be free at the same time? The only solution is that it is subject to laws that the free will imposes on itself. Kant sees a solution to this conceptual problem in several tests that such laws must pass in order not to be contradictory. The argument may be inadequate in an age where these kinds of conceptual necessities are distrusted. As Larmore puts it, 'Kant's intuition needs to be brought down to earth'. Charles Larmore, 'Reflection and Morality' (2010) 27 Social Philosophy and Policy 1, 2. I shall hence focus on modern Kantians - such as Nagel and Korsgaard - who adjusted Kantian ethics to contemporary philosophical circumstances. 
from our ability to reflect. ${ }^{193}$ Her argument is this: we decide what we value through the process of reflective endorsement; if we wish to value anything at all, we must also value the ability that makes valuing possible; this ability is the intrinsically human capability of reflective endorsement; therefore, we must value humanity. ${ }^{194}$

There is much to be said about this and similar arguments, not least because they involve a debatable inference from valuing our own ability of reflection to valuing such an ability in others, or even valuing others because of such an ability. But if they have any plausibility at all, we must question the soundness of the deductive view. This is so for two closely connected reasons. First, if our ability to reflect is at the foundation of ethics, then giving up on it makes little sense. Can we ever give up on our epistemic authority in morals, if moral laws are a consequence of an ability that we all share as humans? This ability is tied to the conception of a mind capable of reflection, so the very idea that we should give in to moral authority without reflection is incoherent. To the extent that the ontology of value depends on the uniquely human capacity to reflect, moral epistemology must also be appropriated to enable us to reach moral answers on our own. The idea is well captured by Hilary Putnam:

If something is a good solution to a problematical human situation, then part of the very notion of its being a good solution is that human beings can recognize that it is. We need not entertain the idea that something could be a good solution although human beings are in principle unable to recognize that it is. That sort of rampant Platonism is incoherent. ${ }^{195}$

\footnotetext{
${ }^{193}$ Korsgaard argues: ' $[\mathrm{O}]$ ur capacity to turn our attention on to our own mental activities is also a capacity to distance ourselves from them, and to call them into question ... The reflective mind cannot settle for perception and desire, not just as such. It needs a reason. Otherwise, at least as long as it reflects, it cannot commit itself or go forward.' Christine M Korsgaard, The Sources of Normativity (Cambridge University Press 1996) 93.

${ }^{194}$ Ibid ch 3.

${ }^{195}$ Hilary Putnam, The Collapse of the Fact/Value Dichotomy and Other Essays (Harvard University Press 2002) 108-109. As I have argued in chapter 2, any account of ethics that is not close to the ways we are as humans - or more robustly as humans here and now - is implausible. The account of ethics that I will offer in the next chapter gives up on the mind-independent universal truths in ethics that would be comparable with scientific truths. The picture is rather different: we move within the web of ethical attitudes, feelings, judgments and principles that evolve and develop. We give up on certain beliefs and acquire new ones as we face practical problems, guided both by our moral emotions and our ability to
} 
To be sure, neither Sunstein nor Waldron are 'rampant Platonists' and they certainly do appreciate the role of foreign law in facilitating moral reflection. ${ }^{196}$ They might still argue that convergence among moral reasoners may give us reasons to question our moral views. We might - for example - be interested in other people's moral opinions if they spend more time and resources on reflection. ${ }^{197}$ But this is fundamentally different from arguing that foreign consensus has a claim over our actions just because it says so, or that it has more than a suggestive value to our own moral judgment. If the consensus ought to figure in moral reflection it should then probably form a part of reflection and not preclude it: in other words, it should be the beginning and not the end of reflection. While the reflective view then needs to account for the proper weight of consensus, this certainly renders the deductive view inadequate.

The second reason to retain a critical and reflective stance towards 'truths' expressed in consensus concerns the autonomy of ethics as an evaluative domain. Recall that the proponents of the claim that consensus points to moral truth must show that people who reason about their moral commitments will actually converge on moral truth. This presupposes an empirical thesis about our ability to transcend inherited and culturally embedded moral values through reflection. But if causal and normative domains are separate, then this empirical thesis - to the extent that it has normative consequences must be further evaluated on moral grounds. If Harman is wrong to confuse the causal and normative explanations, empirical claims cannot simply be taken for granted if they

reflect. This reasoning is not of the deductive kind, but starts from our evaluative standpoint, not from an evaluative point as such. To borrow Putnam's metaphor again: 'My image [of ethics] would be a table with many legs. We all know that a table with many legs wobbles when the floor on which it stands is not even, but such a table is very hard to turn over, and that is how I see ethics: as a table with many legs, which wobbles a lot, but is very hard to turn over.' Hilary Putnam, Ethics without Ontology (Harvard University Press 2004) 43.

${ }^{196}$ For example, this is a mistake in Youngjae Lee, 'International Consensus as Persuasive Authority in the Eighth Amendment' (2007) 156 University of Pennsylvania Law Review 63. Lee correctly notices that the use of foreign law depends on the background theory about the nature of value. He is skeptical towards the connection between the contingent moral attitudes and universal moral truths, but does not deny the existence of universal moral truths as such (for example, that slavery is wrong). However - if there were such truths - then it would be implausible to think they are beyond our reach and that they would not be reflected in the consensus. Moreover, Lee places high hopes in the existence of reasons behind moral judgments that would help us reach true answers, but it is not clear why this method will be universally normatively valid or relevant if this property is denied to the truths reflected in the consensus. ${ }_{197}$ Peter Singer, 'Moral Experts' (1972) 32 Analysis 115. 
lead to unacceptable moral results. For if we cannot escape the maze of evaluative concerns in reaching moral judgments, we must reserve the right to make a moral call on this issue as well.

Thomas Nagel, for example, argues that 'the only way to answer moral skepticism is to meet it with first-order moral arguments' ${ }^{198}$ precisely because the realm of the normative is autonomous in a sense that ' $[\mathrm{w}] \mathrm{e}$ have to have or develop some internal [normative] understanding of the possibility that a belief might be false before any suppositions external to it can bring us to abandon it'.199 By the same token, the confirmation of the existence of moral truth must also begin with some already existing moral belief and not simply from the fact of convergence in foreign attitudes. This thought is best explained with an example. Consider Justice Daniel's consensus-based deductive view from Dread Scott v Sandford:

...the following are truths which a knowledge of the history of the world $[\ldots]$ compels us to know - that the African negro race never have been acknowledged as belonging to the family of nations; that as amongst them there never has been known or recognized by the inhabitants of other countries anything partaking of the character of nationality, or civil or political polity; that this race has been by all the nations of Europe regarded as subjects of capture or purchase; as subjects of commerce or traffic; and that the introduction of that race into every section of this country was not as members of civil or political society, but as slaves, as property in the strictest sense of the term. ${ }^{200}$

Even though Justice Daniel thought he had found 'truth and knowledge' in global consensus, no one would today argue that 'obviousness' of moral principles had been reflected in these laws and traditions. Nor would anyone think that he discovered 'wisdom' in foreign law that is comparable to scientific knowledge. Unless one can come up with an account that would with sufficient precision indicate a point in time where

198 Thomas Nagel, The Last Word (Oxford University Press 1997) vii.

199 Ibid 58.

${ }^{200}$ Dred Scott (Daniel) 475. 
the world has reached moral truth, the answer to this type of argument must be normative: treating people unfavorably because of their race collides with our deepest normative commitments. The big question is - on the assumption that our contingent attitudes are inherently connected to moral truth - how can these historical attitudes be so much off track according to today's standards? Examples like this surely make the conception of a moral truth discernable through reason much less intelligible: they show that we can miserably fail to attain it even upon reflection and reasoning. Moreover, if there is a variety of moral positions that we may happen to occupy at any given time, then why is our position here and now the relevant one to start the reflection with? I will address these issues in the next chapter. Now let us see if the reflective view is a plausible alternative.

\subsection{The reflective view}

The reflective view holds that there is no immediate connection between foreign law and moral truth, but there is a connection between looking at foreign law and becoming aware of appropriate moral answers. The plausibility of the reflective view also depends on its vision of the nature of value. Two questions are relevant. First, is the reflection entailed by the use of foreign law capable of reaching objective and universal moral truths, or always depends on contingent moral attitudes implied by constitutional identity and prevailing moral sentiments? Second - if it is not capable of reaching universal moral truths and depends on contingent attitudes - we need to ask: why are these attitudes normative and why ought they be a subject of reflection? In other words, if the reflective view is to be contiguous with the argument from common sentiment and constitutional identity, we have to close the gap between the 'is' of contingent attitudes and moral 'ought', and understand where the authority of reflection comes from.

The reflective view is the preferred position in both comparative practice and academic commentary. As we have seen, it is the implicit theory behind the use of foreign law in South Africa and Israel. Moreover, most proponents of the use of foreign law favor the reflective view. Vicki Jackson believes that 'ethical engagement' with foreign law may 
help 'a judge to distance herself from her own first reactions, testing them for prejudice and subjecting them to reasoned interrogation', thus offering 'the hope of more impartiality'. ${ }^{201}$ Vlad Perju argues that the use of foreign law can increase the responsiveness and overcome the biases of a legal system. ${ }^{202}$ The idea behind these and similar accounts is well captured by Rosalind Dixon's metaphor of a 'constitutional mirror': foreign law facilitates detachment from the parochial constitutional experience and enables courts to observe it from distance in a more neutral and unbiased way. ${ }^{203}$

The question is whether such a mirror only makes this local constitutional experience more visible, or if it points to something more objective, universal or truth-like. The ambition of the reflective view in this regard is unclear. For example - much like Justice Cheshin in Adalah - Vicki Jackson talks about the 'supra-positive' and 'universal' dimensions of constitutional rights, ${ }^{204}$ but at the same time places weight on particular values and traditions of the constitutional system. How are these 'supra-positive', universal or transcendental elements of constitutional values supposed to be combined with their contingent and historically embedded elements into a coherent ontology of value? We have seen that the idea that foreign law gives an unbiased and universalistic perspective on local moral commitments is present in practice; for instance, it appears in Justice Barak's notion of 'objective' purpose or Justice Ackermann's idea of the 'universal normative core' of a constitution. Notwithstanding the rhetoric, we have also seen that the reach of reflection conducted with the assistance of foreign law is limited, and ultimately echoes local moral commitments. To the extent that the existence of universal and objective normative reasons cognizable through reflection is the only theory that supports the reflective view, this view may well be under-motivated.

The process of detachment facilitated by foreign law does share some common features with the typical understanding of the moral point of view, which asks us to take an

\footnotetext{
${ }^{201}$ Jackson 118-119, footnotes omitted.

${ }^{202}$ Vlad Perju, 'Cosmopolitanism and Constitutional Self-government' (2010) 8 International Journal of Constitutional Law 326.

${ }^{203}$ Dixon 959-960.

204 Jackson 18.
} 
impartial perspective and transcend personal judgments or interests. ${ }^{205}$ The connection between the idea of detachment and the moral point of view appears on many levels. It resonates, for example, with what is taken to be the first moral principle - the so called 'golden rule' - which demands that we treat others in the same way we would like them to treat us. This principle implies that the moral point of view is a standpoint from which our pleasure or pain are equivalent to other people's pleasure or pain. ${ }^{206} \mathrm{On}$ a more general level, the idea is that we cannot see what is morally good if we do not detach from our own perspective. We must somehow dissolve the distinction between the self and the other, and - as Sidgwick puts it - accepts that 'the good of any one individual is of no more importance, from the point of view ... of the Universe, than the good of any other'. ${ }^{207}$ But can foreign law recreate the 'point of view of the universe'?

Thomas Nagel's account of impartial reflection is an apt example of this understanding of the moral point of view. He proposes the following method for reaching objectivity in value judgments: 'begin with the reasons that appear to obtain from my own point of view and those of other individuals; and ask what the best perspectiveless account of those reasons is'. ${ }^{208}$ The thought is the following. Humans are able to occupy an objective perspective ('a view from nowhere') and look at the normative reasons people have. Because we can abstract from our personal and self-interested standpoint, we are able to see the badness of pain not as a consequence of anyone's particular experience, but as an implication of the pain itself being a bad thing in the world. The objective self so construed sees the reason to avoid pain as agent-neutral, and not just bad given what

\footnotetext{
205 This is not only Kant's view. Both Hume and Adam Smith rely on the idea that the moral feeling of sympathy requires us to take the position of a 'judicious' or impartial spectator that can feel other people's experiences as her own. See Adam Smith, The Theory of Moral Sentiments (Knud Haakonssen ed, Cambridge University Press 2002) Marcia Homiak, 'Moral Character' in Edward N. Zalta (ed), The Stanford Encyclopedia of Philosophy (Spring $2011 \quad$ Edition) <\%3Chttp://plato.stanford.edu/archives/spr2011/entries/moral-character/\%3E > .

${ }^{206}$ For example, Rawls' methodology of arriving at the conception of justice includes the 'original position' in which we are asked to imagine ourselves behind the 'veil of ignorance' which prevents us from knowing our personal, social and historical circumstances. In such a way, we should reach a truly moral unbiased and impartial - perspective. Rawls.

${ }^{207}$ Sidgwick 382. Sidgwick actually thought that the golden rule and point of view of the universe are two separate principles of ethics. For an excellent critique of the point of view of the universe, see Williams, Making Sense of Humanity ch 13.

${ }^{208}$ Nagel, The View from Nowhere 141.
} 
an agent's desires and goals are. So the objective self is asked to think 'from no particular point of view about how to regard a world which contains points of view'. ${ }^{209}$ There are three important moves here: first, an objective conception of the world must be broad enough to include and make sense of intrinsically individual experiences such as our subjective pain and pleasure; second, if this is so, we need not presuppose any strange entities to make sense of value judgments, as they do figure in the nonmysterious individual experiences and, by implication, in the objective conception of the world; third, by taking an objective standpoint and looking at these agent-relative value judgments, we are able to see that they are actually agent-neutral because we see that pain is bad in general, and not just that my pain is bad. ${ }^{210}$

These and similar accounts are in the neighborhood of the idea of using foreign law to overcome the contingencies of the specific constitutional system which make our value judgments perspectival. We can imagine a court being such a self that reflects on the existing set of values in the constitutional system, by taking into account foreign evaluative frameworks in order to provide the 'best perspectiveless account' of all these experiences. But does it succeed in emulating this process, and does it come close to this ideal of objectivity? While the argument from foreign law goes in the same direction of stripping off the layers of contingency in our value judgments, it falls short of reaching the point of view that would ultimately reveal the objective normative reason. The reflection it entails always goes back to our own values and we cannot completely transcend our constitutional value system through such an exercise. The argument from universal reason is hence neither completely universal nor consumed by reason. It can never secure Nagel's 'view from nowhere', but only a more modest version of this standpoint, which is more appropriately described as 'a view from everywhere'.

Let me support this claim by looking more closely at the mechanics of the reflection induced by foreign law. There are several virtues of good moral judgment that foreign law might facilitate, but they do not guarantee full detachment from the contingent moral experience. The most obvious one is information. Moral judgment ought to include

209 Ibid 161.

${ }^{210}$ Ibid $160-161$ 
sound empirical premises. For example, in Roe $v$ Wade the court used foreign experiences to support its claim that mortality rates for abortion are the same or lower than for regular childbirth. ${ }^{211}$ The conclusion thus depended on a local value - that higher mortality rates in abortion count against it - and foreign law interfered only with the factual basis of the argument. Similarly, in Washington $v$ Glucksberg justices invoked empirical evidence from the Netherlands while discussing the claim that legalizing euthanasia might lead to abuses. ${ }^{212}$ This is different from using foreign law to illuminate the protected value itself. For example, in the Glucksberg majority opinion, Justice Rehnquist argued that euthanasia is not practiced in western democracies. ${ }^{213} \mathrm{He}$ brought up this fact to support a proposition of value - that euthanasia is not acceptable - which is not related to the empirical question of whether it is difficult to administer euthanasia in a way that would prevent manipulation. Foreign law can thus be used to support both the evaluative and descriptive premise of the argument even in the same judgment. In the latter case, foreign law serves as a pool of social experiments that contributes to our experience without having to go through the process of trial and error. This kind of use of foreign law does not appeal to universal moral truths, but takes a form of hypothetical imperative: the normative goal is already supplied by the local evaluative outlook and looking at how other legal systems have dealt with similar problems might help us to learn how to achieve that goal.

Empirical readjustment of evaluative judgments will hence be most useful when values require the achievement of clear goals. For example, we may wish to see how the level of crime can be decreased, or we may want to know whether a particular type of affirmative action measure will succeed in establishing a long-term and self-standing equal participation. But notice that sometimes it would be difficult to disentangle the empirical and evaluative part of a judgment. Take, for example, the belief that gay people should not adopt because their children would become gay as well. Such a belief is not only factually mistaken, but also rests on a problematic value judgment. The fact that sexual orientation is not 'learned' may refute this argument, but it will not affect the unacceptable value-premise that it is bad for children to be gay. Sometimes value

${ }^{211}$ Roe v Wade 149 n 44 mentioning the law of England, Wales, Japan, Czechoslovakia and Hungary.

212 Washington $v$ Glucksberg 732-734 and (Souter) 785-786.

${ }^{213}$ Ibid $710 \mathrm{n} 8$ and $718 \mathrm{n} 16$. 
judgments are imported from foreign law in the same way, even if the court claims to be seeking information only.

For instance, in Printz v United States, Justice Breyer used foreign law - in his words to 'cast an empirical light on the consequences of different solutions to a common legal problem'; however, the argument was that the balance between 'the practical need for central authority' and the 'democratic virtues of more local control' had been successfully struck in some European states by having the local authorities implement federal laws. ${ }^{214}$ While there are obvious similarities between the idea of federalism in Europe and the United States, it also acquires different meanings in national constitutional systems; the balance between central and local government in a constitutional system depends on the local understanding of federalism, unless one believes in federalism as a Platonic ideal-form. ${ }^{215}$ Breyer's argument therefore does not cast empirical light only: it aims to readjust the American understanding of federalism by exposing it to different conceptions, such as those applied in Europe.

But this exposure to foreign law might foster another virtue of good moral judgment: flexibility. It could be the case that there is a different value that is sub-optimally realized because of an entrenched understanding of federalism. For example, federalism might be motivated by reasons of efficiency, social cohesion, or keeping the government in check. A temperate moral judgment presupposes the ability to re-question one's own position. Looking at foreign law may reveal some of the neglected concerns or might show that the question has been inadequately framed; in such a case, foreign law might prompt the court to overturn its previous judgment.

For example, in Bowers v Hardwick, the Supreme Court upheld Georgia's law, which criminalized consensual sodomy; in so doing it investigated if homosexuals had a constitutionally guaranteed right to engage in sodomy and understood values as being rooted in local traditions. ${ }^{216}$ The majority in Lawrence $v$ Texas overturned Bowers but

${ }^{214}$ Printz v United States 521 US 898 (1997) (Breyer) 976-977.

215 See ibid (Scalia) $921 \mathrm{n} 11$.

${ }^{216}$ Bowers (Burger). 
retained its approach to the nature of value. Justice Kennedy wrote at length about examples from 'Western civilization' that refute the inference in Bowers about the traditional ban on homosexual conduct. ${ }^{217} \mathrm{He}$ thus did not deny that value may be locally constructed, but argued that important aspects of the value of liberty were not taken into account, especially in its implications for privacy and restraint in the state's interference with private life. Kennedy argued that the court ought to understand its previous decisions and the values behind them more flexibly: 'times can blind us to certain truths and later generations can see that laws once thought necessary and proper in fact serve only to oppress. As the Constitution endures, persons in every generation can invoke its principles in their own search for greater freedom'. ${ }^{218}$ Kennedy also thought that once the doubts about a precedent become evident, 'criticism from other sources is of greater significance'. ${ }^{219}$ One of these sources that enables greater reflective flexibility is the laws of the nations that share similar values and heritage. The best way to understand the use of foreign law in Lawrence to elucidate the contours of liberty is not that this concept has a universal meaning to be discovered in the world, but that the core of its meaning is shared with many other countries, and that it includes certain concerns that have been neglected in Bowers. ${ }^{220}$ The question - according to the Lawrence court - was framed wrongly and in so doing it missed important aspects of liberty: it 'demeaned' the claim of the individual as asking for the right to engage in homosexual conduct, while it actually involved their dignity and freedom to be in a personal relationship. ${ }^{221}$

Flexibility usually derives its appeal from yet another virtue of good moral judgment: coherence. The Lawrence court used foreign law to show that Bowers was inconsistent with a set of locally shared values. The aim was not to import universal reasons from foreign law, but to bring local commitments into balance. Yet, coherence is not a guarantor of universal truths, but merely implies that there is a set of evaluative commitments in a community that cannot all be realized at the same time without

\footnotetext{
${ }^{217}$ Lawrence $571-573$.

218 Ibid 579.

219 Ibid 576.

220 Ibid 576-577.

221 Ibid 567.
} 
sacrificing some of them. It requires careful reflection on the consequences of each of the commitments and their relative importance within the local evaluative standpoint.

Reaching coherence is difficult in its own right, and foreign law obviously cannot fully alleviate disagreements. We have seen for example that in Israel there are two sets of values: 'Jewish' and 'democratic', local and cosmopolitan, traditional and modern. These values can sometimes be in tension. In Adalah, both Barak and Cheshin used foreign law to address this tension and reached opposing results. But foreign law helped them strike the balance nonetheless. Looking at jurisdictions that share some values with Israel, they both agreed that the commitment to human dignity entails protection of the right to family life. They disagreed about the way the balance between security and dignity plays out under the circumstances of life in Israel. Each opinion reached coherence between the two different sets of values and concerns by sacrificing one over the other; however, looking at the jurisdictions that Israel identifies with helped the justices understand to what extent these cosmopolitan values can be realized in Israel, and where the local factual circumstances or evaluative commitments ought to take precedence.

Attaining stable coherence often demands another virtue: imagination. Foreign law can thus serve in overcoming what Justice Ackermann calls 'tunnel vision', which prevents the judge from noticing some aspects of values, less visible connections between them, or fruitful ways in which they can be balanced. Justice Chaskalson described the usefulness of foreign law in Makwanyane in the following way: 'foreign authorities are of value because they analyse arguments for and against the death sentence'.222 He thus understood foreign law as a pool of potential arguments, and not as a source of authoritative solutions: by studying foreign law one makes sure that no argumentative rock stays unturned. Chaskalson's opinion in Makwanyane provides a fine example of foreign law being able to expand the imaginative horizons of the court. He used arguments present in foreign law to determine the relevant concerns for his own decision: the arbitrariness and inequality of the death penalty, the consequences for the

${ }_{222} S v$ Makwanyane and Another (Chaskalson) para 34. 
right to life and dignity, the relevance of public opinion, and the balance between other implicated values. ${ }^{223}$ Foreign law can thus point to relevant arguments, possible tradeoffs between values, and creative solutions to constitutional problems. Again, this does not mean that foreign solutions are imported because their source points to moral truth, but because judges believe they are appropriate for domestic circumstances.

Imagination is closely connected to another virtue of good moral judgment: maturity. It seems sensible to expect that a decision in moral matters will be better balanced if the court is more experienced and aware of possible solutions and pitfalls. But sometimes the courts are not experienced enough. Again, Chaskalson's views on foreign law from Makwanyane are illustrative; in his opinion, '[c]omparative "bill of rights" jurisprudence will ... be of importance, particularly in the early stages of the transition when there is no developed indigenous jurisprudence'. ${ }^{224}$ Since the South African Constitutional Court did not have enough familiarity with rights-based review of legislation, it looked for inspiration elsewhere; part of the reason why the South African Constitution encompasses the explicit permission to use foreign law lies in the fact that there was no experience or tradition of dealing with constitutional problems from a liberaldemocratic perspective. This does not mean that conclusions are imported irrespectively of the domestic evaluative commitments. A case in point is Justice Agranat's opinion in Kol Ha'am. This opinion starts from a local commitment to democratic government and then tries to discern the appropriate limitations to free of speech from the practice of more mature jurisdictions that share this commitment such as the United States. Similarly, Justice Barak in Mizrahi Bank looked at the law of other democratic countries to understand the role of judicial review. In both cases, the democratic orientation of the Israeli constitutional system comes from within the local evaluative outlook, but the system lacks relevant experience and looks for clues from more mature democracies. The use of foreign law rests on a belief that progressive and more experienced legal systems have reached desirable and workable solutions, better adapted to contemporary circumstances.

${ }^{223}$ Ibid (Chaskalson) paras 40-109.

${ }^{224}$ Ibid (Chaskalson) para 37. 
Does this imply capitulation of moral judgment, making it a deductive view? It seems that as long as the epistemic conditions are met, we can rely on the results of the moral inquiry of others. Recall that the objection against the deductive view was precisely that it is implausible that we are able to tell that epistemic conditions are met, while at the same time not being capable of reaching the same conclusion ourselves (but not necessarily in isolation). If we know what it takes to make the same decision, why take the detour via foreign law? The issue is not so straightforward. The process can implicate our moral judgment at different stages of accepting someone as an epistemic authority. If we retain our moral capacities in the process, we can see how the use of foreign law in such a case can be useful but not deductive. Engaging with doctrines from more experienced jurisdictions may be epistemically warranted, as a justification for choosing such sources, and not as justification for surrendering moral judgment. When acting with limited resources we sometimes have to make a choice and take into account systems that will - to the best of our knowledge - prove to be useful. A judge would still assess the substantive outcome of the judgment, but the reason to engage with it in the first place may be its origin. This presupposes and does not exclude the capacity to recognize and use the moral judgments of others in order to confirm or synthesize beliefs. And that makes such use of foreign law reflective, not deductive. A reflective understanding of the argument from universal reason can help us notice that this kind of use of foreign law can work both ways: the court we are looking at may be more experienced, but it may also have a baggage of concerns which younger courts do not face, such as doctrine, intentions of framers, or interpretive techniques.

This is why - while new constitutional systems may look at foreign jurisdictions for mature solutions to constitutional problems - the old ones may rely on foreign law to overcome the vice of too much self-containment: good moral judgment thus demands a degree of openness. Much of the use of foreign law in the United States can be explained in this way. Even though it has a lot of experience and maturity, the US constitutional system may entrench certain judgments which neither correspond with the current needs of the society nor fit with the overall framework of its values. In most of the cases the US Supreme Court referred to the fact of foreign consensus - across the board or among countries that share its evaluative perspective - as a confirmation of its own 
conclusions. This could be understood in terms of openness: as a recognition that the maturity of the system, which is responsible for its leadership in the protection of rights, has also ossified specific views which may no longer be acceptable given other evaluative attitudes predominant in the system. This argument may thus be interpreted in light of identity concerns and self-perception, rather than belief that foreign law tracks the truth; for example, the mention of Iran, Pakistan, Saudi Arabia, Yemen, Nigeria, Congo and China in Roper is a reminder that the country cannot remain a frontrunner of human rights protection if these countries have abolished capital punishment for juveniles and the United States has not. However, the value of openness towards global consensus has to be explained by something more substantive than national pride, for pride itself may work both ways, and eventually convince someone of his self-righteousness despite the consensus; furthermore, it is doubtful that the use of consensus is based only on this demeaning sense, in which we see other systems as backwards and realize that even they might be more advanced in certain issues.

Openness to consensus seems like the bulwark of the deductive view. Recall: the argument from consensus may survive even on a non-Platonic deductive view because more people engaged in moral reasoning have better chances to reflectively reach moral truth. The issue directly relates to the understanding of the universality element in the argument from universal reason: we might think that it includes a dilemma between universal human and relativistic or communal values. The question is whether we need to accept this dilemma as categorical. We might have good reasons to retain the choice to reach moral judgments on our own and based on our specific constitutional experience, but to nonetheless appreciate the normative pull of consensus. The question is whether - if we abandon the position that value stems from the standpoint of 'nowhere' or the 'universe' - the reliance on consensus makes sense? In other words, if we understand values as contingent and historically embedded, can we still explain the argument from consensus?

The best explanation of the existence of consensus is that similar values have actually been accepted around the world and that they have led the courts to similar normative judgments. We need not presuppose that all judges are engaged in moral reasoning and 
that as such have better chances to reach moral truth through reason. Rather, a more plausible explanation is that contingent circumstances (evolutionary, sociological, historical, and economic) have produced similar value systems around the world. When relying on consensus, we need only suppose that we share many values with other systems, especially in areas of immense international activity such as human rights. We are both part of the global and our own community's value system. There is nothing mysterious or metaphysical in any of them. Value is again internal to us, only now we are questioning who 'we' are.

What is the normativity of the consensus then? It is probably much more limited than the deductive view would have it, but there still is one. Following the assumption that the circumstances of life on this planet have brought about many similarities in the contingent sets of values around the world, it is then plausible to assume that, if there is a global consensus on some issue, we might be missing out on something in our value judgments if we diverge from it. Because of this, the convergence in the world should make us re-question our value judgments. While it gives us no reason to surrender to consensus, it does carry some weight and invites us to justify our own views again. We may then distinguish our case from the prevailing opinion, or agree with it on substantive moral grounds, and not simply because of the consensus. Thus the reflective view can explain the normative pull of consensus without renouncing our moral agency: consensus in foreign law ignites reflection instead of foreclosing it. Furthermore, it explains why the argument from consensus is not likely to play an important role in practice: the consensus will often point to well-accepted moral principles that are not a part of controversy, pertain to issues that are long settled, or be too thin to illuminate novel directions for policy in modern societies. For example, 'though shalt not steal' is probably an accepted moral principle in most societies, but it is also one of the least controversial ones.

The virtue of openness does not have to imply only the consensus-based use of foreign law. Most cases of the use of foreign law presuppose looking at jurisdictions that share a similar value-framework, so they can clearly contribute to the self-understanding of the system that is making the comparison; if we share values and do different things, there 
is a good chance that we have probably not fully explored our evaluative outlooks. But openness also entails looking at systems that do not share similar background commitments. We have seen that Aharon Barak denies that there can be fruitful comparison between systems that do not have a 'common ideological basis'. ${ }^{225}$ Justice Breyer retreated from his mention of Zimbabwe in Knight $v$ Florida calling it a 'tactical error'. ${ }^{226}$ If we accept the reflective view, there is a way to resist such conclusions. Being exposed to other perspectives could teach us a lot about ourselves. As in Roper, we could realize that some of our values are not as progressive as we previously might have thought. But the more important effect goes in the other direction. By distinguishing other systems we learn where the borders of our evaluative outlook are and we test which values are more central to it. Recognizing that a value system is not a real option for us - that accepting it would demand sacrificing a significant part of our identity can make us re-think some of the moral judgments we share with such a system, and can also confirm our confidence in our own perspective. The benefit of such confrontations is achieving greater self-awareness. It can make us dig deeper into our value system to see whether the moral judgment in question genuinely fits with other judgments we hold important.

These processes are important specifically when the law fails to incite appropriate sensibility towards different perspectives. A good moral judgment includes the ability of role-taking and seeing problems from the perspective of the other with whom we may not agree; while this is already psychologically difficult, the law may further entrench a particular perspective that is not shared by all groups within the society. This is particularly problematic if minorities do not get to articulate their voice within the dominant legal environment. Foreign law may contribute to a different framing of the issue before the court which better accommodates the needs of minorities. For example, in Lawrence the controversy occurred in the context of privacy: the police entered a private residence of the petitioner who was having sex with another man. This fact led the majority to write the opinion in the context of privacy, but the use of foreign law sensitized the court to realize that privacy includes more than the protection of one's

225 Barak, The Judge in a Democracy 198.

226 Dorsen 528. 
home because of its connection with liberty. Justice Kennedy made this point in the opening of his opinion: 'Freedom extends beyond spatial bounds.'227 Unlike Bowers, where the court asked if there is a fundamental right to engage in homosexual sodomy,228 the Lawrence court asked whether the state has a legitimate interest to interfere with the liberty of its citizens in the domain of personal relationships. Foreign law served both to draw the attention of the court to this question, and to confirm that a system committed to liberty must interpret these kinds of state interventions as unjustified. Kennedy thus concluded that ' $[\mathrm{t}]$ he right the petitioners seek in this case has been accepted as an integral part of human freedom in many other countries' and that ' $[\mathrm{t}]$ here has been no showing that in this country the governmental interest in circumscribing personal choice is somehow more legitimate or urgent.'229 Again, the issue is not what privacy means in general, but what are its implications in a system that accepts the values of dignity and liberty.

Finally, another reflective virtue is clarity. The first precondition for moral reflection is to understand clearly what relevant concerns are at stake. We have seen that the use of foreign law frequently pertains to proportionality analysis: a set of analytic stages that the courts go through to determine whether a state policy is justified from the perspective of constitutionally protected values. ${ }^{230}$ For example, the South African Constitutional Court in Makwanyane examined different models of proportionality analysis - from Canada, Germany and the European Court of Human Rights - to find that such reasoning was 'implicit' in the limitation of the rights clause of the constitution. ${ }^{231}$ Similarly, Justice Barak argued in Mizrahi and Adalah that proportionality analysis was the appropriate framework for exploring the boundaries of justified limitations of human rights and - in so doing - he relied on an extensive

\footnotetext{
227 Lawrence 562.

228 Bowers 190.

229 Lawrence 577.

230 Moreover, proportionality analysis has been the most widespread trait of modern constitutionalism. See Alec Stone Sweet and Jud Mathews, 'Proportionality Balancing and Global Constitutionalism' (2008) 47 Columbia Journal of Transnational Law 72.

${ }^{231}$ Section 33(1) of the Interim Constitution of 1993. $S v$ Makwanyane and Another paras 103-112.
} 
examination of foreign approaches to this type of analysis. ${ }^{232}$ Again, proportionality analysis as such does not guarantee much in terms of substantive results, and there is no transfer of values from one system to the other; rather, what happens is that one system finds it useful to rely on a procedure that makes explicit the method of analysis that would otherwise stay implicit. It is a matter of importing a reflective technique, not substantive values.

All these ways of engaging with foreign law help constitutional systems to perfect their own self-understanding and not to acquire knowledge about external truths. The reflective view gives up on robust and eternal objectivity of moral judgments that can be reached through this process. The model of reasoning is based on a set of reflective virtues, rather than on deduction. Unlike the deductive view, according to which we have strong reasons to defer to the foreign epistemic moral authority, the reflective view takes the opposite approach: we do not have reason to yield to other people's moral opinion, but it is beneficial for us to listen to what they have to say. It describes how we can work our way through the evaluative meaning we impose on the world, and not how we can work our way down from the source of value we discover in the world.

The benefits of the reflective view are two-fold. First, it accounts for all the instances of the use of foreign law - including reliance on consensus - without presupposing implausible metaphysical theses. The argument for the use of foreign law is motivated by several reflective virtues that are typically taken to be a staple of good moral judgment. Second, it allows us to develop a unified conception of constitutional ethics, one that can combine the argument from constitutional identity and common sentiment together with the argument from universal reason. However, the crucial question then becomes: what gives the descriptive sociological and psychological facts about our normative attitudes their normativity? Why ought we reflect on our contingent moral attitudes if this procedure fails to lead us to universal and timeless moral truths? Arguments from common sentiment and constitutional identity depend on contingent

232 United Mizrahi Bank Ltd. v Migdal Cooperative Village (Barak) paras 83-99. Adalah Legal Centre for Arab Minority Rights in Israel v Minister of Interior (Barak) 54-75. In particular, Barak was influenced by the Canadian law and the proportionality test developed in $R v$ Oakes [1986] 1 SCR 103. 
moral attitudes relative to our community. The argument from universal reason enables reflection that is also contingently considered to be beneficial to a good moral judgment. These contingent attitudes are descriptive facts, but - the popular axiom claims - facts are normatively inert. This is why we need a conception of value that will justify our ability to rely on our contingent moral attitudes even if they do not lead to mindindependent moral truths to motivate these ethical arguments in constitutional reasoning.

\section{Conclusion}

This chapter analyzed the use of foreign law in constitutional reasoning, understood as an ethical argument which sees value as universal and based on reason. The purpose was to inquire into the justifications for the use of such an argument and to reveal its metaethical foundations. The constitutive elements of such an argument - universality and reasonableness - can be understood in two different ways: deductive and reflective.

According to the deductive view, foreign law acquires the status of objective normative reason once some epistemic conditions are fulfilled. These conditions can pertain, for example, to the existence of consensus in foreign law or to experience of the jurisdiction we are looking at. This view should be rejected. It either presupposes an implausible moral ontology which includes moral facts with causal powers, or subscribes to a variant of moral realism which relies on our capability to reason and cannot without contradiction demand from us to fully surrender to a moral authority.

According to the reflective view, foreign law does not point to universal moral truths, but it is helpful in reaching the reflective state in which we can better grasp our own moral commitments and their implications. While in this view the argument from universal reason remains in the neighborhood of the idea of the view from 'nowhere' or the 'universe' - which should present a point in which we can cognize the value as objective - it falls short of fully recreating it. It is also skeptical towards our ability to grasp evaluative truths that are discontinuous from our contingent and local 
experiences. In the reflective view, we should better think of the use of foreign law as the view from 'everywhere': a useful exercise that can help us develop and clarify our own evaluative framework. As I have argued, the best vocabulary to express this view includes, but is not limited to, several virtues of good moral judgment: information, flexibility, openness, imagination, coherence, clarity, maturity and sensibility.

The ambition of such reflection as a form of reasoning is limited: it presents a search for reflective equilibrium, and not a deduction from objective reasons. By divorcing the use of foreign law from the strong understanding of universality and reasonableness, we are also dispensing with the idea that it will lead us to universal reasons that are robustly objective. The argument from universal reason cannot thus provide the mindindependent foundation of constitutional ethics. There are thus two problems. First, there could still be absolute and mind-independent truths about values attainable through reason. If this is so, then the modest understanding of universality and reasonableness implicit in the reflective view cannot motivate it, and we should be seeking after these mind-independent truths. Second, if there are no such truths discernible through reflection, then why should we reflect upon our values in the first place? Moreover, if we must always go back to our contingent moral intuitions on this view that provide substance for our reflection, how are these facts about our emotive attitudes normative?

All of this makes constitutional ethics metaethically unstable: it needs to explain what makes the sociological fact about contingent intuitions morally relevant, and where the value of reasoning and reflection comes from. These and similar questions are bound to persist unless we have a plausible theory of value that will provide a basis for thinking about the ethical arguments in constitutional reasoning. The task of the next chapter is to develop such a theory. I will argue that the modest idea of practical reasoning is not merely the second-best, but the only one we could possibly hope to have, and that the prospects of overcoming our contingent intuitions and emotional reactions is illusory; moreover, I will try to show that this realization need not lead to a bottomless moral skepticism which renders us unable to make moral judgments at all. 


\section{VALUES AND NORMATIVE JUDGMENT}

\section{Introduction}

Previous chapters have identified a pressing challenge to the judicial use of ethical arguments: common types of ethical arguments in constitutional reasoning suffer from inadequate metaethical foundations. Constitutional courts need a sound theory of value around which their ethical arguments could be constructed. We must therefore ponder the nature of value and normative judgment. In previous chapters, I have already relied on arguments that presupposed specific views about value. The aim of this chapter is to integrate these views into a coherent framework and articulate a philosophical foundation for a theory of constitutional ethics.

Unless a person is unable to act practically, she is asking herself what she ought to do, and is thus experiencing the reality of value. Should I spend the evening with my friends or should I work late? Practical questions like this depend on what I think I have most reason to do, and practical decisions are thus affected by values. To account for the role of values in practical reasoning, it is not enough to explain why I came to think that I ought to work late. Such an explanation can cite a number of causal forces and contingencies in my life, culture, or evolutionary development, which led me to believe that I have most reason to do so. It would certainly be a mistake to neglect such causal explanations, but a full account of value and normative judgment must also address some further features of value-laden practical reasoning. Practical decisions can be subjected to criticism whereby, for example, my friends tell me that I did not have most reason to work late, although I decided to do so. Moreover, some sense must be made of thoughts expressing the normative pull of our values in the form of 'I ought not to feel this'. For example, thinking that I ought not feel guilty for staying late at work signals a gap between what I think I should feel and what I actually feel. ${ }^{1}$ The language of criticism and thoughts of mistaken feelings are intelligible and need to be accounted

\footnotetext{
${ }^{1}$ Allan Gibbard, Reconciling Our Aims: In Search of Bases for Ethics (Oxford University Press 2008) ch 1.
} 
for. ${ }^{2}$ These experiences seem to justify the notion that I could be in error regarding my practical decision, and that such an error includes the truth of the matter concerning the proper way to decide the dilemma, standing apart from whichever mental state $I$ was in while weighing the reasons for and against the decision.

This poses a question of whether the values are brought about by valuing beings or whether they are somehow found in the world. Are there values which could be true independently of all contingent attitudes about them? Expressed in a more recognizable jargon - the question is whether values are mind-dependent or mind-independent. ${ }^{3}$ If the latter is the case, there is a relatively straightforward way to account for the possibility of error in our moral judgments, while the former is typically understood to be more compatible with the scientific worldview and with the reality presupposed by it. The answer to this dilemma, as I will suggest, must not neglect explanations of how we came to occupy a place in the world in which we can experience value. But the answer also depends on the possibility to preserve the reality of our experience of value in the face of such an explanation; it needs to show how we can both be aware and be immersed at the same time in the matrix of the human condition, context, contingency, history, identity, language - in other words, the form of life - that supplies our values with much of their substance.

In previous chapters I expressed doubt that value is something external to us, found in the world outside our psychological sets. ${ }^{4}$ The conclusion followed the idea that there is no evidence of normative properties in the world that could exert causal pressure on our value systems. I shall develop this point at greater length here, and show why our folk normative judgments and values must figure in both theoretical explanations of value and practical normative judgments. The chapter proceeds as follows. First, I will reconstruct the problem about the nature of value in terms of the conflict between the theoretical and practical perspective, and show why some common philosophical approaches to this problem are not satisfactory. Second, I shall examine the nature of

\footnotetext{
${ }^{2}$ Gibbard, Wise Choices, Apt Feelings: A Theory of Normative Judgment 12.

3 Throughout the chapter I will use mind-independent, external, robust, absolute, and universal, as near synonyms that denote a property of values that could be true irrespective of our contingent attitudes.

4. Williams, Moral Luck: Philosophical Papers, 1973-1980 ch 8.
} 
values from the theoretical perspective; this perspective tells us that values are contingent and gives us no reason to trust that they are connected to mind-independent truths. Third, I will clarify what are the consequences of the theoretical on the practical perspective; I shall argue that there is no reason to suspend the practical perspective, and that the redemption of our practical confidence emerges once we are reflective enough about it. The aim is to reach a sustainable understanding of value - arising from the dynamics between confidence and reflection - that is able to preserve both the theoretical and practical perspective.

2. The theoretical and practical perspective

As humans, we are able to occupy two distinct points of view. ${ }^{5}$ When deciding what to do practically, our values seem to us, and we present them to others, as true. Even the most skeptical among us utter things like 'cruelty is wrong', thereby seemingly describing an occurrence in the world as having a property of wrongness, and having it regardless of contingent attitudes about it here and now. The meaning of the concept 'wrong' seems to be fixed by its reference, the episode in the world that our moral judgment is about. On the other hand, when examining our values theoretically, taking the empirical-scientific point of view, we are able to explain our value experiences as causally affected attitudes, contingent on evolution, history, culture, upbringing, or our own choice. ${ }^{6}$ This perspective puts in doubt the claim that the property of wrongness exists in the world regardless of our contingent beliefs about it, or suggests that - if

\footnotetext{
${ }^{5}$ This way of framing the issue owes much to Sharon Street's work. See for example: Street; Sharon Street, 'What is Constructivism in Ethics and Metaethics?' (2010) 5 Philosophy Compass 363; Sharon Street, 'Constructivism about Reasons' in Russ Shafer-Landau (ed), Oxford Studies in Metaethics: Volume 3 (Clarendon Press 2008); Sharon Street, 'Objectivity and Truth: You'd Better Rethink It' unpublished draft <https://files.nyu.edu/ss 194/public/sharonstreet/Writing_files/Paper\%2012\%20for\%20website\%20\%20Objectivity\%20and\%20Truth\%20-\%20You\%27d\%20Better\%20Rethink\%20It.pdf> accessed 16 July 2014.

${ }^{6}$ Gilbert Harman puts the issue in similar terms and argues that the difference between people who are attracted to moral relativism, non-cognitivism, nihilism and those that are moral absolutists lies in their attitude towards science: the former are worried about finding the place for value in the natural world discovered by sciences, and the latter are not worried about this and instead think that ethics depends only on the internal ethical perspective. This framework is roughly correct and I will spell it out in terms of a clash between the theoretical and practical perspectives. See Gilbert Harman, 'Is There a Single True Morality' in Gilbert Harman, Explaining Value and Other Essays in Moral Philosophy (Oxford University Press 2000) ch 5 .
} 
there is such a property - our actual beliefs could happen to be completely unrelated to it. 7

This issue is not mere philosophical hairsplitting. Many feel profound psychological uneasiness arising from the possibility of conflict between these two perspectives. ${ }^{8}$ Derek Parfit, for example, thinks that '...it would be a tragedy if there was no single true morality' ${ }^{\circ}$ and that '[i]f there are no [irreducibly normative, reason-involving] truths, nothing matters'. ${ }^{10}$ We do want our values to matter, and if they matter only if they are true - objectively, once and for all, and independently of what we think about them - then the problem may be daunting. The theoretical perspective could reveal that our values are nothing like that and that we have been deluded. We thus need to see whether there is a conflict between these perspectives, and if there is, how we can continue with our practical life if there is no 'true' reason to do anything at all and everything is perhaps just an illusion. Even if there is no need to feel excruciated by this thought, how can we go on claiming objectivity and truth for our values without having a bad philosophical consciousness? ${ }_{11}$ There are different ways to respond to the pressure towards the unified worldview that would incorporate both practical and theoretical perspectives. Let us examine some options.

\subsection{Suppression}

One strategy is to suppress the compelling character of the theoretical perspective or reduce it to the practical. Typically, the thought is that once the metaethical claims are

\footnotetext{
${ }^{7}$ Sharon Street, 'A Darwinian Dilemma for Realist Theories of Value' (2006) 127 Philosophical Studies 109. See the analysis later on.

8 This can at least partly be explained by our propensity to seek comfort and meaning in our culturally embedded worldview and identity. The psychological pressure for coherence is commonly understood as a defense mechanism. For a quick overview of research in this area, see Jonathan Haidt, 'The Emotional Dog and its Rational Tail: A Social Intuitionist Approach to Moral Judgment' (2001) 108 Psychological Review 814, 821.

${ }^{9}$ Derek Parfit, On What Matters: Volume Two (Oxford University Press 2011$) 155$.

${ }^{10}$ Ibid, 465.

${ }^{11}$ Stephen Darwall, Allan Gibbard and Peter Railton, 'Toward Fin de siècle Ethics: Some Trends' in Stephen L. Darwall, Allan Gibbard and Peter A. Railton (eds), Moral Discourse and Practice: Some Philosophical Approaches (Oxford University Press 1997) 6. Simon Blackburn describes the dilemma neatly: 'The problem is one of finding room for ethics, or placing ethics within the disenchanted, non-ethical order which we inhabit, and of which we are a part.' Blackburn, Ruling Passions: A Theory of Practical Reasoning 49.
} 
leveled on the playing field with our deepest moral convictions they will give way, for they will be confronted with the possibility that anything goes. This thought takes diverse forms. Ronald Dworkin, for example, deprives metaethical claims of any selfstanding relevance. According to him, the problem is logical - if one wishes to allow the effects of metaethical views on substantive values, one is at the same time inferring a normative conclusion from descriptive premises. Such attempts meet a dilemma: either metaethical claims are descriptive and normative inferences from them are guilty of normative fallacy, or alternatively, metaethical claims are normative and cannot without contradiction refute the relevance of all normative claims in general. ${ }^{12}$ Dworkin believes that morality is wholly independent of metaethical concerns, that it 'exercises its own sovereignty',13 but also - more controversially - that 'the question whether moral judgments can be true or false is a substantive moral issue'. ${ }^{14}$ Talk of the subjectivity of values is an expression of morally relevant attitudes, and is to be abandoned as confused because it claims objectivity for itself.

There is much to be said about the particulars of this argument. Suffice it to note that Hume's law that motivates it applies only to deductive inferences, whereas an argument showing that the best explanation of our values casts doubt on their aptness for truth is perfectly sound. ${ }^{15}$ However, the issue is not properly understood as pertaining to the validity of normative arguments, but to the firmness of our belief in the truth of their premises. The real question is, why should concerns about the mind-independence of value make us practically worried? The answer I want to suggest - and where Dworkin's intuition is right - is that the ability to trust in the absolute truth of our normative judgments does play a role within the internal, ethical perspective. For consider: if there is no logical or any other connection between metaethical statements and normative ethical statements, if they do not correspond in any way that would subject them to the demands of coherence, we could simply continue with our practice as if nothing

${ }^{12}$ Dworkin, 'Objectivity and Truth: You'd Better Believe It'; Dworkin, Objectivity and Truth; Dworkin, Justice for Hedgehogs part 1.

${ }^{13}$ Dworkin, 'Objectivity and Truth: You'd Better Believe It' 128.

${ }^{14}$ Dworkin, Justice for Hedgehogs 67.

15 This argument is elaborated at length in Russ Shafer-Landau, 'The Possibility of Metaethics' (2010) 90 Boston University Law Review 479. Furthermore, it is implausible that metaethical statements are normative statements. Take for example the claim that ethical knowledge is a form of practical as opposed to theoretical knowledge: not only can no normative conclusion be deduced from this claim together with some facts, but such a claim would not even indirectly affect the truth of any moral judgment. 
happened; the attempt to reduce metaethical to normative statements would be superfluous, because they could co-exist within a single perspective without loss to any of them. Yet, the problem seems to be more serious. Bertrand Russell puts it nicely: '...I am not guilty of any logical inconsistency in holding to the [subjectivist] interpretation of ethics and at the same time expressing strong ethical preferences. But in feeling I am not satisfied.' ${ }^{16}$ We have to get to the bottom of that feeling and see if it is warranted.

Resistance to the theoretical perspective also comes from the view that it is excessively hegemonic. Thomas Nagel believes that the question about the nature of value is 'about the order of normative explanation. '17 Evaluative judgments cannot be 'explained' by anything else but 'more general or basic evaluative truths, together with the facts that bring them into play'.18 The mode of explanation Nagel has in mind is normative and like Dworkin - he trusts that a causal explanation does not talk to the truth of values: it can be confirmed only by some other irreducibly normative truth. Nonetheless, Nagel argues that the reason to keep these two perspectives separate is not only logical but also ontological: our experiences of value as true are real, and thus any conception of reality which aspires to be comprehensive but neglects this must be incomplete. ${ }^{19}$ It is not possible to reduce our experience of normative truth and recast it in psychological or some other vocabulary, as it would then be very different to how it appears (peculiarly) to us; ${ }^{20}$ such a reduction cannot be made without loss and the world we would be describing would be different from the one in which these experiences exist.

This view demands a serious treatment that cannot be fully attempted here. However, we may notice that - as much as the moral anti-realist may need a theory of ethical

\footnotetext{
${ }^{16}$ Bertrand Russell in Mackie 34. I have already mentioned the problem of 'schizoid attitude' - having ethical views while not believing them to be true. The discussion in this chapter aims at resolving that problem.

${ }^{17}$ Thomas Nagel, Mind and Cosmos: Why the Materialist Neo-Darwinian Conception of Nature is Almost Certainly False (Oxford University Press 2012) 182. For Nagel, 'realism about practical reasons and ethics is not a thesis about the natural order at all, but a purely normative claim'. Nagel, The Last Word 141-2.

${ }^{18}$ Nagel, Mind and Cosmos: Why the Materialist Neo-Darwinian Conception of Nature is Almost Certainly False 182.

${ }^{19}$ See for example ibid ch 5. I am presenting here only a part of Nagel's account to illustrate the view. For the view that the scientific account of reality is not exhaustive see: Putnam, Ethics without Ontology; Parfit ch 31 .

${ }^{20}$ Nicholas Sturgeon defends a form of moral naturalism starting from a similar thought. See for example: Nicholas L Sturgeon, 'Harman on Moral Explanations of Natural Facts' (1986) 24 The Southern Journal of Philosophy 69; Sturgeon, 'Moral Explanations'.
} 
criticism and error - this view needs a theory of illusion; if subjective experiences are to be allowed into the ontology of the world we may want to distinguish between those that are not true despite their appearance of truth (e.g. a drug-induced hallucination) and true because they appear to be true (e.g. value experiences). There must be an epistemological standard that will differentiate truth from illusion. In the case of ordinary perception we have (at the very least) a robust converging phenomenology that could play such a role, but in the case of moral 'perception' we do not: values may not seem 'glaringly' true to others as much as they seem to Thomas Nagel. ${ }^{21}$ Many people recognize that their values are subjective or relative to their culture, but would still express them in a truth-apt language.

The more important question, however, is whether the conflict between these two perspectives is such that it commands the rejection of one or the other. In Nagel's view, if the two perspectives are confronted, the theoretical need not hold sway: 'since moral realism is true, a Darwinian account of the motives underlying moral judgment must be false, in spite of the scientific consensus in its favor.'22 Again: why should evolutionary accounts of morality yield, if the two domains are separate? It seems that we need to start from the other end: while these theories aspire to fend off the possibility for the theoretical to undermine the practical, they fail to appreciate enough the cause of the problem, which lies not in the theoretical domain but in the importance that the absolute truth of normative facts plays within the internal, practical perspective. The key is to resolve the tension within the practical and not to suppress the theoretical.

\subsection{Denial}

In contrast to these views, there are those who acknowledge the pre-eminence of the theoretical perspective and declare the patterns of objectification in the practical

\footnotetext{
${ }^{21}$ Nagel, Mind and Cosmos: Why the Materialist Neo-Darwinian Conception of Nature is Almost Certainly False 196. Moreover, all the attempts to provide 'internal' justification of morality, starting from the practical perspective have so far failed for reasons we cannot hope to overcome. For the best succinct argument of this kind that addresses the inadequacies of all major families of normative ethics in this respect, see Williams, Ethics and the Limits of Philosophy chs 2-5.

${ }^{22}$ Nagel, Mind and Cosmos: Why the Materialist Neo-Darwinian Conception of Nature is Almost Certainly False 188.
} 
perspective bogus, but deny that this should be discomforting or drastically influence the way in which we conduct our lives. Let us consider some examples. John Mackie famously believed that moral utterances implicitly claim objectivity for themselves, but that they are all false. ${ }^{23}$ To support this claim, Mackie took the theoretical perspective and argued for a set of skeptical claims: the best explanation of the differences between moral codes suggests that our actual values are not perceptions of something external to us; objective values would be unlike any other feature of the fabric of the world; it is mysterious how we would know such values; it is not specified how values as features of the world would guide our actions; the occurrence of claims of authority and objectivity of values is best (causally) explained without presupposing the existence of objective values; if objective values supervene on natural features of the world we still do not have anything that resembles a full explanation of this relationship. ${ }^{24}$ Nonetheless, Mackie also noted that it does not follow that we should or can abandon the practical perspective:

The denial of objective values can carry with it an extreme emotional reaction, a feeling that nothing matters at all, that life has lost its purpose. Of course this does not follow; the lack of objective values is not a good reason for abandoning subjective concern or for ceasing to want anything. $[\ldots]$ the people in whom this reaction [decay of subjective concern and sense of purpose] occurs have been tending to objectify their concerns and purposes, have been giving them a fictitious external authority. ${ }^{25}$

Mackie thought that morality 'is not to be discovered but to be made'. ${ }^{6}$ In his view, this cannot be done from scratch but by building on already existing values; ${ }^{27}$ he never explained, however, what exactly gives us the right to go on almost as if nothing happened. ${ }^{28}$

\footnotetext{
${ }^{23}$ Mackie 35.

${ }^{24}$ Ibid ch 1.

${ }^{25}$ Ibid 34.

26 Ibid 134.

27 Ibid ch 5.

${ }^{28}$ Joyce is an error theorist who tries to answer this question from the internal practical perspective. His argument is that the illusion should be maintained for pragmatic reasons: 'The question of what we ought to $d o$, once we have come to see that our moral discourse is a philosophically indefensible illusion, is a practical question. A neglected answer is that the discourse may be maintained, accepted, but not believed
} 
Most of today's relativists also do not refrain from taking the practical perspective. Gilbert Harman, for example, supports a version of moral relativism that holds that the truth of a moral utterance is not absolute but relative to some accepted framework of moral standards. By and large, his views follow from the best theoretical (and causal) explanation of our moral values. But Harman also thinks that:

Moral relativism denies that we should simply give up on morality in the way that a religious skeptic might give up on religion. There are practical reasons to want to retain morality and relative moral judgments. ${ }^{29}$

Since Harman denies that there are any non-relative practical reasons, the reasons he mentions must also be relative. He sees no problem in such a position; the solution for one who utters something about practical reasons is to specify the framework of values from which one is speaking. ${ }^{30}$ This view is coherent, but does not tell us whether the authority with which we speak is undermined. According to Harman, when we judge that what Hitler did was wrong - further assuming, we may add, that he was a perfectly coherent psychopath and that we cannot find a basis in his moral outlook to show that he was wrong judging from his own set of values - it may be 'more appropriate ... to think of Hitler as an enemy. ${ }^{31}$ The loss of ability to claim the absolute validity for our own views moves us into the domain of power rather than authority legitimized by the absolute truth. But are shop-lifters, double-parkers or occasional liars also our enemies? Can we continue thinking they are wrong without conceiving of them as enemies, as someone who offends the core of our identity to the extent that we need to defend (our)selves? The language of power cannot easily substitute the language of truth, and these are questions for the disenchanted practical perspective, and not for the

- that it may have the role of a fiction'. Richard Joyce, 'Darwinian Ethics and Error' (2000) 15 Biology \& Philosophy 713, 730. Surely Joyce would have to agree that it is incredibly difficult to maintain and accept something that one no longer believes in.

${ }^{29}$ Gilbert Harman, 'Moral Relativism' in Gilbert Harman and Judith Jarvis Thomson (eds), Moral Relativism and Moral Objectivity (Blackwell 1996) 43. Emphasis added. See also his 'Relativistic Ethic: Morality as Politics' in Harman, Explaining Value and Other Essays in Moral Philosophy, where he defends his own conception of ethics which follows from the actual values that people within a group accept.

so Harman, 'Moral Relativism' 63.

${ }^{31}$ Ibid 60. 
theoretical. ${ }^{32}$

\subsection{Rationalization}

Finally, there are elaborate and sophisticated quasi-realist attempts to resolve this problem by interpreting our language of moral objectivity in terms of more complex attitudes of norms-acceptance or contingency plans. For example, thinking of moral attitudes in terms of plans - as Allan Gibbard invites us to do - provides an elegant explanation of how moral reasons can be consumed by our internal motives, but also how we can still feel that we ought to have behaved differently, or that we acted wrongly in acting on our own motives: roughly, our plans may not be fully worked out, or we may neglect some of our own commitments. ${ }^{3 s}$ There is much to be valued about this approach. It allows us to speak as if values were objective and permits our utterances to behave as cognitive and truth-apt in (at least some) logical operations. But quasi-realists also claim that trust in the objectivity of moral reasons itself comes from the practical perspective and cannot be vindicated from the theoretical point of view. Simon Blackburn thinks of objectivity as a virtue because - as a matter of internal ethical perspective - it is good to think that, for example, other people's pain is objectively bad. Allan Gibbard translates the claims of objectivity as part of contingency plans for the future, in which we accept that we would still think of our values as true for any counterfactual that may obtain. ${ }^{34}$ This claim - although plausible if we look at it

\footnotetext{
$32 \mathrm{~J}$. David Velleman defends a version of relativism that allows us to remain serious in our moral thinking without absurdity, because there is a common function of morality to enable social life, and so moral progress is made intelligible in relation to that function; however, the function is not valuable in itself, but simply as a part of the human way of life that incorporates having morality. Yet, it is not clear how moral progress, as an evaluative concept, can depend on a non-evaluative fact of morality having a function. For such an argument to work, it must be true that the function of morality is internalized as a morally valuable goal. J. David Velleman, Foundations for Moral Relativism (Open Book Publishers 2013) 96-97.

${ }^{33}$ See for example: Gibbard, Wise Choices, Apt Feelings: A Theory of Normative Judgment and Allan Gibbard, Thinking How to Live (Harvard University Press 2003).

${ }^{34}$ Gibbard's views about the reach of moral objectivity achieved through such expressivist analysis have evolved over time. In Gibbard, Wise Choices, Apt Feelings: A Theory of Normative Judgment pt 3, one of the central arguments was that there are pressures of coherence arising from one's inherited attitudes of norm-acceptance that are necessarily affected by others, so that it would be inconsistent to reject such pressure for future attitudes (ibid 174-183). There is a pressure to engage in conversation with others and argue for the warrant to claim authority that the norms you believe apply to others as well (ibid ch 10). But he rejected the view that there are normative facts. In Gibbard, Thinking How to Live, he refuses to commit to a view about the existence of normative facts and the possibility of non-minimalist moral
} 
only from the practical perspective - needs to be treated with caution because it ultimately fails to avoid conflict with the theoretical. It moves the problem only a bit further, for then these second order attitudes about moral objectivity must also be perspective-dependent and thus relative to a personal framework of values or some kind of social agreement. If for instance, a coherent child-torturer sincerely accepts a contingency plan which specifies that he would believe that torturing children is good under any possible future circumstances, has he earned the right to consider his value system objective? To this, quasi-realists could respond that the question also cannot be answered from the theoretical perspective, and that the response must already presuppose a conception of what it is good for people to think. In other words, it would presumably be bad to think that child-torturers have earned the right to the truth of their value system.

But how can we know who has earned the right to believe in the truth of his particular values? The quasi-realists' answer is satisfying only for those that already believe, because it advises them to continue believing. Let me use an example: the answer to the question whether God exists can appear to be different for a religious person and an atheist, and for the religious person it will certainly depend on his internal religious perspective. But why would the religious perspective apply to the atheist? A religious person would be inclined to think that the atheist is mistaken and would come to think so from the religious perspective. It is crucial to notice that this is done from a perspective, even if it is impossible to shake it off. The problem with this view is then: by taking this route, we may earn the right to use cognitive language for our normative judgments, but how do we earn the right to believe in their truth? While Blackburn is right to say that trust in the objectivity of moral talk could be a virtue, this is precisely where the theoretical and practical interact and create uneasiness. Both perspectives claim to answer the same question and command allegiance. To resolve the uneasiness we should perhaps revisit our virtues and realize that this is a problem for the practical and not the theoretical perspective.

truths (ibid 17-18). Finally, in Gibbard, Reconciling Our Aims: In Search of Bases for Ethics he thinks that coherent planning demands thinking of our psychological normative intuitions as genuine if they obtain under some idealized conditions of judgment (ibid 23). 
Let me now articulate the problem more clearly. We strive towards a unified worldview, where the theoretical and practical do not collide. Both perspectives aim to tell us something important about the nature of values, but their answers differ. Both perspectives are inescapable. Common to the several views rehearsed here is that the theoretical does not do damage to the practical: we are advised to abandon the theoretical, ignore it, or subsume it to the practical. But it is hard to resist the feeling that the theoretical perspective affects the conviction with which we can assert our values as absolute and authoritative. Bernard Williams says - rightfully - that there is 'something blank and unresponsive' in realizing that values may not be objective and that it is incredible that this consciousness should just leave everything where it was and not affect the ethical thought itself. ${ }^{35}$ What these views neglect is the fact that the cognitive form of moral language does assume an answer to the theoretical problem and that we tend to assert our moral views as universally true. ${ }^{36} \mathrm{We}$ thus need to acknowledge that the theoretical perspective has practical consequences, to the extent that the practical advances theoretical claims. The goal is to retain both perspectives: to claim that it is always good to adopt the theoretical perspective would indeed be selfdefeating, but to suppose that we need to abandon science in order to have values is equally baffling. The key is to carefully fine-tune the two perspectives until they are compatible. Let us first see where the theoretical perspective leaves us; after that, I shall say what is its proper effect on the practical.

3. The theoretical: values and contingency

There are good theoretical reasons to believe that values are mind-dependent and contingent: in other words, that there are no reasons for action independent from valuing attitudes present in our psychological sets. ${ }^{37}$ Two clarifications are in order. First, this

\footnotetext{
${ }_{35}$ Williams, Ethics and the Limits of Philosophy 159.

${ }^{36}$ Moreover, such views put us in an unstable situation in which we go back and forth between the theoretical and the practical depending on the perspective currently taken. This is easy to see if we look at an example: the realization that the instances of ethical progress - such as the abolition of slavery - were a mere change in beliefs is unsettling. To judge the abolition of slavery as a progressive move, we put on our practical hats. Once we put on the theoretical hat we see that it was not progress but a mere change, and so on without the possibility to settle on a single unified position.

${ }^{37}$ Following Bernard Williams, we can say that the statement 'A has reason to $\phi$ ' is best understood as saying 'A has some motive which will be served or furthered by his $\phi$-ing' Williams, Moral Luck:
} 
view does not entail radical subjectivism about value. Even if there are no ahistorical, acontextual and a priori values, they can be both ubiquitous and profoundly convergent. Given the commonalities in the circumstances of human life - scarcity of resources, necessity of cooperation, inevitability of death - it would actually be surprising if there were no overlap between the existing moral codes. Talk of mind-dependence, contingency and relativity does not imply cultural relativism, and can accommodate relativity to the common moral experiences that we share as humans. Second, this view does entail that there are no ethical truths external to our existing attitudes. There are no moral facts as standards fully independent from these attitudes taken as a whole, the facts that could possibly be true even if everyone thought they were not.

However, any single argument trying to demonstrate mind-dependence and the contingent nature of values would be too sweeping. I will thus focus on a claim that is more modest but at the same time captures the nature of our practical predicament: the best causal accounts of the origins of our current values show that they are a consequence of contingent circumstances rather than the perception of external and absolute ethical truths. It does not follow from this that there cannot be objective values outside our existing value-frameworks and antecedent to our experience (although the argument certainly gives us reason to doubt this), but it does follow that our existing value-frameworks are contingent and bear no obvious relation to any realm of value outside them. This creates a gap between the realm of objective values (if there are any) and our existing values leading to a paralyzing practical conclusion: all our actions are most probably morally wrong as they are a consequence of our existing values; even when our actions are not wrong, this is a matter of sheer coincidence; and finally, even when they happen to be right we cannot know if this is the case. ${ }^{38}$

Philosophical Papers, 1973-1980 101. Values could be mind-dependent and non-contingent, as there is a broader way to conceive of mind-dependence - in such a case, reasons would be mind-dependent but necessarily supervening on, or following from the necessary features of minds like ours. However, it is impossible to make this relation of necessity intelligible.

${ }^{38}$ Similar arguments from evolutionary and causal-theoretical explanations have been put forward among others - by Michael Ruse, Taking Darwin Seriously: A Naturalistic Approach to Philosophy (Blackwell 1986) ch 6; Gibbard, Thinking How to Live ch 13; Richard Joyce, The Evolution of Morality (MIT Press 2006) ch 6; Philip Kitcher, 'Biology and Ethics' in David Copp (ed), The Oxford Handbook of Ethical Theory (Oxford University Press 2006) and Philip Kitcher, The Ethical Project (Harvard University Press 2011); and Street, 'A Darwinian Dilemma for Realist Theories of Value'. Sharon Street puts the problem particularly clearly in the form of a dilemma for the realists, and my explanation of the issue is influenced 
Notice that causal accounts of the origins of our values need not undermine their truth. Concluding about the truth of a belief from its origins only is a genetic fallacy, for any origin of a belief is logically compatible with its truth. ${ }^{39}$ I can, for example, be hallucinating about there being a chocolate on the kitchen shelf while in fact there is a chocolate on the kitchen shelf, so my belief is true regardless of its origin. The same holds for ethics, since my ethical beliefs may be true even if they are a consequence of evolution and socialization. Nonetheless, we can still question whether our moral attitudes satisfy epistemic standards that would permit the assumption that they are grasping a mind-independent truth, external to these attitudes taken as a whole. To the extent to which our ethical beliefs are analogous to the hallucination case they are most probably not true, ${ }^{40}$ if the benchmark for their truth is a robust relation of correspondence between our moral attitudes and external normative facts.

To vindicate trust in the truth of our moral beliefs, one would need to offer an account that shows how the causal forces that generated moral beliefs did so in a way that makes them match the external facts. The best causal explanations, however, show the opposite: they explain the origins of our beliefs without presupposing a connection with the external moral facts. Let me focus on evolutionary explanations to demonstrate this, but notice here that if moral attitudes can in principle be a result of causal forces, then any causal argument - sociological, cultural, psychological, historical - delivers the same

by her formulation. However, I shall articulate the challenge for realists in different terms and focus more on its practical consequences.

${ }^{39}$ Even the most famous argument about the origins of morality, Nietzsche's 'On the Genealogy of Morality', should probably not be read as a direct debunking of morality through its origins but as an argument that shows how and why we came to have morally unacceptable (ascetic) values (see Friedrich Wilhelm Nietzsche, On the Genealogy of Morals and Ecce Homo (Walter Kaufmann ed, Walter Arnold Kaufmann and R. J. Hollingdale trs, 2 edn, Vintage Books 1989)). This reading, which is plausible but not beyond controversy, is offered in Brian Leiter, 'Nietzsche' in M Forster and K Gjesdal (eds), The Oxford Handbook of Nineteenth Century Philosophy (Oxford University Press forthcoming) <http://papers.ssrn.com/sol3/papers.cfm?abstract_id=2148074 > accessed 18 July 2014. Nietzsche is not always clear about his stance towards genetic fallacy. For example, in Human, All Too Human: A Book for Free Spirits (R. J. Hollingdale tr, Cambridge University Press 1996) 72, Nietzsche - talking this time about religion - takes a different view: 'the idea of a God is disturbing and humiliating as long as it is believed, but how it originated can at the present stage of comparative ethnology no longer admit of doubt; and with the insight into this origination that belief falls away'.

40 See Joyce, The Evolution of Morality 179-84. 
result; ${ }^{41}$ evolutionary explanation simply happens to be general enough and particularly credible so as to serve as a good illustration of a more general point.

\subsection{Evolutionary origins of values}

Although contemporary accounts of evolutionary origins of our moral sentiments and capacity for normative guidance are at least partly speculative, ${ }^{42}$ their insights seem plausible enough to support this conclusion: the best causal explanation of the emergence of normative thinking and ethical concepts does not presuppose the existence of external normative facts. ${ }^{43}$ Following Allan Gibbard we can formulate the question as follows: do our normative judgments represent the features of the world? ${ }^{44}$ We can easily make evolutionary sense of our perceptual judgments as representing the features of the world. Natural selection benefits those whose sensory system supports reliable descriptive judgments about external reality. The ability to spot the external fact that there is a cliff in front of me or that there is a bear in my cave is beneficial for reproductive success. The best explanation of this ability presupposes that there really are such things as cliffs and bears, because we need to judge these situations accurately in order to survive. In contrast, the best evolutionary explanation of our normative judgments does not presuppose the representation of external features of the world: we do not have the capacity for moral judgment in order to respond to normative facts but - as Gibbard puts it - in order to 'coordinate our activities in mutually beneficial ways' ${ }^{45}$

\footnotetext{
${ }^{41}$ This is - of course - valid as long as we cannot show that this process is epistemically reliable to track the truth.

${ }^{42}$ Some influential accounts are: W. D. Hamilton, 'The Genetical Evolution of Social Behaviour. I' (1964) 7 Journal of Theoretical Biology 1; W. D. Hamilton, 'The Genetical Evolution of Social Behaviour. II' (1964) 7 Journal of Theoretical Biology 17; Elliott Sober and David Sloan Wilson, Unto Others: The Evolution and Psychology of Unselfish Behavior (Harvard University Press 1998). On key issues in evolution and moral philosophy see Walter Sinnott-Armstrong (ed), Moral Psychology, Volume 1. The Evolution of Morality: Adaptations and Innateness (MIT Press 2007).

${ }^{43}$ In the next pages I will follow the structure of Allan Gibbard's early account of the development of our normative capacities, adding some details to it (Gibbard, Wise Choices, Apt Feelings: A Theory of Normative Judgment ch 6). Other accounts share a similar structure and ultimately go in the same direction. See for example Kitcher, The Ethical Project; Joyce, The Evolution of Morality; Street, 'A Darwinian Dilemma for Realist Theories of Value'.

${ }^{44}$ Gibbard, Wise Choices, Apt Feelings: A Theory of Normative Judgment 106.

45 Ibid 107.
} 
This argument must explain how the ability for coordination and norm-governed behavior would be evolutionarily beneficial for our ancestors. The burden is to show why humans would have engaged in behavior which is apparently costly for them individually but beneficial for the group. Most theories of the evolutionary development of moral sentiments start from the widely accepted 'kin-selection' hypothesis: psychological altruism in humans - our ability to act on motives the content of which is not ultimately derived from our own benefit - develops from altruism towards one's own children and kin; altruistic motives toward kin with whom we share genetic material would be more reliable and thus more adaptive for securing the success of one's genes than egoistic ones. ${ }^{46}$ Once we became capable of altruistic behavior - hence sacrificing some of our immediate desires for the benefit of others - it could spread to non-kin. The emergence of social norms would be fostered by two factors. On the one hand, life in a social group would be favored by evolution: sharing resources, tasks and knowledge would be beneficial for our reproductive success. On the other, cooperation would be constantly under threat if there were a possibility of opting out whenever the immediate benefits of pro-social behavior are outbalanced by the benefits of egoistic behavior.

Hence, the best way to understand the circumstances of the life of our ancestors is to think of them as reiterations of the prisoner's dilemma - there are mutual benefits for reproductive success to be gained if a system of cooperation is in place, but at the same time each system could always be replaced by another that would make someone better off. ${ }^{47}$ In hunter-gatherer societies there were plenty of situations where coordination would enhance the chances of reproductive success for all, and non-cooperation would undermine them. Under these circumstances, the capacity that supports cooperation would be selected, even at some immediate cost for the individual. If our emotional propensities are subject to evolutionary influence at all, it is reasonable to expect that many of them would have a coordinating purpose, including the capacity for normative

\footnotetext{
${ }^{46}$ See: Hamilton, 'The Genetical Evolution of Social Behaviour. II' Hamilton, 'The Genetical Evolution of Social Behaviour. I'; Sober and Wilson; Armin W Schulz, 'Sober \& Wilson's Evolutionary Arguments for Psychological Altruism: A Reassessment' (2011) 26 Biology \& Philosophy 251.

${ }^{47}$ Gibbard, Wise Choices, Apt Feelings: A Theory of Normative Judgment 62-66; Kitcher, The Ethical Project.
} 
guidance itself. ${ }^{48}$ Charles Darwin's early take on this question reaches a similar conclusion:

A tribe including many members who, from possessing in high degree the spirit of patriotism, obedience, courage and sympathy, were always ready to aid one another and to sacrifice themselves for the common good would be victorious over most other tribes; and this would be natural selection. ${ }^{49}$

This explanation includes a leap, whereby altruism develops at one's own cost to sustain a system that would only indirectly benefit the individual that incurs the cost. Groups in which non-kin altruism were in place would be more prosperous and thus provide a better environment for passing on genes. To be relatively secure from egoistic impulses, a system of cooperation would have to promote altruistic behavior towards members of one's own group including non-kin. Contemporary empirical research - although not entirely beyond controversy - shows that differences in genetic material between the groups themselves supported competition between groups that led to group-based altruism, and accounts for the gap between concern for one's own and the group's reproduction..$^{50}$ If one's group includes more kin-members than the outside group, one's reproductive success would be directly supported by altruism towards group members as opposed to outsiders; this especially being the case when there was a real threat of lethal intergroup competition. ${ }^{51}$

Thus - while early coordination was probably based on expected direct gains for the individual from cooperation - a stable system of cooperation would demand the development of emotional mechanisms to surpass egoistic motives, such as shame in those that fail to reciprocate and resentment of such behavior in others. The emergence of reputation and punishment could enable altruistic behavior towards others even when the benefactor is ultimately not at the receiving end of the transaction. Those with a

${ }^{48}$ Gibbard, Wise Choices, Apt Feelings: A Theory of Normative Judgment 67.

${ }^{49}$ Charles Darwin, The Descent of Man, and Selection in Relation to Sex (J.T. Bonner and R.M. May eds, Princeton University Press 1981 [1871]) 162.

${ }^{50}$ Samuel Bowles, 'Group Competition, Reproductive Leveling, and the Evolution of Human Altruism' (2006) 314 Science 1569.

${ }^{51}$ Ibid. 
good reputation would be chosen for future exchanges of benefits and cooperation, and an individual's past performances would be rewarded or punished by others. ${ }^{52}$ Building on the situation in which we shared motivational tendencies for cooperation similar to other animals, we gradually developed a complex system of 'language-infused governance of emotions' ${ }^{53}$ that is capable of controlling our feelings and allows for much more advanced coordination. Having linguistic ability, we are able to be fully informed and aware of other people's past behavior, to evaluate nonexistent situations, and to further develop and accept systems of norms or plans to coordinate our behavior. ${ }^{54} \mathrm{We}$ use our normative capacities to manage emotions by engaging in 'normative discussion, actual or imaginative, as we take positions, subject ourselves to the demands of consistency, and undergo mutual influence'. ${ }^{55} \mathrm{~A}$ system of reflective governance of emotions enables modifications of moral feelings and social learning of moral behavior that we recognize today.

If evolution has generally been able to affect our abilities, powers and the psychological setup, then there is a very plausible explanation of the emergence and content of normative capacities and moral emotions in terms of their evolutionary function. The explanation comes from the theoretical perspective: the 'function' is defined descriptively, as something that would be favored by natural selection and it has only an explanatory and not justificatory role. As the first approximation we can draw the following conclusion. The best explanation of our perceptual judgments needs to assume some correspondence between these judgments and facts about our surroundings. Their function is to represent the world as it is as accurately as possible. Our normative judgments, however, do not represent anything in the world but serve a coordinating function. They have mostly been perpetuated by the reproductive rewards of coordination and our ability to develop this system further through conscious action. ${ }^{56}$ The lesson is that the emergence of the initial ability for normative guidance

\footnotetext{
${ }^{52}$ See Joyce, The Evolution of Morality ch 1 and in particular 31-33.

${ }_{53}$ Gibbard, Reconciling Our Aims: In Search of Bases for Ethics 15.

${ }^{54} \mathrm{On}$ the role of language and culture in the development of morality, see Haidt $826-8$.

${ }_{55}$ Gibbard, Wise Choices, Apt Feelings: A Theory of Normative Judgment 81.

${ }^{56}$ Of course, our normative concepts can pick out a natural property in the world as being the thing to do or resent; according to Williams, thick moral concepts have both a descriptive and normative component and in that sense they do represent something (See Williams, Ethics and the Limits of Philosophy 140143). For example, when we say that someone is evil we both describe him as evil and we make a
} 
and many of our actual beliefs have a sound causal explanation that does not presuppose the apprehension of mind-independent moral facts.

Now, evolutionary explanation of moral behavior is not complete. Not all of our current moral attitudes are a direct consequence of evolution, as they sometimes go beyond the simple goal of group coordination and the feelings that sustain it. Other influences have interfered in the meantime, including - importantly - our capacity to govern moral feelings. People feel empathy towards members of much wider groups, and altruism is exhibited towards complete strangers or animals. Hence, the content of moral feelings may not be fully explained as an adaptation (a fitness-enhancing phenotypic trait) but as a consequence of an adaptation: perhaps our capacity for altruism that was necessary for reproductive success in small, partly kin-based hunter-gathering groups developed beyond its strict evolutionary function. Moreover, as our normative systems become more sophisticated and culturally mature, layers need to be added to the basic evolutionary narrative. Once humans acquired the capacity for normative guidance, the process of ethical change became socially embedded and guided: moral values were developed as a reaction to previous failures to secure cooperation and are informed by as Kitcher puts it - 'social apprehension of the ways in which cooperation has broken down'. ${ }^{57}$ Existing moral codes and values were socially elaborated in reaction to concrete circumstances in different societies, and thus took different shapes and forms. Moreover, the context in which the capacity for normative guidance operates has changed, not only in terms of the environment that presented our ancestors with different problems to solve, but also in terms of the development of new desires and needs; for example, a desire to develop one's talents could have become more prominent once the desire for food, shelter and health had been secured. ${ }^{58}$ Finally, the evolutionary explanation does not presuppose that we are genetically determined to make specific

normative statement about his behavior. However, even if normative judgments do represent something in the world, they are not normative in virtue of this representation. The descriptive component of a thick judgment that represents something in the world could be replaced by a descriptive judgment without loss to this representation, but without capturing the prescriptive part of the judgment. Gibbard, Wise Choices, Apt Feelings: A Theory of Normative Judgment 110-120 and Gibbard, Thinking How to Live chs 1 and 2 .

${ }^{57}$ Kitcher, The Ethical Project 98.

${ }_{58}$ Ibid 137. Contemporary sociology documents similar processes today in terms of a change from materialistic (security) to post-materialistic values (autonomy). See Ronald Inglehart, The Silent Revolution: Changing Values and Political Styles among Western Publics (Princeton University Press 1977). 
moral judgments. Instead, a more plausible picture is this: our unreflective behavioral dispositions are affected by evolution and are likely to be fitness-enhancing as they are in other animals; as a consequence of evolution, we also acquired the ability to reflect on moral motives and be normatively guided; using this ability, we further molded our unreflective dispositions through culture and social learning. ${ }^{59}$ We should thus be careful not to subscribe to genetic determinism and assume that evolutionary biology can completely illuminate the content of our present moral sentiments. But if evolution has played a role in the development of our moral attitudes, it should be able to explain at least some of our contemporary values. Let me use some examples. ${ }^{60}$

First, take one of the simplest and most universal reasons that people recognize: the reason to, ceteris paribus, avoid life-threatening dangers. This value makes perfect sense in evolutionary terms - clearly, staying alive is quite helpful if one wishes to reproduce, while dying is not. Compare this to an account that would claim that we were selected to recognize the true fact that we have reasons to, ceteris paribus, avoid life-threatening dangers, and that it just so happens that this is also beneficial for our reproductive success. At best, such an explanation introduces one step too many and at worst it is not an explanation at all. Second, we have seen that in the evolutionary explanation altruism spreads in circles, from closer kin-based to wider groups. This is again confirmed by our actual attitudes: most people think that they should care more about their children than distant relatives, about relatives than compatriots, about compatriots than foreigners, and about humans than animals. ${ }^{61}$ People believe, for example, that their children should inherit their houses, that their tax contributions should be used to support the welfare of their countrymen rather than distant others, and that eating human flesh is much worse than enjoying a beef burger. Although we are able to change and govern our emotions - and we witness important transformations in all these areas - it is remarkable that the amount of actual care for different groups still corresponds to their significance for spreading our genes. Moreover, even if the emotions of care spread

\footnotetext{
${ }^{59}$ Street, 'A Darwinian Dilemma for Realist Theories of Value' 118-119.

60 The discussion here builds on Sharon Street's examples from ibid 114-117.

${ }^{61}$ While it has sometimes been argued - especially by philosophers of utilitarian provenance - that morality implies strong impartiality or that it allows partiality because it facilitates the desired consequences better, the requirement of impartiality has been extensively criticized and shown to be detached from our contingent moral intuitions. See for example Susan Wolf, 'Moral Saints' (1982) 79 Journal of Philosophy 419 and Williams, Making Sense of Humanity ch 13.
} 
beyond our immediate group, this is not detached from the evolutionary template: because evolution favored seeing in-group members as deserving receivers of our care, moral change proceeds precisely through an extension of the notion of an in-group member. So, for example, what we see as moral progress usually presupposes a realization that other creatures are similar to ourselves, and what we see as moral regress typically presupposes dehumanizing other beings to conceive of them as less similar to us. ${ }^{62}$ Third, if we look at emotions that would be necessary to support the rudimentary systems of cooperation, we still find them today: for example, we respect and praise those that reciprocate or act altruistically, and resent those that do not reciprocate or are egoistic. ${ }^{33}$ Fourth, evolution can even explain why we would believe that our values are objective, universal and absolute. If a system of values is beneficial for reproductive success, it would be much more efficient and adaptive if people thought about it in these terms.

Evolution gives us an explanation of why we do not have these and countless other possible values, and does so without presupposing that our values track any mindindependent - transcendent or natural - moral facts. ${ }^{64}$ The force of explanation is astonishing if we understand it against the background possibility that we could have in fact thought of values as purely optional, valued breaking promises, praised torturing one's own children, or admired suicidal behavior. As Sharon Street observes, the scope of possible evaluative judgments is potentially enormous and evolutionary explanation derives its force from an outstanding overlap between our actual moral judgments and those that would be favored by natural selection. ${ }^{65}$ The alternative explanation - one that would suggest that our values do reflect mind-independent moral facts - carries the burden of showing how exactly we have evolved to track these facts.

\footnotetext{
${ }^{62}$ For a discussion in the context of animal rights, see Peter Singer, 'Morality, Reason, and the Rights of Animals' in Frans de Waal (ed), Primates and Philosophers: How Morality Evolved (Princeton University Press 2006).

${ }^{63}$ In the evolutionary account, the function of morality is to 'promote social cohesion' and 'reinforce social fabric' by resisting egoistic behavior that prevents forming mutually beneficial coalitions. Kitcher, 'Biology and Ethics' 172.

${ }^{64}$ Street, 'A Darwinian Dilemma for Realist Theories of Value' 113-121.

${ }^{65}$ Ibid $113-121$.
} 
Let us now look at the problem more analytically. There are three pieces of the puzzle we need to connect in a way that would make sense. First, there is an attitudeindependent moral truth (T); second, there are our contingent moral attitudes $(\mathrm{C})$; third, there are attitudes that are favored by evolution (E). ${ }_{66}$ There is an important correlation between $\mathrm{C}$ and $\mathrm{E}$ : if the evolutionary explanation above is correct, then we can see why our contingent moral attitudes correspond to the attitudes that would be favored by evolution. The connection to be ultimately explained is between our contingent moral attitudes $\mathrm{C}$ and attitude-independent truth $\mathrm{T}$; however - and this is the crucial point - if $\mathrm{C}$ is strongly influenced and importantly corresponds to E, then we also need an explanation of the correlation between $\mathrm{E}$ and $\mathrm{T}$. In other words, we need to see why tracking mind-independent moral truth would be favored by evolution. Moreover, until the relationship between $\mathrm{C}$ and $\mathrm{T}$ is spelled out, we cannot help ourselves with $\mathrm{C}$ to prove that something is $\mathrm{T}$, for that would beg the question: one cannot assume the connection between $\mathrm{C}$ to $\mathrm{T}$ while at the same time trying to account for it. Finally, it will not work to show that whatever $\mathrm{E}$ is also $\mathrm{T}$, for that would again need to be assessed (if it is plausible at all) starting from $\mathrm{C}$, and we need an independent and nonquestion begging reason to think that $\mathrm{C}$ tracks $\mathrm{T}$. The conundrum boils down to an old epistemological challenge to moral realism with an evolutionary twist: on the one hand, to access moral truth we always start from our contingent attitudes about it, but it is not clear what would make us reliable trackers of mind-independent moral truth; on the other hand, numerous causal forces (evolutionary ones being the most obvious) affect our contingent moral attitudes, and these causal forces are not connected in any way with independent moral truths. The realist model cannot work unless all these relationships are intelligible. ${ }^{67}$ Notice that the realist answer to the problem could roughly take two routes: one would deny or relax the relationship between $\mathrm{E}$ and $\mathrm{C}$, and then show that $\mathrm{C}$ somehow tracks $\mathrm{T}$, the other would accept the correlation between $\mathrm{E}$ and $\mathrm{C}$, and then show that $\mathrm{E}$ favors $\mathrm{T}$. Let me explain why both routes fail.

\footnotetext{
${ }^{66}$ See Gibbard, Thinking How to Live 264-267.

${ }^{67}$ Sharon Street concludes that the realists faces a dilemma: on the one hand, they can deny the connection between $\mathrm{E}$ and $\mathrm{T}$ but that would mean that we have no hope of getting to $\mathrm{T}$, for $\mathrm{C}$ is correlated to $\mathrm{E}$; on the other, they can assert the relation between $\mathrm{T}$ and $\mathrm{E}$ but this is unacceptable because the best explanation of $\mathrm{C}$ does not have to presuppose anything about T. Street, 'A Darwinian Dilemma for Realist Theories of Value' 109.
} 
3.2 Diminishing evolutionary influence

In setting out the argument in a similar form, Sharon Street, for example, supposes that our contingent moral attitudes are 'thoroughly saturated with evolutionary influence'.68 One objection could claim that this assumes too much in terms of science, and deny that $\mathrm{C}$ importantly corresponds to E. But this is not crucial for the argument. We can grant that the evolutionary explanation of our values is plausible but limited. A modest thesis following from the evolutionary account given above could be this: on the one hand, the emergence of our capacity for normative guidance - as other capacities in humans - has been a consequence of evolution; on the other, our values - as other psychological traits - have generally been under the influence of evolutionary forces and a portion of their content is a consequence of their fitness-enhancing propensity (e.g. having reasons to avoid dangers or to care about offspring). To refute this modest connection between $\mathrm{E}$ and $\mathrm{C}$ and pursue the objection, the realist would need an alternative explanation that would reject the evolutionary influence and at the same time offer a more plausible genealogy of our values (coupled, of course, in the second step with a claim that such development is oriented towards the apprehension of independent moral truths $\mathrm{T}$ ).

To my knowledge, the existing causal explanations of moral attitudes do not include such claims. It is easy to see why. Although evolution does not provide a complete causal explanation of values, the alternatives that would replace it do not seem to be better candidates to demonstrate that they match external normative truths. While evolution is at least a universal phenomenon, other explanations show the contingency in even starker terms because they must account for the enculturation of values. For example, we could look at the ways in which the major religions shaped our values, ${ }^{69}$ but then we would have to ask which one managed to get things right and why. Thus any other causal explanation would get us even further from the desired fit, for it would soon be clear that the convergence in our moral attitudes decreases once other causal

\footnotetext{
68 Ibid 114.

${ }^{69}$ For the classical example of a sociological causal explanation of moral values see Max Weber, The Protestant Ethic and the Spirit of Capitalism (Routledge 2001).
} 
factors are taken into consideration. ${ }^{70}$ To sidestep the problem, the realist must either deny that our contingent attitudes $\mathrm{C}$ are subject to causal influences, or show that the external moral truth $\mathrm{T}$ is a stronger causal force than evolution $\mathrm{E}$ and other factors that affect our attitudes.

A more sophisticated argumentative path would be to grant the evolutionary influence on our normative capacities and the content of our values, but argue that our ability for normative guidance over time becomes detached from evolutionary influences and starts to track normative truths. This explanation would both accept the limited connection between $\mathrm{E}$ and $\mathrm{C}$, and argue for a correlation between $\mathrm{C}$ and $\mathrm{T}$, without presupposing anything from $\mathrm{E}$ to $\mathrm{T}$ directly. It would hence have to demonstrate the possibility that our value-judgments took off and became - even if gradually - discontinuous with the contingent moral attitudes, and - moreover - that once they took off they also started to fit the external normative facts. Let us then focus on the possibility of the transformation of our contingent attitudes $\mathrm{C}$ and once more put aside the problem of $\mathrm{C}$ tracking T. The appealing intuition behind this objection builds on the limited reach of evolutionary explanations of our abilities, and hence attempts to account for the role of human invention, choice and social learning. For example, the ability to read English or do microbiology has grown out of the linguistic and cognitive capacities we have as humans, but the skills we have on the basis of these capacities are not innate but have to be learned and have undergone substantial refinement that need not have full evolutionary explanation. ${ }^{71}$ Perhaps something similar happened with our capacity for normative guidance: through reflection we were able to overcome the evolutionary influence on our moral attitudes.

While reflection undoubtedly plays a role in shaping our attitudes, the question is whether there is autonomous or 'pure' moral reflection that is able to counterbalance evolutionary and social causal forces. The classical Kantian picture of reflection presupposes examination of a moral attitude as an object of impartial attention while

\footnotetext{
${ }^{70}$ This is why the pressure to reject the relevance of causal explanations as such is strong. We have seen that, for example, Thomas Nagel bites the bullet and denies the truth of evolutionary theory because it undermines moral realism, and this is possibly the most honest realist answer to the problem.

${ }^{71}$ Gibbard, Thinking How to Live 265-266; Street, 'A Darwinian Dilemma for Realist Theories of Value' 142 .
} 
being unaware of other moral dispositions and one's identity. ${ }^{72}$ The theoretical and the practical perspective are here analogous: both presuppose disconnection from contingent experiences and our ability to call them into view in the quest for truth. But, this picture implausibly equates - as Bernard Williams notices - reflection with detachment. ${ }^{33}$ The mistake in this view is that it must presuppose some contingent motivation to engage in reflection in the first place and to accept its outcome. ${ }^{74}$ In the case of theoretical reflection, the pre-reflective and reflective self both search for truth, and that provides the unity of motivation; in the case of practical reflection, if we leave all of our contingent desires and motivations before we enter reflection, we then also have no reason to care about the result of the reflective exercise at all. Reflection cannot supply us with the complete practical motivation, as it is supposed to do in this picture: evaluative attitudes must enter the equation if we expect to see them at the other end, and these attitudes come from a place that is causally affected.

The question - whether a fully detached reflection can create discontinuity between $\mathrm{E}$ and $\mathrm{C}$ - is however best understood as an empirical one. Research shows that a completely detached moral reflection is an illusion; at best, we reason about moral attitudes from the perspective of other attitudes, adjusting them to the ones we find more important, or trying to achieve a higher level of coherence in our moral outlook. ${ }^{75}$ But once we reach the bedrock of firmly established moral intuitions - emotionallyladen evaluative attitudes - or a reflective coherence of these intuitions, there is nothing to support them further. Jonathan Haidt has demonstrated that our immediate reactions to moral problems are automatic and emotional, and reasoning mostly provides post hoc rationalization or attempts to change the opinion of other people. ${ }^{76}$ Multiple

\footnotetext{
${ }^{72}$ See for example: Kant, Groundwork for the Metaphysics of Morals; Nagel, The View from Nowhere. The problem of practical identity is taken up by Korsgaard, but she diverges from the Kantian tradition, because in her account those that do not care about anything at all - and thus have no practical identity would also have also no categorical moral reasons to act. See Korsgaard.

${ }^{73}$ Williams, Ethics and the Limits of Philosophy 69 and 110-119.

${ }^{74}$ Ibid ch 4 and especially 66-69.

${ }^{75}$ See: Haidt; Harman, Mason and Sinnott-Armstrong.

${ }^{76}$ As Haidt puts it, 'Psychologists ... have freed themselves from the worship of reason in the late $19^{\text {th }}$ century, when they abandoned the armchair and went into the laboratory'. Haidt 816 . The phenomenon served to some philosophers that drew an analogy between perception and moral intuition, arguing that there are response-dependent properties possessed by objects, discovered by appropriate sensitivity. See: John McDowell, Mind, Value, and Reality (Harvard University Press 1998) chs 7 and 8; David Wiggins, Needs, Values, Truth: Essays in the Philosophy of Value (Blackwell 1987) ch 5.
} 
mechanisms that prevent completely detached reflection are at work when we reason morally: we tend to side with our own group and with the people we like, we stick to the existing moral views, we aim to bring our beliefs into coherence with attitudes which are crucial for our identity and self-perception, and we seek to confirm and justify our immediate intuitions rather than to truly question them. ${ }^{77}$ This is not to say that we cannot trigger new intuitions or change attitudes through reflection and persuasion, but most of the people most of the time do not engage or are not capable of such reflection, and so the transformative potential of reflection is limited. ${ }^{78}$ There are thus serious doubts about the ability of reflection to generate a radical disconnect with evolutionarily affected moral attitudes. If we are able to overcome the evolutionary influence on our attitudes and discover the true way to live $\mathrm{T}$, we should be able to do so as 'normal human beings in normal conditions'. ${ }^{79}$

To surpass this problem, one could turn to the role of extraordinary individuals that spur revolutionary ethical changes. Compare: in the same way that scientists have been able to improve our common theoretical sense, progressive individuals - philosophers included - could have managed to ignite progress within our common ethical sense. The analogy, however, needs more detail. Much of scientific progress proceeds in a way similar to the method of 'reflective equilibrium', familiar from ethics: taking some beliefs and theories to be true and questioning others. ${ }^{80}$ In both science and ethics, we are repairing the ship while at sea, ${ }^{81}$ and there is always some continuity with previous beliefs and intuitions. ${ }^{82}$ To the extent that there is gradualness in ethical thinking, we should not expect the $\mathrm{E}$ to $\mathrm{C}$ connection to be lost by any amount of reflection, and all of our subsequent ethical attitudes would still be continuous with the initial ones, affected by evolution. Yet, there is a crucial difference: we have an evolutionary explanation of why our theoretical beliefs represent the world as it is, and why ethical attitudes do not.

\footnotetext{
${ }_{77}$ Haidt $820-822$.

${ }^{78}$ Ibid 819-824.

79 Gibbard, Thinking How to Live 267.

${ }^{80}$ Naturalist realists used this correct observation about the sciences to argue that ethics and science are in fact analogous. See: Sturgeon, 'Moral Explanations'; Nicholas Sturgeon, 'Moral Explanations'; Boyd; Brink. Much of this chapter argues that the analogy between the theoretical and practical perspective is misleading.

${ }^{81}$ The metaphor is from Williams, Ethics and the Limits of Philosophy 113.

${ }^{82}$ Harman, Mason and Sinnott-Armstrong.
} 
If a radical ethical change by reflection were possible, it would occur in episodes of revelation, perhaps similar to those of scientists making paradigm-changing discoveries, where new observations play a crucial role. It is indeed tempting to make this parallel and describe ethical intuitions about certain events as 'perceptions', as we often make our judgments instantly and with an immediate emotional reaction. However, it is impossible to make these judgments without having an already acquired propensity to react in a certain way. We are only able to make sense of moral problems starting from socially embedded concepts; otherwise we would not think of them as problems in the first place. Some people may be capable of a more reflective approach to moral issues that generates significant changes in their and other people's attitudes, but the process through which this happens is also not accurately described as revelation or perception but as - particularly imaginative, sensitive and reflective - endorsement of moral emotions that are not too far from the already existing ones taken as a whole.

History also does not mention moments of eye-opening ethical revelations. ${ }^{83}$ After studying actual historical records on the role of reformers in ethical changes, Kitcher for example concludes that there is no reference to sudden discoveries of an external ethical reality or of unexpected forces that revealed themselves upon observers: ' $[\mathrm{t}]$ he historical figures who figure in ethical transitions ... do not start from some situation in which they lack ethical convictions, follow a process of reasoning or observe some facet of reality, and thereby arrive at a well grounded belief in an ethical judgment', ${ }^{84}$ but they approach the issue in the vocabulary of their culture and make proposals on the basis of information they find salient'. ${ }^{55}$ Typically, ethical changes include a realization that current attitudes are based on a factual mistake (e.g. discovering that women are not less capable than men) coupled with a steadily growing emotional reaction that this insight does not cohere with the prevailing attitudes. The process ends with a new emotional stability that is found by adjustments in other incoherent attitudes. ${ }^{86}$

${ }^{83}$ See generally: Kitcher, The Ethical Project chs 4 and 5; Jerome B Schneewind, The Invention of Autonomy: A History of Modern Moral Philosophy (Cambridge University Press 1998) ch 23.

${ }^{84}$ Kitcher, The Ethical Project 179.

${ }^{85}$ Ibid.

${ }^{86}$ Ibid 178-186. The motivation to bring into coherence the most important parts of our worldview is also explicable in psychological terms. For the most part it is a 'defense motivation' or 'terror 
Moreover, to be truly inspiring, these changes initiated by remarkable individuals need to build on actual social attitudes and prevailing sentiments, and are best described - if we are to use scientific metaphors - not as discoveries but as successful and possibly useful inventions. ${ }^{87} \mathrm{~A}$ realistic understanding of moral reflection thus confirms the continuity between $\mathrm{E}$ and $\mathrm{C}$. The fact that changes are always more gradual than they may seem does not of course prove that over time change will not be comprehensive or even complete; however, since there is a significant overlap between the moral attitudes favored by evolution and actual contingent attitudes today $(\mathrm{E} \Rightarrow \mathrm{C})$, we have all the reason we need to doubt this. Finally, even if change did happen, we still do not have an explanation why more reflection would lead to moral truth $(\mathrm{C} \Rightarrow \mathrm{T})$.

\subsection{Expanding evolutionary influence}

The second strategy a realist could adopt would be to accept the influence of evolution on our contingent moral attitudes $(\mathrm{E} \Rightarrow \mathrm{C})$, but argue that there is a correlation between evolutionarily favored attitudes and morally correct ones $(\mathrm{E}=\mathrm{T})$. As this explanation needs to account for the relationship between $\mathrm{E}$ and $\mathrm{T}$ it must at a minimum start with a claim that there is an overlap between the two. But it must also offer an argument why this is so, for it would otherwise restate the problem: it would simply accept a correlation between $\mathrm{E}$ and $\mathrm{C}$ and assert that it just so happens that $\mathrm{E}$ and $\mathrm{T}$ are connected. This is, of course, not enough to defend moral realism because the question is precisely how to account for the relationship between $\mathrm{E}$ and $\mathrm{T}$, which would then support $\mathrm{C}=\mathrm{T}$, the connection we are ultimately after. We may think of two ways in which the argument could be provided.

management' strategy (Haidt 820-821) whereby we shift to our own cultural worldview once we are faced with unsettling truths about our existence. We feel 'crippling anxiety' when confronted with challenges to our self-definitional attitudes, which include moral values (ibid 821).

${ }^{87} \mathrm{On}$ a general level, we may notice that these moments occur when societies that are going through major transformations need new solutions to coordination problems, or when two sets of incongruent beliefs that follow these changes collide: perhaps this happened when Christian culture surpassed the ancient cultures of Greece and Rome, or nowadays when modern secular societies strive to overcome their religious roots and find new models for cohesion and cooperation. See Schneewind 550-551, and also chs 23 and 24, where Schneewind discusses how Kant's moral philosophy grew out of the concerns of his time, and depended on his cultural background. 
The first does not claim any independent causal link between $\mathrm{E}$ and $\mathrm{T}$, but merely tries to establish correspondence between the two. In such a case, evolution may or may not have made $\mathrm{C}$ track the truth $\mathrm{T}$, but we have an independent confirmation that $\mathrm{E}$ and $\mathrm{T}$ are identical. The form of the argument is indeed correct, as establishing a causal connection between $\mathrm{E}$ and $\mathrm{T}$ is not necessary - if $\mathrm{E}=\mathrm{C}$ and $\mathrm{E}=\mathrm{T}$ then it follows that $\mathrm{C}=\mathrm{T}$. But such an argument suffers from the structural problem identified above: it cannot offer an account of moral truth $\mathrm{T}$ that will hold independently of our contingent moral attitudes $\mathrm{C}$, and that is exactly the relationship that needs to be specified $(\mathrm{C}=\mathrm{T})$. Independent confirmation that $\mathrm{E}$ correlates to $\mathrm{T}$ can come from the theoretical or practical perspective, and David Copp's treatment of this issue can illustrate the problems with both approaches. ${ }^{88}$

Copp agrees that evolutionary forces have significantly affected our actual moral attitudes, but wants to refute the evolutionary challenge by providing an account of the 'truth conditions for moral propositions's9 that aims to shed attitude-independent light on $\mathrm{T}$. In his view, moral standards are true if they are included in or implied by the moral code the currency of which in the relevant society would enable the society better to serve its basic needs than would the currency of other sets of norms'. ${ }^{90}$ Let us assume that this desideratum can be sufficiently specified and that his theory is able to discriminate between true and untrue standards. We can see that Copp's theory presupposes a significant overlap between $\mathrm{E}$ and $\mathrm{T}(\mathrm{E} \approx \mathrm{T})$ and - because evolution does favor norms that better satisfy the needs of societies such as cooperation and cohesion we can further assume that he succeeds in establishing this.

But how does it fare as a theory of 'truth conditions of normative propositions'? Such a theory must hold true without recourse to contingent attitudes $\mathrm{C}$ for it would otherwise

\footnotetext{
88 David Copp, 'Darwinian Skepticism about Moral Realism' (2008) 18 Philosophical Issues 186. Copp does not explicitly differentiate the two versions of the possible response that I wish to distinguish here: the internally moral one, arguing that $\mathrm{E} \approx \mathrm{T}$ holds, and the external one that wishes to explain how this happened. For the response, see Sharon Street, 'Reply to Copp: Naturalism, Normativity, and the Varieties of Realism Worth Worrying About' (2008) 18 Philosophical Issues 207.

89 Copp, 'Darwinian Skepticism about Moral Realism’ 198, 199.

${ }^{90}$ Ibid 200. According to Copp, this is a 'realist theory according to which the moral facts are identical to certain ordinary natural facts having to do with the needs of the societies'. Ibid 203.
} 
not settle the issue. This depends on whether Copp's theory includes substantive views about $\mathrm{T}$; in other words, whether the ideas that it relies on - such as that each society has 'needs' and that a moral code has a 'function' - are evaluative or not. Copp is ambivalent on whether his theory takes the theoretical or practical perspective and does not clearly delineate between the two:

My argument for the society-centered theory rests [...] on second-order philosophical intuitions, including the idea that morality has the function of making society possible, and on the standard-based account of the semantics of normative judgment. To be sure, we would not find the society-centered view to be plausible if its implications conflicted dramatically with our moral views $[\ldots]$ Yet my argument does not rest on our moral intuitions. Indeed, I think we can imagine a Martian philosopher, with different substantive moral intuitions than we have, nevertheless coming to accept the society-centered theory for the very reasons that led me to the society-centered view. ${ }^{91}$

The problem in this passage is that Copp makes his theory both dependent and independent from contingent moral views: it would be implausible if it did not match our moral views but it supposedly does not depend on such views. Where does the confusion come from? Let us see how the Martian philosopher (call him Marty) would understand the problem.

Suppose Marty is approaching our planet as an anthropologist and takes the theoretical perspective. He examines our moral codes and indeed concludes that Copp's account accurately represents important truths about our practices. Has Marty found the absolute moral truth T? No, because Marty needs to examine our actual moral practices and attitudes $\mathrm{C}$ to generalize to his conclusion, and if our contingent attitudes $\mathrm{C}$ were very different, then his account of T would be different as well. Now, to this Copp could object that his theory gives us only the 'truth conditions' for moral propositions, a metaethical framework fully independent from contingent moral attitudes C. This would mean that Copp's theory is defined in a sufficiently formal way to accommodate

\footnotetext{
${ }^{91}$ Ibid. Perhaps the reason why Copp is convinced by his second-order philosophical intuitions is because he thinks they are immune to evolutionary influence: 'It is implausible ... that the content of the secondorder intuitions that I invoked has been strongly influenced by evolutionary psychology' (ibid).
} 
the differences between sets of contingent attitudes $\mathrm{C}$ and $\mathrm{Cm}$, valid on Earth and Mars respectively ${ }^{92}$ Martians could define the needs of their society in a morally repugnant way judging from our perspective $\mathrm{C}$ : they may, for example, favor mass rape as the best way in which their society can reproduce, or they may think that the basic 'need' of their society is not reproduction and coordination but complete annihilation of its own members. Would $\mathrm{Cm}$ then qualify as a true moral code on Copp's test? If yes, then Copp's theory does not include any normative assumptions and can accommodate both $\mathrm{C}$ and $\mathrm{Cm}$ as true sets of beliefs. However, it cannot then separate between $\mathrm{C}$ and $\mathrm{T}$. This is because $\mathrm{T}$ would then only restate the set of contingent evaluative attitudes in any given society $(\mathrm{C}, \mathrm{Cm}) .{ }^{93}$ Moral truth $\mathrm{T}$ is then equivalent to whatever the society contingently believes is the case $\mathrm{C}$ : it tells us to do whatever we anyway think we should do. But notice that the notion of mind-independent truth $\mathrm{T}$ presupposes at least the possibility that some of the contingent attitudes $\mathrm{C}$ may not be true, and that it needs to hold true independently of actual moral attitudes. To say that $\mathrm{T}$ is always depends on $\mathrm{C}$ gives up on the notion of $\mathrm{T}$ as mind-independent, and is something that anti-realists would gladly accept.

Suppose on the other hand that Marty takes the practical perspective and wants to find out how to live. Would Marty be convinced that David Copp from planet Earth has found the true way of living T? No, if the contingent attitudes $\mathrm{C}$ and $\mathrm{Cm}$ are not similar. To answer the internal moral question about the best way of living that would also retain the critical distinction between $\mathrm{C}$ and $\mathrm{T}$, Copp's theory would need to do some

\footnotetext{
${ }^{92}$ Russ Shafer-Landau offers an argument that is supposed to sidestep the problem. In his view, someone who thinks that torturing children for fun is moral simply fails to understand what morality is. Thus, the concept of morality has semantic boundaries which allow us to define morality in non-moral terms, so the Martian morality simply does not count as true morality. This definition is supposed to hold without any moral assumptions feeding into the conception of absolute moral truth $\mathrm{T}$. However, this argument does not go through. Evolutionary explanations aim to account for the evaluative rather than narrowly defined moral attitudes, so we cannot sneak in evaluative assumptions on the basis of semantics, because that would still beg the question (C would be equalized with $\mathrm{T}$ ). See Russ Shafer-Landau, 'Evolutionary Debunking, Moral Realism and Moral Knowledge' (2012) 7 Journal of Ethics \& Social Philosophy 1, 1112 .

${ }_{93}$ This is actually the view Copp holds: he thinks that his philosophical intuitions that support his theory are not 'moral views that speak how to behave'. (Copp, 'Darwinian Skepticism about Moral Realism' 204) If this is the case, then his theory simply accommodates any contingent value that a society may have and is thus saying that $\mathrm{T}$ is whatever is C. For example, a theory that claims that the truth of any moral proposition depends on its coherence with the set of other accepted propositions would also be formal, in the sense that we cannot infer any normative conclusion from it only, without knowing other evaluative attitudes.
} 
independent normative work and help us tell true from false moral judgments. But if it allows us to say that $\mathrm{C}$ is true and $\mathrm{Cm}$ is not, it already contains normative assumptions that are dependent on the set of contingent beliefs (in this case $\mathrm{C}$ ) and cannot thus show, but can only presuppose, that $\mathrm{C}=\mathrm{T}$. Recall that Marty could hold a set of beliefs that is completely different from Copp's theory: perhaps Martians never depended on living in groups and never experienced competition for resources, and the struggle for reproduction under the conditions of life on Mars has led them to hold a completely different set of moral attitudes. Copp's theory, based on C, would be very different from Marty's contingent attitudes $\mathrm{Cm}$, and he would reject it as a true way of living judging from his own worldview. ${ }^{94}$

To conclude, the theory is thus either too thin or too thick to be independent from contingent attitudes about morality: an account of moral truth $\mathrm{T}$ would need to point to things that are worth pursuing in life independently of our own views about them. The problem is that there are no normative theories of moral truth $\mathrm{T}$ that would strike every imaginable observer as correct. Even if most people find them plausible, they do so because they already occupy a particular spot in the universe with a set of contingent

${ }^{94}$ Although I deal with Copp's argument here, many other objections to evolutionary skepticism about absolute ethical truths take a similar form and suffer from the same inadequacies. See for example David Enoch, 'The Epistemological Challenge to Metanormative Realism: How Best to Understand It, and how to Cope With It' (2010) 148 Philosophical Studies 413. Enoch assumes that survival is roughly good independently of our attitudes $(\mathrm{T})$ and then shows how it is plausible that $\mathrm{E}$ matches $\mathrm{T}$ because our evolutionarily induced attitudes fit the truth that he presupposed (ibid 430-435). This does not explain anything, as he asserts $\mathrm{T}$ starting from $\mathrm{C}$, and assumes the relationship between $\mathrm{C}$ and $\mathrm{T}$ that he needs to explain. Nonetheless, he raises an important point which I will address later on: if one is not allowed to use any $\mathrm{C}$ to account for $\mathrm{T}$, if it has to be done independently, then this may amount to general skepticism about perceptual judgments as well because evolution itself does not have an evolutionarily deep vindication (ibid 435). A similar argument is put forward by Erik J Wielenberg, 'On the Evolutionary Debunking of Morality' (2010) 120 Ethics 441. He assumes certain facts about rights (T). As he puts it: 'the presence of the very cognitive faculties that cause (or at least causally contribute to) my belief that I have certain rights also entails that I have those very rights' (ibid 458). In this view, cognitive capacities 'entail' moral facts $(\mathrm{T})$ and lead us to believe that we have those rights (C), so we supposedly have an explanation that connects $\mathrm{C}$ and $\mathrm{T}$ (the same capacity that is constitutive of $\mathrm{T}$ makes us believe $\mathrm{C}$, and $\mathrm{C}=\mathrm{T}$ holds). However, it is not at all clear why would cognitive capacities 'entail' certain facts about rights if we do not show this starting from C. Perhaps this is why Wielenberg - similarly to Enoch supposes that the relationship of supervenience of moral facts on natural facts is a relationship which has 'no further explanation' (ibid 460), just like laws of nature have no such explanation or vindication. The supervenience of moral facts on natural facts is then a 'necessary feature of the universe' (ibid 461), a fundamental fact that cannot be explained. To say that there is no need for or possibility of explanation is not the same as to offer one and hence does not answer the problem. However, this answer - as I understand it - poses a variation of the question identified by Enoch: why would we not ask for a deep vindication for evolution if we ask one for morality, as they both may be simply the most fundamental facts about the universe? 
attitudes. Therefore, either Copp's second order philosophical intuitions are theoretical, in which case he has offered a theory of moral truth that generalizes and makes best sense of the existing social practices and contingent attitudes $\mathrm{C}$, or he has given us a moralized account of $\mathrm{T}$ from the practical perspective that also presupposes $\mathrm{C}$. In each case, he has not accessed to $\mathrm{T}$ without recourse to $\mathrm{C}$, which is something that the successful rebuttal of the objection would need. ${ }^{95}$

The only way to surpass the problem is to take the other route identified above: to try to establish a causal link between $\mathrm{E}$ and $\mathrm{T}$. This path would affirm $\mathrm{E} \Rightarrow \mathrm{C}$, but also argue that $\mathrm{E} \Rightarrow \mathrm{T}$ holds. It would show that it is no coincidence that our moral attitudes are true and would - as Gibbard puts it - offer a 'deep vindication' of our ability to make true moral judgments. ${ }^{96}$ For the reasons already mentioned it does not suffice to simply assert that whatever is evolutionarily beneficial is good, as this claim would have to be supported by an argument that starts from our contingent attitudes $(\mathrm{C}=\mathrm{E}$ and $\mathrm{C}=\mathrm{T})$. Moreover, the claim is implausible if one actually starts from C. From the fact that doing $\phi$ fulfills our evolutionary function, it does not follow that there is a moral requirement to $\phi$ : for example, if my biological function were to reproduce it would not follow that I have a moral duty to reproduce or donate to the sperm bank as much as I can. ${ }^{97}$ There is a difference between biological functions and moral oughts. As Joyce puts it, '[j] ust as the fact that the function of an assassin is to kill people doesn't imply that he has any reason to do so ... the ascription by the same logic of a biological function to humans would not imply any practical reason to fulfill the function'.98 This illustrates our inability to surpass the contingent evaluative attitudes in our moral judgments $\mathrm{C}$ and reach directly absolute moral truths $\mathrm{T}$. If we assume that E really does determine $\mathrm{T}$, then it would follow that discovering biological facts about evolution could settle

\footnotetext{
${ }^{95}$ Copp could argue that we are able to grasp moral truths $\mathrm{T}$ by pure theoretical reflection or some transcendental process but that is implausible for the reasons already mentioned.

${ }^{96}$ Gibbard, Thinking How to Live ch 13.

97 The last example is from Robert Nozick, The Nature of Rationality (Princeton University Press 1993) 30: 'Males now are not, I presume, beating at the doors of artificial insemination clinics in order to become sperm donors, even though that would serve to increase their inclusive fitness.' Nozick's point is different than mine - to draw attention to the fact that even if we are predisposed to increase reproductive fitness it does not mean that we are predisposed to be most reproductively fit at all costs.

${ }_{98}$ Joyce, The Evolution of Morality 174.
} 
moral problems: for instance, the discovery about the most evolutionarily beneficial norms for conducting abortion would determine the outcome of the abortion debate. ${ }^{99}$ But this is manifestly not plausible - this debate can be settled only by engaging in moral persuasion within the contingent moral practice $\mathrm{C}$ - and facts about evolution would rarely if ever count for something in our evaluative judgments.

The final way for a realist to get out of the conundrum is thus to suppose that evolution would make us track T. This explanation would have to show that there is some evolutionary benefit to grasping an independent moral truth $\mathrm{T}$, in addition to accepting contingent norms beneficial for reproductive success. However, presupposing moral truth is superfluous in the best explanation of the origins of our moral attitudes. Consider an example: contingent attitudes $\mathrm{C}$ are such that we provide more care for those that we consider our in-group members. This is the explanandum. The anti-realist evolutionary explanans is that this attitude - for all the reasons mentioned - promoted reproductive success of the members of the group. The alternative realist explanans is that grasping moral truth $(\mathrm{T})$ of favoring in-group members promoted reproductive success. There are two problems the latter explanation needs to face, coming both from the theoretical and practical perspective. First, it is not clear how its explanans sheds light on the explanadum it sets out to explain: it adds an unnecessary element to the story and does not show why we happened to have the attitudes we have. It tells us that we ended up having these attitudes because they are true, which is not better than simply asserting the belief in $\mathrm{C}=\mathrm{T} .{ }^{100}$ Second, moving to the practical perspective, this explanation commits itself to the view that $\mathrm{C}$ (such as caring more for the in-group members) is always in the neighborhood of $\mathrm{T}$. This is because on this account evolution brings contingent attitudes to match $\mathrm{T}$. But the thought that $\mathrm{C}=\mathrm{T}$ would make many feel uncomfortable, for if we believe in absolute moral truth we may want to leave the possibility that we could all be wrong in our current moral attitudes towards the members of outside groups. So how can we tell whether valuing the members of our group more than outsiders is morally correct? This brings us to the next problem.

\footnotetext{
99 Ibid $176-177$.

${ }^{100}$ Sharon Street argues that the anti-realist explanation is more parsimonious, clearer and sheds more light on the phenomenon. Street, 'A Darwinian Dilemma for Realist Theories of Value' 129-134.
} 
The $\mathrm{E} \Rightarrow \mathrm{T}$ explanation faces problems when the dimension of temporal change in contingent moral attitudes $\mathrm{C}$ is introduced. Evolution is an indefinite process and if $\mathrm{T}$ is by definition absolute and static, then it follows that we can never reach it. This gap between $\mathrm{E}$ and $\mathrm{T}$ thus defeats the possibility that $\mathrm{C}$ could match $\mathrm{T}$. Our contingent attitudes $\mathrm{C}$ are undoubtedly in a constant state of flux, changing over time, and if $\mathrm{E} \Rightarrow \mathrm{C}$ is true then the process will continue endlessly into the future. If - at the same time we are approximating to moral truth $(\mathrm{E} \Rightarrow \mathrm{T})$ then the question is: has that already happened or is it about to happen? Again, the temptation is to assess the proximity of $\mathrm{C}$ to $\mathrm{T}$ at any given point in time starting from our current contingent attitudes. This is where the realist explanation may face a morally unacceptable consequence, because it is forced to argue that any prevailing attitudes $\mathrm{C}$ must approximately be true, because evolution has brought us in the ballpark of normative truths $\mathrm{T}$. But the moral plausibility of this claim depends on the time at which the argument is made: for example, we would get different answers from ancient Egyptians, the founding fathers of the US, or hipsters living in Brooklyn. We can always find out tomorrow that our attitudes of today are morally repugnant. Or - even more problematic - we could feel that things have changed for the worse. It does not help to argue that $\mathrm{T}$ also changes over time to fit the factual circumstances: if we believe in $T$ then we surely want to say that slavery was wrong period, not that slavery is wrong under present circumstances. The same argument from $\mathrm{E} \Rightarrow \mathrm{T}$ could have been made when slavery was widely accepted. We are not warranted to assume that we have reached the end of evolution at any particular moment. How can we ever know if we have reached the truth T? We cannot, except by judging from our contingent attitudes. But for all we know we may be very far from $\mathrm{T}$, and - in fact - it is most probably beyond our reach as we indefinitely evolve in our attitudes. So we constantly search but never find $\mathrm{T}$, and we need to face the consequences of this thought. 


\subsection{Defying evolution}

Finally, let me address the main objection to this view. Most counter-arguments are defensive: they neither show the existence of mind-independent moral truths $(\mathrm{T})$ with causal powers, nor offer convincing alternative accounts that show how we would reliably track them; ${ }^{101}$ rather, they typically draw the analogy between our knowledge of moral facts and mathematical or philosophical facts, pointing to the 'companions in innocence'. ${ }^{102}$ However, these could well be the 'companions in guilt' - for example, one could reject the view that there are distinct 'philosophical facts'; ${ }^{103}$ or they may not be 'companions' at all - for instance, one could indicate that a significant portion of mathematical knowledge figures in scientific explanations. ${ }^{104}$ But there is a potentially more threatening objection of this sort which concerns the benefit of the doubt that we

\footnotetext{
${ }^{101}$ Moral naturalists do claim that there are moral facts that are identical or supervene on natural facts and thus have causal powers. Replying to Harman's challenge about the role of moral facts in the best scientific explanations, naturalists of this sort argue that robustly true moral facts do play a role in scientific explanations. See for example: Sturgeon, 'Moral Explanations' Sturgeon, 'Harman on Moral Explanations of Natural Facts'; Boyd; Brink. For a successful and succinct rebuttal of these claims see Leiter, 'Moral Facts and Best Explanations'. There is simply no evidence that any social science explanation ever supposed the truth of moral beliefs and gained anything in terms of its explanatory potential; moreover, it is not clear why would they need to suppose the actual truth of our moral beliefs instead of just our belief in their truth. For example, if moral truth played any causal role in the abolition of slavery, nothing is added in terms of scientific explanation if we suppose that the abolitionists' beliefs were true instead of simply saying that abolitionists believed their beliefs were true (if they actually did). An additional layer of problems is that - on all these accounts - it is not clear how the characteristic practical relevance of morality, the 'ought' that we feel, can be a property of external, natural facts. This would make moral facts different from any other natural fact. For a convincing argument of this kind see Joyce, The Evolution of Morality ch 6.

${ }^{102}$ Street, 'A Darwinian Dilemma for Realist Theories of Value' 129-134.

103 The example of 'philosophical facts' is from Wielenberg $28-29$.

${ }^{104}$ The analogy with mathematics is roughly this: in both ethics and mathematics, there is no object that our judgments are about, and we are able to reach judgments simply by reasoning about them. (See for example formulation of the problem in Thomas Scanlon, 'The Appeal and Limits of Constructivism' in James Lenman and Yonathan Shemmer (eds), Constructivism in Practical Philosophy (Oxford University Press 2012) 226-227. Yet, most of us do not doubt that mathematical judgments can be true in a robust sense. However, the evolutionary explanation of our mathematical ability presupposes that it would help us judge reality accurately, and realize, for example, that $2+2$ are 4 instead of 2 (say, tigers hunting us in the jungle, quite useful information for reproductive success). Further, many true mathematical facts figure in scientific explanations, while true moral facts play no such role. As Gibbard puts it 'at least for arithmetic and geometry, mathematics is part and parcel of empirical knowledge', the fact that we have knowledge of mathematics is one 'aspect' of our empirical abilities (Gibbard, Reconciling Our Aims: In Search of Bases for Ethics 21). Even the mathematical facts that do not figure in scientific explanations presuppose the truth of and are continuous with mathematical facts that do figure in scientific explanations, and - moreover - they may come to be scientifically useful in future. See more generally on this question: W. V. Quine, ‘Two Dogmas of Empiricism’ (1951) 60 The Philosophical Review 20; Quine, "Two Dogmas of Empiricism"; Hilary Putnam, Philosophy of Logic (Harper \& Row 1971) chs 7 and 8. A recent counter-argument to the view expressed here is Justin Clarke-Doane, 'Morality and Mathematics: The Evolutionary Challenge' (2012) 122 Ethics 313.
} 
grant to perceptual and moral judgments respectively. The objection is well captured by Russ Shafer-Landau:

If we are required to suspend judgment about all perceptual beliefs - as we must, if required to do so in the moral case - then we will most likely not be in a position to confirm the reliability of our perceptual faculties. We must presuppose the truth of at least some central, widely uncontroversial perceptual beliefs in order to get the confirmation of our perceptual faculties off the ground. But if we are allowed such liberties in the perceptual realm, we should be given similar license for morality. And then the debunking game is up. ${ }^{105}$

Shafer-Landau here relies on the notion of parity in reasoning between perceptual and moral judgments. If we are not able to resort to $\mathrm{C}$ in order to vindicate the existence of $\mathrm{T}$, then equally we cannot presuppose the truth of contingent perceptual judgments to vindicate the facts about the objects of our perception. We must grant the same initial plausibility to both.

The objection does not do much damage to the argument in this form. To show this we need not rely on the differences between the phenomenology of our perceptual and moral judgments: in other words, to the fact that we tend to agree about the things we see, while we disagree about the things we ought to do. Instead, recall that the evolutionary test shows why our perceptual judgments are true - their accuracy in tracking mind-independent truth is beneficial for reproductive success, but the same case cannot be made for moral judgments. The objection thus must raise the stakes higher, for it must deny that the evolutionary test is valid. It could then take the following route: the belief in evolution itself must presuppose the truth of some of our perceptual judgments that are at the foundation of our ability to do science. If so, then the argument is circular, as the very test that is supposed to vindicate our perceptual judgments must presuppose the truth of some of them. If we cannot assume that $\mathrm{C}=\mathrm{T}$ is true in the moral case, then we equally cannot presuppose the contingent truth of

${ }^{105}$ Shafer-Landau 28. I will discuss the objection in a more damaging form thus departing somewhat from Shafer-Landau's formulation. 
evolutionary beliefs (Cevolution) to show the truth of evolution (Tevolution). Therefore, evolutionary discrediting of moral attitudes analogously discredits beliefs about evolution. More fundamentally, the idea would be that just like the 'one thing physics cannot do is account for its own possibility', ${ }^{106}$ evolution cannot stand on its own feet to explain itself. The dilemma is this: either moral truth enjoys the same benefit of the doubt as the truth of evolution, and values are as well among the fundamental features of the universe; ${ }^{107}$ or evolutionary explanation 'hammers itself into the same ground into which it had previously pounded morality'. ${ }^{108}$ If we do not want to end up with a skeptical view about evolution itself, we need to give up on the evolutionary test for truth and knowledge.

Notice however that the objection misinterprets the target of the evolutionary test of our epistemic abilities in the moral domain. The evolutionary test does not aim to offer an all-encompassing account of knowledge, but - much more modestly - to point out that if evolutionary theory is right we have reasons to doubt our ability to track mindindependent moral truths. It is notoriously difficult to show that there is no evil demon that controls our senses, that the world around us exists, or that it functions according to scientific laws. So the argument does not aspire to do that. It does not offer an epistemic foundation from which we could derive all our justified beliefs. It argues instead - that the belief in the possibility that our moral attitudes match the external normative truths does not sit well with the web of beliefs that we are quite confident about. ${ }^{109}$ Now, it is then equally open to anyone to argue that unless we show why our perception and scientific theories are true we cannot rely on them to cast doubt on our knowledge of mind-independent moral truths. The flipside of this objection is that among its premises it must question the truth of evolution and the validity of scientific

\footnotetext{
${ }_{106}$ Putnam, The Collapse of the Fact/Value Dichotomy and Other Essays 106.

${ }^{107}$ For this kind of view, see Nagel, The Last Word 140: 'Practical reason, like theoretical reason, may be among the fundamental biological possibilities on which natural selection operates...'.

108 Peter Railton, 'Darwinian Building Blocks' in Leonard D Katz (ed), Evolutionary Origins of Morality: Cross-Disciplinary Perspectives (Imprint Academic 2000) 57, cited in Joyce, The Evolution of Morality 183. ${ }^{109}$ It could even be argued that this is as much as we can say in general about knowledge, but the argument from evolution does not need this. It needs only to presuppose the truth of evolution. For a non-foundationalist approach to knowledge see Quine 39-43.
} 
forms of explanation. ${ }^{110}$ The counter-argument to the objection is thus a reductio ad absurdum. While evolutionary theory and the perceptual judgments that are at its basis may not enjoy an epistemically privileged status, the realist modus tollens is hard to swallow: evolutionary theory implies that we cannot be certain about the truth of our moral judgments, we are certain about the truth of our moral judgments, therefore evolutionary theory is false. ${ }^{111}$

We are in a way back at the beginning. The commitment to the possibility of knowledge of mind-independent moral truths puts us in an uneasy position between the theoretical and the practical perspective. There are good theoretical reasons to doubt that our attitudes track mind-independent moral truths. The reason why some find the realist modus tollens against evolution convincing is because they think that the theoretical is intrusive on the practical. It seems as if they must give up on their moral attitudes and suspend all moral judgments until the theory is demonstrated to be false. So they choose differently: to retain the practical at the expense of the theoretical. But practical consequences are different.

4. The practical: confidence and reflection

Our inability to reach the realm of mind-independent values ends in a paradox: the practical perspective is inescapable and includes value-judgments; we can only make these judgments on the basis of our contingent values which are disconnected from the presupposed realm of robustly true values; what we ought to do (reason from robustly true values) bears no systematic connection to what we can do (reason from our own values), hence the ought-talk is completely confused as we have no hope to ever actually willingly do what we ought to do. How should we treat our moral judgments upon this realization? The problem could lead to a stalemate. It could seem that - when it comes to living our lives - we are deeply misguided. Performing the right action becomes unavoidably a matter of luck and coincidence. Blackburn describes the problem lucidly:

${ }^{110}$ It is not a coincidence that Shafer-Landau's preferred solution to the problem is to simply presuppose $a$ priori, metaphysically necessary moral truths (Shafer-Landau 31).

${ }^{111}$ This seems to be Nagel's view. See Nagel, Mind and Cosmos: Why the Materialist Neo-Darwinian Conception of Nature is Almost Certainly False 188 and the discussion of this view in the first section of this chapter. 
'the nightmare is one of being left no basis for trust in [one's own] judgment. It is the fear of being left unable to judge at all and so, in an entirely literal sense, the fear of losing [one's] mind.' ${ }^{112}$ It is not surprising that the theoretical perspective faces opposition. We want to think of ourselves as reliable in deciding how to live.

I want to argue that there are two consequences of this predicament for the practical perspective. They both pertain to the second order evaluative attitudes that determine how we treat our first-order normative judgments. The first is liberating and reassuring: instead of hopelessly trying to reach the values that are completely beyond us, we need confidence in our existing values, and - in fact - confidence is inescapable because the only thing we can do is practically reason from our own values. ${ }^{113}$ If we cannot close the gap between the independent realm of values and our current values, the only path we have is to stop worrying about absolute moral truth and reaffirm our practical identity that includes a set of contingent evaluative attitudes. The second consequence pulls in the opposite direction: we need to incorporate insights about the inevitability of contingency in practical thinking into the reflection about existing values. The realization that our ethical attitudes are contingent and that the only thing we can do is reason from the existing value-frameworks should promote a thoughtful, selfaware and flexible approach to practical questions. ${ }^{1{ }^{14}}$ Reflection, as a counterbalance to confidence, thus incorporates a number of normative ideas about the virtues of good moral judgment. The need for reflection emanates from the non-absolute and noneternal character of (our) moral values, but does not claim to be a universally valid requirement itself: on the one hand, it is a moral sensitivity that seems appropriate for a moral framework that placed high hopes in externally validated normative truth, and on the other, it emphasizes the values that are already part of our moral framework but

112 Blackburn, Ruling Passions: A Theory of Practical Reasoning 294. Blackburn's view is that moral judgments can only make sense against the background norms that enable them and that already include normative suppositions. The psychological problem he is talking about here arises when these background norms come into question.

113 The term 'confidence' or 'practical confidence' is mentioned in Bernard Williams' and Allan Gibbard's work (Williams, Ethics and the Limits of Philosophy 171-172 and Gibbard, Thinking How to Live ch 13). Although the term is the same, I do not borrow the notion behind it. In my parlance, confidence includes the feeling that one can rely on one's own values that comes from the realization that there is nothing to support them further and that the practical perspective is inescapable.

${ }_{114}$ Rorty described a person having a similar reflective attitude as a 'liberal ironist'. My approach here is similar in sentiment but very different in the details and doctrines that support it. See Richard Rorty, Contingency, Irony, and Solidarity (Cambridge University Press 1989) ch 4. 
now gain more prominence given the change of balance against the value of believing in absolute moral truth. Moral judgments, in this model, ought to include a more modest attitude towards our own moral position, and rely on persuasion and imagination, rather than authority and truth. Ethical choices are then to be made in the process of interaction between confidence and reflection, immersion and detachment, action from and deliberation upon our own values.

\subsection{Confidence}

Where does this practical confidence come from? We have seen that many believe that the contingent character of values is not a problem at all, or - if it is - that it affects only those that afforded our values more authority than they could actually have. ${ }^{15}$ To an extent this is correct. Notice that the problem arises only if we suppose that values are mind-independent. The practical perspective that does not subscribe to this premise is not damaged if it turns out that values are mind-dependent: there is no need for deep vindication, because there is nothing to be vindicated. But this view thrives on a too sharp distinction between the theoretical and the practical and fails to appreciate some important aspects of the problem.

Let me use an example. There are causal - evolutionary, sociological, or psychological explanations of our propensity to laugh. But there is also an important difference between causally explaining why something is funny and laughing at someone's joke or experiencing humor internally; there is also a difference between external statements about humor and internal humorous statements, and one could comprehend one kind of statement without understanding the other. Imagine a scientist who understands humor perfectly well from the external perspective, but, that at the same time, never laughs, finds nothing funny, and is unable to experience humor properly from the internal perspective. He would still be able to study humor as a phenomenon, describe it and point to its causes. Similarly, one could be witty without understanding or being able to explain why we laugh.

\footnotetext{
${ }^{115}$ See the discussion of Mackie's and Harman's view in this chapter.
} 
There is an analogy with the evaluative domain. We are able to explain normativity scientifically and experience it internally, and these two enterprises seem very different. For example, Dworkin's claim that metaethical statements are normative statements is analogous to saying that by explaining humor from the external perspective one is actually joking. ${ }^{116}$ Moreover, the explanation of the cause of our propensity to laugh would not have any lasting effect on what we find funny. Suppose you went with our scientist to a comedy show, and he explains to you that you will be laughing only because by so doing you increase your reproductive prospects or because the jokes are incongruent with your cultural worldview. It would neither spoil the fun nor have a chilling effect (besides the fact that you went out with a very boring person). Likewise, learning about the contingency of values need not practically affect us.

There is an important difference however. It is easy for us not to take humor seriously. Although the grammar of humor reveals a similar pattern to moral grammar seemingly ascribing a property of 'being funny' to natural facts - it is not difficult to accept disagreement about humor and say things like 'he lacks a sense of humor' or 'I find it funny but she doesn't'. Not so with morality. In the moral case, it is hard to keep the external and internal point of view separate: there is nothing funny about injustice or evil, and we do tend to think that one can be robustly right or wrong in practical matters. The argument that aspires to retain confidence in our values cannot thus merely rely on the distinction between the theoretical and practical. We want our values to be true to be confident in them, and the commitment to the truth of values is inherent to the moral practice and discourse. ${ }^{117}$

A more plausible argument for practical confidence builds on the commitment of moral practice and discourse to the mind-independent truths of values, but realizes that this is a normative commitment. It treats the requirement of believing in mind-independent normative truths as one of the normative premises within our practical outlook. The

\footnotetext{
${ }^{116}$ See the discussion of Dworkin's view in this chapter. Closer to Dworkin's position would be to say that metaethical statements are analogous to bad jokes.

${ }_{117}$ This point however, should not be overstated. Commitment to the robust truth of moral beliefs is often a matter of degree. For example, we may think that torturing children for fun is robustly and come-whatmay wrong, but that whether we ought to have a welfare state is a matter of opinion. A more precise formulation is then: we consider some of our contingent moral attitudes robustly true.
} 
idea is this: the practical perspective - once conscious of the paradox that renders us incapable of knowing how to live our lives - ought to reject the commitment to absolute moral truths as a parasite that threatens its existence. Judging from the practical perspective, we should choose to renounce one of the evaluative assumptions we find untenable, for it is incoherent with the very possibility of occupying the practical perspective. As long as we believe in the correspondence of our moral attitudes with mind-independent truths we are bound to lose confidence in our values; but if we abandon this assumption, the practical perspective is not in peril. The practical perspective is thus vindicated from within, as the reasoning remains within the boundaries of the practical. ${ }^{118}$

The reasoning does not deduce anything from 'is' to 'ought' and takes the following form. The normative premise is: P1) to know how to live or what to do, one should grasp mind-independent normative truths. $\mathrm{P} 1$ is then combined with a descriptive premise supplied by the theoretical perspective: $\mathrm{P} 2$ ) we cannot grasp mind-independent normative truths. This leads to a normatively unacceptable conclusion: $\mathrm{C}$ ) we do not know how to live or what to do. Since the conclusion is unacceptable, we drop the first premise. The structure of the reasoning follows the pattern that we regularly observe in moral practice: if a general principle leads to highly counter-intuitive conclusions in the factual context to which it applies, we abandon the principle. ${ }^{19}$ The thesis we should then accept is that one need not know mind-independent truths to know how to live or what to do.

\footnotetext{
${ }_{118}$ This is the view Sharon Street ultimately takes. See for example: Sharon Street, 'Does Anything Really Matter or Did We Just Evolve to Think So?' in Alex Byrne and others (eds), The Norton Introduction to $\begin{array}{llll}\text { Philosophy (Norton } & \text { forthcoming } & \text { 2014) }\end{array}$ <https://files.nyu.edu/ss194/public/sharonstreet/Writing.html> accessed 21 July 2014; and Street, 'Coming to Terms with Contingency: Humean Constructivism about Practical Reason' 55-57. Street rejects 'the implausible skeptical result that most of our evaluative judgements are off track' (Street, 'A Darwinian Dilemma for Realist Theories of Value' 109), which is a conclusion that follows from the practical perspective. It is not clear however how she avoids the skeptical result the realists are worried about, for it consists precisely in giving up on our ability to grasp external normative truths. A deflationary account of truth would not satisfy the realists as being non-skeptical.

119 The reasoning does not violate Hume's law because it does not deduce anything from is to ought directly. In an attempt to reach reflective coherence, we reject the implausible principle. For a more skeptical view about the prospects of evolutionary ethics to bridge the gap between 'is' and 'ought', see Elliott Sober, From a Biological Point of View: Essays in Evolutionary Philosophy (Cambridge University Press 1994) 102-104 and 109-111.
} 
The intuition behind this argument is right, but some clarifications are in order. There are two main reasons why the argument may not quite succeed in redeeming our confidence. First, it may appear that the valueless perspective is a real option. On the one hand, we may well embrace the conclusion that we do not know what to do or how to live. On the other, the question of what to do or how to live may be different from the questions of what do we ought to do or how we ought to live. We could then abandon the latter, moralized version of the practical perspective, and proceed on the basis of the former, starting from some other motivation; for example, instead of asking what ought we to do, we could ask what do we really want. Thus - to retain practical confidence we need to realize that there is no valueless practical perspective and that these questions cannot be completely separate. Second, and connected to this, confidence could be lost in interaction with others who hold a different set of values. The problem is clearest when we confront the amoralist, a person that does not care about moral values at all. If the amoralist is not inherently irrational or acting against his own happiness, he does not have any reason to be moral; and if the amoralist need not be committed to absolute moral truths, how do we have the authority (and hence confidence) to impose our values on him? Thus, we need some other source of confidence that would replace the belief in mind-independent truths.

To answer the first problem, it is enough to understand that even if we could choose to abandon our current values, this would be an ethical choice nonetheless. The practical perspective is inescapable and such choice would follow from whatever we think we have most reasons to do. ${ }^{120}$ Even deciding to do nothing is deciding to do something. For

120 One way to show that values are inescapable in the practical perspective would be to demonstrate that there are no two distinct questions that we face: 'what to do?' and 'what ought I to do?' Gibbard, for example, thinks that 'ought questions and reason questions are by their very nature questions of what to do'. Gibbard, Thinking How to Live 9. To do something, one needs to settle on what one ought to do. The thought is that motivational content is the defining feature of ought-statements, so I cannot 'settle on what I ought to do and still ask what to do' without failing to understand what ought-statements mean (ibid 158). This view is controversial enough for the realist to reject it, as there are clearly cases in which the motivational content of 'ought' fails to supply us with enough motivation to act. For example, the statement 'I ought to return the book to the library but I won't because I feel lazy today' is intelligible: the 'ought' does motivate me but not to the extent that I act upon it; moreover, I need not simultaneously think that I ought not to return the book or that feeling lazy justifies my actions. I think Blackburn's approach is more nuanced in that he admits that 'externalists can win individual battles', but argues that 'internalists win the war' because the cases of the weakness of the will that are counterexamples to internalism are always 'parasitic ... upon a background connection between ethics and motivation'. As he puts it: "They are cases in which things are out of joint, but the fact of a joint being out presupposes a 
example: deciding not to blame someone for stealing is to allow the thief to get away with stealing without being blamed. This may be justified for a number of reasons - he may, for instance, be stealing because this is the only way for him to survive - but the judgment is still to be made from the practical perspective. When confronted with situations like that we have a practical choice: how do we act? Every decision will necessarily be answerable to our set of values. It is then highly improbable that the fact that values are contingent would prevail over the strong moral reasons we have to punish murderers, praise altruism, or help those in need. Even if we could decide not to act upon our moral motives and follow our intuitions, this would at the same time mean that we allow the actions that we resent. ${ }^{121}$ Why should we do this? Suspending moral judgments is an option only 'for those who can afford to think of their lives as play'. ${ }^{122}$ The fact that values are contingent is practically insignificant in comparison to the amount and gravity of evil in the world. To conclude: because suspending moral judgment is also a moral judgment, and because the practical perspective is inescapable, we have no reason to prefer the seemingly valueless perspective to our own moral attitudes.

This leads to the second challenge. For if this is true, we can only follow our own contingent set of values. The others may have different values; worse still, they may not have moral values at all or may not care about them. If the first problem asks 'why values?' the second asks 'why your values?' What then gives us the right - or confidence - to impose our views? The problem is typically framed in terms of disagreement, but this is not the most helpful way of approaching it. If we are to retain confidence in our values, then even agreement cannot help us: it is far from clear why anyone's contingent agreement would matter at all. Its normativity would be in doubt as much as the normativity of any other contingent attitude. ${ }^{123}$

normal or typical state in which it is not out'. Blackburn, Ruling Passions: A Theory of Practical Reasoning 61

${ }^{121}$ See Blackburn, Ruling Passions: A Theory of Practical Reasoning 294 for a similar argument.

122 Ibid.

${ }^{123}$ This is not to downplay the problem of disagreement but to understand what the question is really about. But disagreement is also always a matter of degree, for there must be something to disagree about, something recognized as a problem. The theoretical understanding of the normative domain suggests that there will be a significant overlap between human cultures and that there is a lot of convergence between existing moral codes, at least in their central features. There could be a disagreement about the substantive moral judgment but no disagreement about the best way to tackle it or reach agreement, so 
To answer what we need, we must realize what we have lost. Belief in the mindindependent character of our values served to justify our own identity rather than to show to the amoralist that he should comply with our values. If the failure to confirm their mind-independent character causes a loss of confidence in our practical identity, it is probable that the confidence can be re-affirmed with reference to identity. It will, in other words, find its source not in truth but in the self. As Williams puts it, 'the point is not that the intuitions should be in some ultimate sense correct, but that they should be ours'; but - he continues - 'The problem is who we are'. ${ }^{124}$ The source of confidence is then to be found in the process of answering both what does we stand for and what do we stand for. Such confidence rejects the assumption that we must make the amoralist care and asks instead whether we care enough. It then reveals the core of moral attitudes which we cannot give up on, and which - even on reflection - do not yield to competing concerns about their lost authority. It also includes the awareness of other experienced forms of life and takes into account the fact that ours may be one among many; it situates, understands, and embraces our position in the world together with our evaluative perspective.

This challenge will however inevitably affect confidence. Compared to truth, identity seems too weak a foundation. The next section will thus say more about this and contrast confidence with the idea of reflection. But it is important to recognize that the effects are not sweeping. The problem must again be addressed from one's practical perspective. We are bound to become uncertain about some moral judgments if we reflect enough. ${ }^{125}$ Yet, some things we will resent so much that we can think of our action against them as a self-defense or — better to say — defense of the self: they will disturb our worldview to the extent that the loss of confidence will seem insignificant. Philippa Foot coveys this thought with particular elegance:

we can still often rely on this second-order agreement: norms become pervasive wherever humans get in touch with each other. In my model, disagreement is addressed within the idea of reflection.

${ }^{124}$ Williams, Ethics and the Limits of Philosophy 102. This comment relates to the contractualist moral theory towards which Williams is sympathetic as a normative theory but not as a metaethical theory. It leaves the question of confidence open.

${ }^{125}$ It is important to realize that the reflection is an integral part of our practical outlook that is equally inescapable. Moreover, it may seem - as it seems to Williams - that the reflection may destroy the moral knowledge we had pre-reflectively. I am not sure if this is the best formulation of the idea, but reflection can certainly make us less or more confident in our judgments and intuitions. See ibid ch 8 . 
We are apt to panic at the thought that we ourselves, or other people, might stop caring about the things we do care about, and we feel that the categorical imperative gives us some control over the situation. But it is interesting that the people of Leningrad were not struck by the thought that only the contingent fact that other citizens shared their loyalty and devotion to the city stood between them and the Germans during the terrible years of the siege. Perhaps we should be less troubled than we are by fear of defection from the moral cause; perhaps we should even have less reason to fear it if people thought of themselves as volunteers banded together to fight for liberty and justice and against inhumanity and oppression. ${ }^{126}$

The thought is that to the extent it is possible to think of some parts of our practical perspective in these terms, there is hope that confidence can be restored. Once we realize that the role of truth was to give us confidence, we are faced with a dilemma: should we care about the fact that - for example - a perfectly coherent psychopath who values torturing children for fun does not in so doing fail to be rational, or about the fact that we do not want to allow torturing children. ${ }^{127}$ It is absurd, judging from the practical perspective, to conclude that we ought not to react to prevent that, even if our judgment does not have the absolute or timeless character we thought it did have.

The question is then whether the argument can justify the confidence on the part of those that do, for example, value torturing children for fun. The fact that values are contingent leaves us without an argument that would prove the absolute irrationality of an immoral set of beliefs. There are two responses to this. First, the obsession of moral theory with the amoralist and with the challenge he poses to the reasons to be moral should be somewhat softened by the approach that is aware of the causal origins of our contingent moral attitudes. Instead of showing the inherent irrationality of the

\footnotetext{
${ }^{126}$ Philippa Foot, 'Morality as a System of Hypothetical Imperatives' (1972) 81 The Philosophical Review 305, 315-316.

127 As Williams puts it: 'We may be able to show how a given practice hangs together with other practices in a way that makes social and psychological sense. But we may not be able to find anything that will meet a demand for justification made by someone standing outside those practices. We may not be able, in any real sense, to justify it even to ourselves. A practice may be so directly related to our experience that the reason it provides will simply count as stronger than any reason that might be advanced for it.' Williams, Ethics and the Limits of Philosophy 114.
} 
amoralist (for why should he care about being rational?) or demonstrating that his position is conceptually impossible, such an approach notes that his position will be empirically exceptional because we share very similar propensities and conditions of life. ${ }^{128}$ The amoralist, on this reading, has been a bit of a red herring in the debate: prejudice is much more a consequence of not taking into account the full implications of one's moral outlook through reflection than of being consistently prejudiced. ${ }^{129}$ Second, once we do face a consistent amoralist, the judgment of whether he has earned the right to have confidence in his values would still have to be assessed from our practical perspective, just as our confidence has been restored from within. As we have seen, care for our own values will simply outweigh care for the amoralist.

There is an element of faith in this conception of confidence. Whereas confidence based on mind-independent moral truths stems from faith in God or universal and absolute moral standards, the disenchanted practical perspective builds confidence on its faith in humanity. This is a leap of faith nonetheless; it is possible - regardless of the evolutionary explanation of the convergence of human values - that we will some day wake up in a world completely unknown to us, ruled by the amoral. Unlike the confidence given by the absolute belief in the righteousness of our own practical perspective, such confidence will have nothing non-contingent and universally valid to cling to. However, confidence would not be what matters if it somehow turns out that humans are inherently evil: the loss of hope would be a luxury that we cannot afford. In the meantime, we have all the moral reasons we need to prefer a confidence that is based on trust in humanity. Such confidence is profoundly humane, for it celebrates our capacities instead of suppressing them: instead of thinking of practical perspective as a set of unchangeable principles written in stone, we now realize that values can change, and that we can even choose them; instead of externally imposed values, we see their deep connection with our identity and all other concepts through which we experience and make sense of life; instead of thinking about our contingent values as misguided because they are causally affected, we are now free to embrace them. At the bottom of

\footnotetext{
${ }^{128}$ For an introduction to the problem of the amoralist, see Bernard Williams, Morality: An Introduction to Ethics (Harper \& Row 1972) ch 1.

129 Williams, Ethics and the Limits of Philosophy 115-117.
} 
our moral judgments - we now realize - there can be nothing else than our deep intuitions about how to live.

\subsection{Reflection}

The notion of confidence leaves us with the picture of values as deeply held but nonetheless contingent; they are probably best understood as intuitions - states of mind the content of which is an emotional attitude towards actions, situations or events that are evaluated as positive or negative, good or bad, right or wrong. ${ }^{130}$ Judging from the practical perspective we ought to place trust - indeed have confidence - in these intuitions: there can be nothing better to replace them, for the very idea that something could be better must start from these intuitions. ${ }^{131}$ Yet, such confidence is both defeasible and a matter of degree. Contingent intuitions are the foundation of moral judgments, but they are at the same time their foundation only. Once their ability to track mind-independent truths is demystified, we need some other approach to judging these intuitions as warranted or trustworthy.

One option would be to consider all the intuitions we have as justified. Such a response, however, would be insensitive to the fact that the warrant that has supported our intuitions so far - the mind-independent truth - is beyond our reach; the quality and

\footnotetext{
${ }^{130}$ Gibbard calls these psychological and empirical facts about what to value de facto intuitions and defines them as follows: judgments made confidently, on no further grounds, with no felt need for further grounds even upon challenge'. Gibbard, Reconciling Our Aims: In Search of Bases for Ethics 23. In his model, these intuitions become normative, de jure intuitions (states of mind 'that we ought to place some trust in', ibid) if it is the one that would be held under the ideal conditions of judgment.

${ }^{131}$ Some utilitarian philosophers argue that a part of our deontological intuitions should be dropped because they are imposed on us by evolutionary or other causal forces. For example, Peter Singer believes that evolutionary biology and neuroscience ought to undermine our confidence in referring to intuitions in ethics altogether, and that the way forward for ethics consists in 'separating those moral judgments that we owe to our evolutionary and cultural history, from those that have a rational basis'. Peter Singer, 'Ethics and Intuitions' (2005) 9 The Journal of Ethics 331, 351 . What he fails to see is that it is impossible to make this argument without relying on intuitions, and that the theoretical perspective tells us that our practical perspective consists only of these causally affected intuitions. So what Singer thinks is 'rational' is just another intuition, which we can prefer only from our practical perspective; even if we have reason to prefer judgments made in the 'cool hour', such reason can only be another causally affected intuition. For a comprehensive and successful argument against faulty normative judgments based on neuroscience research see Michael S. Pardo and Dennis M. Patterson, Minds, Brains, and Law: The Conceptual Foundations of Law and Neuroscience (Oxford University Press 2013) ch 3.
} 
force of confidence cannot simply be the same. Nietzsche motivates this idea convincingly:

But why do you listen to the voice of your conscience? And what gives you the right to consider such a judgment true and infallible? For this faith - is there no conscience for that? Have you never heard of an intellectual conscience? A conscience behind your "conscience"? Your judgment "this is right" has a prehistory in your instincts, likes, dislikes, experiences, and lack of experiences. "How did it originate there?" you must ask, and then also: "What is it that impels me to listen to it?" [...] the firmness of your moral judgment could be evidence of your personal abjectness, of impersonality; your "moral strength" might have its source in your stubbornness - or in your inability to envisage new ideals. [...] if you had thought more subtly, observed better, and learned more, you certainly would not go on calling this "duty" of yours and this "conscience" of yours duty and conscience. Your understanding of the manner in which moral judgments have originated would spoil these grand words for you, just as other grand words like "sin" and "salvation of the soul" and "redemption" have been spoiled for you. ${ }^{132}$

Nietzsche argues that learning about the origins of moral attitudes ('intellectual conscience') ought to destabilize their 'firmness', 'strength', or 'grandness' so that it becomes unclear why we need to 'listen' to them anymore. In other words, the theoretical perspective exposes the contingent nature of values, so they lose their authority over us and we lose our confidence in them. ${ }^{133}$ The message, however, is not one of despair but of caution; Nietzsche warns us that we have these values because we might have lacked character, or been inflexible, fearful, and unimaginative in our moral judgments. Our confidence cannot be based on the self-righteous conception of values:

\footnotetext{
132 Friedrich Nietzsche, The Gay Science; With a Prelude in Rhymes and an Appendix of Songs (Walter Kaufmann tr, Vintage Books 1974) 263-264 footnotes ommitted.

${ }^{133}$ It could seem as if the theoretical perspective is not 'behind' but 'above' the practical in this picture, as Nietzsche starts this section with an exclamation: 'Long live physics!' (ibid 263). But this would be to move too quickly. In a beautifully paradoxical ending to the section, Nietzsche says that what moves us towards the theoretical is one of our values: 'long live physics! And even more so that which compels us to turn to physics - our honesty!' (ibid 266). The connection and interaction between the two perspectives is thus more nuanced. See also ibid 283-285 where he openly admits the fundamental difference between the two perspectives.
} 
You admire the categorical imperative within you? This "firmness" of your socalled moral judgment? This "unconditional" feeling that "here everyone must judge as I do"? Rather admire your selfishness at this point. And the blindness, pettiness, and frugality of your selfishness. For it is selfish to experience one's own judgment as a universal law... ${ }^{134}$

The point here is not to abandon the practical altogether - which as we have seen is impossible - but to approach our judgments in a self-conscious way. ${ }^{135}$ Notice the subtlety of the argument: Nietzsche does not argue that we ought to abandon the values simply because they have a causal pedigree, but because they may be a result of attitudes that we find normatively unacceptable. Instead of re-asserting the absolute value of our practical outlook, Nietzsche's idea is both to look at our own values more critically and to overcome them to the extent they are constraining and unimaginative: 'Let us therefore limit ourselves to the purification of our opinions and valuations and to the creation of our own new tables of what is good...' ${ }^{136}$ Confidence thus needs to be counterbalanced with an attitude to our moral intuitions that is aware of their contingent character and that is creative enough to overcome them. We might have taken our values for granted without being reflective enough.

Now, overcoming, counterbalancing, or revaluating values is puzzling to say the least: each such attempt must specify the evaluative perspective from which it departs and explain why some values enjoy a privileged status. For example, Nietzsche thought that we need a revaluation of all values or at least the ones predominant at his time, that impeded the development of what he considered to be valuable and strong character; ${ }^{137}$ in so doing, he departed from a substantive idea about the life worth living, had quite a bit of confidence in his own intuitions, and was skeptical of any convergent practical

\footnotetext{
${ }^{134}$ Ibid 265.

${ }^{135}$ His ultimate point is that one needs to discover oneself and create new values that can never be the values of others, let alone everyone. His skepticism here follows from his understanding of action as unique and unrepeatable (ibid 265). A discussion of this view would take us too far afield; suffice it to note that we need not subscribe to it even if we accept his exposition of the problem and some of the consequences.

${ }^{136}$ Ibid 265-266.

137 '... belief in morality, in all morality, falters-finally a new demand becomes audible. Let us articulate this new demand: we need a critique of moral values, the value of these values themselves must first be called in question'; Nietzsche, On the Genealogy of Morals and Ecce Homo 20.
} 
perspective. ${ }^{138}$ But even without subscribing to Nietzsche's concrete proposals or to the perplexing idea of revaluation of all values, we can see that his diagnosis of the problem is apt. The loss of the ability to claim the absolute truth for our values does challenge the way we ought to treat them, unless we wish to engage in self-deception.

So how to approach this problem? Instead of starting from first-order intuitions about the good life, a more promising route is to adjust the second-order evaluative attitudes about these first-order intuitions, for this is where the problem has arisen. ${ }^{139}$ The exercise then does not remain at the level of deciding what to do, but takes place at the level of planning or deciding what to value. ${ }^{140}$ The question is which of the intuitions and judgments deserve our confidence, which ones are worth our trust even after reflection. The goal is not to cede to the theoretical as the 'conscience behind conscience', but to be able to think of the theoretical and the practical as a single coherent conscience. What we need then is to outline the fundamentals of the process of reflection through which we could curb the excessive confidence.

Before I explain this in more detail let me clarify the fundamentals of the approach. First, I argued in previous chapters that the move from agent to appraiser relativism is baffling: the ideal of universal tolerance cannot follow straight from the fact that contingent sets of evaluative beliefs are different. The approach here is fundamentally different. The normative allure of reflection and respect for other points of view comes

\footnotetext{
${ }_{138}$ The metaphysical status of the perspective from which Nietzsche re-evaluates our values is contested. Foot for example thinks that he is appealing to one set of intuitions about good character and good life that has some purchase within our own evaluative outlook (see 'Nietzsche: The Revaluation of Values' in Philippa Foot, Virtues and Vices and Other Essays in Moral Philosophy (Clarendon Press 2002 [1978]) ch 6 esp 88-89). This view may not be the best exegesis of Nietzsche's views (see e.g. Brian Leiter, 'Nietzsche's Metaethics: Against the Privilege Readings' (2000) 8 European Journal of Philosophy 277, 287-290) but it certainly makes sense as an independent position. It fits with my notion of confidence and with the view that we cannot escape the practical perspective, while at the same time avoids Nietzsche's skepticism about common morality or lack of interest in those that do not share his evaluative standpoints.

139 This view then can remain contingent and perspectival as long as it is intuitively plausible and builds on already existing contingent evaluative attitudes within our practical outlook; the more idiosyncratic it is the less successful and acceptable it will be as a normative argument. We could start - with Nietzsche from first-order intuitions; nonetheless, the problem is the second-order normative commitments that are no longer tenable, and the patch to the practical perspective will be more apposite if it addresses the problem directly and at the level where there is more agreement.

${ }^{140}$ I think here of higher order volitions or the ability of 'reflective self-evaluation' that is often thought of as being constitutive of personhood. See Harry G. Frankfurt, 'Freedom of the Will and the Concept of a Person' (1971) 68 The Journal of Philosophy 5, 7.
} 
from within our contingent set of evaluative beliefs that has lost the absolute confidence in its rightfulness; we are moving, in other words, completely within the practical realm once the encounter with the theoretical is resolved. Second, I also argued that reflection could not get us to mind-independent truths in the practical domain, and that the authority of reflection could not be based on the analogy between theoretical and practical reason. In the model I now propose, we are moved to reflect, but for a different reason: although confidence is inescapable, reflectiveness refines a disproportionate confidence based on a belief in the mind-independent truth of our values. Third, although I will clarify which attitudes should gain more prominence under this model, it is doubtful that any approach of this kind could arrive at a clear-cut measurement for the trustworthiness of intuitions, let alone a quantitative measurement. The outcome of such an exercise will always depend on untidy intuitions, experiences, contexts and the types of interactions we engage in. The hope is only to outline a vocabulary in which we can cogently express these reflective concerns.

What then are the elements of reflection? Roughly, a reflective attitude will be critical towards dogmatism and self-deception, mindful of other forms of life, thoughtful, flexible and capable of taking different perspectives. It is perhaps best to think of reflection along two interdependent dimensions: internal and external. The internal dimension of reflection concerns finding out what one really values and how firm these values are even upon recognizing their contingency. The external dimension relates to the treatment of other value systems - which we now realize are as contingent as ours and asks how they affect our values, how much respect, leeway or tolerance we are ready to grant them, and how we deal with unavoidable disagreements.

Turning to the internal dimension of reflection, the question is, where to start? We need to figure out which are the attitudes we can initially be more confident about. One cannot start the reflection from nothing, and the talk of choice or planning what to value can in this sense be slightly misleading. Reflection can neither begin from a normatively blank, non-evaluative standpoint, nor can it entail a radical choice of values, 
independent from any contingent attitude. ${ }^{141}$ As I suggested before, confidence can find refuge in identity. Identity is here understood in a thin sense: it comprises a set of values that are a precondition for occupying the evaluative perspective. ${ }^{142}$ Thus it is not that identity is valuable in and of itself; rather, the idea is that it is inescapable. As Charles Taylor puts it, identity refers us to certain evaluations which are essential because they are the indispensable horizon or foundation out of which we evaluate or reflect'; to be without them is be to be 'a kind of extensionless point, a pure leap into the void'. ${ }^{143}$ The turn to identity is therefore a consequence of the fact that a revaluation of values must proceed from one's own standpoint, incrementally and by holding some of values constant, while changing others. It is impossible to overcome oneself in one go, and evaluative judgments that are part of our identity are unavoidable.

There is also another slightly more robust sense in which the core of our values is inescapable: we cannot stop having them and continue being ourselves. The thought here is that if I choose to abandon these values, I seize to be the $I$ that made this choice. It is practically impossible to renounce this core of self-constituting values without losing integrity, and it is normatively perplexing to demand such a deep psychological alienation from the attitudes through which one makes sense of life. Quite literally, it would isolate the agent 'from his actions and the source of his action in his own convictions'. ${ }^{144}$ Because a self that evaluates is necessary for any evaluation, in an attempt to detach from these deepest evaluative commitments and projects both components could be lost: the possibility to evaluate and the self.

\footnotetext{
${ }^{141}$ As Charles Taylor puts it: 'a radical choice between strong evaluations is conceivable, but not a radical choice of such evaluations'. The point is that even if we do face moral dilemmas that can only be decided by choice and not by further evaluation, the fact that the options normatively command or claim something is not a matter of choice, and the dilemma itself is not chosen. Charles Taylor, Human Agency and Language: Philosophical Papers I (Cambridge University Press 1985) 29.

${ }^{142}$ Korsgaard also starts from having a practical identity as a precondition for finding anything else valuable, but she argues that this fact forces us to value the ability of having a practical identity as such, and thus also the humans who have this ability. There is a typically Kantian leap in conclusion here: from valuing my ability to valuing the ability as such, let alone valuing other people for having it. See Korsgaard; for a typical criticism along those lines, see R. Jay Wallace, 'Constructivism about Normativity: Some Pitfalls' in James Lenman and Yonathan Shemmer (eds), Constructivism in Practical Philosophy (Oxford University Press 2012). In my conception, no concrete normative consequence follows from valuing one's identity, and the whole model depends on its intuitiveness within our contingent evaluative outlook.

143 Taylor 35.

${ }^{144}$ Bernard Williams, 'A Critique of Utilitarianism' in J.J.C. Smart and Bernard Williams (eds), Utilitarianism For and Against (Cambridge University Press 1973) 116. He puts forward this argument in the context of utilitarianism, but it applies here with the same force.
} 
It is inevitable for reflection to begin with introspection, which implies distinguishing more and less genuine interpretations of one's own identity. The notion of identity does assign introspection some normative weight, as the process consists in a 'struggle of self-interpretations', and includes finding out 'which is the truer, more authentic, more illusion-free interpretation, and which on the other hand involves a distortion of the meanings things have for me.' ${ }^{145}$ Because asking which values are absolutely true becomes pointless, we ask which values are truthful to the way we are or the way we want to be: the focus on identity thus helps us exchange the talk of robust mindindependent truth with a more modest talk of authenticity or sincerity. This incorporates the idea that values forming identity are different from just any values we happen to have at that particular moment; it distinguishes those values that we want to be identified with, ones that characterize the kind of subject we wish to be recognized as. Identity involves, in other words, dimensions of depth and integrity. For example, I may highly value and take pleasure in excessive eating and drinking at one point or the other, but I am quite certain that I do not want this value to define me and I am not at all confident that this is the value I wish to retain. If I reflect, I recognize these desires as trivial and temporary. When I ponder existential and self-definitional commitments, I list those values that make me the person I want to be. The question to be asked then is: upon the loss of which values would I cease to be who I am? Which are the ones that I cannot renounce? Where are the limits of the detachment that I am capable of? The core of the values revealed by these questions will form not the timelessly true starting point of reflection, but a sincere and inescapable one. To be confident in them is to retain sanity.

Yet identity - understood as a set of self-definitional values - cannot become the ultimate vantage point for evaluation. It presents a core of certainty that we can be presumptively confident about in the process of reflection, and can also be incrementally re-examined in the course of it. This is because - if values are not mind-independently true - we are freer to detach from them in order to attune our moral sensibilities. Let me mention two mechanisms in particular. First, we may wish to achieve more coherence

\footnotetext{
145 Taylor 27.
} 
within the practical perspective. In this picture, coherence is not a demand of mindindependent rationality, in a sense that I must bring my beliefs in coherence if they are all to be true. Instead, coherence becomes a pressing concern upon the realization that I may not be able to attain all of my ends; some of my values can exclude each other. ${ }^{146}$ If all values are taken for granted, we do not always see the analogies, relations, and inconsistencies among them; if we understand values as contingent, the conflict between them becomes more intelligible, as they are not a consequence of a flawless divine plan or timeless truth. Similarly, bringing our values or conflicting courses of action into coherence stops being dependent on figuring out which one is universally true, but rather lies in considering the alternatives and settling on the one that makes more sense within our contingent practical outlook. ${ }^{147}$ Second, thinking of values as non-eternal opens new venues for creativeness and choice: it allows us to be more imaginative. Imagination provides a counterbalance to the conserving tendency of coherence, and helps us develop moral views beyond those already implied by our existing standpoint. In this view, values are not fully determined in advance but can be changed to fit the circumstances of life and evaluative horizons can evolve. We stop seeing past attitudes as always wrong and current as always right: we are allowed to question, abandon or replace them.

In the process of figuring out how to live, we build new connections between existing values and form novel emotional reactions. The final outcome of the internal dimension of reflection should be greater self-awareness. The hope is that we will be able to map the web of our evaluative attitudes with some precision, and shall perhaps be capable of indicating different spheres of intuitions, forming radiuses from the core of our identity to its outer boundaries. We should also be able to spot the connections between them and see how the changes in the outer range affect the ones in the core, and the other way round.

The external dimension of reflection pertains to the interaction with other practical outlooks. This dimension itself consists of two sets of concerns. First, contact with

\footnotetext{
${ }_{146}$ Gibbard, Reconciling Our Aims: In Search of Bases for Ethics 29.

${ }^{147}$ Blackburn also adds that coherence is a demand of fairness in a sense giving careful thought and equal gearing to all implicated concerns. Blackburn, Ruling Passions: A Theory of Practical Reasoning 309-310.
} 
different evaluative standpoints helps us clarify what exactly we believe in. An important part of reflection consists in being exposed to other forms of life, and pondering whether they could be a real option for us. So the external dimension builds on the internal but also refines it. If we are no longer certain that our values are absolutely true, we are prone to be more open and flexible. If we settle on a set of values, we can still coherently think that this is not the outlook that is obligatory for others, and the way we look at the world need not be the one others must embrace. This opens up a possibility to realize that others have managed to lead a more fulfilling life, or that they chose their values more courageously and with less self-deception. Interaction with them may lead us to reconsider some of the assumptions within our system of values that we did not question, and - given that these assumptions are no longer necessary in a metaphysical but only psychological sense - we may treat them more flexibly. We can also realize that others have chosen badly, and after the encounter we want to hold on even more strongly to our own set of values. The important point is that the experience of interaction can be unsettling, in that our own value system becomes more porous, but that it also can be reaffirming once we realize that there is nothing else for us to think.

Second, the external dimension determines how we treat others. This is a distinct issue, and one that is shaped by the political context and relationships of power. Within the whole reflective exercise one's position in a society will matter a great deal; however, when it comes to the treatment of others it will matter even more, for one could be in a position to change the entitlements of others. Nonetheless, the inability to claim the absolute truth for one's values can point to general sensibilities that seem apposite on both a personal and institutional level. Once we cannot immediately refute other practical outlooks by pointing to the absolute truth of our own, we need to engage with them. To engage means first to understand. It is appropriate - if an evaluative standpoint is not in an irresolvable conflict with our own - to make an effort to comprehend the reasons of this other perspective from within. Confidence based on identity is modest enough to realize that there could be more than one way of life worth living, and ought to make us more sensitive and responsive to the different ways in which the fundamental questions of how to live could be answered. 
It is sometimes argued that being suspicious of mind-independent ethical truths leads to indifference towards one's own evaluative standpoint and towards others, so that it makes tolerance superfluous. Bernard Williams suggests that 'with indifference and skepticism ... the point will be reached at which nobody is interested enough in the disagreements for there to be anything to put up with, and toleration will not be necessary.' ${ }^{148}$ The view assumes that to tolerate also means to think of something as unacceptable, misguided or wrong, and that toleration ... is required only for the intolerable'. ${ }^{149}$ This is not implausible, but it does overstate the consequences: doubts about the character of ethical truths need not lead to apathy in which it is impossible to disapprove of something. It does mean, however, that there will be more indifference at the borders of our practical perspective, more tolerance in its middle, and more caution at its core. To lose the trust in truth is not to stop caring, but it does call for more restraint. Besides, it can actually generate more engaged and empathic attitudes rather than indifference. The contingency and perspective dependence of values reveals somewhat paradoxically - our common human predicament. The values we hold on to enable us to make sense of and cope with our existence. Awareness of this is one step from feeling empathy and understanding for others who struggle in a similar way. ${ }^{150}$ The idea is that a reflective attitude makes it possible to see each other as participants in a common enterprise - even with significant differences in concrete moral attitudes rather than as foes. The result should be a more careful and considerate approach to those that do not share all the details of our perspective.

This, of course, will not resolve the problem of disagreement. Any mind-dependent conception of value must presuppose a certain amount of agreement, and could thus dissolve in the face of disagreement. Recall that I criticized some emotivist arguments for presupposing agreement without providing a framework within which it could be overcome. In the conception I am proposing, agreement is also presupposed; it is not based on sheer optimism, for it is explained by the shared circumstances of life that lead

\footnotetext{
${ }^{148}$ Bernard Williams, ‘Toleration: An Impossible Virtue?’ in David Heyd (ed), Toleration: An Elusive Virtue (Princeton University Press 1996) 25.

149 Ibid 18.

${ }^{150}$ Samuel Scheffler for example talks about 'fraternity' and 'solidarity' that is fostered by the fact that 'we must all confront the normative dimension of human experience'. Samuel Scheffler, Equality and Tradition: Questions of Value in Moral and Political Theory (Oxford University Press 2010) 332 and ch 12.
} 
to a significant overlap between different moral codes. But it also supplies the framework in which disagreement can be resolved and managed. A reflective attitude towards one's own practical perspective implies responsiveness to other perspectives and - given that they are not less true than ours - enables us to accommodate differences without deeply regretting each concession or seeing it as fundamentally wrong. Disagreement could be superficially resolved through authority, and this was possible with the robust mind-independent truth in hand. Upon reflection, we move from authority to persuasion, as we cannot always assert our own position. But the equilibrium achieved through persuasion is more stable and in the long run will prove to be a better foundation for resolving disagreements than authority. Lack of absolute confidence makes us responsive to the specific demands of others and pushes us to find solutions that are sensitive to their perspective; agreement reached on this basis is more likely to achieve a true balance of perspectives and interests.

It is an illusion to think that a mere realization that absolute truths are beyond our reach will prevent radical conflicts of evaluative perspectives. However, if such a conflict comes, a reflective attitude may prepare us to ask the right questions. The reaction will depend on where the interaction occurs, and some conflicts will stop being seen as important while others will deserve our confidence and assertiveness. If another evaluative standpoint violates the core of our values, we need to ask: is it justified in this particular case to force others into our own worldview, to impose our own identity on them? The answer will depend on how inescapable this particular judgment is for our own practical identity, and how incompatible is the identity of the others. It is perhaps easy to retain confidence when we face the amoralist, but much less so when we face someone whose form of life could be a real option for us. We will then need to inquire whether we are practically able to live with the fact that we may be merely affirming our own views, and understand how that fits with our other ethical convictions. This will be the ultimate test of confidence. 


\section{Conclusion}

In this chapter, I argued that there is a tension between two perspectives - theoretical and practical - that needs to be resolved. The need stems from the aspiration to have a unified worldview in which there would be enough space for both perspectives. The theoretical perspective tells us that we have no reason to trust that the values within the practical perspective correspond to mind-independent facts. I relied on the argument from evolution to show this, but the gist is that any credible causal explanation of values raises doubts about their ability to track mind-independent truths. To the extent that we do not want to have a schizoid attitude in which we at the same time believe and do not believe that our values are robustly true, we need to adjust either the practical or the theoretical perspective. I opted for adjusting the practical. This is not because given the results that the theoretical perspective has delivered - any attempt to renounce it would be in vain. Rather, it is because the practical can survive this encounter and in so doing become stronger. The assumption that there are mindindependent normative truths undermines confidence in values; it makes values seem unreachable. This ought to be rejected on normative grounds. We have no reason to sustain the belief in robust mind-independence, for it makes us seem incompetent to answer the most crucial question of human existence: how should I live? Once this assumption is rejected, we enter a process of reaffirming and curtailing our practical confidence through reflection. It is in this process that values are revealed and shaped.

At the foundation of this approach are evaluative intuitions. We depart from these simple emotional reactions, and then try to understand and situate them within the framework of other attitudes, and further connect them to other experiences through which we make sense of life. On the one hand, evaluation demands introspection, coherence and imagination, in order to regain confidence through greater selfawareness and with a reference to the most central evaluative attitudes forming our identity. On the other hand - when faced with different evaluative frameworks - it calls for caution, openness, flexibility, tolerance and persuasion. These normative suggestions are not deduced from absolute moral truths; the only hope is that they would be intuitive enough within our contingent practical perspective. 
The next chapter will reconstruct the ways in which ethical arguments in constitutional interpretation fit together, starting from this understanding of value. We will hence look at the ideas of confidence and reflection through the lens of constitutional practice. I shall argue that - taken together - ethical arguments actually used by courts can be adjusted to reflect the process in which moral judgments are and ought to be made. There is an appealing analogy between constitutional and ordinary ethics; however, this analogy needs to be appropriated to the institutional and social context in which the courts operate. 



\section{CONSTITUTIONAL ETHICS, CONFIDENCE AND REFLECTION}

\section{Introduction}

Divergent visions of moral value have surfaced throughout the analysis of ethical arguments. Let me briefly recapitulate. There are three relatively systematic patterns of value-based constitutional reasoning. The argument from constitutional identity relies on a specific conception of $i d e n t i t y$ as a source of value. It departs from the identity of a community governed by a constitution to resolve moral problems, both in the abstract (as an identity that arises from having a constitution as such) and concrete sense (as an identity that grows out of the particular constitutional tradition). The argument from common sentiment appeals to the current emotive intuitions of a particular community. It refers to the moral feelings of the population as expressed directly or through institutions such as legislatures, juries, and courts. The argument from universal reason uses the language of reason and is not community-bound. In particular, the argument holds that normative reasons can be cognized by looking at how other jurisdictions have grappled with the same question.

These arguments are not completely adequate when taken in isolation from each other. First, they are profoundly intertwined: identity cannot be detached from the emotive moral intuitions of citizens, emotive intuitions should in some sense be reasonable, and a plausible conception of reason cannot replace but must build on existing emotive intuitions. Second, their normativity is unclear: why does identity matter?; how are the contingent emotive intuitions of a community normative?; what is the authority of reflection? The last chapter provided a conception of value that accommodates these divergent sources and explains their interaction using notions of confidence and reflection. In this conception, values are complex evaluative attitudes that arise in a process of simultaneous engagement with our emotive intuitions and detachment from our personal point of view through reflection in an attempt to understand and develop our own identity. There is an important similarity between this process and constitutional ethics. When used together in constitutional reasoning, the three 
apparently divergent ethical arguments come to be supported by a unified conception of value: constitutional ethics may emulate the ordinary moral point of view by departing from contingent emotive intuitions and developing them through reflection, in order to gain confidence and further advance the underlying constitutional identity.

This however cannot settle the issue. While such a conception of value is capable of connecting different ethical arguments into a plausible and coherent constitutional ethics, the analogy must be explored further. It needs to be situated in the institutional context of judicial reasoning. The purpose of this chapter is to flesh out in more detail how the theory developed in the last chapter applies to constitutional reasoning and to show how it relates to other normative concerns that we may have in this domain. Rather than bringing new insights, the goal is to connect the arguments that have already been put forward into a coherent framework and - in so doing - resolve some pending issues. The chapter proceeds in three steps. The first part translates and appropriates this theory of value to the context of constitutional reasoning; the purpose is to move the discussion from the abstract level of metaethics to the more concrete and specific level of constitutional ethics. The second part discusses the theory of constitutional ethics in the context of typical dilemmas of constitutional interpretation. The third part concludes.

\section{From metaethics to constitutional ethics}

We have seen that many constitutional arguments demonstrate uncertainty about the place of value in the universe. The last chapter provided the theoretical umbrella for thinking about these issues. But it is not sensible to straightforwardly apply ordinary ethical thinking to the constitutional context. The problem is that there is also a multitude of other normative concerns that apply to constitutional reasoning which do not arise in ordinary moral reasoning. A constitutional framework establishes a system of government and authority, and there is a difference in duties that we may impose on ourselves and duties that a public authority may impose on us. To be sure, all these concerns are first-order normative issues that are explained by the devised metaethical framework: they must ultimately be attributable to us as the bearers of evaluative 
attitudes. There is no escape from this. But these other normative concerns become important precisely by virtue of the metaethics that affords a constitutive role to contingent moral intuitions; the very metaethical framework that explains these intuitions also prioritizes them.

This is why application of the metaethical framework is primarily an issue of translation. Constitutional ethics needs to be developed by building an analogy with the ordinary moral point of view and not through its direct implementation. And if we look closely at the arguments used in constitutional reasoning we may notice that the translation is already under way. The identity that courts refer to is not personal but constitutional: it is supposed to be attributable to the constitutional community as a whole. Common sentiments are not the private feelings of a judge but the dominant sentiments of the public. Reflection presupposed by the argument from universal reason is directed at a better self-understanding and development of the deep moral commitments of the constitutional system. ${ }^{2}$ Yet, the translation of metaethics to the constitutional domain is more complicated: there is the problem of the appropriate perspective and suitable role of courts in this process. Let me explain.

The first question is how to determine the relevant perspective. The moral point of view is a process of immersion in emotional reactions and reflection upon them in search of deep moral commitments. This provides the framework for making moral decisions, including a moral reading of the constitution. But when we move from the personal to the political domain - even if the general framework stays the same - the key question becomes who decides and in whose name. This will inevitably demand an adaptation of the framework as the relevant facts have changed: we now do not decide for ourselves but for the political community as a whole. This is one of the primary reasons why ethical arguments in constitutional reasoning differ from ordinary ethical arguments as they evolve in a specific institutional and legal context. It is implicit in the existing

\footnotetext{
${ }^{1}$ We should - for example - respect these contingent normative intuitions to the extent that they can be reflectively attributed to our identity as persons living in democratic polities at the beginning of $21^{\text {st }}$ century.

${ }^{2}$ Of course, we cannot exclude a more skeptical view that this is just masking the personal preferences of judges. However, the thesis tried to show both how we may prevent this and why we may want to prevent this.
} 
ethical arguments - and it also seems apposite as we move from individual to political or legal decision making - that the self that the courts depart from becomes the collective self of the community that bestows upon them the power to decide in their name. Identity, emotions and reason thus all come back to the evaluative attitudes that can be properly attributed to the constitutional community in question.

But there is more than one perspective implicated and thus more than one moving target. There is the perspective of the individual, who is a member of a collective judicial institution, and who decides in the name of the community. None of these perspectives can be silenced in constitutional ethics, nor should they be. There is however strong reason for a judge - once she understands the contingency of her moral attitudes - to show a high level of respect for the opinions and identity of the people whose entitlements she is empowered to change. Recall that reflection, among other things, entails figuring out what do we stand for and what do we stand for. ${ }^{3}$ A judge performing this exercise ought to realize that she is delivering a decision for the people, and what people stand for is what actually matters: the constitutional community is thus the unit which determines the relevant perspective.

This default perspective is unstable and can only serve as a starting point. On the one hand, a judge will have a set of evaluative attitudes which form part of her identity. While the role of a judge in a society ought to affect the confidence with which she asserts her own personal views, this does not mean that she can renounce them completely. Her identity however ought to incorporate the identity of being a judge which presupposes certain virtues that should make her cautious in deciding against public opinion. Furthermore, the contingency of value should remind her that she is justified in doing so only when public emotions are insufficiently reflective and diverge from the profound moral values embedded in constitutional identity.

On the other hand, there need not be an easily discernible core of evaluative attitudes in modern political communities, or - more precisely - it is more difficult to find such attitudes in controversial constitutional cases. There is often a multitude of competing

\footnotetext{
${ }^{3}$ See chapter 5 .
} 
identities and opinions and it would be naïve to simply presuppose a unified community of value as a justificatory foundation for moral decisions; such an assumption about a coherent and cohesive set of values would not even be warranted in the case of a single individual, let alone a complex constitutional community. ${ }^{4}$ Courts must be aware of the fact that there is more than one site at which the converging evaluative attitudes are formed. The metaethical theory developed in the last chapter elucidates the perspective of the individual as she makes ethical choices and assumes that some of these choices are made in the context of overlapping common attitudes that arise on different levels: local, national, supranational or global. Courts need to manage these various sites of normativity in a way that both finds common ground between them and corrects their excessive confidence.

The second question identified above pertains to the appropriate role of courts in this process. The bottom line is that constitutional ethics must derive its confidence from the deep evaluative commitments of the constitutional community as a whole and that courts ought to correct this confidence through increased reflection. Instead of imposing their own evaluative attitudes, the courts need to be the guardians of reflectiveness. We have thus come to the issue of democracy and the legitimacy of judicial review through a detour that enables us to explain why the courts ought to respect public opinion under the circumstances of discretion. ${ }^{5}$ Democratic concerns feed into the theory of constitutional ethics on at least three levels: first, respect for the democratic will follows from the realization that there are no universal and timeless answers which undercuts the confidence of the courts in claiming the truth for their own views; second, much of our contingent intuitions about the way in which moral problems ought to be resolved in modern political communities point to democratic representation as the most appropriate institutional venue; third, democratic representation better echoes common intuitions and identity, while it might secure even more reflection than judicial review. ${ }^{6}$

\footnotetext{
${ }^{4}$ Williams, Moral Luck: Philosophical Papers, 1973-1980 72—73.

${ }^{5}$ But instead of arguing from moral disagreement to democracy, which - as we have seen - makes the argument open to the very same disagreement challenge and does not explain why agreement matters, we now have an answer to both of these puzzles. See the earlier discussion of Waldron, 'The Core of the Case Against Judicial Review' and Posner.

${ }_{6}^{6}$ This is an empirical question that we need not resolve here. Let us not forget the focus of the study. It is not asking should there be written constitutions, should we have judicial review, or should judges generally prefer justified authority to moral value. It is inevitable that under the current system some
} 
The theory hence accommodates and vindicates democratic sensibilities but simultaneously accounts for the intuition that the majority ought not to prevail all the time. The democratic process can fail to be representative and reflective. We should not forget that many moral changes that we are proud of are a consequence of judicial oversight of common sentiments, and that they included reflection upon our own deep commitments. The theory of constitutional ethics grants the courts a critical edge over communal sentiments in two principal ways: by explaining the authority of reflection, and by differentiating between the normativity of superficial emotive reactions and inescapable moral attitudes that are constitutive of identity. It gives the courts reason to defer to more representative branches of government - or perhaps foster their reflectiveness through carefully crafted decisions - but also to step in if the process is not reflective enough or suffers from an unwarranted confidence which makes one perspective silence the others. ${ }^{7}$

\subsection{Identity}

With this scheme in mind we can proceed to see how constitutional ethics so understood could be applied. Values are complex evaluative attitudes pertaining to a set of similar moral problems. They include particular moral judgments and the principles that explain them, and arise in a dynamic and continuous process of immersion into and reflection upon our contingent attitudes. Values are in other words partly constructed in this process. The process is best understood as an everlasting quest for selfunderstanding by a constitutional and political community. At its center is the evolving identity reaffirmed by reflection upon our contingent attitudes. Identity thus denotes the deepest evaluative commitments that persist through reflection.

choices will need to be made by judges instead of the political process. This is not to say that we should prefer judicial review; in fact, we would have reasons to prefer the political process capable of both reflecting common moral attitudes and reflection upon them. Or perhaps a process that includes a weak form of judicial review. A more general institutional theory could be based on this metaethics, but the focus of the study is narrower: it attempts to make sense of judicial ethical arguments under currently dominant systems.

${ }^{7}$ In its outcomes, this is intentionally reminiscent of Ely's famous democratic theory of judicial review, although the underlying foundation is different. See John Hart Ely, Democracy and Distrust: A Theory of Judicial Review (Harvard University Press 1980). 
Constitutional identity - akin to personal identity in everyday ethical decisions - plays a crucial role in constitutional ethics. It is however important to underline that there is nothing valuable about identity as such; rather, the normative significance of identity arises from the inescapability of occupying an evaluative standpoint with some core ethical commitments in order to make any normative judgment. This affects how we ought to treat it: we cannot fully overcome it but we ought not to assert it in an overly confident manner. Identity - on this understanding - becomes different from mere tradition or an unreflective celebration of national specificities. ${ }^{8}$ It is an ever-changing and dynamic category, a process rather than an endpoint. It is a source of confidence but is also consistently challenged by critical reflection through which we rethink and reimagine it.

The argument from constitutional identity is on the borderline between legal-proper and ethical-legal arguments, and only its fluid character and the idea that it will lead to apposite moral answers put it in the latter group. ${ }^{9}$ It derives its normative force from its proximity to the constitution and constitutional practices, to the extent that they can be understood as the embodiment of the deepest evaluative commitments of a community. As other ethical arguments, it can be traced back to the moral attitudes of the people living under the constitution, but in this case such attitudes emerge in virtue of having a constitution. This gives it an additional weight for - arguably - constitutions can often

\footnotetext{
${ }^{8}$ For a helpful distinction along these lines see Daniel Augenstein, 'The Contested Polity: Europe's Constitutional Identity between Religious and Secular Values' [2009/3] University of Edinburgh School of Law Working Paper Series, $1-2$.

${ }^{9}$ It has been outside the scope of the thesis to discuss the relative importance of ethical arguments over more traditional legal arguments such as textual or doctrinal; on the one hand, it would have taken us too far afield in answering whether there is a duty to obey the law in general, and on the other, ethical arguments appear in a niche of cases in which ethical concepts from the constitution are interpreted under the circumstances of discretion. But the distinction between legal and ethical arguments - I also insisted is not clear-cut in the sense that ethical arguments gain legal force over time and become legally accepted ways in which ethical concerns enter judicial reasoning. This means that their acceptability will (partly) depend on the general normative force of the law itself. In whichever way we think of grounds of legal duties - in terms of stability, ability of law to better coordinate human behavior, accumulated wisdom of previous generations, or simply in terms of the contingent belief of people that law creates genuine moral duties - we cannot neglect that constitutions carry certain normative force as long as they respect our central normative concerns and stay within the boundaries of our wider evaluative frameworks.
} 
be understood as being expressive of settled and authentic values in contrast to more fluctuating common sentiments. ${ }^{10}$

The content of constitutional identity can however be thin under modern circumstances. First, the ability to discern some moral answers from constitutional practice as a whole - but not from any authoritative decision in particular - will depend on the richness of ethical, legal and political processes that the system has gone through during its evolution. It will give more substantial answers when there are layers of meaning that have been ascribed to constitutional practices through an organic development of constitutional community (as is the case in mature constitutional systems such as the US), but also when new constitutional regimes establish themselves in an attempt to transform or simply give effect to existing deep evaluative commitments (as is the case in South Africa). In most systems there is an idea about the general principles that the constitutional framework embodies; however, it can take a lot of time for these rudimentary normative tendencies to develop and become accepted as a part of the identity of the constitutional community.

Second, individual and cultural differences are rife in modern political communities, and constitutional identity is often different from more substantial and concrete identities, and from the worldviews they entail. We have seen that even in countries which opt for a specific constitutional identity - such as Israel - this identity is not tangible and is subject to persistent re-imagination and disagreement over its content. ${ }^{11}$ The most controversial issues in constitutional adjudication arise precisely in virtue of disputed interpretations of the constitutional authority of the state, and because of divergent visions of identity embedded in the constitution.

It is for this reason that the theories discussed in chapter 2 fail to successfully legitimize judicial review with reference to constitutional identity. ${ }^{12}$ They wish to kill two birds with one stone: constitutional identity ought to tie the moral judgment of the court to

\footnotetext{
10 This of course will not always be the case, but part of the very notion of identity is that it will be contested and developed over time. For this conception of constitutional identity, in 'disharmonic' terms, see Jacobsohn, Constitutional Identity.

${ }^{11}$ See ibid ch 6 .

${ }^{12}$ See the discussion of Bobbitt and Waluchow in chapter 2.
} 
the constitution and reduce discretion at the same time. While they fail to deliver this both because deep moral attitudes cannot be far from the democratic will of the citizens and because they are often too thin to render concrete results - their general intuition is right: if there are evaluative attitudes that can be properly ascribed to the identity of the constitutional community as a whole they should present the focal point of judicial moral inquiry. As I have argued, this is because attitudes forming the constitutional identity are a subset of our general moral attitudes that enable us to conduct our lives together in modern political communities, and because there is nothing that transcends these practices that we could rely on instead.

Although constitutional identity may not be thick enough to, by itself, legitimize robust judicial review of legislation by legally reducing judicial discretion, it is not completely without bite. Constitutional identity derives its force from general reasons to have a constitution and specific reasons to have a particular constitution; in both instances reasons are understood as shared evaluative attitudes that people have towards the legal framework that establishes the system of government and rights in the constitution. It would of course be an illusion to think that all citizens at all times share the evaluative commitments that arise in the inherently elite-driven processes of constitution-making and constitutional interpretation; however, constitutions are typically part of the common evaluative experience of a political community and express the terms in which it establishes itself qua political community. ${ }^{13}$ It is then not implausible to assume that the continuous acceptance of this constitutional framework establishes two tendencies that carry normative weight and that constitutional ethics needs to account for.

The first is the general strand of constitutional identity, which assumes that the constitution establishes a safeguard for the protection of minorities and demands an additional level of reflective scrutiny over state action. We can also understand this requirement in terms of the dialectic between confidence and reflection: it places a burden on constitutional authority to reflect on its moral judgment and take the

\footnotetext{
${ }^{13}$ As Walker puts it, constitutions are 'joined by a claim collective self-authorisation'. Neil Walker, 'Taking Constitutionalism Beyond the State' (2008) 56 Political Studies 519, 530. As such they 'may provide a resilient but flexible structure for political-ethical debate, an anchor for a continuing conversation about the meaning of political community that operates in a Janus-faced manner to strengthen that political community'. Ibid 532 .
} 
perspective of minorities into account as much as possible. As we have seen, this general demand can support - together with other arguments - an array of specific judgments: from the establishment of judicial review of legislation (US, Israel), to banning the display of crucifixes in classrooms (Germany), and allowing gay marriage (South Africa). ${ }^{14}$ More importantly, it provides an additional reason to balance different points of view and serves as a reminder that we commonly commit to securing the conditions for the flourishing of a plurality of perspectives, even against our initial emotional reactions. This general constitutional identity is embedded in the very notion of having a constitution; it is a contingent - but nearly universal - feature of modern political systems and a specific way in which our political communities resolve the problem of political authority.

The second strand is the particular constitutional identity that pertains to the values arising in the constitutional practice of one constitutional system that may not be shared by other systems. This strand of identity is capable of delivering more substantive results as it contains more precise evaluative commitments: for example, it shows that the understanding of equality is formal in the United States and substantive in South Africa, or that the specific conception of dignity plays a prominent role in Germany. A constitutional ethics that is divorced from the search for universal, mindindependent and timeless moral truths relieves these types of arguments from a constant struggle to demonstrate their normative import. If the source of moral obligations are non-contingent moral truths then we cannot explain different traditions as normative: there is a sense that we are inferring normative conclusions from descriptive premises, and that - given the variety of identities even among the liberaldemocratic constitutional systems - we are somehow desperately off-track in our moral judgments. If political morality is premised upon the simple model of universal values applied to specific facts, we can justify the variety of evaluative commitments arising from different constitutional identities only as a consequence of the application of values to these facts and not - much more plausibly - as simply different but nonetheless genuinely normative requirements.

\footnotetext{
${ }^{14}$ See the discussion of constitutional identity in chapter 2.
} 
Such metaethics allows us to see that a constitutional system may be justified - upon reflection and, importantly, from its own practical point of view - in retaining these specific values even in spite of consensus in the world. For example, we have seen that the particular identity of the US constitutional system has sometimes been upheld in spite of global trends, while South African constitutional identity has set these global standards as aspirational. In the model of constitutional ethics based on confidence and reflection, there need not be anything inherently wrong with these different choices. They must only be - again on reflection - true of constitutional community. Analogously, this model does not prevent us from criticizing such choices from our own practical perspective; nothing precludes us from persuading others that there are different solutions that better conform to their needs, interests and values. ${ }^{15}$ Finally, while the attitudes forming identity are central, they are not static; as I have argued, they evolve and acquire further content - for example - through interaction with other systems.

Most constitutional dilemmas cannot however be resolved by a straightforward inference from constitutional identity. ${ }^{16} \mathrm{~A}$ theory that aims to make sense of ethical choices under the circumstances of legal indeterminacy should be careful not to recreate the problem by suggesting a similarly indeterminate solution. For example, if constitutional identity includes a notion of substantive equality, this does not tell us if gay marriages are permitted or required, and it does not say much about the kinds of affirmative action measures policy-makers can employ; it provides only tendencies and sensibilities that ought to be incorporated in thinking about these issues which at times may not be specific enough. This does not mean that weighing different ethical concerns can be presented in a precise formula, ${ }^{17}$ but it is to say that there are other ethical arguments that bear on the explication of ethical concepts and need to figure in a sound conception of constitutional ethics.

\footnotetext{
${ }^{15}$ To underline, this conclusion will follow from a specific practical point of view. Our judgment about other systems will - conversely - follow from our point of view, so it means that even if we accept that there is divergence we can criticize it from our own framework of values.

${ }_{16}$ As Gary Jacobsohn aptly observes, 'constitutional identity will be fashioned - and refashioned through the struggle over constitutional identity'. , Constitutional Identity 135.

${ }_{17}$ This is for example the main inadequacy of Alexy's balancing formula. See for example Robert Alexy, $A$ Theory of Constitutional Rights (Oxford University Press 2002).
} 


\subsection{Sentiments}

To gain additional content constitutional ethics must turn to less deep but more concrete emotive intuitions of the members of the constitutional community present in the argument from common sentiment. It may seem that the thesis supports an ambivalent position towards this argument. While I have rejected that our emotive attitudes can present the exclusive basis of constitutional ethics, I have also argued that there is nothing beyond such responses taken together that can provide its metaphysical foundation. This is not yet another incarnation of a 'schizoid attitude': seeing the world in both causal and normative terms while being unable to resolve the tension. Instead, I have maintained that the role of common sentiments ought to be subtler. They are essential, but corrigible through reflection.

Contingent moral agreement matters to the extent to which it is reflective. The argument from common sentiment often assumes the inability to reason about values; ${ }^{18}$ however - while it is true that there will be a point where we will have to say that there is nothing more to go by except our moral intuitions - this point will come much later than it is envisaged by the argument from common sentiment. It will not necessarily occur in the moment we realize that there is an agreement in the community. Through reflection we have the means to inquire about the depth and quality of such agreement even if there is nothing outside of our psychology to tell us where things might have gone wrong. The argument from common sentiment attempts to couch its normativity in the vocabulary of objectivity, ${ }^{19}$ while it can only be properly understood in terms of inescapability. The difference is in the way we treat our converging emotive reactions: the latter understanding demands that we accept them but with a dose of skepticism, and with a critical and open mind.

It is important to notice many connections between the argument from common sentiment and constitutional identity. Common sentiments will supply constitutional

\footnotetext{
${ }^{18}$ See for example the discussion of Scalia's opinion in Lawrence, Marshall's in Furman v Georgia, Powell's in McCleskey v Kemp, La Forest's opinion in United States v Allard, Swiss Court's in Müller v Switzerland, all in chapter 3.

${ }_{19}$ See the discussion in chapter 3.
} 
identity with much of its content. In an attempt to figure out what people truly think and want, one cannot neglect their opinions and wishes. It is a false assumption that identity can give courts a fully detached Archimedean point from which they can assess moral opinions of the day, for these opinions must feed into the conception of identity. But identity in turn demands a certain depth of opinions before they gain normative force.

An example of how this interaction could be managed is the Canadian 'shocks the conscience' doctrine discussed in chapter 3. Recall that through this doctrine the court tied its moral judgment to the prevailing emotive reaction of Canadians. The court did so in order to understand the concept of 'fundamental justice' from the constitution and - in light of this concept - evaluate penal practices of another country and allow or deny extradition. But the justices did not fully surrender their judgment to the majority's emotive reactions. They accepted the fact that moral opinions are at the bottom a matter of emotional intuitions that cannot be fully explained, systematized and rationalized. However - moving away from the pure version of the argument from common sentiment in the early case law - they focused on intuitions that are strong, immutable, irreversible, deep, and central: they described giving up on these intuitions as 'unimaginable' and 'inconceivable'. ${ }^{20}$ This is not to say, in the Kantian spirit, that these emotive moral reactions suffer from a contradiction that makes them inconceivable; rather, they are unimaginable for Canadians at a given point in time.

The link between common sentiments and identity is thus fundamental: there is no identity without common sentiments but not all sentiments are important enough to survive reflection. The last chapter has shown that identity involves the dimensions of depth and integrity, which can help us decide which values are more authentic and truthful to the way we are - or even more importantly - the way we want to be. For example, chapter 3 has discussed some trends in American constitutional jurisprudence that neglect this and instead search for unconstrained sentiments, ${ }^{21}$ relieve them from the burden of reasoning,, ${ }^{22}$ or even celebrate their illogical character. ${ }^{23}$ They appear to

\footnotetext{
${ }^{20}$ See the discussion of Kindler $v$ Canada (Minister of Justice) and United States v Burns in chapter 3.

${ }^{21}$ See the discussion of Stevens' opinion in Spaziano v Florida in chapter 3.

${ }^{22}$ See the discussion of Marshall's opinion in Furman $v$ Georgia in chapter 3.
} 
understand the contingent foundations of moral judgments, but in fact they fail to see that our practical confidence cannot be unrestricted. The courts have a role in managing practical confidence and correcting it for a lack of reflection and authenticity.

There is more than one way in which this can be done but it is important that - in an effort to correct the excessive confidence of common sentiments - the courts should not simply assert confidence in their own sentiments. For instance, the argument from common sentiment could be acceptable to the extent that the process behind it reflects common sentiments and at the same time reflects upon them. By taking this approach, the courts could focus on the quality of the process from which they learn about common sentiments instead of trying to conduct it themselves. This may transform the argument in practice: the question would not then be which institution or public opinion poll better represents emotive intuitions, but which one does it without making the intuitions overly confident. The choice whether to defer to legislatures, juries, or referendums can thus also be based on the assessment of the ability of these processes to induce reflection, and not only of their capacity to accurately represent common sentiments.

This may seem as a complete renouncement of common sentiments as an acceptable ethical argument. But this is not so. Common sentiments are the essential ingredient of constitutional ethics even if they are transformed in this way. Let me explain. It is often the case that the understanding of ethical concepts from the constitution - such as equality and dignity - evolves over time. The typical question in this context is when is it appropriate for courts to give effect to moral changes that amend previously established doctrines. ${ }^{24}$ In the approach taken here we ought to ask whether these new sentiments can be ascribed to the community as a whole and - if so - whether they are a consequence of a thoughtful process that did not succumb to initial and pre-reflective emotive reactions without thinking them through in an open and flexible process. To the extent that sentiments have these qualities we should prefer the new settlement based on the novel understanding of these concepts.

${ }^{23}$ See the discussion of Scalia's opinion in Lawrence in chapter 3.

${ }^{24}$ See for example Raz, 'On the Authority and Interpretation of Constitutions: Some Preliminaries'. 
There will of course be a need for a fine balance between the rigidity of constitutional amendment procedure (that ought to guarantee the fundamental character of the moral change) and the legitimate scope of judicial freedom to decide such issues. Much will also depend on the difference between, on the one hand, the interpretive leeway left by elusive constitutional concepts and, on the other, moral judgments that transgress the boundaries of these concepts. Notice however the inescapability of sentiments: they are both the point of departure and the ultimate result of the exercise. When we find the new equilibrium it will be constituted by common sentiments. ${ }^{25}$

Not only are common sentiments central to an understanding of our own constitutional ethics, the realization that there is nothing beyond these contingent sentiments also affects the way we approach other moral equilibriums. The example is ECtHR's margin of appreciation doctrine. Recall that this doctrine roughly means that under the circumstances of discretion the ECtHR will not interfere with national approaches to some moral problem in the case there is no emerging consensus in Europe on the same issue. The court has often been criticized for taking the relativist approach: if there are right moral answers independent of our sentiments, it is probably a mistake to defer to different sites at which consensuses are formed. ${ }^{26}$ As we have seen, the issue cannot be understood as merely institutional for even institutional choice must follow from a conception of what is better or worse. But if we understand the problem in terms of confidence and reflection, we can see why the margin of appreciation and deference to parochial sentiments could be justified.

\footnotetext{
25 This of course intentionally alludes to John Rawls' work. Much of contemporary moral theory is inspired by his work, this thesis included. But - as I hope has become obvious from the thesis - there are clear metaethical differences that I do not suppose, while he eventually does: on my account there is no such thing as an 'unreasonable' ethical outlook in a robust sense and thus I follow a different path of trying to get to the core of our own outlook through identity to understand this 'unreasonableness'. See in particular his Political Liberalism (Columbia University Press 1993). Even though he can be credited for initiating many of the discussions which I touch upon in the thesis, Rawls tries to steer away from metaethics with his political conception of objectivity (see John Rawls, 'Kantian Constructivism in Moral Theory' in Samuel Richard Freeman (ed), Collected Papers (Harvard University Press 1999)), while I believe that metaethics is indispensable. Finally, his inspiration is Kantian and mine Humean. However, the conclusions I reach are in many ways reminiscent of his, and I acknowledge his work as an immense source of inspiration for this thesis.

${ }^{26}$ Letsas. However, we could for example have a second-order reason to respect the autonomy of those that formed moral agreement hence it could be a mistake to defer to national compacts even on the realist approach.
} 
This approach explains why the convergence in moral feelings is normatively important. If there is for example no agreement that can be ascribed to the identity arising under the framework of the European Convention, then the confidence of the court to impose moral answers ought to be undermined. If there is a core of values that cannot be renounced without the Convention ceasing to be what it is, then the court ought to interfere. Furthermore, the respect granted to moral agreements depends on their quality: on the one hand, if national moral agreements are not reflective enough this should make the court more willing to step in; on the other, if the consensus arising in Europe is not reflective and sensitive to different perspectives then it ought to be treated with less esteem.

The foundational role of moral sentiments perhaps makes constitutional ethics less stable or predictable, but is able to account for some of the intuitions about the restricted role of courts under the circumstances of a plurality of moral frameworks without at the same time completely abandoning judicial oversight. It does so by explaining why local specificities matter, and also why they may be inadequate. For example, we sometimes feel that the court paid more respect to some national measure than it should have done: but this feeling arises from the view that the court failed to see important parts of European moral identity - and our commitments that arise from it and not from the fact that it failed to grasp universal moral answers. It thus does not leave the courts without leverage to assess national measures, but makes them aware of the underpinnings of this leverage and thus more careful about its use. They must be confident; nonetheless their confidence can only come through reflection.

\subsection{Reason}

Pursuing the analogy between ordinary and constitutional ethics, we may understand arguments from constitutional identity and common sentiments as parts of constitutional confidence. Although I have reinterpreted both of these arguments to include the idea of reflectiveness, they are always a more or less accurate representation of the existing commitments of the constitutional community. However - as the last chapter showed - 
we can only achieve practical confidence through relentless reflection. This provides a counterbalance to the possible undue confidence of judgments stemming from identity and prevailing moral intuitions. The notion of constitutional ethics that I defend neither embraces identity for its own sake nor celebrates common sentiments as such: their force arises from their unavoidability and not from their intrinsic worth. We thus ought to be critical to both of these sources of evaluative intuitions while at the same time we have nothing but these intuitions to provide us with the necessary critical perspective. The conception of constitutional reason is hence limited but essential: reflection is repairing the ship of constitutional ethics while at sea, but the ship must constantly be repaired to be able to sail.

The goal of reflection is to understand the ethos of a constitutional community and settle on a judgment in the particular case that would be apposite from the perspective of such an ethos. This is anything but an easy task. The identity of a community often entails a struggle between different self-interpretations, sometimes even to the extent that the struggle itself becomes a part of the identity. ${ }^{27}$ As Walker puts it, constitutionalism could be conceived of as 'an ethical discourse under a constant process of re-imagining and reconstruction'. ${ }^{28}$ It is then better to think of identity as a set of selfdefining but evolving moral attitudes, which are not simply discovered in the process of reflection and contestation but also arise from it. The goal of reflection is greater selfawareness but also the imaginative development of the (collective and political) self. ${ }^{29}$

The thesis has argued that one of the best ways to achieve this is to engage with other constitutional systems. Constitutionalism aims to restrain the exercise of public authority by legal means: this central idea is interpreted in uncountable different ways but many of the questions the courts need to answer are similar. While this does not entail that there are right answers to these questions, a comparison can be useful. The

\footnotetext{
${ }^{27}$ See for example the discussion on two different limbs of Israeli constitutional identity - 'Jewish' and 'democratic' in chapter 3. Gary Jacobsohn calls this feature 'constitutional disharmony', which is to an extent necessary but in Israel takes a more dramatic form than perhaps in some Western liberal democracies (Jacobsohn, Constitutional Identity ch 6). See also Hirschl, Comparative Matters: The Renaissance of Comparative Constitutional Law ch 1.

${ }^{28}$ Walker 525.

${ }^{29}$ See more on the analogy between individual and collective identity and on the consequences on moral reflection in Habermas, Between Facts and Norms: Contributions to a Discourse Theory of Law and Democracy 94-99.
} 
analogy with individual ethical judgments can be pursued here as well. Although we may have different goals, hopes and dreams, we eventually face the same questions. Through engagement we can realize which of our commitments are more central and which we can sacrifice. We can for example see that because of a mere habit we accepted things we do not really want, or that some of our goals do not fit our moral outlook anymore.

It is not all that different with constitutional systems. Through a careful comparison it is possible to grasp the range of available options and choose the one that is truer to the central commitments of the constitutional system. I expressed this intuition in the vocabulary of virtues of reflective judgment: information, flexibility, coherence, imagination, maturity, openness, sensibility, and clarity. In chapter 4 I also detailed the ability of the use of foreign law to foster each of these virtues. There is no need to repeat these arguments here: it is clear from the discussion why such reflective virtues are compatible with arguments from common sentiment and constitutional identity. The problem is that this approach will not enable us to see true reasons, but only reasons that are true of us. We fall short of reaching objective mind-independent values and fall back on contingent social facts about our (often parochial) moral attitudes. The last chapter went to great lengths to show that this is inevitable and that we ought not to be concerned about it: all we can do in the end is to figure out how we want to live together.

In the course of answering this question, judicial practice often recognizes this interconnectedness of arguments from sentiment, identity and reason. Let me illustrate this with an example. Acknowledging the metaethical tensions behind his moral reading of the constitution, Justice Sachs in Makwanyane dedicates a whole part of his opinion to the question of 'the source of values' ${ }^{30}$ As he explains, 'the function given to this court by the Constitution is to articulate the fundamental sense of justice and right shared by the whole nation as expressed in the text of the Constitution'. ${ }^{31}$ In Sachs's view, the task of the constitutional court is to pronounce the moral sensibilities of the entire

\footnotetext{
$30 S v$ Makwanyane and Another paras 358-391 (Sachs).
}

${ }^{31}$ Ibid para 362. 
community as expressed in the constitution. The starting point for interpretation is thus constitutional identity and the assumption that the constitution does express the fundamental moral commitments of the population: the idea is that 'the Constitution speaks for the whole society'. ${ }^{32}$ But this is not enough, for the text is often not clear and the consequences of constitutional values are underdetermined.

On the one hand, an important dimension of the process of interpretation includes a keen appreciation for 'traditions, beliefs and values of all sectors of South African society's3 and for the 'evolution of core values in all sections of the community'. ${ }^{34}$ This part of the inquiry connects constitutional ethics to deeper layers of common evaluative experience; it extends the search for value from the particular strand of constitutional ethics to common sentiments. For example, clues and values are to be found in 'traditional African jurisprudence'. ${ }^{55}$ On the other hand, a counterbalance to this is the general strand of constitutional identity, because 'one of the functions of the Constitution is to protect unpopular minorities from abuse'. ${ }^{36}$ This is why the court does not 'automatically invoke each and every aspect of traditional law as a source of values'. ${ }^{37}$ Furthermore, the general component of constitutional identity paves the way for reflection, as the court rejects 'spontaneous and irrational form [s] of crowd behaviour', ${ }^{38}$ searches instead for 'the rational and humane adjudicatory approach', ${ }^{39}$ and - in particular - pursues 'openness, accommodation and tolerance' in 'free discourse and rational debate'. ${ }^{40}$ Justice Sachs' outline of the sources of evaluative judgment nicely illustrates how the particular limb of constitutional identity finds additional foothold in societal traditions and common sentiments, and how the general limb of constitutional identity demands further reflection upon this foundation. Together they feed back into a conception of constitutional identity that is then both reasonable and ours.

\footnotetext{
32 Ibid para 362.

${ }^{33}$ Ibid para 361.

${ }^{34}$ Ibid para 373.

35 Ibid.

36 Ibid para 369.

${ }^{37}$ Ibid para 383.

38 Ibid para 381

39 Ibid para 382

40 Ibid para 391.
} 
This thesis attempted to reveal the deeper philosophical foundations of this approach, and to demonstrate why it would make sense as an answer to the question about the source of value. But there are additional complications to this picture in the context of public authority and I must be careful not to stretch the analogy beyond its limits. We must investigate what reflection ought to entail when the unity of the reflective subject dissipates in the political context and the court still must decide in the name of all. This by no means implies that the overall approach can be different: the nature of normative judgment is the same regardless of the context. There are however some concerns that might play out differently when a judge is deciding how we ought to live in contrast to when a judge is deciding how she ought to live.

I have explained before why the default perspective of constitutional ethics ought to be the perspective of the constitutional community as a whole. Perhaps the best way to think about the problem of the appropriate perspective is to understand constitutional decision-making as a point of intersection of a multitude of evaluative frameworks. The concentration of public authority at the constitutional level makes a constitutional community's perspective relevant: because constitutional systems remain the central bearers of authority - and conversely, because we tend to think that any accumulation of public authority is to be justified in constitutional terms - interactions between different evaluative frameworks are particularly salient in constitutional interpretation. ${ }^{41}$ Constitutional interpretation is therefore a point of introspection where these frameworks come to meet and where they need to be accommodated. Constitutional identity becomes important in this process because it consists of a set of deep evaluative commitments that define our collective thinking about justified political authority and about ways to resolve conflicts that arise in the course of exercising such authority. But because normativity is generated on different levels - individual, cultural, national, transnational and international - the friction along their borderlines is inevitable.

\footnotetext{
${ }^{41}$ This claim holds partly as a matter of definition of constitutionalism: if supra-national legal constructs such as the EU are considered constitutional, this vocabulary expresses the fact that they become the main locus of power and authority and we thus want to subject them to at least some of the principles that justify such authority on the domestic level. On taking constitutional ideas beyond the frame of the nation-state see: Neil Walker, 'The Idea of Constitutional Pluralism' 65 The Modern Law Review 317 and Mattias Kumm, 'The Cosmopolitan Turn in Constitutionalism: On the Relationship between Constitutionalism in and beyond the State' in Jeffrey L. Dunoff and Joel P. Trachtman (eds), Ruling the world? Constitutionalism, International Law, and Global Governance (Cambridge University Press 2009).
} 
I should not even pretend that an account of constitutional ethics could solve all of these issues. There is no blueprint for easy constitutional solutions. The theory instead aims to illuminate the complex relationship between divergent sources of value in constitutional interpretation, provide the vocabulary to express different concerns that ought to bear on these problems, and - finally - organize some of the normative intuitions pertaining to complicated constitutional problems. Moreover, we must also remember that the alternative is doubtful without having any obvious advantages: assuming mind-independent moral values will not make these problems go away; if anything, it makes them seem extraordinary. Having in mind these caveats, let us see how the modest idea of reason together with the argument from identity and sentiments copes with quintessential constitutional dilemmas.

\section{Constitutional ethics and constitutional dilemmas}

It is useful to distinguish between two different dimensions of the problem of changing or divergent moral attitudes: we can tentatively call them diachronic and synchronic. The first concerns the evolution of moral attitudes in a community and their proper effect on constitutional interpretation; the second concerns the horizontal tensions that exist at a certain point in time internally (within the constitutional system) and externally (between constitutional systems). If the theory of ethical arguments based on constitutional confidence and reflection pertains to situations in which moral concepts are applied, it needs to tell us something more about these problems. While on the level of ethics of personal choices we may assume the unity of the self that reflects - and hence downplay the importance of the evolution of attitudes over time or internal moral conflicts and dilemmas - this problem is considered to be the principal problem of political philosophy.42 We can nonetheless approach this issue from the viewpoint of ethics and extend the analogy to some fruitful conclusions.

\footnotetext{
${ }_{42}$ This is for example the motivating concern behind Rawls, Political Liberalism. I do not make the distinction between ethics and morality or ethics and political morality as many authors - sometimes for quite different reasons - do (See for example Williams, Ethics and the Limits of Philosophy ch 10 and Habermas, Between Facts and Norms: Contributions to a Discourse Theory of Law and Democracy 94-99). Deciding how to live - individually or collectively - is the same question as far as the conception of value
} 


\subsection{Diachronic changes}

Let us start from the less challenging problem: diachronic differences in moral attitudes. This problem could be understood in terms of a choice between two different sources of legitimacy. On the one hand, there is the legal form of legitimation according to which the constitution derives its authority from its lawmaker, and on the other there is the popular or democratic form of legitimation encapsulated in the idea that people should govern themselves. There are many interconnections between these two sources and they often work together: the central idea of modern constitutionalism is that the will of the people ought to stay within the boundaries of law, but also that the law ought to reflect the will of the people. ${ }^{43}$ Clashes between these two sources of legitimation cause some perplexing paradoxes of constitutional theory: for example, the possibility of an unconstitutional amendment to the constitution, or the ability of people to limit and retain their sovereignty at the same time. ${ }^{44}$ In the domain of constitutional adjudication this tension is most visible when there is a new moral equilibrium that contradicts the attitudes that were dominant at the time of constitution making. For example: how can the death penalty be unconstitutional if it was constitutional when the constitution was adopted? It seems that options are exclusionary: we either comply with the authority of the constitution-maker or defer to contemporary opinions.

There are roughly two ways to deal with this problem. One is to suppose that there is an overarching common-denominator source of legitimacy that allows us to compare these options: for instance, we could situate the source of constitutional legitimacy in the will of the people, so if the will has changed then we ought to follow it even against the constitution that is (or should be) a mere expression of this will. ${ }^{45}$ The other is to

is concerned. Morality in a pejorative sense is also of no help for this project either: I did not aim to differentiate between right or wrong 'moralities'.

${ }^{43}$ Constitutional theory has struggled with this question of the relationship between collective agency and autonomy ever since Rousseau. See Jean-Jacques Rousseau, The social contract and Other Later Political Writings (Victor Gourevitch ed, Cambridge University Press 1997).

${ }^{44}$ For an exploration of these themes see Martin Loughlin and Neil Walker, The Paradox of Constitutionalism: Constituent Power and Constitutional Form (Oxford University Press 2007).

${ }^{45}$ Of course this entails that for the will to be expressed it first has to be organized, which is a problem that may lead to some unfortunate theoretical solutions. For a paradigmatic example see Schmitt's 
assume that the constitution itself commands that new moral attitudes ought to affect its interpretation: for example, the constitution may entrench an abstract notion of equality and leave it to future generations to figure out the concrete details of its application. ${ }^{46}$

The problem is that if we take the first approach then any converging attitude will justify constitutional change, while the very idea behind a constitution is that it is a more stable framework that does not give way to any popular mood or fashion; the concept of the constitution cannot be thus simply replaced by popular will but it has to stay intrinsically connected to it. The second approach supposes that the constitution delegates the decision to the people but this neither tells us what kind of change in attitudes justifies a change in the meaning of constitutional concepts, nor does it explain the cases in which the assumption that this was the will of constitution-makers does not hold; we thus need to inquire into the quality of attitudes that legitimate the change in constitutional interpretation.

Constitutional ethics as explained here can further specify these two lines of argument: it considers both sources of legitimacy as parts of a single narrative of moral identity evolving in relation to the constitution, and this determines the amount of respect that ought to be given to conserving and innovative elements of interpretation. As I have already argued, the courts ought to give effect to deep and reflective transformations in moral attitudes that are not excessively confident. On this approach, there is no mystery in the fact that moral attitudes both evolve and remain genuinely normative. Their normativity does not arise from their proximity to universal moral truths but from our inability to renounce them. This also means that not every popular opinion ought to be equally respected: the model gives us an argument why only widely and reflectively accepted attitudes matter.

concept of the political that - in his view - must predate the state and be based on a 'friend-enemy' distinction. According to Schmitt: '[t] he concept of the state presupposes the concept of the political', while ' $[\mathrm{t}]$ he specific political distinction to which political actions and motives can be reduced is that between friend and enemy'. Carl Schmitt, The Concept of the Political (George Schwab tr, Expanded edn, University of Chicago Press 2007) 19 and 26.

${ }^{46}$ For example: Dworkin, Freedom's Law: The Moral Reading of the American Constitution. 
At the same time, the process of constitution-making or constitutional amendment is the most appropriate venue for expressing a change in the moral identity of the community. If a polity wishes to renounce a discredited ethical concept, or a particular understanding of an ethical concept, the best way to do that is to change the constitution. However - as these concepts are typically underdetermined and there are further political obstacles to constitutional change - the courts may give effect to novel ethical attitudes through their interpretation. They have the justification to do so to the extent that a new equilibrium has been reached through a reflective and inclusive process. ${ }^{47}$

It will of course not be easy to tell whether moral change is deep enough to justify a change in constitutional interpretation. There is a significant leeway left for the courts to decide this and they must be reflective and ready to challenge their own assumptions. A clear sign that the change is deep enough is that it is not possible to imagine that a different judgment could be justified; some attitudes become so obvious over time to the extent that other possibilities seem plainly 'wrong'. As Justice Kennedy put it in Lawrence v Texas: 'times can blind us to certain truths and later generations can see that laws once thought necessary and proper in fact serve only to oppress'.48

But Kennedy's opinion in Lawrence is an example of a reflective judicial approach that transforms such obvious 'truths'. Kennedy admits that 'for centuries there have been powerful voices to condemn homosexual conduct as immoral' and that 'for many persons these are not trivial concerns but profound and deep convictions accepted as ethical and moral principles to which they aspire and which thus determine the course of their lives'. ${ }^{49}$ The power of his challenge to such ethical practice comes from the reflective point of view, which demands a more detached perspective and changes the relevant question. In Kennedy's view, '[t] he issue is whether the majority may use the

\footnotetext{
${ }^{47}$ Although it is not in focus here, we may even get a sense of the relationship between other legal arguments and ethical arguments in this example. Ethical arguments gain force from new moral understandings that are reflectively adopted even if not effectuated through the political process that might be clogged; however, other legal arguments have force until it is clear that there is such a new prevalent attitude. All this holds, of course, under the assumption that the political and legal system is generally legitimate.

${ }_{48}$ Lawrence 579 (Kennedy) emphasis added.

${ }^{49}$ Ibid 571.
} 
power of the State to enforce these views on the whole society'. ${ }^{50}$ The challenge to this approach comes then from a different direction. The problems arise when there is an emerging agreement that is not fully accepted but it is quite probable that it will be accepted at some point. Most practical problems I dealt with in previous chapters are of this kind. Should capital punishment be abolished or gay marriage be recognized? There is every possibility that people will come to think at some point that they should, and that they will consider some of our current practices to be deeply unjust.

The most difficult task for the court is to settle these kinds of issues. The temptation is to push the decision in the direction that becomes obvious to those that had the time and resources to reflect enough about it: courts may be in a privileged position of both being immersed in communal values and facing persistent challenges to these values in the legal process. While there cannot be steadfast rules for these situations, the interaction between constitutional confidence and reflection could give us some guidance. The question to ask is whether the new consensus that is emerging is more reflective than the previous one. If the new consensus is reflective and conforms better to all other values that we hold important, it means that its confidence is in better shape and the courts could therefore embrace it. It is not uncommon for the courts to help us to overcome our own illusions and give effect to new moral attitudes that better fit with our moral framework. We have also seen that convergence in foreign law could provide significant clues in this regard: in Roper the court 'confirmed' the developing domestic consensus by looking at foreign law. ${ }^{51}$ Because we share the same set of questions as humans living in modern constitutional systems, it is possible to glimpse the future developments of our own system by looking at foreign law, without necessarily deducing conclusions directly from it. The court in Roper dealt with an ongoing diachronic change in moral attitudes and prompted a new interpretation even before there was a clear and definitive change in moral sentiments and identity, but it could sense the direction of the emerging constitutional confidence on the basis of foreign law.

${ }^{50}$ Ibid.
${ }^{51}$ Roper v Simmons. 
This is obviously a thin line and courts must not be excessively confident in their own judgment. The very idea of constitutional identity as a source of normativity demands a cautious approach until the new equilibrium emerges: we should remember how beneficial waiting can be if the new agreement in sentiments proves to be unacceptable later on. The task is delicate and courts often rush into inducing changes they believe are apposite - no one wants to be remembered as being the one who opposed moral progress. ${ }^{52}$ But they should also exercise the appropriate amount of modesty as a decision that comes too early affects the formation of a new equilibrium and may polarize the public to the extent that is almost impossible to overcome. People come to identify themselves with one or the other position and refuse to be reflective about it: Roe $v$ Wade being a classic example. ${ }^{53}$ So the courts must not preclude reflection with their own confidence even if they are convinced of their own position.

\subsection{Synchronic differences}

This brings us to a more pressing issue of synchronic divergence in moral attitudes. It is relatively unproblematic for the court to change the understanding of an ethical concept from the constitution when there is a clear, confident, reflective, and self-aware convergence of moral attitudes in the community. Much more common are horizontal differences and disagreements at the same point in time. The unity of the reflective self is challenged from both directions: by sites of normativity internal and external to the constitutional system.

The former problem is the classic question of the relationship between the majority and minority that liberal democracies have struggled with ever since the rise of modern constitutionalism. Once political authority could no longer be justified by reference to God the question became: what opinions can we impose on others even upon realization that they are just our opinions? The reflective restraint advocated by constitutional

\footnotetext{
${ }^{52}$ It is also too demanding to ask the judges to completely overcome their own moral identity and do what they deem utterly wrong because of their institutional position; instead we should perhaps choose judges better if we want to avoid this, as their own moral judgment (which is at times necessary) must come from somewhere.

${ }^{53}$ Roe v Wade.
} 
ethics is thus already present in the DNA of constitutionalism and the disenchanted political authority it establishes. These themes have also been explored at length in political philosophy. We may for example notice the same intuition in Rawls' move toward the 'political, not metaphysical conception of justice' and his reliance on 'overlapping consensus's4 in an attempt to sidestep the question of moral truth and instead build his political theory on the 'background culture' of liberal democratic societies. ${ }^{55}$ The idea is to proceed from the agreement between different moral outlooks and clarify the ways in which it can be advanced through the use of publicly shared values and standards. ${ }^{56}$ It is obvious that constitutional ethics - when situated within the context of liberal democratic constitutionalism and its values - shares many affinities with such approaches. But instead of circumventing the metaphysical question, as I have argued in this thesis, the only honest, stable and viable solution is to face it directly. ${ }^{57}$ What constitutional ethics then needs to do is to say more about how confidence is retained if we fully embrace its non-metaphysical underpinnings, and when 'unreasonable' simply denotes something that we reject from our own standpoint after reflection.

The question is thus whether such diffidence - to use Hayek's term to describe this sort of liberal skepticism - leaves constitutional ethics without enough confidence. ${ }^{58}$ We have

\footnotetext{
${ }^{54}$ John Rawls, 'Justice as Fairness: Political not Metaphysical' (1985) 14 Philosophy \& Public Affairs 223, 226.

${ }_{55}^{5}$ Rawls, Political Liberalism 14.

${ }_{56}$ On Rawls' idea of public reason and duty of civility, see ibid $212-214$.

${ }_{57}$ As I have already argued, any such Kantian/contractarian approach - to the extent to which it aims to answer the metaphysical and not only normative question - must explain the source of the initial normative intuitions and authority of reflection or 'public reason' (or in Habermas' version the normative presuppositions of ideal discourse, see for example Justification and Application: Remarks on Discourse Ethics (MIT Press 1993)). To the extent that these are only normative approaches - as in Rawls' restatement of his theory as merely 'political' - they are valuable but are always under threat from a 'schizoid attitude' when the convergence in moral attitudes breaks down.

${ }^{58}$ While the label 'liberal' is used in so many ways that it raises more questions than it provides answers, Hayek's following remarks about liberalism are applicable to much of contemporary Western liberal democratic and rights-based constitutional systems: 'What I have described as the liberal position shares with conservatism a distrust of reason to the extent that the liberal is very much aware that we do not know all the answers and that he is not sure that the answers he has are certainly the rights ones or even that we can find all the answers. He also does not disdain to seek assistance from whatever non-rational institutions or habits have proved their worth.

The liberal differs from the conservative in his willingness to face this ignorance and to admit how little we know, without claiming the authority of supernatural forces of knowledge where his reason fails him. It has to be admitted that in some respects the liberal is fundamentally a skeptic — but it seems to require a certain degree of diffidence to let others seek their happiness in their own fashion and to adhere
} 
seen that constitutional ethics builds its confidence on a convergence in identity and sentiments. But we have also seen in chapter 3 that the convergence model of ethics may dissolve in the face of disagreement. From there I have been building a case for the unavoidability of reflection, also with a view that it could restore confidence. It is probably an illusion to think that conflicts can be completely avoided or that convergence can be fully rebuilt through reflection. There is no moral endpoint towards which we converge, so we can only hope that reflection itself will give us enough common ground to keep searching for appropriate solutions in an attempt to overcome the differences. But there are reasons to trust that this hope is not idle: first, reflection consists of a set of intuitions on which we do converge after the primary loss of confidence; second, reflection eliminates undue confidence hence allowing us to overcome differences and accommodate the views of others; third - when disagreement cannot be overcome - this approach prioritizes more reflective views for they have reached the core of moral attitudes that cannot be renounced.

Let me be a bit more specific. Two problems dominate the discussion of internal divergence in moral attitudes: cultural differences and moral disagreements. The approach to these problems follows from the general gist of constitutional ethics. While it is inevitable that some attitudes will prevail over others, they can only achieve this in a manner that is sensitive to the fact that they are not strictly speaking right. The result is a need to accommodate as much as possible the views of others that are not infringing upon the core of our identity, but also that this accommodation becomes less of a concession because it is not considered as fundamentally wrong. As Taylor argues, the first precondition to reaching 'genuine, unforced consensus' is to accept the possibility that our moral views need not be true and open ourselves to the moral imagination of others. ${ }^{59}$ Instead of relying on the authority of moral truth, courts ought to promote persuasion and accommodation.

consistently to that tolerance which is an essential characteristic of liberalism.' F.A. Hayek, The Constitution of Liberty (Routledge \& Kegan Paul 1960) 406-407. In a similar vein, Nagel reports that 'Robert Frost defined a liberal as someone who can't take his own side in an argument.' Thomas Nagel, 'Moral Conflict and Political Legitimacy' (1987) 16 Philosophy \& Public Affairs 215.

${ }^{59}$ Charles Taylor, 'Conditions of an Unforced Consensus on Human Rights' in Joanne R. Bauer and Daniel Bell (eds), The East Asian Challenge for Human Rights (Cambridge University Press 1999). 
Courts are however in a specific position, for they must sometimes take the perspective of an impartial spectator between two equally entrenched worldviews: they do not have the privilege of not caring about the solution because they have to decide. In such cases they ought to build on and further develop constitutional identity in order to accommodate differences within a common framework. This demands fine-tuning of the argument from identity, sentiments and reason - as described in the first part of this chapter - in order to find a point at which they intersect. But there may well not be such a point: in the case of an intractable conflict, the courts will have to impose the prevailing view to the extent to which it is reflective and self-aware. Sometimes the non-reflective worldviews will just have to give way. The right question to ask then is whether such moral worldviews imperil our constitutional identity to the extent that the absence of reaction amounts to the loss of such identity. Being able to live with this reaction is the only thing that can tell us that the decision was proper. An important part of this process - and a consequence of seeing values as contingent - involves giving up on the idea that there are always neat solutions to moral problems (perhaps as part of a divine plan) which would enable us to avoid choice and judgment. ${ }^{60}$

A challenge to this view may come from those that think that there is no overlapping consensus or that it is so thin that reliance on it renders the court's position feeble. Moral disagreement is sometimes considered to be the problem of constitutional interpretation. ${ }^{61}$ I have already explained in chapter 3 why disagreement might be a nonstarter normative argument: disagreement in any human practice can only exist against the background of prevailing agreement, ${ }^{62}$ and such arguments must explain why contingent moral agreement is normative in the first place. The thesis has primarily been concerned with the latter question. While the problem of disagreement becomes even more obvious in the approach that rejects the mind-independent conception of value, once we understand why agreement matters and which qualities make it important, we might seek creative solutions to enable it. The thesis has argued

\footnotetext{
${ }^{60}$ Bernard Williams is illuminating on this point: 'If there is such a thing as the truth about the subject matter of ethics - the truth, we might say, about the ethical — why is there any expectation that it should be simple? In particular, why should it be conceptually simple, using only one or two ethical concepts, such as duty or good state of affairs, rather than many? Perhaps we need as many concepts to describe it as we find we need, and no fewer.' Williams, Ethics and the Limits of Philosophy 17.

${ }^{61}$ See for example Waldron, Law and Disagreement.

${ }^{62}$ See Patterson.
} 
that the depth and integrity of moral agreement give us practical confidence: such agreement arises in the process of thoughtful endorsement of our moral sentiments and the reflective overcoming of our differences. Constitutional ethics should thus not understand disagreements as a fatal feature of our moribund moral practices, but an important part of figuring out how we want to live together through engagement with each other's opinions.

The important institutional consequence of constitutional ethics based on confidence and reflection is that the courts should respect the will of the people to the extent that it can be ascribed to the reflective identity of the constitutional community. It follows that they should also respect the process of consensus-formation to the extent that it contributes to the realization of this goal: they ought to enable an open debate in which an agreement will be reached without excessive confidence in any of the sides involved. This issue is mostly a matter of institutional design and thus outside of the scope of the thesis that focuses on constitutional interpretation and the interplay between ethical arguments; but it is important to underline that - once we wish to explore how constitutional ethics fits with other pieces of the political and institutional puzzle - we can see that it demands this kind of institutional wisdom and modesty from courts. There will be times where disagreement is instigated by a non-reflective confidence of the parties involved, but at times disagreement shall form a part of reflection, and the courts will need to be sensible to this fact and decide when to interfere accordingly.

Apart from synchronic differences internal to a constitutional system, there are also external sites of normativity that challenge unwarranted constitutional confidence from the outside. Interactions between different constitutional systems and clashes between their claims of authority are ever more frequent: while it has probably never been plausible to imagine constitutional communities as insular and self-sufficient evaluative frameworks, today it is quite certainly impossible. The thesis has tried to show that one dimension along which the friction between values occurs in constitutional interpretation is between local and global evaluative commitments. The conception of value from the last chapter makes the possibility of overlap between these commitments less puzzling and constitutional systems even more open to the possibility of external 
influence: as humans who share a certain historical moment and social context, we also share similar moral attitudes. Even to the extent there is no shared evaluative framework, foreign influences are an almost indispensable part of the reflective exercise that courts ought to undertake in the course of making an appropriate normative judgment.

The question however is to what extent local identity and sentiments ought to be protected when they conflict with the larger evaluative frameworks that we participate in. Constitutional discourse always articulates the idea of self-government and establishes the principles of political organization of a community, but this need not impede the possibility of re-imagining the terms on which such community is established and organized. ${ }^{63}$ To what extent should polities accommodate the competing claims of other constitutional systems is a question that probably cannot be answered in the abstract. Much depends on the context in which such problems arise and the kind of entity that makes the competing claim. ${ }^{64}$ Nonetheless: constitutional ethics should at least point to the questions the courts need to ask when facing such dilemmas.

From the perspective of constitutional ethics, interactions between constitutional systems on the post-national level are explicable in terms of the dynamics between constitutional confidence and reflection. One obvious way in which claims of competing authority coming from entities beyond the nation state add to this dynamic is through increased reflection. We have seen that internal sources of disagreement contribute to the common goal of figuring out how to live together. But it is also clear that significant parts of our constitutional identity remain unchallenged in these disagreements; for instance, because minorities do not get to voice their concerns, or because national constitutional communities build on the pre-existing and relatively homogeneous

\footnotetext{
63 Walker, 'The Idea of Constitutional Pluralism’ 340-359.

64. The question has for example gained much prominence in constitutional theory of the European Union, especially after several constitutional courts started using 'national' or 'constitutional' identity as a concept that affects the competences of the EU or derogation from rules and principles of EU law. For an overview of these developments, see Monica Claes, 'National Identity: Trump Card or Up for Negotiation?' in Alejandro Saiz Arnaiz and Carina Alcobero Llivina (eds), National Constitutional Identity and European Integration (Intersentia 2013). For an account of constitutional identity in the context of EU federalism, see Francois-Xavier Millet, 'The Respect for National Constitutional Identity in the European Legal Space: An Approach to Federalim as Constitutionalism’ in Loïc Azoulai (ed), The Question of Competence in the European Union (First edition. edn, Oxford University Press 2014).
} 
evaluative outlooks embedded in distinct cultural or ethnic backgrounds. Over time our contingent and parochial values become entrenched and begin to be treated as eternal and ahistorical truths. The reflective challenges to the established constitutional confidence then come from the outside: constitutional systems inevitably start to question their worldviews once they begin to participate in larger structures that acquire constitutional space of their own. ${ }^{65}$

In the language of confidence and reflection, it is possible to see some of the dialogue occurring between constitutional and supra-national courts - especially in the case of the EU - as initiating a healthy existential crisis on the part of national constitutional identity and as the reflective shaping of an emerging supranational constitutional identity. As is well known, the German Constitutional Court has - in a series of judgments since the 1970s - challenged the supremacy claims of the Court of Justice of the European Union ${ }^{66}$ and asserted its authority to review EU law on the basis of fundamental rights, ${ }^{67}$ distribution of competences, ${ }^{68}$ and principles and state functions central to German constitutional identity. ${ }^{69}$ Without doubt, the German court has at times been too confident about the ethical core of German constitutional identity and has thus failed to articulate it in a coherent way. ${ }^{70}$ But - notwithstanding these shortcomings - we may also notice that the very fact that the court has been forced to spell out the evaluative commitments of the constitutional system that cannot be renounced has generated a great deal of reflection.

\footnotetext{
${ }^{65} \mathrm{I}$ assume here a rather non-controversial claim that certain constitutional features can be shared on a post-national level; that is, that the 'constitutional' dimension of governance is not an all-or-nothing property, and that it is not of necessity tied to the nation-state framework. See more in Walker, 'The Idea of Constitutional Pluralism'.

${ }^{66}$ Before the Lisbon Treaty of 2009: the European Court of Justice.

${ }^{67}$ Internationale Handelsgesellschaft von Einfuhr- und Vorratsstelle für Getreide und Futtermittel (1974) 37 BVerfGE 271; [1974] CMLR 540, and Re Wünsche Handelsgesellschaft (1986) 73 BVerfGE 339; [1987] CMLR 225.

${ }^{68}$ Brunner v European Union Treaty 89 BVerfGE 155; [1994] CMLR 57.

${ }^{69}$ Lisbon Judgment (2009) 2 BvE $2 / 08$.

70 See for example Daniel Halberstam and Christoph Möllers, ‘The German Constitutional Court Says "Ja zu Deutschland!"' (2009) 10 German Law Journal 1241.
} 
The German Constitutional Court has attempted to express the inalienable essential features' 71 and 'identity' 72 of the constitutional system: in other words, to find the vital self-defining attitudes without which the system loses the foundation that enables it to make any evaluative judgment. The fact that the court has gone through quite a bit of adjustment in its position - alternating between harder and softer approaches to EU law - testifies that these evaluative commitments of the system are rebuilt and reshaped in the process rather than discovered. ${ }^{73}$ We should therefore not expect that confidence could be established once and for all on the basis of an argument detecting the conceptually indispensable features of the state (as the court perhaps attempted to do in its Lisbon judgment); ;4 instead, the process of rethinking these features will allow us to settle on a judgment that seems apposite in the particular historical moment from the standpoint of the reflective commitments of the particular political community.

On the other side, the interaction has forced the CJEU to take into account concerns about the justification of its own authority. As a response to these challenges, the CJEU developed the EU constitutional framework to better fit expectations about the appropriate normative underpinnings of its supremacy claims. ${ }^{75}$ In so doing, it had to accommodate the specific constitutional traditions of member states, ${ }^{76}$ but also asserted its authority when it considered such accommodation impossible or inappropriate. ${ }^{77}$

\footnotetext{
${ }^{71}$ Internationale Handelsgesellschaft von Einfuhr- und Vorratsstelle für Getreide und Futtermittel (in the context of fundamental rights).

${ }^{72}$ Lisbon Judgment inter alia paras $240-252$.

${ }^{73}$ For example, a less confrontational judgment in Honeywell (2010) 2 BvR 2661/06 came out one year after the Lisbon decision, claiming that it would apply ultra vires control of EU law, thus retreating to the position from the Maastricht judgment (Brunner v European Union Treaty).

${ }_{74}$ There is a sense in which the court failed to support its argument about essential state functions. See on this more in Halberstam and Möllers.

${ }^{75}$ Most importantly it included fundamental rights as the basis of review and this has eventually led to the adoption of the Charter of Fundamental Rights. See more in Gráinne De Búrca, 'The Evolution of EU Human Rights Law' in Paul Craig and Gráinne De Búrca (eds), The Evolution of EU Law (2 edn, Oxford University Press 2011).

${ }^{76}$ See for example in the context of the already mentioned specifically German conception of dignity: C36/02 Omega Spielhallen- und Automatenaufstellungs-GmbH v Oberbürgermeisterin der Bundesstadt Bonn [2004] ECR I-9609.

77 At times it also demonstrated excessive confidence in the fundamental freedoms of the EU and thus failed to see opportunities for accommodation. This has perhaps been the case in the context of the right to strike in C-438/05 International Transport Workers' Federation v Viking [2007] ECR I-10779 and C341/05 Laval un Partneri Ltd v Svenska Byggnadsarbetareförbundet [2007] ECR I-1 1767.
} 
There is still much truth in Weiler's account of the interaction between national, which satisfies the need for communal and emotional attachment, and supranational, which remedies the excessive irrationality of the national. ${ }^{78}$ Although constitutional ethics starts from very different premises, the intuition it explores is similar: normative judgment arises from the interaction both along the local-universal and emotion-reason dimensions of our ethical experience. However, the supranational can no longer be merely seen as the embodiment of reason, or as a collective super-ego that remedies the excesses of the national, instinctive and emotional $i d$. We ought to treat both national and supranational as sites that generate evaluative attitudes, acquire constitutional identity of their own, ${ }^{79}$ and gain confidence through accommodation of each other's claims.

The emphasis on a specifically constitutional identity could clarify what exactly is at stake. Constitutional identity is not necessarily embedded in previous communal attachments, but also arises from the very act (or practice) of self-constitution. It is thus a particular kind of identity: it presents a set of attitudes that govern our ideas about how common affairs ought to be conducted. Constitutional identity provides a compass for pursuing normative claims in the public domain without promoting deception about the special worth of any particular community: it precisely challenges these kinds of illusions and forces us to confront the contingency of our moral attitudes. ${ }^{80}$ It is not surprising that new constitutional identities can evolve in a supranational context and gain normative traction. While they do perhaps lack the excessive confidence of ethno-

\footnotetext{
${ }^{78}$ J.H.H. Weiler, The Constitution of Europe: "Do the New Clothes Have an Emperor?" and Other Essays on European Integration (Cambridge University Press 1999) ch 10 esp 347.

79 This is most clear in the interaction with systems external to the EU when the specific constitutional identity of the EU is protected. See in particular (stressing the importance of fundamental rights and judicial review, repeating the pattern visible when domestic constitutional identity is asserted): C-402/05 $\mathrm{P}$ and C-415/05 P Kadi and Al Barakaat International Foundation v Council and Commission [2008] ECR I-6351 and C-584/10 P, C-593/10 P and C-595/10 P European Commission and Others v Yassin Abdullah Kadi nyr.

80 This distinguishes it from liberal nationalism and communitarianism. I am however reluctant to ascribe a label or opinion to a loose intellectual and political project as a whole as many nuances might be lost. For example, communitarianism need not value any particular community as such but just underline that communal heritage crucially influences the way we see the world in normative terms.
} 
cultural attachments, they do not lack the emotional and motivational content that directs our normative thinking. ${ }^{81}$

One could then ask: why does a constitutional perspective matter? Why - among all other identities - should we choose constitutional? After all, in the clash between other more deeply embedded identities, the seemingly fragile constitutional identity could easily vanish. Its worth is not intrinsic: the normativity of such an identity does not follow from the fact that it satisfies a human need for social attachment, or from the necessity of such attachment for social cooperation and solidarity. As such, it is also not exclusive: it presents just one possible evaluative system among many.

Part of the answer comes from the already explained perspective of the court that makes the decision in the name of constitutional community and with a constitutional warrant to do so. But a more important reason follows from the empirical and normative resilience of constitutional identity. Empirically, constitutional identity has proved to be more robust than it may appear at first; it arises precisely from the clashes of different identities as the most viable way to resolve the problem of collective action and political organization of a particular society, and has survived many (although certainly not all) such challenges. It is accepted as a point of reference for people who advance normative claims in the public context and as such has more relevance for our common life than we may sometimes think it does. Normatively, its force stems from the fact that the reflective restriction of the instinctive moral impulses is a sensible reaction after their contingent foundation is exposed. Constitutional identity - in the liberal-democratic form discussed here - seems as the least self-righteous option that can still guarantee

\footnotetext{
81 The idea here comes close to the concept of constitutional patriotism, although I do find constitutional patriotism puzzling as long as it presupposes universalist normative foundations and wishful thinking about their widespread acceptance in the population. The concept aims to gain normativity from universal values, and motivational force from parochial and communal emotions and thus runs the risk of amounting to a noble dream (but still a dream) that everyone actually accepts universal values. My account is different in two senses: first, I aim to explain the source of value and evaluative attitudes, while constitutional patriotism can only be an attitude and not the source itself; second, I do not presuppose universal values to motivate my account of constitutional identity but only contingent and prevailing attitudes that arise in relation to the constitution. Notwithstanding the differences I do find that constitutional patriotism is possibly an attractive way of thinking about these issues (if successfully clarified). See more on constitutional patriotism in Habermas, Between Facts and Norms: Contributions to a Discourse Theory of Law and Democracy 490-515 and Jan-Werner Müller, 'A General Theory of Constitutional Patriotism' (2007) 6 International Journal of Constitutional Law 72.
} 
enough confidence for an effective public authority. In other words, constitutional identity sometimes $i s$ the point of intersection between confidence and reflection: it embodies the optimal level of attachment and detachment that is appropriate for a disenchanted normative perspective.

\section{Conclusion}

This chapter has discussed the implications of metaethics on the judicial pursuit of the source of value: it applied the ethics of confidence and reflection to the constitutional context. The important message is that moral judgments arise from the interplay between identity, sentiments and reason. The ambition of the chapter was to illuminate these distinct sources of value and shed some light on their interaction. But an equally important message is that finding answers to constitutional dilemmas is not easy: the process does not involve discovery, but invention, imagination and - most importantly persuasion. The hope is that constitutional ethics can give us the vocabulary to express the concerns that ought to play an important role in this quest.

One might find this answer dissatisfying. It may appear that the theory of constitutional ethics does not have enough practical bite. On the one hand, it leaves many things as they are: the theory only finds a distinct place for ethical arguments that already exist in comparative practice. On the other hand, it abstains from giving fixed answers to concrete moral problems: instead of clear-cut solutions it promotes an abstract process that can lead to quite different results. Let me finish with some observations about these important issues.

First, while the theory of constitutional ethics does not introduce radical changes, it does unsettle the usual ways in which these issues are addressed, and - in so doing allows us to see some of the disputes about constitutional interpretation in a new light. Recall that in many systems arguments from identity, sentiments and reason exclude each other and sometimes lead to a standstill between different conceptions of legitimacy. In other systems some of these arguments are used in a very different way 
or not at all. Constitutional ethics therefore does have an important transformative potential.

Second, to the extent that constitutional ethics does not aim to transform the practice or resists transformations that are definite and crude - this is consistent with its metaethical foundations. Our moral practice itself is not neat. This fact should probably be celebrated: it allows us to experience emotional attachments, reason about them, and choose the course of action with our will. Devising an exact formula that should give us exact moral answers would go against the spirit of the thesis, and against the very idea that there ought to be enough space for different perspectives and for their development over time. Nonetheless, constitutional ethics does try to devise an approach to moral problems that - hopefully - makes sense from our current moral perspective, and - even more hopefully - allows the courts to realize what it takes to make a sound normative judgment.

Third - and perhaps most important - there is a lot of space for future work within this framework of thinking about constitutional ethics. Apart from the issue of the concrete application of constitutional ethics, there is much to be said about the import of each ethical argument in different contexts, both national and post-national. There is also a lot to be explored in terms of the institutional consequences of constitutional ethics, and in terms of the consequences of institutional context on constitutional ethics. Possibly there are also interesting questions for other branches of law. There is - in other words - more reflection to be done to be if we wish to be confident in constitutional ethics itself. 


\section{CONCLUSION}

The thesis began with a vignette about Socrates' contestation of Euthyphro's views on the source of moral value. Their dialogue ends with Euthyphro leaving the scene, unwilling to accept further challenges that could undermine his judgment. It is a great victory for Socrates and his philosophical method. And we should probably celebrate it as a triumph of reason over unreflective beliefs. But there is something to be said about Euthyphro. While we may condemn him as a dogmatic theologian, we should also be aware that there is a bit of Euthyphro behind every moral judgment: an inescapable level of confidence in our contingent moral attitudes accompanies each moral choice we make. Metaphorically speaking, moral decisions are made in a process similar to the dialogue between Socrates and Euthyphro, and require finding the internal balance between these two poles of our moral experience.

The thesis argued that difficult questions about the nature of value arise from the tension between the theoretical and practical perspective. The practical perspective aims to answer a theoretical question about the mind-independence of moral values, and in so doing undermines our confidence in such values. We can regain confidence in the practical perspective by rejecting its theoretical claims. But when these theoretical claims are rejected, the redemption of our practical perspective is possible only through reflection that curbs the excessive confidence. Values are then revealed and reshaped in the dynamics between practical confidence and reflection. Confidence denotes the inescapability of the self and of the contingent evaluative attitudes it entails in making any moral judgment. Reflection denotes the process of challenging and questioning these attitudes. A credible conception of value, one that leaves enough space for both the practical and theoretical perspective, suggests that the appropriate moral judgment emerges from the equilibrium between confidence and reflection. Such judgment arises from a disenchanted practical perspective that incorporates reflective virtues - such as self-awareness, maturity, coherence, imagination, sensitivity, openness, and flexibility - in a process that integrates both Euthyphro's and Socrates' point of view. 
Two types of conclusions follow for constitutional adjudication: critical and constructive. First, when taken separately, all three regimes of ethical arguments identified in comparative constitutional practice - the argument from constitutional identity, common sentiment and universal reason - are supported with inadequate conceptions of value and fail as self-standing approaches to moral judgment. The argument from common sentiment combines the emotivist and relativist elements that do not allow for the reflective endorsement of moral attitudes; the argument from universal reason relies on cognitivist universalism which presupposes a detached practical perspective that would render us incapable of making any moral judgment; the argument from constitutional identity is between these two poles, which makes it both unable to give enough substance to our moral judgments and provide sufficient critical distance towards them. Expressed in the vocabulary of confidence and reflection: the argument from common sentiment is overly confident; the argument from universal reason is implausibly reflective; and the argument from constitutional identity is neither confident nor reflective enough.

Second, when taken together, these arguments have a potential to refashion the moral perspective of a constitutional court so that it conforms to a sound conception of value. On the model this thesis proposed, judicial moral inquiry departs from the emotive intuitions of a constitutional community present in the argument from common sentiment; these intuitions are then challenged with the argument from universal reason through reflective exposure to different moral perspectives; finally, the goal of this exercise is to contribute to a better understanding and development of constitutional identity. The thesis maintained that combining these arguments allows constitutional courts to emulate the moral point of view in a process that is both sensitive to different moral perspectives and attuned to the institutional position of the court in the constitutional system. It further argued that this framework enables us to perceive some common problems of constitutional adjudication - such as diachronic changes and synchronic differences in moral opinions - in a new light and explore the limits of confidence with which the courts can assert particular moral views. Constitutional ethics that has been defended in this thesis contends that courts - when they make moral judgments - ought to respect the moral intuitions of the people which can be 
reflectively attributed to their constitutional identity. If Euthyphro sat on a constitutional court today, this is the answer he could give to Socrates.

The goal of the thesis was to develop a conception of constitutional ethics that would give due regard to both our existing moral attitudes and our ability to change them through reflection: it intended to leave space for the people to choose their constitutional destiny, while being aware that their choices do not occur in a normative vacuum, but in the context of contingently shared moral attitudes. The hope is that the model of constitutional ethics it developed resonates with some of the intuitions we have about our common life in modern constitutional communities, and that it can assist us in developing them further. But perhaps even more importantly, the thesis attempted to show that there are pressing metaethical questions - for example, how our contingent moral attitudes can be genuinely normative, why accommodation of otherness does not lead to self-defeating relativism, and what the authority of reflection is - that cannot and should not be neglected when we discuss the place and role of moral judgments in constitutional adjudication. Unless we tackle these questions, we are destined to run around in circles, without a clear idea of where to search for value. Even if we must have some of Euthyphro's confidence to make moral judgments, we can only figure out how to live together if we embrace Socrates' reflection. 


\section{LIST OF CASES}

\section{Constitutional Court of South Africa}

Coetzee v Government of the Republic of South Africa, Matiso and Others v Commanding Officer Port Elizabeth Prison and Others 1995 (4) SA 631

Du Plessis and Others v De Klerk and Another 1996 (3) SA 850

Ferreira v Levin; Vryenhoek v Powell 1996 (1) SA 984 (CC)

Kv Minister of Safety and Security 2005 (6) SA 419 (CC)

Minister of Finance and Other v Van Heerden 2004 (6) SA 121 (CC)

Minister of Home Affairs and Another v Fourie and Another 2006 (1) SA 524 (CC)

Mistry v Interim National Medical and Dental Council and Others 1998 (4) SA 1127

National Coalition for Gay and Lesbian Equality v Minister of Justice and Others 1999 (1) SA 6

President of the Republic of South Africa and Another v Hugo 1997 (4) SA 1

Prince v President of the Law Society of the Cape of Good Hope 2002 (2) SA 794

Sv Makwanyane and Another 1995 (3) SA 391

Sv Zuma and Others 1995 (2) SA 642

\section{Court of Justice of the European Union}

European Commission and Others v Yassin Abdullah Kadi C-584/10 P, C-593/10 P and C595/10 P nyr

International Transport Workers' Federation v Viking C-438/05 [2007] ECR I-10779 
Kadi and Al Barakaat International Foundation v Council and Commission C-402/05 P and C-415/05 P [2008] ECR I-6351

Laval un Partneri Ltd v Svenska Byggnadsarbetareförbundet C-341/05 [2007] ECR I11767

Omega Spielhallen- und Automatenaufstellungs-GmbH v Oberbürgermeisterin der Bundesstadt Bonn C-36/02 [2004] ECR I-9609

\section{European Court of Human Rights}

Otto-Preminger-Institut v Austria (13470/87) [1994] ECHR 26 (20 September 1994)

Müller v Switzerland(10737/84) [1988] ECHR 5 (24 May 1988)

Murphy v Ireland (44179/98) [2003] ECHR 352 (10 July 2003)

Wingrove v United Kingdom (17419/90) [1996] ECHR 60 (25 November 1996)

Handyside v United Kingdom (5493/72) [1976] ECHR 5 (7 December 1976)

\section{Federal Constitutional Court of Germany}

Abortion Decision I(1975) 39 BVerfGE 1

Aviation Security Case (2006) 115 BVerfGE 118

Brunner v European Union Treaty 89 BVerfGE 155; [1994] CMLR 57

Honeywell (2010) 2 BvR 2661/06

Internationale Handelsgesellschaft von Einfuhr- und Vorratsstelle für Getreide und Futtermittel (1974) 37 BVerfGE 271; [1974] CMLR 540

Kruzifix-decision (1995) 93 BVerfGE 1

Lisbon Judgment (2009) 2 BvE 2/08 
Lüth(1958) 7 BVerfGE 198

Re Wünsche Handelsgesellschaft (1986) 73 BVerfGE 339; [1987] CMLR 225

\section{Supreme Court of Canada}

Canada v Schmidt 1 SCR 500 [1987]

Kindler v Canada (Minister of Justice) 2 SCR 779 [1991]

Multani v Commission scolaire Marguerite-Bourgeoys [2006] 1 SCR 256

$R v$ Big M Drug Mart Ltd (1985)18 DLR (4th) 321

$R v$ Oakes [1986]1 SCR 103

United States v Allard 1 SCR 564 [1987]

United States v Burns 1 SCR 283 [2001]

\section{Supreme Court of Israel}

Adalah Legal Centre for Arab Minority Rights in Israel v Minister of Interior HCJ 10650/03 (2006)

Kol Ha'am v Minister of Interior HCJ 73/53 (1953)

MK Zahava Gal-On (Meretz-Yahad) v Attorney General HCJ 466/07 (2012)

United Mizrahi Bank Ltd. v Migdal Cooperative Village CA 6821/93 (1995) 


\section{Supreme Court of the United States}

Marbury v Madison 5 US 137 (1803)

Dred Scott v Sandford 60 US 393 (1856)

Reynolds v United States 98 US 145 (1878)

Lochner v New York 198 US 66 (1905)

Schenck v United States 249 US 47 (1919)

Brown v Board of Education of Topeka 347 US 483 (1954)

Trop v Dulles 356 US 86 (1958)

Miranda v Arizona 384 US 436 (1966)

Furman v Georgia 408 US 238 (1972)

Roe v Wade 410 US 113 (1973)

Gregg v Georgia 428 US 153 (1976)

Coker v Georgia 433 US 584 (1977)

Gardner v Florida 430 US 349 (1977)

Regents of the University of California v Bakke 438 US 265 (1978)

Enmund v Florida 458 US 782 (1982)

New York v Quarles 467 US 649 (1984)

Spaziano v Florida 468 US 447 (1984)

Bowers v Hardwick 478 US 186 (1986)

McCleskey v Kemp 481 US 279 (1987)

Thompson v Oklahoma 487 US 815 (1988) 
Stanford v Kentucky 492 US 361 (1989)

Employment Division v Smith 494 US 872 (1990)

Adarand Constructors Inc v Peña 515 US 200 (1995)

Printz v United States 521 US 898 (1997)

Washington v Glucksberg 521 US 702 (1997)

Knight v Florida 528 US 990 (1999)

Atkins v Virginia 536 US 304 (2002)

Gratz v Bollinger 539 US 244 (2003)

Grutter v Bollinger 539 US 306 (2003)

Lawrence v Texas 539 US 558 (2003)

McCreary County v ACLU of Kentucky 545 US 844 (2005)

Roper v Simmons 543 US 551 (2005)

Parents Involved in Community Schools v Seattle School District No 1551 US 701 (2007)

Kennedy v Louisiana 554 US 407 (2008) 



\section{BIBLIOGRAPHY}

Ackerman BA, We the People: Foundations (Belknap Press 1991)

Ackermann LWH, 'Constitutional Comparativism in South Africa: A Response to Sir Basil Markesinis and Dr Jörg Tiedke' in Markesinis B and Tiedke J (eds), Judicial Recourse to Foreign Law: A New Source of Inspiration? (UCL Press)

Alexy R, A Theory of Constitutional Rights (Oxford University Press 2002)

Alford RP, 'In Search of a Theory for Constitutional Comparativism' (2005) 52 UCLA Law Review 639

—, 'Roper v. Simmons and Our Constitution in International Equipoise' (2005) 53 UCLA Law Review 1

Anscombe GEM, 'Modern Moral Philosophy' (1958) 33 Philosophy 1

Audi R, The Good in the Right: A Theory of Intuition and Intrinsic Value (Princeton University Press 2004)

Augenstein D, 'The Contested Polity: Europe's Constitutional Identity between Religious and Secular Values' [2009/3] University of Edinburgh School of Law Working Paper Series

Ayer AJ, Language, Truth, and Logic (2 edn, V. Gollancz 1946)

Balaguer M, 'Platonism in Metaphysics' in Zalta EN (ed), The Stanford Encyclopedia of Philosophy (Spring 2014 Edition) <http://plato.stanford.edu/archives/spr2014/entries/platonism/>

Balkin J, 'Framework Originalism and the Living Constitution' (2009) 103 Northwestern University Law Review 549

—, Living Originalism (Harvard University Press 2011)

Barak A, Purposive Interpretation in Law (Princeton University Press 2005)

—, The Judge in a Democracy (Princeton University Press 2006)

Barnett R, 'An Originalism for Non-originalists' (1999) 45 Loyola Law Review 611 
Bentele U, 'Mining for Gold: The Constitutional Court of South Africa's Experience with Comparative Constitutional Law' (2009) 37 Georgia Journal of International and Comparative Law 219

Berger R, 'Ronald Dworkin's The Moral Reading of the Constitution: A Critique' 72 Indiana Law Journal 1099

Berman MN, 'Originalism Is Bunk' (2009) 84 NYU Law Review 1

Bickel AM, The Least Dangerous Branch: The Supreme Court at the Bar of Politics (BobbsMerrill 1962)

Blackburn S, Spreading the Word: Groundings in the Philosophy of Language (Oxford University Press 1984)

—, Ruling Passions: A Theory of Practical Reasoning (Clarendon Press 1998)

Bobbitt P, Constitutional Fate: Theory of the Constitution (Oxford University Press 1982)

- Constitutional Interpretation (Blackwell 1991)

Bobek M, Comparative Reasoning in European Supreme Courts (Oxford University Press 2013)

Bowles S, 'Group Competition, Reproductive Leveling, and the Evolution of Human Altruism’ (2006) 314 Science 1569

Boyd RN, 'How to Be a Moral Realist' in Sayre-McCord G (ed), Essays on Moral Realism (Cornell University Press 1988)

Breyer S, 'Keynote Address' (2003) 97 Proceedings of the Annual Meeting of the American Society of International Law 265

Brink DO, Moral Realism and the Foundations of Ethics (Cambridge University Press 1989)

Bronaugh R, 'Persuasive Precedent' in Goldstein L (ed), Precedent in Law (Clarendon Press 1987)

Calabresi SG and Zimdahl SD, "The Supreme Court and Foreign Sources of Law: Two Hundred Years of Practice and the Juvenile Death Penalty Decision' (2005) 47 William and Mary Law Review 743 
Camus A, The Myth of Sisyphus and Other Essays (A.Knopf 1964)

Claes M, 'National Identity: Trump Card or Up for Negotiation?' in Saiz Arnaiz A and Alcobero Llivina C (eds), National Constitutional Identity and European Integration (Intersentia 2013)

Clarke-Doane J, 'Morality and Mathematics: The Evolutionary Challenge' (2012) 122 Ethics 313

Cohon R, Hume's Morality: Feeling and Fabrication (Oxford University Press 2008)

Coleman JL, The Practice of Principle: In Defence of a Pragmatist Approach to Legal Theory (Oxford University Press 2001)

Copp D, Morality, Normativity, and Society (Oxford University Press 1995)

—_, 'Darwinian Skepticism about Moral Realism' (2008) 18 Philosophical Issues 186

Darwall S, Gibbard A and Railton P, 'Toward Fin de siècle Ethics: Some Trends' in Darwall SL, Gibbard A and Railton PA (eds), Moral Discourse and Practice: Some Philosophical Approaches (Oxford University Press 1997)

Darwin C, The Descent of Man, and Selection in Relation to Sex (Bonner JT and May RM eds, Princeton University Press 1981 [1871])

Davis DM, 'Constitutional Borrowing: The Influence of Legal Culture and Local History in the Reconstitution of Comparative Influence: The South African Experience' (2003) 1 International Journal of Constitutional Law 181

De Búrca G, 'The Evolution of EU Human Rights Law' in Craig P and De Búrca G (eds), The Evolution of EU Law (2 edn, Oxford University Press 2011)

Denis L, 'Kant and Hume on Morality' in Zalta EN (ed), The Stanford Encyclopedia of Philosophy <http://plato.stanford.edu/entries/kant-hume-morality/>

Dixon R, ‘A Democratic Theory of Constitutional Comparison' (2008) 56 The American Journal of Comparative Law 947

Dorsen N, 'The Relevance of Foreign Legal Materials in U.S. Constitutional Cases: A Conversation between Justice Antonin Scalia and Justice Stephen Breyer' (2005) 3 International Journal of Constitutional Law 519

Durkheim E, Durkheim and the Law (Lukes S and Scull A eds, St. Martin's Press 1983) 
Dworkin R, 'Lord Devlin and the Enforcement of Morals' (1966) 75 Yale Law Journal 986

—, Taking Rights Seriously (Duckworth 1977)

—, Law's Empire (Belknap Press 1986)

- Freedom's Law: The Moral Reading of the American Constitution (Harvard University Press 1996)

— ' 'Objectivity and Truth: You'd Better Believe It' (1996) 25 Philosophy \& Public Affairs 87

—, 'Comment' in Scalia A (ed), A Matter of Interpretation: Federal Courts and the Law (Princeton University Press 1997)

—_, Justice for Hedgehogs (Belknap Press of Harvard University Press 2011)

Dworkin R and others, 'Assisted Suicide: The Philosopher's Brief [27 March 1997] The New York Review of Books

Ely JH, Democracy and Distrust: A Theory of Judicial Review (Harvard University Press 1980)

Engle E, 'European Law in American Courts: Foreign Law as Evidence of Domestic Law' (2007) 33 Ohio Northern University Law Review 99

Enoch D, 'The Epistemological Challenge to Metanormative Realism: How Best to Understand It, and how to Cope With It' (2010) 148 Philosophical Studies 413

Fallon RH, ‘A Constructivist Coherence Theory of Constitutional Interpretation' (1987) 100 Harvard Law Review 1189

— Implementing the Constitution (Harvard University Press 2001)

Foot P, 'Morality as a System of Hypothetical Imperatives' (1972) 81 The Philosophical Review 305

—, 'Does Moral Subjectivism Rest on a Mistake?' (1995) 15 Oxford Journal of Legal Studies 1

—, Moral Dilemmas and Other Topics in Moral Philosophy (Oxford University Press 2002) 
—, Virtues and Vices and Other Essays in Moral Philosophy (Clarendon Press 2002 $[1978])$

Frankfurt HG, 'Freedom of the Will and the Concept of a Person' (1971) 68 The Journal of Philosophy 5

Garland D, Peculiar Institution: America's Death Penalty in an Age of Abolition (Oxford University Press 2010)

Geach PT, 'Assertion’ (1965) 74 Philosophical Review 449

Gensler H, 'Cultural Relativism' in Shafer-Landau R (ed), Ethical Theory: An Anthology (2 edn, Blackwell 2013)

Gibbard A, Wise Choices, Apt Feelings: A Theory of Normative Judgment (Clarendon Press 1990)

—, Thinking How to Live (Harvard University Press 2003)

—, Reconciling Our Aims: In Search of Bases for Ethics (Oxford University Press 2008)

Ginsburg RB, "A Decent Respect to the Opinions of $[$ Human $\rceil$ Kind": The Value of a Comparative Perspective in Constitutional Adjudication' 2005 Cambridge Law Journal 575

Goldschmit C, Gross M and Schachar Y, '100 Leading Precedents of the Supreme Court - A Quantitative Analysis’ (2004) 7 Haifa University Law Review 243

Goodman $\mathrm{R}$ and Jinks $\mathrm{D}$, 'How to Influence States: Socialization and International Human Rights Law' (2004) 54 Duke Law Journal 621

Green L, 'Legal Positivism' in Zalta EN (ed), The Stanford Encyclopedia of Philosophy $<$ http://plato.stanford.edu/archives/fall2009/entries/legal-positivism/>

Gross M, Haris R and Schachar Y, 'References Patterns of the Supreme Court in Israel - Quantitative Analysis' (1996) 26 Hebrew University Law Review 115

Guyer P, 'Moral Feelings in the Metaphysics of Morals' in Denis L (ed), Kant's Metaphysics of Morals: A Critical Guide (Cambridge University Press 2010)

Habermas Jr, Moral Consciousness and Communicative Action (MIT Press 1990)

—, Justification and Application: Remarks on Discourse Ethics (MIT Press 1993) 
- Between Facts and Norms: Contributions to a Discourse Theory of Law and Democracy (MIT Press 1996)

Haidt J, 'The Emotional Dog and its Rational Tail: A Social Intuitionist Approach to Moral Judgment' (2001) 108 Psychological Review 814

Halberstam D and Möllers C, 'The German Constitutional Court Says "Ja zu Deutschland!"' (2009) 10 German Law Journal 1241

Hamilton WD, 'The Genetical Evolution of Social Behaviour. I' (1964) 7 Journal of Theoretical Biology 1

_ , 'The Genetical Evolution of Social Behaviour. II' (1964) 7 Journal of Theoretical Biology 17

Hare RM, The Language of Morals (Clarendon Press 1952)

Harman G, The Nature of Morality: An Introduction to Ethics (Oxford University Press 1977)

_- 'Moral Relativism' in Harman G and Thomson JJ (eds), Moral Relativism and Moral Objectivity (Blackwell 1996)

—, Explaining Value and Other Essays in Moral Philosophy (Oxford University Press 2000)

Harman G, Mason K and Sinnott-Armstrong W, 'Moral Reasoning' in Doris JM and Group MPR (eds), The Moral Psychology Handbook (Oxford University Press 2010)

Hart HLA, Law, Liberty and Morality (Oxford University Press 1962)

—, 'Positivism and the Separation of Law and Morals' in Essays in Jurisprudence and Philosophy (Clarendon Press 1983)

—, The Concept of Law (2 edn, Clarendon Press 1994)

Hayek FA, The Constitution of Liberty (Routledge \& Kegan Paul 1960)

Himma KE, 'Inclusive Legal Positivism' in Coleman JL and Shapiro S (eds), The Oxford Handbook of Jurisprudence and Philosophy of Law (Oxford University Press 2002)

Hirschl R, Towards Juristocracy: The Origins and Consequences of the New Constitutionalism (Harvard University Press 2004) 
- Comparative Matters: The Renaissance of Comparative Constitutional Law (Oxford University Press 2014)

Homiak M, 'Moral Character' in Zalta EN (ed), The Stanford Encyclopedia of Philosophy (Spring 2011 Edition) <http://plato.stanford.edu/archives/spr2011/entries/moralcharacter $/ \% 3 \mathrm{E}>$

Horwich P, 'The Frege-Geach Point' (2005) 15 Philosophical Issues 78

Hume D, Enquires Concerning the Human Understanding and Concerning the Principles of Morals (Selby-Bigge LA ed, 2 edn, Clarendon Press 1902 [1777])

—, A Treatise of Human Nature (Selby-Bigge LA and Nidditch PH eds, 2nd edn, Clarendon Press 1978)

Inglehart R, The Silent Revolution: Changing Values and Political Styles among Western Publics (Princeton University Press 1977)

Jackson VC, 'Constitutional Comparisons: Convergence, Resistance, Engagement' 119 Harvard Law Review 109

Jacobsohn GJ, Constitutional Identity (Harvard University Press 2010)

—, 'Constitutional Values and Principles' in Rosenfeld M and Sajo A (eds), The Oxford Handbook of Comparative Constitutional Law (Oxford University Press 2012)

Joyce R, 'Darwinian Ethics and Error' (2000) 15 Biology \& Philosophy 713

—, The Evolution of Morality (MIT Press 2006)

Kant I, Groundwork for the Metaphysics of Morals (Wood AW tr, Yale University Press 2002)

- Critique of Practical Reason and Other Works on the Theory of Ethics (Abbott TK tr, Barnes \& Noble Books 2004)

Kavanagh A, 'The Idea of a Living Constitution' (2003) 16 The Canadian Journal of Law and Jurisprudence 55

Kitcher P, 'Biology and Ethics' in Copp D (ed), The Oxford Handbook of Ethical Theory (Oxford University Press 2006)

—, The Ethical Project (Harvard University Press 2011) 
Koh HH and Treanor WM, 'Keynote Address: A Community of Reason and Rights' (2008) 77 Fordham Law Review 583

Komesar NK, Imperfect Alternatives: Choosing Institutions in Law, Economics, and Public Policy (University of Chicago Press 1994)

- Law's Limits: The Rule of Law and the Supply and Demand of Rights (Cambridge University Press 2001)

Kommers DP, 'Germany: Balancing Rights and Duties' in Goldsworthy J (ed), Interpreting Constitutions: A Comparative Study (Oxford University Press 2007)

Korsgaard CM, The Sources of Normativity (Cambridge University Press 1996)

Kramer L, The People Themselves: Popular Constitutionalism and Judicial Review (Oxford University Press 2004)

Kumm M, 'The Cosmopolitan Turn in Constitutionalism: On the Relationship between Constitutionalism in and beyond the State' in Dunoff JL and Trachtman JP (eds), Ruling the world? Constitutionalism, International Law, and Global Governance (Cambridge University Press 2009)

Larmore C, 'Reflection and Morality' (2010) 27 Social Philosophy and Policy 1

Larsen JL, 'Importing Constitutional Norms from a "Wider Civilization": Lawrence and the Rehnquist Court's Use of Foreign and International Law in Domestic Constitutional Interpretation' (2004) 65 Ohio State Law Journal 1283

Lee Y, 'International Consensus as Persuasive Authority in the Eighth Amendment' (2007) 156 University of Pennsylvania Law Review 63

Leiter B, 'Nietzsche's Metaethics: Against the Privilege Readings' (2000) 8 European Journal of Philosophy 277

—, 'Moral Facts and Best Explanations' (2001) 18 Social Philosophy \& Policy 79

—, 'Explaining Theoretical Disagreement' (2009) 76 The University of Chicago Law Review 1215

—, 'The Demarcation Problem in Jurisprudence: A New Case for Scepticism’ (2011) 31 Oxford Journal of Legal Studies 663 
—, 'Why Legal Positivism (Again)?' [2013] University of Chicago Public Law Working Paper 442

—, 'Nietzsche' in Forster M and Gjesdal K (eds), The Oxford Handbook of Nineteenth Century Philosophy (Oxford University Press forthcoming) <http://papers.ssrn.com/sol3/papers.cfm?abstract_id=2 148074>

Letsas G, 'Two Concepts of the Margin of Appreciation' (2006) 26 Oxford Journal of Legal Studies 705

Levinson S, Looking Abroad When Interpreting the U.S. Constitution: Some Reflections' (2004) 39 Texas International Law Journal 353

Loughlin M and Walker N, The Paradox of Constitutionalism: Constituent Power and Constitutional Form (Oxford University Press 2007)

Lyons D, 'Ethical Relativism and the Problem of Incoherence' (1976) 86 Ethics 107

MacCrudden C, 'Human Dignity and Judicial Interpretation of Human Rights' (2008) 19 European Journal of International Law 655

Mackie JL, Ethics: Inventing Right and Wrong (2 edn, Penguin 1990 [1977])

Mak E, Judicial Decision-Making in a Globalised World: A Comparative Analysis of the Changing Practices of Western Highest Courts (Hart Publishing 2013)

Markesinis B and Fedtke J, Judicial Recourse to Foreign Law: A New Source of Inspiration? (UCL Press 2006)

Mautner M, 'The Decline of Formalism and the Rise of Values' in Mautner M (ed), Law and the Culture of Israel (Oxford University Press 2011)

Mazie SM, Israel's Higher Law: Religion and Liberal Democracy in the Jewish State (Lexington Books 2011)

McCrudden C, 'Common Law of Human Rights?: Transnational Judicial Conversations on Constitutional Rights' (2000) 20 Oxford Journal of Legal Studies 499

— ' 'Judicial Comparativism and Human Rights' in Örücü E and Nelken D (eds), Comparative Law: A Handbook (Hart Publishing 2007)

McDowell J, Mind, Value, and Reality (Harvard University Press 1998) 
Mill JS, 'Hedonism' in Shafer-Landau R (ed), Ethical Theory: An Anthology (2 edn, Blackwell 2013)

Millet F-X, 'The Respect for National Constitutional Identity in the European Legal Space: An Approach to Federalim as Constitutionalism' in Azoulai L (ed), The Question of Competence in the European Union (First edition. edn, Oxford University Press 2014)

Möller K, 'On Treating Persons as Ends: The German Aviation Security Act, Human Dignity, and the Federal Constitutional Court' [2006] Public Law 457

Moore GE, Principia Ethica (Baldwin T ed, 2 edn, Cambridge University Press 2000 [1903])

Moore MS, Placing Blame: A Theory of the Criminal Law (Oxford University Press 1997)

Müller J-W, ‘A General Theory of Constitutional Patriotism' (2007) 6 International Journal of Constitutional Law 72

Nagel T, The View from Nowhere (Oxford University Press 1986)

—, 'Moral Conflict and Political Legitimacy' (1987) 16 Philosophy \& Public Affairs 215

—

- Mind and Cosmos: Why the Materialist Neo-Darwinian Conception of Nature is Almost Certainly False (Oxford University Press 2012)

Navot S, Israel: Creating a Constitution - The Use of Foreign Precedents by the Supreme Court (1994-2010)' in Groppi T and Ponthoreau M-C (eds), The Use of Foreign Precedents by Constitutional Judges (Hart Publishing 2013)

Nietzsche F, The Gay Science; With a Prelude in Rhymes and an Appendix of Songs (Kaufmann W tr, Vintage Books 1974)

Nietzsche FW, On the Genealogy of Morals and Ecce Homo (Kaufmann W ed, Kaufmann WA and Hollingdale RJ trs, 2 edn, Vintage Books 1989)

—, Human, All Too Human: A Book for Free Spirits (Hollingdale RJ tr, Cambridge University Press 1996)

Nozick R, The Nature of Rationality (Princeton University Press 1993) 
O'Connor SD, 'Keynote Address' (2002) 96 Proceedings of the Annual Meeting of the American Society of International Law 348

Pardo MS and Patterson DM, Minds, Brains, and Law: The Conceptual Foundations of Law and Neuroscience (Oxford University Press 2013)

Parfit D, On What Matters: Volume Two (Oxford University Press 2011)

Patterson D, 'Normativity and Objectivity in Law' (2001) 43 William and Mary Law Review 325

Patterson DM, Law and Truth (Oxford University Press 1996)

Pavlakos G, Our Knowledge of the Law: Objectivity and Practice in Legal Theory (Hart Publishing 2007)

— - 'Practice, Reasons, and the Agent's Point of View' (2009) 22 Ratio Juris 74

Perju V, 'Cosmopolitanism and Constitutional Self-government' (2010) 8 International Journal of Constitutional Law 326

Plato, The Collected Dialogues of Plato (Hamilton E and Cairns H eds, 14 edn, Princeton University Press 1989)

Porat I, 'The Use of Foreign Law in Israeli Constitutional Adjudication' Paper Presented in a Conference on Israeli Constitutional Law (Tel Aviv, May 2010)

Posner R, 'Foreword: A Political Court' (2005) 119 Harvard Law Review 32

Post R and Siegel RB, 'Democratic Constitutionalism' in Balkin JM and Siegel RB (eds), Constitution in 2020 (Oxford University Press 2009)

Prinz JJ, The Emotional Construction of Morals (Oxford University Press 2007)

Putnam H, Philosophy of Logic (Harper \& Row 1971)

—, The Collapse of the Fact/Value Dichotomy and Other Essays (Harvard University Press 2002)

— Ethics without Ontology (Harvard University Press 2004)

Quine WV, 'Two Dogmas of Empiricism’ (1951) 60 The Philosophical Review 20 
Quine WV, 'The Scope and Language of Science' in The Ways of Paradox and Other Essays (Harvard University Press 1976)

Railton P, 'Darwinian Building Blocks' in Katz LD (ed), Evolutionary Origins of Morality: Cross-Disciplinary Perspectives (Imprint Academic 2000)

—, 'Realism and Its Alternatives' in Skorupski J (ed), The Routledge Companion to Ethics (Routledge 2010)

Rautenbach C, 'South Africa: Teaching an 'Old Dog' New Tricks? An Empirical Study of the Use of Foreign Precedents by the South African Constitutional Court (19952010)' in Groppi T and Ponthoreau M-C (eds), The Use of Foreign Precedents by Constitutional Judges (Hart Publishing 2013)

Rawls J, 'Justice as Fairness: Political not Metaphysical' (1985) 14 Philosophy \& Public Affairs 223

—, Political Liberalism (Columbia University Press 1993)

—, 'Kantian Constructivism in Moral Theory' in Freeman SR (ed), Collected Papers (Harvard University Press 1999)

—, A Theory of Justice (Rev. edn, Belknap Press 1999 [1971])

Raz J, The Authority of Law: Essays on Law and Morality (Clarendon Press 1979)

—, The Concept of a Legal System: An Introduction to the Theory of the Legal System (2 edn, Oxford University Press 1980)

—, 'Authority, Law and Morality' in Ethics in the Public Domain: Essays in the Morality of Law and Politics (Clarendon Press 1994)

— ' 'On the Authority and Interpretation of Constitutions: Some Preliminaries' in Between Authority and Interpretation: On the Theory of Law and Practical Reason (Oxford University Press 2009)

Risse-Kappen $\mathrm{T}$ and Sikkink K, 'The Socialization of International Human Rights Norms into Domestic Practices: Introduction' in Risse-Kappen T, Ropp SC and Sikkink K (eds), The Power of Human Rights: International Norms and Domestic Change (Cambridge University Press 1999)

Rorty R, Philosophy and the Mirror of Nature (Princeton University Press 1979) 
—, Contingency, Irony, and Solidarity (Cambridge University Press 1989)

Rosen A, 'Two Logics of Authority in Modern Law' (2014) 64 University of Toronto Law Journal 669

Rosenfeld M, The Identity of the Constitutional Subject: Selfhood, Citizenship, Culture, and Community (Routledge 2010)

Ross WD, The Right and the Good (Clarendon Press 1930)

Rousseau J-J, The social contract and Other Later Political Writings (Gourevitch V ed, Cambridge University Press 1997)

Ruse M, Taking Darwin Seriously: A Naturalistic Approach to Philosophy (Blackwell 1986)

Sapir G, 'Constitutional Revolutions: Israel as a Case-study' (2009) 5 International Journal of Law in Context 355

Scalia A, 'Foreign Legal Authority in the Federal Courts' (2004) 98 Proceedings of the Annual Meeting of the American Society of International Law 305

Scanlon T, 'The Appeal and Limits of Constructivism' in Lenman $\mathrm{J}$ and Shemmer Y (eds), Constructivism in Practical Philosophy (Oxford University Press 2012)

Schauer F, 'Easy Cases' (1985) 58 Southern California Law Review 399

—_, 'Authority and Authorities' (2008) 94 Virginia Law Review 1931

Scheffler S, Equality and Tradition: Questions of Value in Moral and Political Theory (Oxford University Press 2010)

Schmitt C, The Concept of the Political (Schwab G tr, Expanded edn, University of Chicago Press 2007)

Schneewind JB, The Invention of Autonomy: A History of Modern Moral Philosophy (Cambridge University Press 1998)

Schulz AW, 'Sober \& Wilson's Evolutionary Arguments for Psychological Altruism: A Reassessment' (2011) 26 Biology \& Philosophy 251

Segal Z, 'The Israeli Constitutional Revolution: The Canadian Impact in the Midst of a Formative Period' (1997) 8 Forum Constitutionnel 53 
Shafer-Landau R, Moral Realism: A Defence (Oxford University Press 2003)

—_, 'The Possibility of Metaethics' (2010) 90 Boston University Law Review 479

—_, 'Evolutionary Debunking, Moral Realism and Moral Knowledge' (2012) 7 Journal of Ethics \& Social Philosophy 1

Shapiro MM and Stone Sweet A, On law, Politics, and Judicialization (Oxford University Press 2002)

Shapiro S, 'On Hart's Way Out' in Coleman JL (ed), Hart's Postscript: Essays on the Postscript to the Concept of Law (Oxford University Press 2001)

- 'What is the Rule of Recognition (and Does it Exist)?' in Adler MD and Himma KE (eds), The rule of recognition and the US Constitution (Oxford University Press 2009)

Sidgwick H, The Methods of Ethics (7th edn, McMillan 1962 [1907])

Singer P, 'Moral Experts' (1972) 32 Analysis 115

—_, 'Ethics and Intuitions' (2005) 9 The Journal of Ethics 331

—, 'Morality, Reason, and the Rights of Animals' in de Waal F (ed), Primates and Philosophers: How Morality Evolved (Princeton University Press 2006)

Sinnott-Armstrong (ed) W, Moral Psychology, Volume 1. The Evolution of Morality: Adaptations and Innateness (MIT Press 2007)

Slaughter A-M, 'A Typology of Transjudicial Communication’ (1994) 29 University of Richmond Law Review 99

— - 'A Global Community of Courts' (2003) 44 Harvard International Law Journal 191

—, A New World Order (Princeton University Press 2004)

Smith A, The Theory of Moral Sentiments (Haakonssen K ed, Cambridge University Press 2002)

Sober E, From a Biological Point of View: Essays in Evolutionary Philosophy (Cambridge University Press 1994) 
Sober E and Wilson DS, Unto Others: The Evolution and Psychology of Unselfish Behavior (Harvard University Press 1998)

Stavropoulos N, 'Legal Interpretivism' in Zalta EN (ed), The Stanford Encyclopedia of Philosophy (Summer 2014 Edition)

<http://plato.stanford.edu/archives/sum2014/entries/law-interpretivist/>

Stevenson CL, Ethics and Language (Yale University Press 1944)

Stone Sweet A and Mathews J, Proportionality Balancing and Global Constitutionalism' (2008) 47 Columbia Journal of Transnational Law 72

Street S, 'A Darwinian Dilemma for Realist Theories of Value' (2006) 127 Philosophical Studies 109

- 'Constructivism about Reasons' in Shafer-Landau R (ed), Oxford Studies in Metaethics: Volume 3 (Clarendon Press 2008)

- ' 'Reply to Copp: Naturalism, Normativity, and the Varieties of Realism Worth Worrying About' (2008) 18 Philosophical Issues 207

-, 'Objectivity and Truth: You'd Better Rethink It' unpublished draft <https://files.nyu.edu/ss 194/public/sharonstreet/Writing_files/Paper\%2012\%20for\% 20website\%20-\%20Objectivity\%20and\%20Truth\%20\%20You\%27d\%20Better\%20Rethink\%20It.pdf>

—, 'What is Constructivism in Ethics and Metaethics?' (2010) 5 Philosophy Compass 363

—, 'Coming to Terms with Contingency: Humean Constructivism about Practical Reason' in Lenman J and Shemmer Y (eds), Constructivism in Practical Philosophy (Oxford University Press 2012)

—, 'Does Anything Really Matter or Did We Just Evolve to Think So?' in Byrne A and others (eds), The Norton Introduction to Philosophy (Norton forthcoming 2014) <https://files.nyu.edu/ss 194/public/sharonstreet/Writing.html>

Sturgeon NL, 'Harman on Moral Explanations of Natural Facts' (1986) 24 The Southern Journal of Philosophy 69

—, 'Moral Explanations' in Sayre-McCord G (ed), Essays on Moral Realism (Cornell University Press 1988) 
Sturgeon NL, 'Relativism' in Skorupski J (ed), The Routledge Companion to Ethics (Routledge 2010)

Sunstein CR, One Case at a Time: Judicial Minimalism on the Supreme Court (Harvard University Press 1999)

- A Constitution of Many Minds: Why the Founding Document Doesn't Mean What It Meant Before (Princeton University Press 2009)

Taylor C, Human Agency and Language: Philosophical Papers I (Cambridge University Press 1985)

—, 'Conditions of an Unforced Consensus on Human Rights' in Bauer JR and Bell D (eds), The East Asian Challenge for Human Rights (Cambridge University Press 1999)

Tripathi PK, 'Foreign Precedents and Constitutional Law' (1957) 57 Columbia Law Review 319

Tripkovic B, 'Judicial Comparativism and Legal Positivism' (2014) 5 Transnational Legal Theory 285

Tushnet MV, 'Referring to Foreign Law in Constitutional Interpretation: An Episode in the Culture Wars' (2006) 35 University of Baltimore Law Review 299

Velleman JD, Foundations for Moral Relativism (Open Book Publishers 2013)

Waldron J, 'Particular Values and Critical Morality' (1989) 77 California Law Review 561

—, Law and Disagreement (Clarendon Press 1999)

—_, 'The Core of the Case Against Judicial Review' (2006) 115 Yale Law Journal 1346

—, 'Do Judges Reason Morally?' in Huscroft G (ed), Expounding the Constitution: Essays in Constitutional Theory (Cambridge University Press 2008)

—, "Partly Laws Common to All Mankind" Foreign Law in American Courts (Yale University Press 2012)

Walker N, 'The Idea of Constitutional Pluralism’ 65 The Modern Law Review 317

— , 'Taking Constitutionalism Beyond the State' (2008) 56 Political Studies 519 
Wallace RJ, 'Constructivism about Normativity: Some Pitfalls' in Lenman $\mathrm{J}$ and Shemmer Y (eds), Constructivism in Practical Philosophy (Oxford University Press 2012)

Waluchow WJ, A Common Law Theory of Judicial Review: The Living Tree (Cambridge University Press 2007)

—, 'Constitutional Morality and the Bills of Rights' in Huscroft G (ed), Expounding the Constitution: Essays in Constitutional Theory (Cambridge University Press 2008)

Weber M, The Protestant Ethic and the Spirit of Capitalism (Routledge 2001)

Weiler JHH, The Constitution of Europe: "Do the New Clothes Have an Emperor?" and Other Essays on European Integration (Cambridge University Press 1999)

Wielenberg EJ, 'On the Evolutionary Debunking of Morality' (2010) 120 Ethics 441

Wiggins D, Needs, Values, Truth: Essays in the Philosophy of Value (Blackwell 1987)

Williams B, Morality: An Introduction to Ethics (Harper \& Row 1972)

—-, 'A Critique of Utilitarianism' in Smart JJC and Williams B (eds), Utilitarianism For and Against (Cambridge University Press 1973)

—, Moral Luck: Philosophical Papers, 1973-1980 (Cambridge University Press 1981)

—, Making Sense of Humanity (Cambridge University Press 1995)

—, 'Toleration: An Impossible Virtue?' in Heyd D (ed), Toleration: An Elusive Virtue (Princeton University Press 1996)

—_, 'Philosophy as a Humanistic Discipline' (2000) 75 Philosophy 477

—, Ethics and the Limits of Philosophy (2 edn, Routledge 2006 [1985])

Wolf S, 'Moral Saints' (1982) 79 Journal of Philosophy 419

Wong D, 'Relativism’ in Singer P (ed), A Companion to Ethics (Blackwell 1991)

—, Natural Moralities: A Defense of Pluralistic Relativism (Oxford University Press 2006)

Young EA, 'Foreign Law and the Denominator Problem’ 119 Harvard Law Review 148 